Unlimited

Release
SAND93-0529

Printed May 1993
Distribution

Category UC-405

\title{
Some Parametric Flow Analyses of a Particle Bed Fuel Element
}

\author{
Dean Dobranich \\ Nuclear Technology Department \\ Sandia National Laboratories \\ Albuquerque, NM 87185
}

\begin{abstract}
Sbstract
Parametric calculations are performed, using the SAFSIM computer program, to investigate the fluid mechanics and heat transfer performance of a particle bed fuel element. Both steady-state and transient calculations are included, addressing such issues as flow stability, reduced thrust operation, transpiration drag, coolant conductivity enhancement, flow maldistributions, decay heat removal, flow perturbations, and pulse cooling. The calculations demunstrate the dependence of the predicted results on the modeling assumptions and thus provide guidance as to where further experimental and computational investigations are needed. The calculations also demonstrate that both flow instability and flow maldistribution in the fuel element are important phenomena. Furthermore, results are encouraging that geometric design changes to the element can significantly reduce problems related to these phenomena, allowing improved performance over a wide range of element power densities and flow rates. Such design changes will help to maximize the operational efficiency of space propulsion reactors employing particle bed fuel element technology. Finally, the results demonstrate that SAFSIM is a valuable engineering tool for performing quick and inexpensive parametric simulations addressing complex flow problems.
\end{abstract}

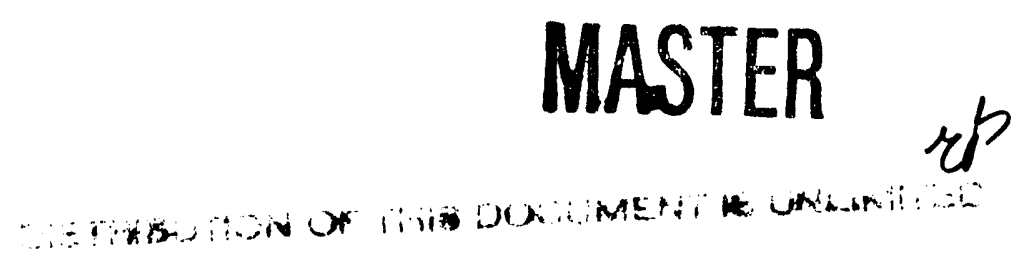




\section{Acknowledgments}

The work described in this document (SNTP-R-SNL-93-0017) was funded by the Space Nuclear Thermal Propulsion (SNTP) program. The SNTP program is sponsored by the Air Force and run by the Phillips Laboratory in Albuquerque, New Mexico. The color figures appearing in this document were produced by a SAFSIM postprocessor created by James R. Hipp (Sandia Organization 6515). Special thanks to Jim, who developed the computer program on his own time. Thanks also to the technical reviewers: David F. Beck, (currently Organization 6512, on his way to Organization 2723-1), and Frederick G. Blottner, (Organization 1511), for taking the time to wade through this composition. 


\section{Contents}

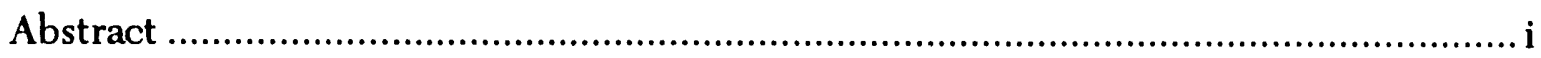

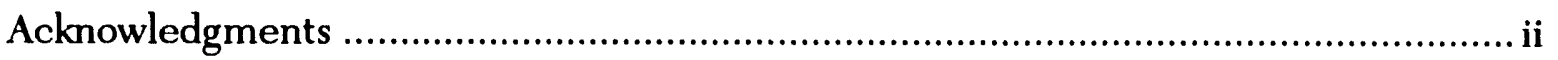

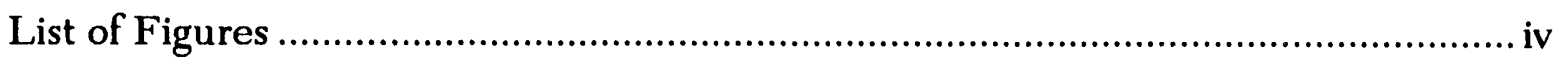

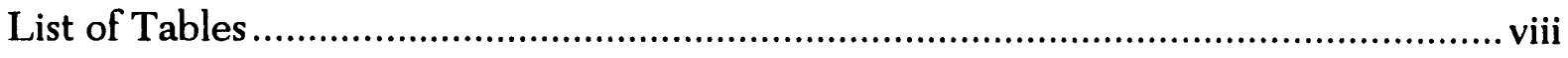

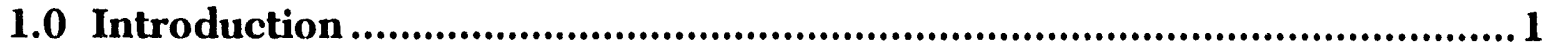

2.0 Assumptions and Input Model Description ....................................... 3

3.0 A Few Words About Flow Stability ................................................ 18

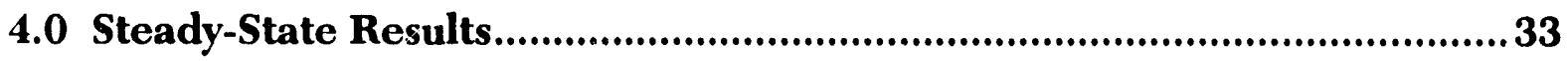

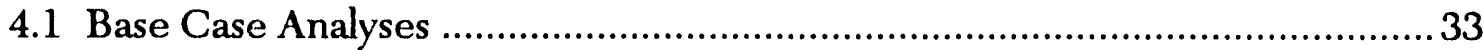

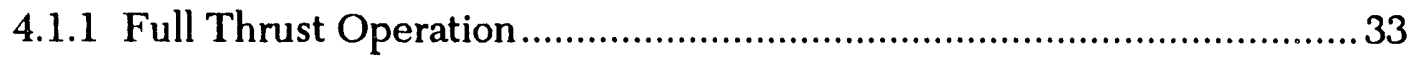

4.1.2 Reduced Thrust Operation ....................................................... 37

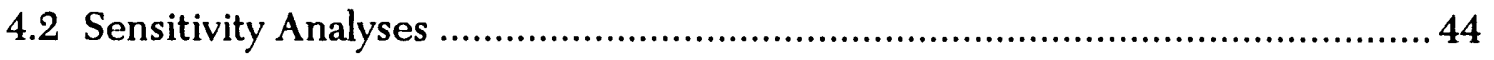

4.2.1 Transpiration Drag............................................................ 45

4.2.2 Moderator Heat Addition ........................................................ 46

4.2.3 Coolant Dispersion Conductivity Enhancement ......................... 47

4.2.4 Thermal Radiation Heat Transfer from Bed to Cold Frit.................. 49

4.2.5 Bed Friction Factor Correlation .............................................. 49

4.2.6 Element Entrance Coolant Temperature .................................... 49

4.2.7 Helium Coolant..................................................................... 50

4.2.8 Cylindrical Element Design................................................ 51

5.0 Transient Results.................................................................. 54

5.1 Decay Heat Removal .................................................................. 54

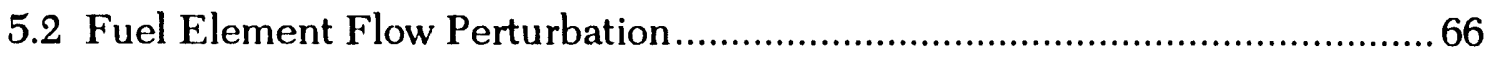

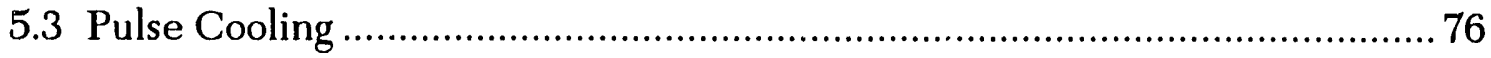

6.0 Summary, Observations, and Conclusions .........................................87

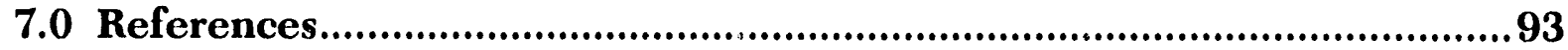

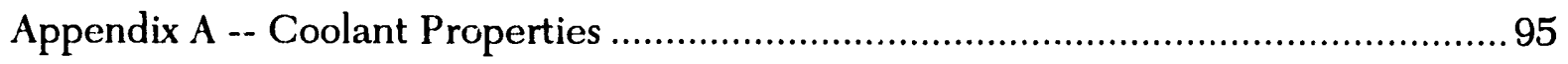

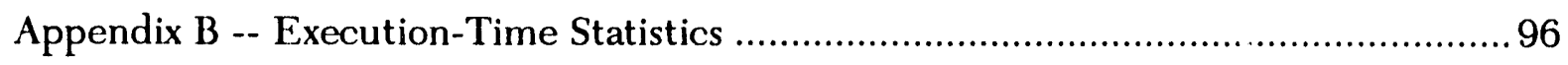

Appendix C -- Base Case Steady-State Output ............................................... 97 


\section{$\underline{\text { List of Figures }}$}

Figure

1. Particle Bed Fuel Element Ceometries. 13

2. SAFSIM Conical Fuel Element Input Model Schematic.... 14

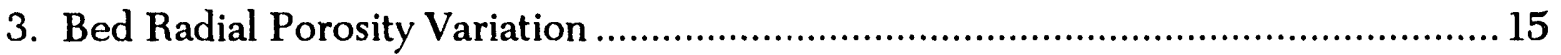

4. Relative Radial Power Density Profile in the Fuel Bed.................................. 15

5. Relative Radial Power Profile in the Fuel Bed ............................................. 16

6. Relative Axial Linear Heat Generation Rate in the Fuel Bed............................ 16

7. Fission and Decay Power Versus Time.................................................. 17

8. Power Deposited in the Element and Outside the Element ........................... 17

9. Channel Pressure Drop Characteristic Curves ........................................... 25

10. Pressure Drop Characteristic Curves With an Added Cold Frit ........................ 25

11. Pressure Drop Characteristic Curves for Two Different Channels.....................26

12. Graphical Solution of Two-Channel Flow Redistribution ............................... 26

13. Mass Flux Ratio for a Two-Channel Flow System ...................................... 27

14. Temperature Response for a Two-Channel Flow System ............................ 27

15. Pressure Distributions in the Two Channels .............................................28

16. Pressure Gradients in the Two Channels......................................................28

17. Temperature Distributions in the Two Channels ........................................ 29

18. Temperature Gradients in the Two Channels ........................................... 29

19. Temperature Distributions With Axial Conduction Included ..........................30

20. Critical Mass Flux Stability Regimes (Two-Channel System) ...........................30

21. Temperature Ratio Stability Regimes (Two-Channel System) .......................... 31

22. Mass Flow Rate for a Flow Redistribution Transient (Two-Channel System) ......31

23. Bed Temperature for a Flow Redistribution Transient (Two-Channel System) ... 32

24. Axial Temperature Profiles in the Fuel Element at Full Thrust..........................35

25. Axial Mass Flux Distribution at Full Thrust................................................... 35

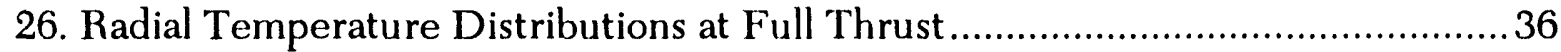

27. Axial Temperature Profiles in the Inlet Plenum and Cold Frit .........................36

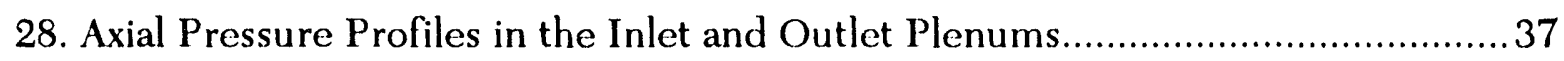




\section{List of Figures (Continued}

Figure

$\underline{\text { Pas,e }}$

29. Axial Pressure Profiles in the Inlet and Outlet Plenums at 0.05 Thrust Ratio ...... 't0

30. Particle Centerpoint Temperature Profiles at Reduced Thrust ....................... 40

31. Normalized Mass Flux Profiles at Reduced Thrust...................................... 41

32. Friction Factor Ratio Profiles in the Inlet Plenum at Full and Reduced Thrust .. 41

33. Friction Factor Ratio Profiles in the Outlet Plenum at Full and Reduced Thrust 42

34. Radial Temperature Distribution in a Fuel Particle..................................... 42

35. Chamber Temperature as a Function of Thrust Rat:o ................................ 43

36. Specific Impulse Ratio as a Function of Thrust Ratio ................................... 43

37. Pressure Response at Reduced Thrust................................................... 44

38. Effect of Modeling Assumptions on Calculated Cold Frit $l / d$.......................... 45

39. Effect of Transpiration Drag on the Particle Centerpoint Temperature Profile .. 46

40. The Effect of Moderator Heat Addition and Coolant Dispersion Conductivity Enhancement on the Particle Centerpoint Temperative. Profile.....................47

41. Effect of Coolant Dispersion Conductivity Entancemesit on the Coolant Radial Temperature Profile (Base Case Conditions) ............................................ 48

42. Effect of Coolant Dispersion Conductivity Enhancement ', n the Cold Frit Axial

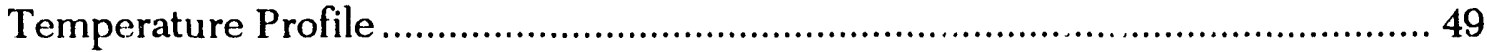

43. Effect of Coolant Entrance Temperature on the Particle C€iıcerpoint Temperature Profile .............................................................................. 50

44. Effect of Using Helium Coolant on the Particle Centerpoint Temperature Profile (0.1 Thrust Ratio) ............................................................... 51

45. Comparison of Cold Frit Axial Resistance Profiles for the Conical and Cylindrical Element Designs.... 52

46. Particle Centerpoint Temperatıre Profiles at Reduced Thrust fur the Cylindrical Element Design 53

47. Comparison of Specific Impulse Ratio for the Conical and Cylindrical Designs .. 53

48. Relative Power Deposited in the Fuel Element and Moderator Versus Time..... 60

49. Time-Dependent Coolant Temperature Response ...................................... 61

50. Time-Dependent Particle Centerpoint Temperature Response........................ 61

51. Fuel Element Pressure Response Versus Tirne .................................... 62

52. Time-Dependent Bed Surface Temperature Response (top axial bed level) ....... 62 


\section{List of Figures (Continued)}

Figure $\quad$ Page

53. Time-Dependent Bed Surface Temperature Response (bottom axial bed level) .. 63

54. Bed Surface Temperature Radial Profiles ..................................................63

55. Specific Impulse Ratio Versus Time (Base Case Transient) ...........................64

56. Required and Ideal Base Case Transient Flow Rates .................................64

57. Mass Flow Rate Correction Factor Versus Time (Base Case Transient) .............65

58. Mass Flow Rate Correction Factor Versus Relative Power (Base Case) .............65

59. Pressure Profiles in Cold Frit, Bed, and Hot Frit at $20 \mathrm{~s}$..............................66 66

60. Mass Flux Acceptability and Stability Maps for the Conical Element ................. 71

61. Temperature Ratio Acceptability and Stability Maps for the Conical Element.... 71

62. Imposed Flow Perturbation Mass Flux With the Acceptability and Stability Maps of the Conical Element ........................................................... 72

63. Particle Centerpoint Temperature for the Flow Perturbation Transient ............. 72

64. Bed Surface Temperature for the Flow Perturbation Transient (bottom level).... 73

65. Bed Surface Temperature for the Flow Perturbation Transient (top level) ......... 73

66. Bed Surface Radial Temperature Profiles (Flow Perturbation Transient) ........... 74

67. Outlet Plenum Coolant Temperature Response (Flow Perturbation Transient) .. 74

68. Surface Temperature Axial and Radial Profiles at $20 \mathrm{~s}$ (Flow Perturbation) ........ 75

69. Surface Temperature Axial and Radial Profiles at $60 \mathrm{~s}$ (Flow Perturbation) ........ 75

70. Particle Centerpoint Temperature Response to Pulse Cooling ........................ 80

71. Bed Surface Temperature Response in Bottom Axial Level (Pulse Cooling) ....... 80

72. Bed Surface Temperature Response in Top Axial Level (Pulse Cooling)............81

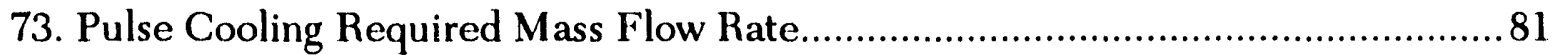

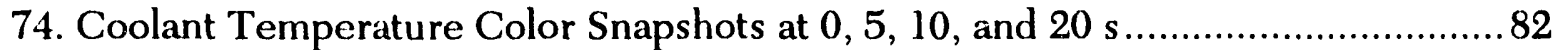

75. Coolant Temperature Color Snapshots at 60.7, 64.4, 79.8, and $84.1 \mathrm{~s}$ (Pulse Cooling).

76. Coolant Temperature Color Snapshots at 171.1 and $174.9 \mathrm{~s}$ (linear and logarithmic scales, Pulse Cooling).

77. Chamber Temperature During Pulse Cooling ........................................... 85

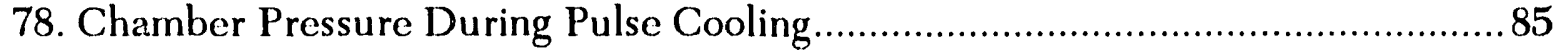

79. Pressure at the Nozzle Throat During Pulse Cooling................................. 86 


\section{List of Figures (Concluded)}

Figure

Page

Cl. Fluid Mechanics Finite Element Schematic ...

97 


\section{$\underline{\text { List of Tables }}$}

Table Page

1. Friction Factor Correlation Constants................................................... 19

2. Transient Mass Flow Rate Boundary Condition ...........................................54

3. Mass Flow Rate Correction Factors ....................................................... 57

4. Correlations for Mass Flow Rate Correction Factor as a Function of Time..........58

5. Correlations for Power as a Function of Time..............................................59

6. Coolant Inventories Required for Decay Heat Removal ................................59

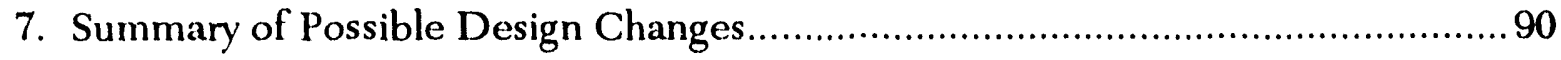

B 1. Steady-State Execution-Time Statistics ........................................... 96

B2. Transient Execution-Time Statistics.................................................. 96 


\subsection{Introduction}

The particle bed reactor ${ }^{1,2}$ is an advanced nuclear reactor concept with tremendous potential for space propulsion applications. The particle bed reactor offers the advantages of high thrust-to-weight and high specific impulse operation. These advantages arise primarily due to the high surface area-to-volume ratio of a packed bed of powerproducing fuel particles which affords high power density and high-temperature operation. The challenge is to design a particle bed fuel element that allows removal of the generated power without exceeding maximum operating temperature or structural limits. Furthermore, it is desirable to have a design that minimizes the uel element coolant mass flow rate at all operational power levels in order to maximize oper-

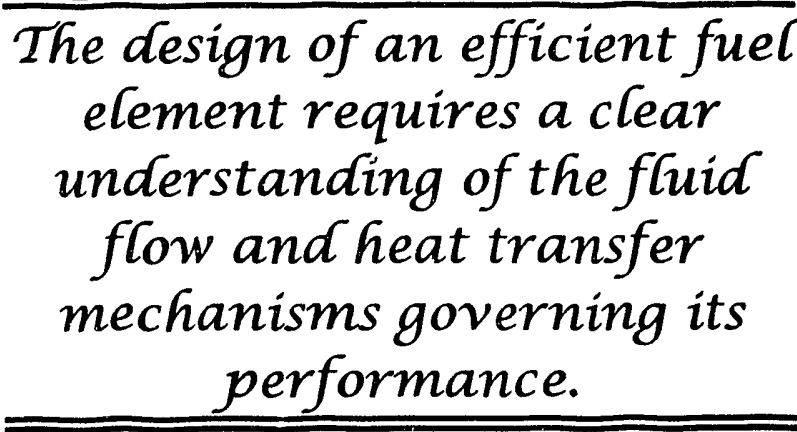
ational efficiency. The design of an efficient fuel element requires a clear understanding of the fluid flow and heat transfer mechanisms governing its performance.

The parametric analyses described in this document address some of the fluid flow and heat transfer issues associated with operation of a particle bed fuel element. The calculations on which these analyses are based were performed using the SAFSIM (System Analysis Flow SIMulator) computer program. ${ }^{3}$ SAFSIM is a one-dimensional (1-D), general-purpose computer program that provides engineering simulations of complex flow problems. As such, it is well suited to provide first-look, parametric performance calculations for conceptual fuel element designs with minimal computer resources. The analyses were not intended to be exhaustive in scope. Instead, an attempt was made to touch on many of the important issues of concern with regard to steady-state and transient particle bed fuel element performance. The analyses help to identify where more detailed work (both computational and experimental) is required. The addressed issues are provided in the following list:

1. Stability of gas flow systems

2. Cold frit axial resistance profile tailoring for optimum coolant efficiency

3. Steady-state operation at full thrust (power)

4. Reduced thrust operation

5. Effect of transpiration drag on wall friction in the inlet and outlet plenums

6. Effect of moderator heat addition to the inlet plenum coolant

7. Effect of coolant conductivity enhancement due to fluid dispersion in the packed bed of fuel particles

8. Effect of thermal radiation heat transfer from bed to cold frit

9. Effect of friction factor correlations for flow in the packed fuel bed

10. Effect of fuel element coolant inlet temperature

11. Effect of using helium instead of hydrogen coolant 
12. Effect of a cylindrical instead of a conical fuel element design

13. Removal of decay heat following reactor shutdown

14. Effect of an element flow perturbation during decay heat removal

15. Pulse cooling during decay heat removal.

The initial objective of this work was to obtain a reasonable estimate of decay heat removal (item 13) coolant requirements for a fuel element ground test facility, accounting for flow maldistributions within the fuel element. An estimate of coolant mass flow rate is important with respect to supply tank sizing. As work proceeded, it became clear that determining such an estimate is strongly dependent on the assumed element design, the assumed operating conditions, and the numerical modeling assumptions. Thus the need to address all of the other items in the list evolved out of the desire to provide reasonable estimates of decay heat removal cooling requirements. Because much was learned from these parametric analyses, it was felt worthwhile to document the results. As such, this report provides an overview of particle bed element modeling requirements and performance predictions. Many plots are included to demonstrate the complexities of the predicted performance. A variety of plot formats are employed to aid in the visualization process. Because there are so many figures, they are placed at the end of the respective section or subsection to provide continuity of the text.

The fifteen issues are not discussed in the order that the analyses were performed nor in order of increasing or decreasing complexity. Instead, they are ordered precursively such that understanding of each issue helps in the understanding of the issues that follow. Therefore, the reader is encouraged to be patient when a discussion appears that does not seem immediately relevant. In general, the topics of all the sections and subsections are related. Therefore, frequent cross references are made to help direct the reader to related discussions.

The next section provides a brief description of the assumptions used and the input model developed for all the analyses to follow. Thus a consistent model description appears in a single section for easy reference, with further details included in the pertinent sections and subsections. Section 3 then provides a quick tutorial on gas flow stability in heated flow channels. These two sections should provide the reader with sufficient information to properly interpret, appreciate, and understand the many results presented in the remainder of the document.

\section{"For the understanding may set the imagination into motion or, on the other hand, be set into motion by it."}

Rene Descartes, Rules for the Direction of Mind 


\subsection{Assumptions and Input Model Description}

The SAFSIM computer program served as the computational tool for all calculations described in this document. An overview of SAFSIM is provided in Reference 3. For completeness, many comments concerning SAFSIM are included in this section and throughout the results sections. SAFSIM is a computer program under development to investigate the steady-state and transient performance of complex flow systems at an engineering level. It provides approximate solutions to complex problems involving fluid flow, heat transfer, and reactor dynamics and is therefore a valuable tool for performing parametric simulations of conceptual nuclear reactor designs.

SAFSIM solves the equations governing compressible or incompressible fluid flow (conservation of mass, momentum, and energy) using a 1-D finite element network approach. Also, SAFSIM solves the equation governing the transfer of energy within a solid structure (the conduction equation) with appropriate convection, heat flux, or temperature boundary conditions. Again, a l-D finite element approach is used. Any number of fluid flow networks and heat transfer structures can be included. Thus, the user can "build" a geometric representation of any system by appropriately coupling networks of fluid flow and heat transfer finite elements. (Solution of the reactor dynamics equations, based on a point kinetics model with feedback, can also be coupled to the fluid mechanics and heat transfer solutions if desired.)

Although the fluid flow and heat transfer solutions are 1-D, any number of flow paths can be connected in series or parallel to provide a pseudo multidimensional representation of a system. For example, a particle bed fuel element is modeled as several parallel radial flow paths for the cold frit, fuel bed, and hot frit connected by axial flow inlet and outlet plenums. As long as the heat and fluid flow are predominately in the radial direction within the element, this approach is reasonable. (Special SAFSIM features account for the turning of the flow in the plenums and are discussed later.) Fortunately, the 1-D network approximation is very good for many flow systems and situations of interest, as will be demonstrated in the results discussions.

Although many fuel elements could be connected to form an entire reactor, only a single particle bed fuel element is modeled for these analyses. Two SAFSIM input models were created to represent the fuel element. One model is based on a conical element design and the other model is based on a cylindrical element design. Figure 1 is included to demonstrate the two different element geometries. Most calculations in this document are based on the conical element design; the cylindrical element design is used in parametric calculations described in Section 4.2.8. The motivation for the conical element design is to provide an outlet plenum pressure drop (dominated by changes in the dynamic pressure) that remains relatively constant at different fuel element mass flow rates. As will be demonstrated, this is one way to reduce the performance degradation that occurs during reduced power operation. 
The conical element was selected to have a taper ratio of 1.6 , which is the ratio' of the outlet plenum exit diameter to the outlet plenum diameter at the top of the element. ( $A$ conical element with this taper ratio is not necessarily the optimum geometry; additional parametric calculations could address this issue. However, manufacturability, assembly, and structural characteristics should also be addressed.) The exit diameter was selected to provide an exit Mach number of 0.2 during full power operation. This Mach number is consistent with the NERVA 4 reactors and may not be appropriate, or optimum, for particle bed elements. Coating erosion was one of the concerns with respect to Mach number for the NERVA reactors. The cylindrical element model was created assuming a uniform outlet plenum diameter. This diameter was chosen to equal the outlet plenum exit diameter of the conical element. The bed outer diameter was then determined to provide the same fuel bed volume as the conical element. Both fuel elements are $0.8 \mathrm{~m}$ in height.

The cold frits are assumed to be $3 \mathrm{~mm}$ thick and made of porous stainless steel. A porosity of 0.28 is used along with an effective pore diameter of $25 \mu \mathrm{m}$. The hot frits are assumed to be $3 \mathrm{~mm}$ thick and made of graphite with $250-\mu \mathrm{m}$ diameter holes drilled radially through for coolant flow. The inlet plenum gap is $3 \mathrm{~mm}$ wide at the top and $1 \mathrm{~mm}$ wide at the bottom. The fuel particles are assumed to be $400-\mu \mathrm{m}$ diameter spheres, each consisting of an inner uranium dicarbide fuel region surrounded by a porous buffer layer of carbon which in turn is coated with a layer of high density carbon and another layer of zirconium carbide. Such multilayered fuel particles and their thermal and structural performance are discussed in Reference 5; material properties are also taken from this Reference. These conical and cylindrical fuel element designs are hypothetical and the dimensions were selected to provide what is believed to be a reasonable geometry. These preliminary designs provide a starting point for analysis and discussion.

A schematic of the conical element design, color coded by region, is provided in Figure 2. Both input models consist of 145 fluid mechanics finite elements and 177 structure heat transfer finite elements. Nine of the structure finite elements are in the moderator and 42 structure finite elements are used to model six individual fuel particles. The remaining 126 structure finite elements are used to model the hot frit, bed, and cold frit. The models each contain a total of 34 heat transfer structures. There are nine axial levels and 14 radial regions in the fuel element. Ten of the radial regions are in the fuel bed, two are in the cold frit, and two are in the hot frit. Analogous to the multiple axial levels, the finite element networks could be extended to model several azimuthal sectors to account for any azimuthal variations of power, porosity, and so forth. However, for these preliminary calculations, no azimuthal variations are assumed and the models are axisymmetric about the vertical axis.

The reader is reminded that although the SAFSIM input models contain multiple axial and radial regions, the models are 1-D. Coolant and heat can flow radially in each of the axial bed levels but cannot flow axially between the levels; axial flow occurs only in the inlet and outlet plenums. It is expected that a full multidimensional calculation would provide somewhat different results; however, these 1-D network calculations provide a

page --4 
very ge sd approximation of fuel element performance with significantly less computer resources than would be required for comparable multidimensional calculations.

Except for one parametric case using helium, the coolant is assumed to be para hydrogen and is treated as an ideal gas with temperature-dependent thermophysical properties. The coolant properties are provided in Appendix A. Coolant enters at the top of the fuel element and flows axially down the inlet plenum between the cold frit and the assumed beryllium moderator (not shown in Figure 2). The coolant then turns radially inward as it flows through the cold frit, fuel bed, and hot frit. Finally, the coolant turns again in the outlet plenum and flows axially downward to the fuel element exit. Note that the top and bottom axial levels are one-half the height of the other equal-height levels; this increases numerical resolution near the entrance and exit of the fuel element. Also, the thicknesses of the ten radial finite elements in the fuel bed become progressively smaller towards the cold frit because the coolant and bed temperature gradients are largest near the bed entrance for most operational scenarios.

Distributed flow manifold finite elements are used to represent the inlet and outlet plenums. These special finite elements provide three ports for entering/exiting flow (compared to two ports for the standard 1-D finite elements). Including three ports allows this finite element to account for the merging of the flow streams in a manifold or tee. Such a pseudo two-dimensional (2-D) finite element is necessary to predict the changes in dynamic pressure along the entire plenum lengths. Calculation of the dynamic pressure in the inlet and outlet plenums is essential to the accurate prediction of the particle bed element performance.

The distributed flow manifold finite element provides options for automatic determination of the loss coefficients, via correlation, ${ }^{6}$ to account for the drag due to transpiration flow in the annular inlet plenum at the cold frit (sucking flow) and in the outlet plenum at the hot frit (blowing flow). For flow in the design direction, wall friction drag is enhanced between the inlet plenum fluid and cold frit due to a thinning of the boundary layer and diminished between the outlet plenum fluid and hot frit due to a thickening of the boundary layer. The correlations also account for turning losses. The transpiration drag options for loss coefficients are used in both input models, and the effect of the piedicted drag on the fuel element performance is discussed in Section 4.2.1.

In addition to affecting pressure drop, transpiration flow affects the convection heat transfer occurring between the coolant in the inlet plenum and the cold frit, and between the coolant in the oullet plenum and the hot frit due to the axially-flowing coolant. The correlation of Petukhov ${ }^{7}$ is used in both plenums to determine the heat transfer coefficient for this convection. This heat transfer coefficient correlation is a function of the calculated friction factor. Because SAFSIM determines an effective friction factor that accounts for the transpiration flow added loss coefficients, the enhancement or deenhancement of convection due to transpiration flow is also accounted for. 
The body force due to gravity is included in the inlet and outlet plenums based on an acceleration of $9.8 \mathrm{~m} / \mathrm{s}^{2}$. This is the acceleration on earth at sea level and is frequently referred to as a 1-g environment. Because of the low coolant density, the pressure drop due to gravity (potential energy) is much smaller than that due to friction and dynamic effects. It should be noted that for some potential nuclear rocket applications, the acceleration may be much greater than $1 \mathrm{~g}$, and may have a minor impact on the flow field.

The correlations of Achenbach ${ }^{8}$ for friction factor and convection heat transfer coefficient in a porous media are used in the bed and cold frit finite elements for all Reynolds numbers. The friction factor and convection heat transfer coefficient for radial flow through the hot frit is based on the correlations of Petukhov, which are the same as used for axial flow in the inlet and outlet plenums. The correlations of Petukhov are used only for turbulent flow (Reynolds numbers greater than 4000). For laminar flow (Reynolds numbers less than 2200), the friction factor is calculated as 64 divided by the Reynolds number, and the heat transfer coefficient is based on a constant Nusselt number of 3.66. Reynolds number weighted averages of the laminar and turbulent values are used for transition flow $(2200<R e<4000)$ for both the friction factor and the heat transfer coefficient. The correlations of Petukhov are also used for flow past the moderator.

The radial porosity variation in the bed due to wall effects is included in the SAFSIM input model based on the following simple exponential equation: ${ }^{9}$

$$
\varepsilon=\varepsilon_{\infty}+\left(1-\varepsilon_{\infty}\right) \mathrm{e}^{\left[\frac{-2 s}{d}\right]}
$$

where

$\varepsilon$ is the local bed porosity,

$\varepsilon_{\infty}$ is the average bed porosity away from the walls $(0.37$ assumed),

$s$ is the radial distance from the wall, and

$d$ is the particle diameter.

This correlation accounts for the fact that at a wall (frits), the porosity equals 1.0. Away from the frits, the porosity is assumed to equal 0.37 . Figure 3 shows the bed porosity as a function of bed racial position for the top and bottom axial levels of the fuel element model. (Note that the inside radius of the bottom axial level is greater than the outside radius of the top axial level because of the assumed tapered element design.) The higher porosity near the frits reduces the surface area and the amount of power generated at those locations and thus affects the radial temperature profiles in the bed.

Loss coefficients, in the form of both $K$ factors and additional $l / d$, are added to the cold frit to vary the axial flow distribution through the fuel element. [ $K$ factors $(f l / d)$ and additional $l / d$ are two common methods of adding resistance in fluid mechanics modeling to account for multidimensional or other nonstandard geometric effects.] $K$ factors are 
first added uniformly to all cold frit finite elements to provide a cold frit pressure drop that is roughly five times that of the fuel bed at full power steady-state conditions. Additional $l / d$ is then added to the outer radial region of cold frit finite elements to tailor the flow distribution through the fuel element. The added $l / d$ loss coefficients are determined iteratively, using SAFSIM, such that the centerpoint temperature of all fuel particles at the exit of the bed are equal at full power conditions. Thus, the centerpoint temperature axial profile is uniform at the bed exit. Note that the particle centerpoint temperature, and not the bed surface or coolant temperature profile, is the basis for adjusting the cold frit resistance. Such tailoring of the cold frit axial resistance is important with respect to optimizing the propulsive performance of the element (this is discussed in Section 4.0). It should also be pointed out that the just described method of adding resistance to the cold frit may not provide representative pressure drops at all flow rates and temperatures. The method should be checked and appropriately modified when actual cold frit performance data becomes available.

Each axial level of the bed is modeled as a heat transfer structure with ten radial finite elements. Although not required by SAFSIM, there is a one-to-one correspondence between structure and fluid mechanics finite elements in the bed. The material properties for the bed are an average of the properties of the individual materials comprising the particles (specific heat is mass weighted and density is volume weighted). An effective bed conductivity is used that accounts for conduction at the particle contact points and for thermal radiation from particle to particle. (Conduction within the coolant is included in the thermal energy equation for the fluid mechanics solution.) The effective bed conductivity is based on the work of Schotte ${ }^{10}$ and is a function of particle diameter, bed porosity, solid conductivity, and emissivity. For the small-diameter particles assumed in this fuel element model, the bed conductivity is dominated by thermal radiation and Schotte's equation reduces to:

$$
k_{b e d}=1 \cdot 10^{-10} T^{3}
$$

where

$k_{\text {bed }}$ is the effective bed conductivity in units of $\mathrm{W} / \mathrm{m}-\mathrm{K}$, and

$T$ is the bed surface temperature in $\mathbf{K}$.

Each axial level of the hot and cold frits is also modeled as a separate heat transfer structure with two radial finite elements. In addition to coolant conduction, heat transfer by thermal radiation from the surface of the bed to the hot and cold frits is included in the input models. Emissivities of 0.5 were assumed for the hot frit, bed, and cold frit surfaces. Also, a view factor of 1.0 was assumed for the bed-to-frit therrnal radiation. A single structure could have been used to model the hot frit, bed, and cold frit materials for each axial level. However, it was found that because of the very different power densities and properties of the three regions, unreasonable results occurred at the interface nodes. 
Modeling the bed of fuel particles as a pseudo material with representative properties is computationally efficient. However, this approach relies on the use of a temperaturedependent "lumped" heat capacity for the particles based on the heat capacities of the individual materials within the particle (fuel and coatings). Such a model for transient conduction is referred to as a multiple-lump, lumped-capacitance model. As an engineering rule of thumb, a lumped-capacitance approach is adequate for transient conduction modeling as long as the Biot number is less than a value of about 0.1. The Biot number is defined as the ratio of the thermal resistance due to fluid convection at the surface to the resistance to conduction within the solid. The Biot number for the fuel particles ranges from about 0.2 to 1.0. To remedy this in the lumped-capacitance model, it is possible to modify the heat transfer coefficient to approximately account for the large internal conductive resistance of the particles. The following equations, generalized from Reference 11, provide the necessary heat transfer coefficient correction for a structure with spherical geometry:

$$
\begin{gathered}
h^{\prime}=\frac{U h}{w^{\prime} h+U} \\
U=\left[\sum_{j=1}^{n} \frac{1}{U_{j}}\right]^{-1} \\
U_{0}=\infty \\
U_{j}=\frac{k_{j}}{R^{2}}\left(\frac{r_{j} r_{j+1}}{r_{j}-r_{j+1}}\right) \text { for } j=1 \text { to } n-1 \\
U_{n}=\frac{2 k_{n}}{3 R} \\
w^{\prime}=\frac{\sum_{j=1}^{n} m_{j} c_{j}\left(w_{j}+w_{j-1}\right)}{2 \sum_{j=1}^{n} m_{j} c_{j}} \\
w_{0}=0
\end{gathered}
$$




$$
\begin{gathered}
w_{j}=\frac{U}{U_{j}}+w_{j-1} \quad \text { for } j=1 \text { to } n-1 \\
w_{n}=1
\end{gathered}
$$

where

$h^{\prime}$ is the effective heat transfer coefficient for the multiregion sphere,

$U$ is the effective inverse resistance for the sphere,

$h$ is the unmodified heat transfer coefficient,

$w^{\prime}$ is an effective weighting factor for the sphere,

$n$ is the number of radial regions,

$j$ is the region index ( $j=1$ for the outermost radial region),

$U_{j}$ is the inverse resistance of region $j$,

$k_{j}$ is the thermal conductivity of region $j$,

$R$ is the outside radius of the sphere,

$r_{j}$ is the outside radius of region $j$,

$m_{j}$ is the mass of region $j$,

$c_{j}$ is the specific heat of region $j$, and

$w_{j}$ is a weighting factor for region $j$.

The values of $w^{\prime}$ and $U$ in Equation (3) are temperature dependent because the material properties are temperature dependent. It was found that the value of $w^{\prime}$ varied only slightly as a function of temperature and that a single value of 0.31 was representative of all temperatures for the assumed particle. The value of $U$, however, varies greatly with temperature. Therefore, the following expression, based on a curve fit of the $U$ versus temperature results, provides the temperature-dependent value of $U$ :

$$
U=\frac{106,692.77+66.12 T}{1+0.006463 T}
$$

where

$U$ is in units of $\mathrm{W} / \mathrm{m}^{2}-\mathrm{K}$, and

$T$ is the structure temperature in $\mathrm{K}$.

It is important to recognize that the structure temperature predicted with this approach is not an average particle temperature. Instead, it represents the effective temperature required to give the correct transient heat transfer response accounting for the internal resistance of the particles. Comparison of the effective temperature with the temperature predicted by a model employing multiple finite elements in a fuel particle indicates that the effective temperature is close to the particle surface temperature. Thus, 
for convenience, this temperature is referred to as the bed surface temperature throughout this document.

In addition to the bed heat transfer structures, additional structures are included in the SAFSIM input models to represent individual fuel particles with multiple layers. Six fuel particle structures are included, five are convectively coupled to the coolant in levels $1,3,5,7$, and 9 at the bed exit and one in level 9 at the bed entrance. Level 1 is at the bottom and level 9 is at the top. Seven conduction finite elements are used in each particle. These supplemental structures allow the prediction of the temperature distribution within a particle, which is of interest for particle bed element calculations. Redundant heat addition to the coolant is avoided by specifying the number of COPIES ( $a$ SAFSIM input variable) to equal zero for these structures.

The conduction model just discussed is but one method of modeling the bed and fuel particles using SAFSIM. This method includes all the relevant physics (including both inter and intraparticle conduction) and, based on experience, was found to provide the best overall combination of accuracy and efficiency.

In addition to conduction within the bed structure, conduction occurs within the coolant flowing th: ough the bed. Coolant conduction in a porous media is enhanced due to dispersion effects as the coolant takes its tortuous path over and between the particles. SAFSIM accounts for the dispersion conduc:ivity enhancement through use of the following correlation: ${ }^{12}$

$$
k^{\prime} / k=\phi \operatorname{Re} P r
$$

where

$k^{\prime}$ is the conductivity modified for dispersion effects,

$k$ is the unmodified coolant thermal conductivity,

$\phi$ is the dispersion conductivity coefficient,

$R e$ is the superficial Reynolds number based on particle diameter, and

$\mathrm{Pr}$ is the Prandtl number based on the unmodified conductivity.

The coefficient, $\phi$, in this correlation can be specified for each porous media finite element in the model and typically ranges from 0.2 to 0.5 . The sensitivity of the results to this coefficient is discussed in Section 4.2.3.

The analyses discussed in this document are intended to address fuel element performance as opposed to reactor performance. However, it is necessary to model some portion of the reactor moderator because heat is transferred to the coolant from the moderator as it flows down the inlet plenum. This heating has an impact on the flow distribution entering the element. Therefore, a $1-\mathrm{cm}$-thick annular ring of beryllium 
moderator is assumed to surround the fuel element. The effect of heat addition from the moderator to the coolant is discussed in Section 4.2.2.

The axial power density profile in the fuel bed is assumed to be uniform. The radial power density profile is determined for each of the nine axial levels assuming an exponential shape based on the following equation:

$$
\Omega=\mathrm{e}^{-\Sigma_{a} r}+\mathrm{e}^{-\Sigma_{a}(2 \delta-r)}
$$

where

$\Omega$ is the relative power density,

$\Sigma_{a}$ is the neutron absorption coefficient in the bed (a value of $203 \mathrm{rr}^{-1}$ was assumed),

$r$ is the distance from the bed outer radial position, and

$\delta$ is the bed thickness.

The resulting power density profiles for the top and bottom axial levels of the conical element are provided in Figure 4. The profile is different for each level due to the axiallyvarying bed thickness of the tapered element. The power profile (power density integrated over the volume) for the top and bottom axial levels is provided in Figure 5. The power dips at the inner and outer radial locations because of the increase in bed porosity at those locations, as was demonstrated in Figure 3. Although the axial power density profile is assumed to be uniform, the power profile is not uniform because the bed volume is different for each axial level. Figure 6 shows the linear heat generation rate (power per unit bed height) as a function of axial position. (A relative axial position of zero references the bottom of the element and a position of one references the top.) The nonuniform profile is important to note because it means that the axial power profile can be modified by the element designer by changing the taper of the hot and cold frits. Advantage of this power shaping option should be taken when designing a fuel element.

For the transient calculations, the time dependence of power is determined by solution of the point reactor dynamic equations. Fifteen delayed neutron precursor groups are used based on data for beryllium moderated systems. The decay constants and delayed neutron fractions are taken from Keepin. ${ }^{13} \mathrm{~A}$ value of 1.068 is used for the ratio of the effective delayed neutron fraction to the total delayed neutron fraction to account for neutron leakage from the reactor. The effective prompt neutron generation time is $5.4 \cdot 10^{-4} \mathrm{~s}$ and the total delayed neutron fraction $(\beta)$ is 0.00711 . Solution for the decay power is also included in the reactor dynamics model. Eleven decay heat groups are used with the decay constants and decay heat fractions based on the American Nuclear Society (ANS) standard. ${ }^{14}$ The total decay heat fraction is 0.0699 , which means that approximately $7 \%$ of the instantaneous neutron power appears as decay heat. The prompt fission power is $93 \%$ of the neutron power. 
Reactor shutdown is modeled assuming the insertion of $\$ 10$ of negative reactivity over a 1-s time interval by the rotation of control drums. The following sinusoidal relationship provides the time dependence of reactivity insertion used in the transient calculations:

$$
\frac{\partial \tilde{\rho}}{\partial t}=-15.7 \sin (\pi t)
$$

where

$\tilde{\rho}$ is the reactivity in $\$\left(\Delta k_{\mathrm{e}} / \beta k_{\mathrm{e}}\right.$ where $k_{\mathrm{e}}$ is the effective multiplication factor), and $t$ is the time after shutdown initiation in $\mathbf{s}$.

During operation, some of the thermal power is generated by fission and some by gamma and beta rays. Also, some of the power appears essentially immediately (prompt power) and some is delayed (decay power). It is assumed that $95 \%$ of the prompt power and $50 \%$ of the decay power is deposited in the fuel bed. This is important because the fraction of thermal power deposited in the element, relative to the power deposited in the moderator, changes with time after reactor shutdown as the prompt power diminishes. Figure 7 shows the decay, fission, and thermal power for the first $60 \mathrm{~s}$ following reactor shutdown following steady-state operation. Figure 8 shows the thermal power deposited inside and outside the fuel element. These figures are included here to demonstrate the changing bed/moderator power distributions that occur during reactor shutdown and during reduced power operation.

The shape of the power density profile in the bed is assumed to remain constant at all power levels. For very low power levels, this may not be a valid assumption because a large fraction of the power may be produced by gamma and beta radiation from the decay of fission products. The absorption coefficients of gamma and beta rays are different than the absorption coefficient of fission generated neutrons. Detailed neutronic calculations are required to define the power density profiles as a function of power level and power history. Because the neutronic calculations depend on the design of the entire reactor, this issue is not addressed further in these preliminary thermal analyses.

A choked flow boundary finite element at the fuel element exit models a converging nozzle. A discharge coefficient of 0.98 was assumed for the nozzle. Also, a backpressure of $0.1 \mathrm{MPa}$ was selected. As long as the flow remains choked, this backpressure selection has no impact on the element performance. The throat area of the nozzle was selected to provide a fuel element exit pressure of $7 \mathrm{MPa}$ during full power operation. The coolant temperature at the entrance to the fuel element is assumed to be $200 \mathrm{~K}$. Also, a mass flow rate is specified as a boundary condition at the fuel element entrance. A mass flow rate boundary condition is employed because the use of a pressure boundary condition would require the inclusion of a controller to properly adjust the pressure, via valve opening or 
pump speed variations, to achieve the desired flow rate. Using the mass flow rate boundary condition was simpler for these parametric analyses.

The design steady-state average power density in the bed is assumed to be $40 \mathrm{MW} / \mathrm{L}$. This is a goal for particle bed technology. Bed power density is defined as the thermal power deposited in the bed divided by the total geometric volume of the bed. The cold frit power density is assurned to be $0.37 \mathrm{MW} / \mathrm{L}$, the hot frit power density is $0.46 \mathrm{MW} / \mathrm{L}$, and the moderator power density is $0.046 \mathrm{MW} / \mathrm{L}$. The mass flow rate of the fuel element was selected to provide an exit coolant temperature of $3000 \mathrm{~K}$ during full power steadystate operation. This flow rate, calculated to be $0.65497 \mathrm{~kg} / \mathrm{s}$, defines the steady-state base case and results in a maximum particle centerpoint temperature of $3275 \mathrm{~K}$. These performance parameters are consistent with the performance goals outlined at the June 11 \& 12, 1992, Space Nuclear Propulsion Meeting sponsored by NE 50 and attended by representatives of NASA, DOE, and DOD.

The amount of information required to fully describe a particle bed element input model is enormous and not all of the information is provided in this section. Hopefully, enough information is provided to allow the reader to properly interpret the computed results. This section should also make it clear that many assumptions must be made before a flow and heat transfer simulation of a particle bed fucl element can be initiated. The parametric analyses discussed in this document indicate the sensitivity of the results to some of these assumptions. Some computer execution-time statistics are provided in Appendix $B$ to demonstrate the arnount of com-

The amount of information required to fully describe a particle bed element input model is enormous... many assumptions must be made before a simulation can be initiated. puter time required to perform detailed, $1-D$ network fuel element calculations using the SAFSIM computer program.

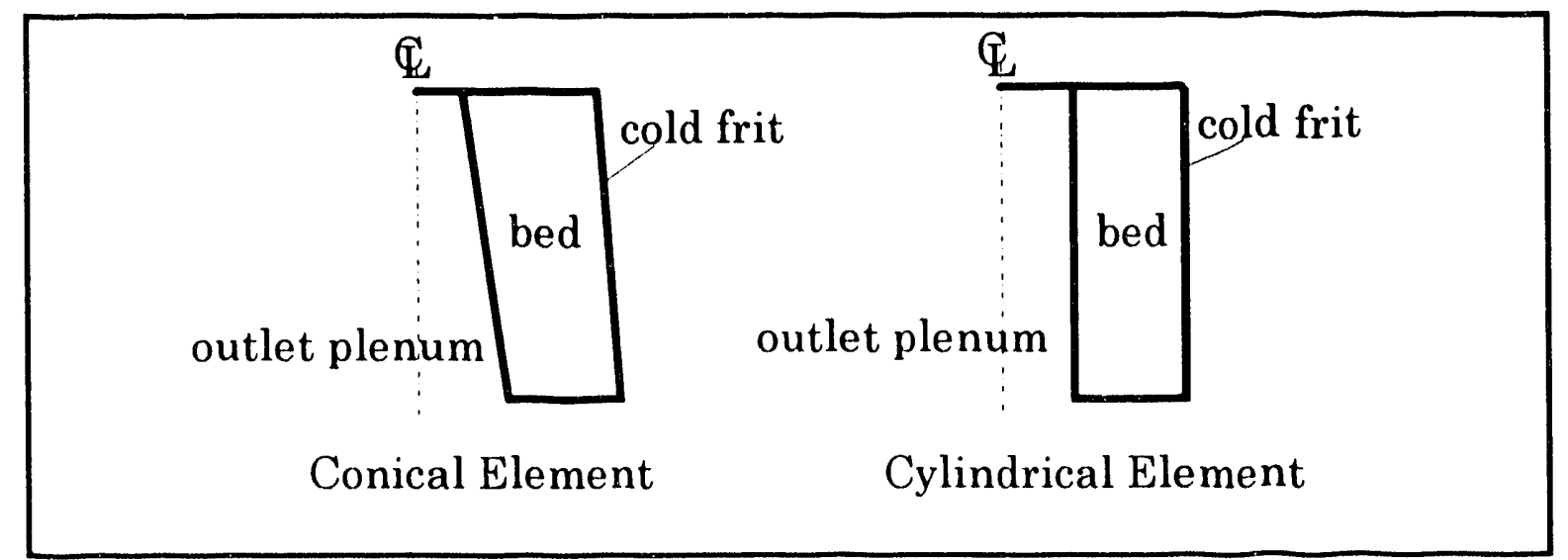

Figure 1. Particle Bed Fuel Element Ceometries 


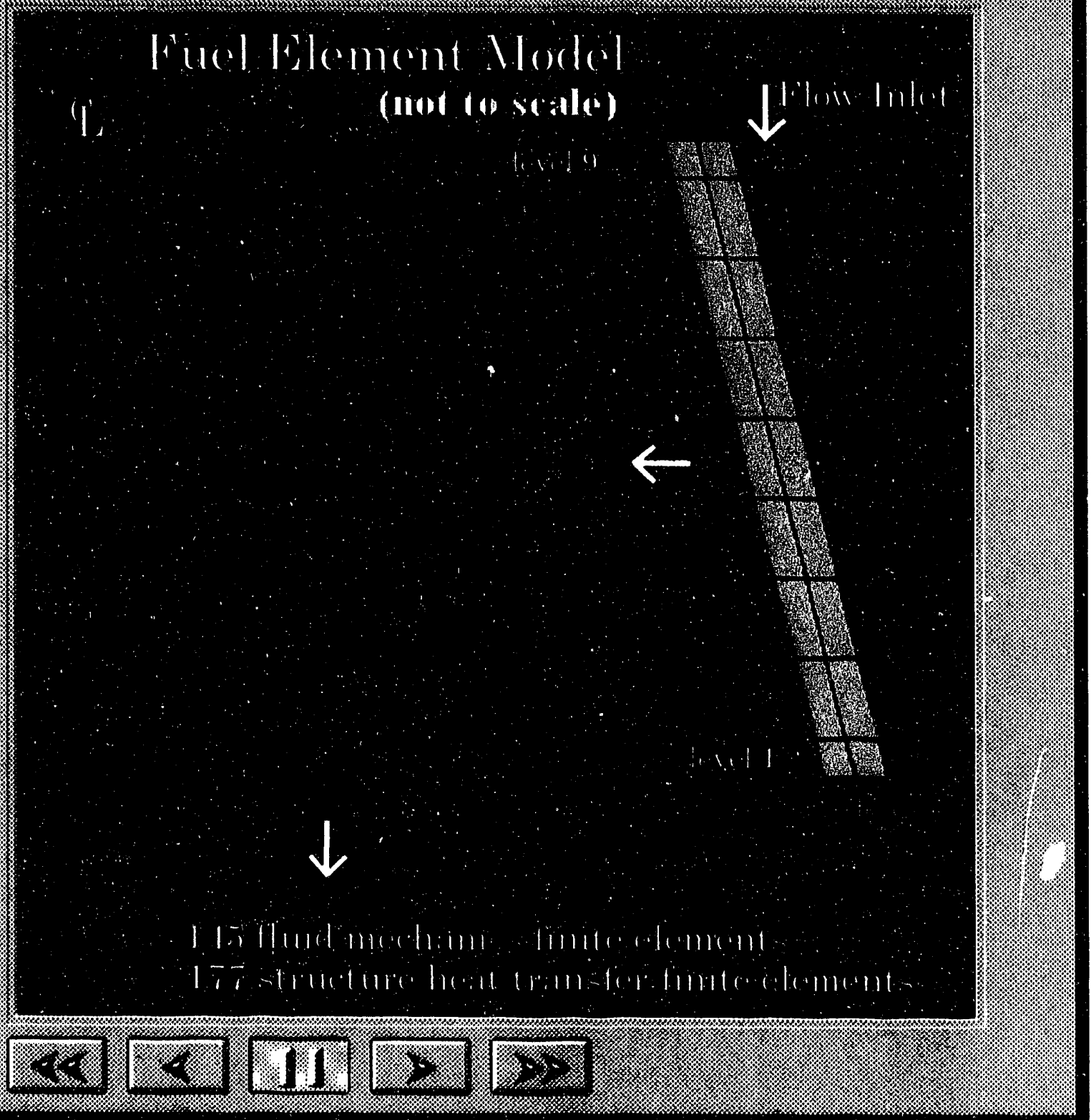

Figure 2. SAFSIM Conical Fuel Element Input Model Schematic 


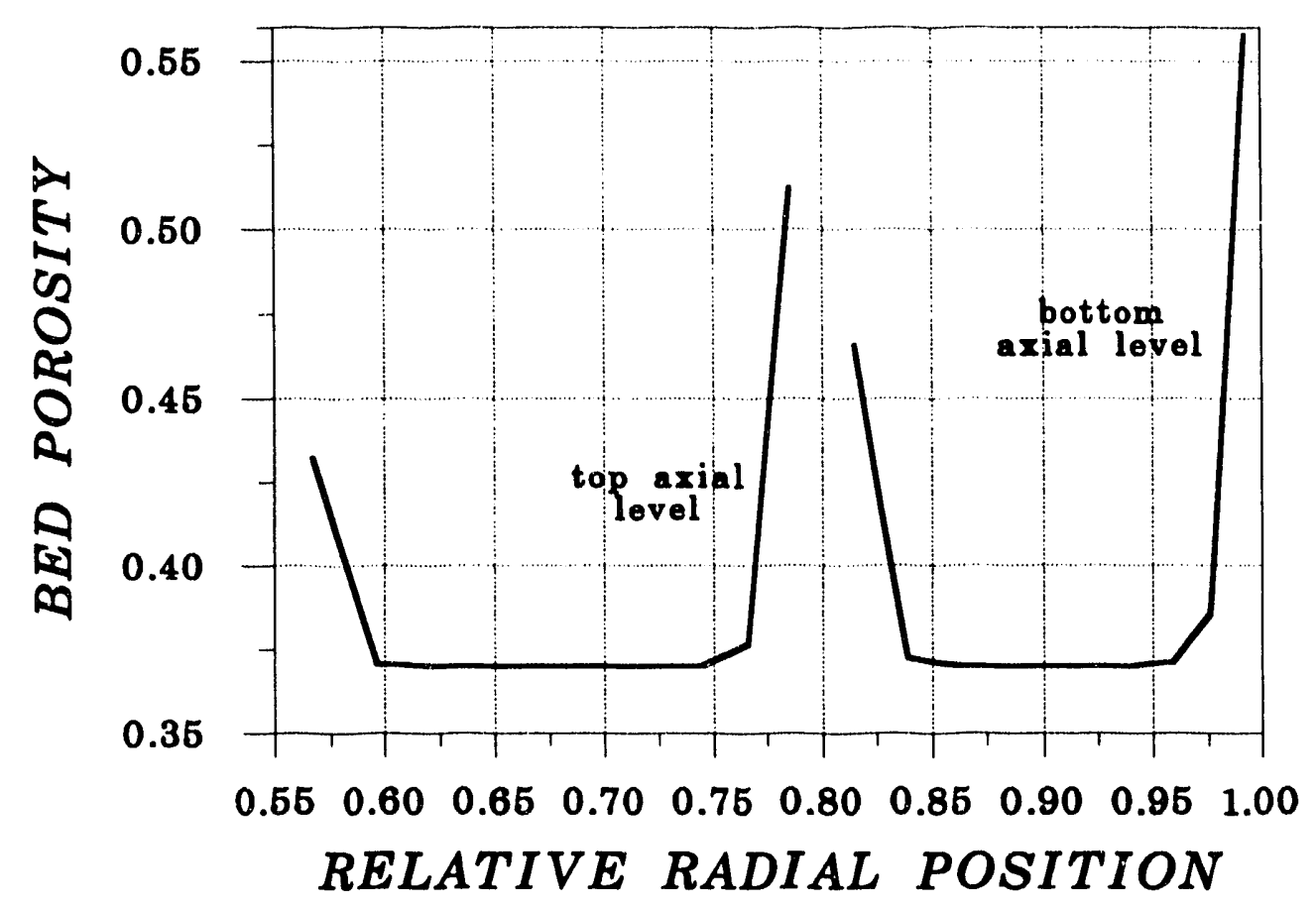

Figure 3. Bed Radial Porosity Variation

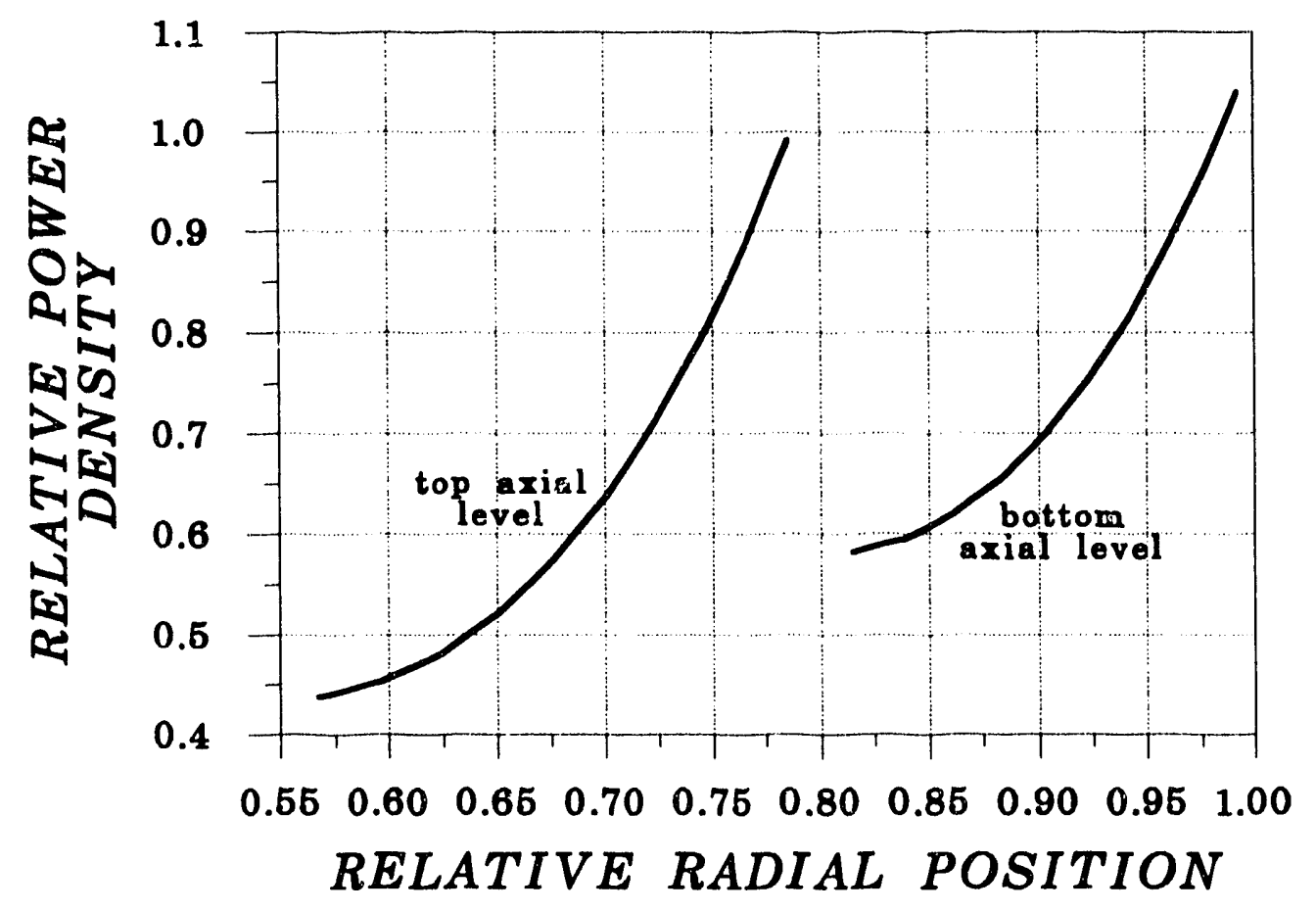

Figure 4. Relative Radial Power Density Profile in the Fuel Bed 


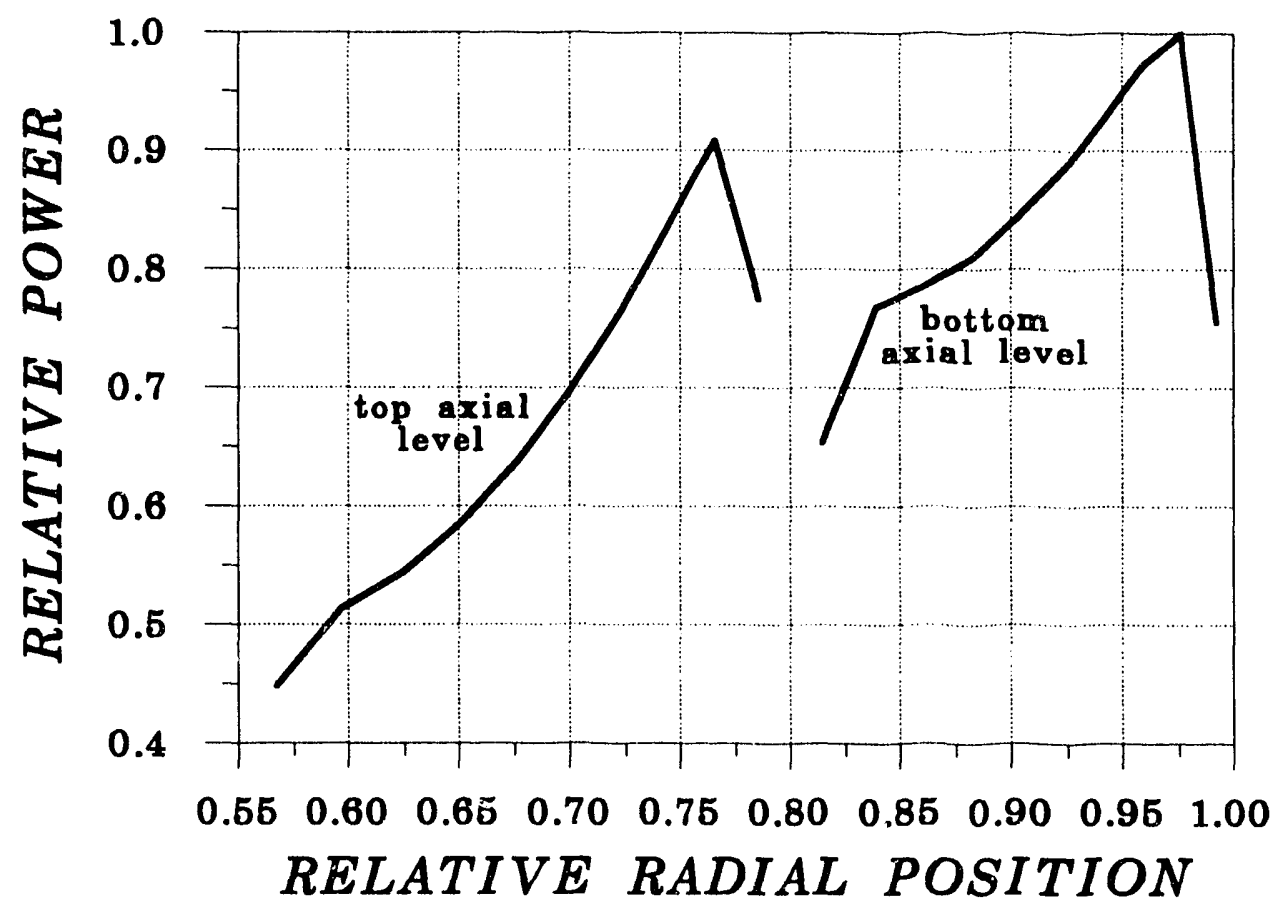

Figure 5. Relative Radial Power Profile in the Fuel Bed

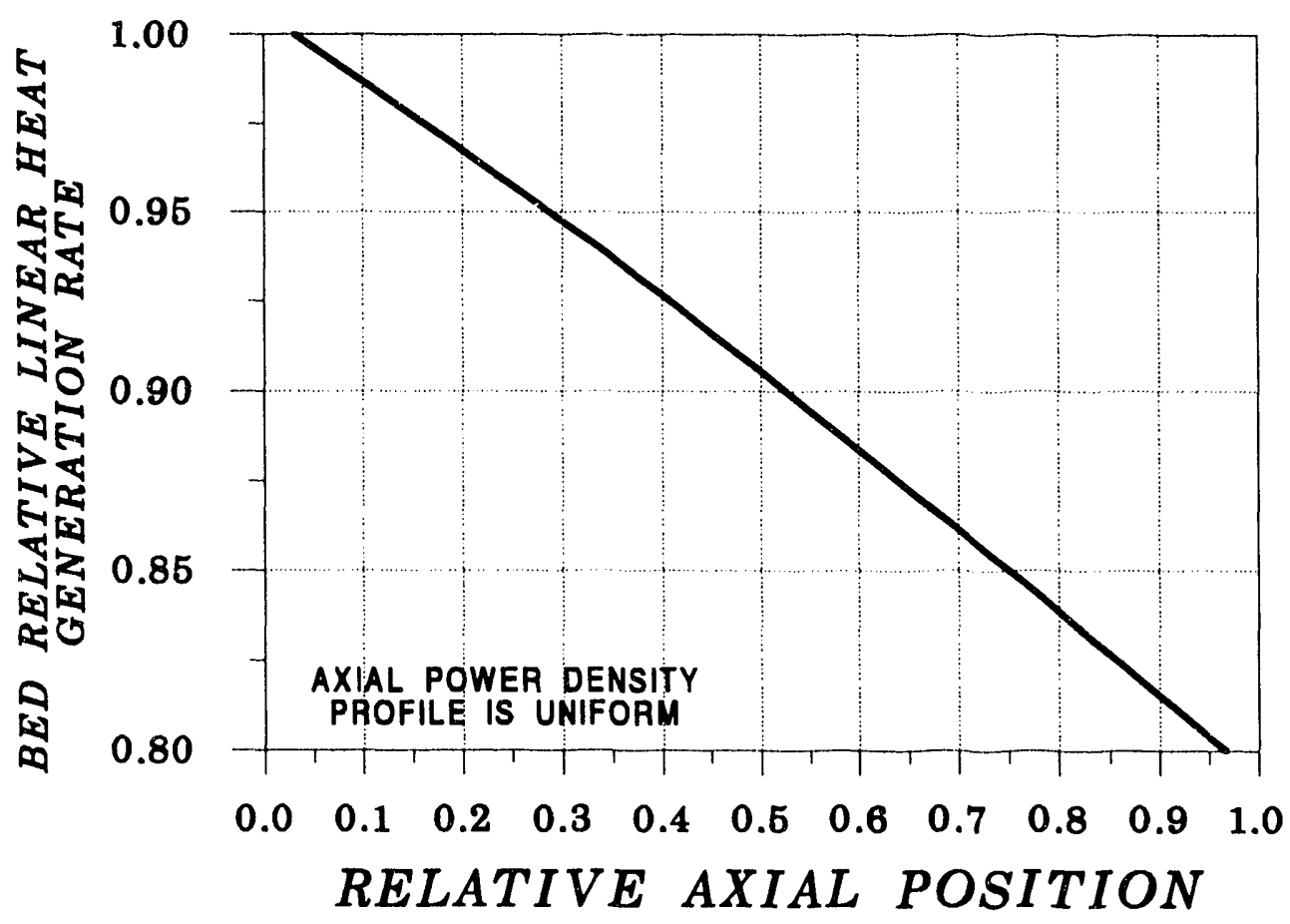

Figure 6. Relative Axial Linear Heat Generation Rate in the Fuel Bed 


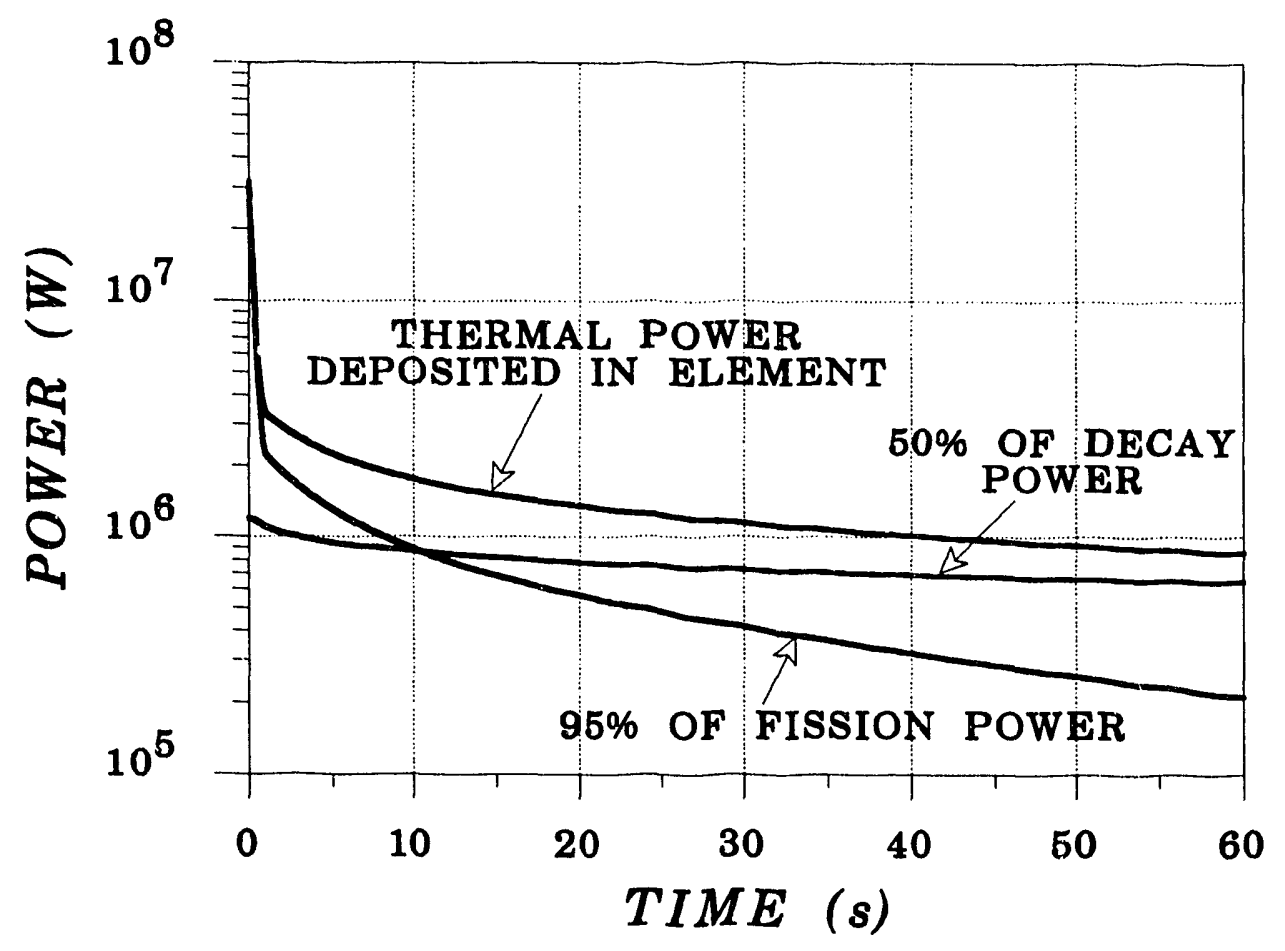

Figure 7. Fission and Decay Power Versus Time

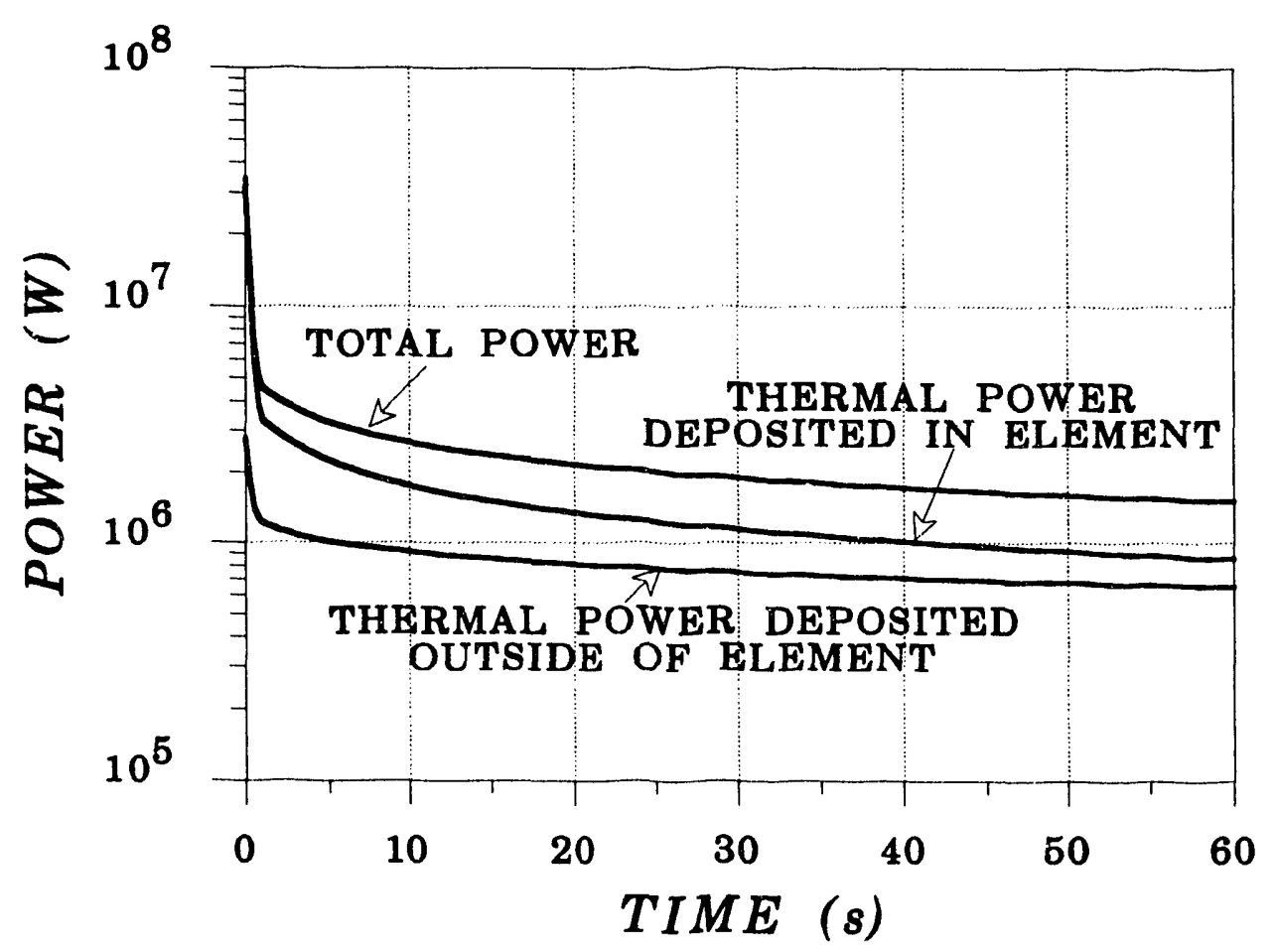

Figure 8. Power Deposited in the Element and Outside the Element 


\subsection{A Few Words About Flow Stability}

Before proceeding with a discussion of the fuel element parametric analyses, the issue of flow stability in gas flow systems needs to be addressed. This section is included to provide the reader with an engineering explanation of an issue that has received considerable attention in the space reactor community. ${ }^{15,16}$ This simplified explanation relies on calculations for one specific flow system and hopefully will leave the reader with a qualitative feel for the phenomena.

Whenever a gas flows between two reservoirs or plenums through parallel channels containing heat sources, there exists the potential for flow instability. The result of such an instability is to starve one or more of the channels of gas flow. The following equation for the pressure drop of the gas in a flow channel serves as the starting point for the explanation of this phenomena:

$$
\Delta p=f \frac{l}{d} \frac{G^{2}}{2 \rho}
$$

where

$\Delta p$ is the frictional pressure drop,

$f$ is the friction factor,

$l$ is the flow length,

$d$ is a characteristic length,

$G$ is the mass flux $(\rho v)$,

$v$ is the gas velocity, and

$\rho$ is the gas density.

This equation indicates that the pressure drop is proportional to the square of the mass flux and is based on a simple steady-state momentum balance for flow in a 1-D channel, neglecting kinetic and potential energy. The key to its use is the determination of the friction factor. Empirical correlations for the friction factor have been developed for engineering applications. A general form of these correlations can be expressed as:

$$
f=\left(\frac{a}{\varepsilon^{3}}\right)\left[c_{1}\left(\frac{a}{R e}\right)^{c_{2}}+c_{3}\left(\frac{a}{R e}\right)^{c_{4}}+c_{5}\right]
$$

where

$f$ is the friction factor,

$a=1$ for pipe flow, and $a=1-\varepsilon$ for porous media (packed bed) flow,

$\varepsilon$ is the bed porosity (1 for pipe flow),

page -- 18 
$c_{1}, c_{2}, c_{3}, c_{4}$, and $c_{5}$ are constants (see Table 1 ),

$R e$ is the superficial Reynolds number $(\varepsilon G d / \mu)$, and

$\mu$ is the dynamic viscosity of the gas.

The Reynolds number in these equations is based on the superficial flow area, which is the area if the channel were empty. For pipe flow, the porosity is equal to 1 and the characteristic length in the Reynolds number is the pipe diameter. For a packed bed channel, the characteristic length is the particle diameter. Table 1 provides the values of the constants appearing in this equation for different flow situations.

Table 1. Friction Factor Correlation Constants

\begin{tabular}{|l|l|c|c|c|c|c|}
\hline & & \multicolumn{5}{|c|}{ Constants } \\
\hline Correlation & \multicolumn{1}{|c|}{ Comments } & $c_{1}$ & $c_{2}$ & $c_{3}$ & $c_{4}$ & $c_{5}$ \\
\hline $\begin{array}{l}\text { Laminar Pipe } \\
\text { Flow }\end{array}$ & $\begin{array}{l}\text { Re }<2300 \\
\text { (theoretical) }\end{array}$ & 64 & 1 & 0 & 0 & 0 \\
\hline $\begin{array}{l}\text { Turbulent Pipe } \\
\text { Flow }\end{array}$ & $\begin{array}{l}4,000<\text { Re }<50,000 \\
\text { (smooth surface) }\end{array}$ & 0.316 & 0.25 & 0 & 0 & 0 \\
\hline $\begin{array}{l}\text { Turbulent Pipe } \\
\text { Flow }\end{array}$ & $\begin{array}{l}30,000<\text { Re }<10^{6} \\
\text { (smooth surface) }\end{array}$ & 0.184 & 0.2 & 0 & 0 & 0 \\
\hline Ergun ${ }^{17}$ & Packed Bed Flow & 300 & 1 & 0 & 1 & 3.5 \\
\hline $\begin{array}{l}\text { Modified } \\
\text { Ergun }{ }^{18}\end{array}$ & $\begin{array}{l}\text { Packed Bed Flow } \\
\text { (smooth surface) }\end{array}$ & 360 & 1 & 0 & 1 & 3.6 \\
\hline $\begin{array}{l}\text { Modified } \\
\text { Ergun'18 }\end{array}$ & $\begin{array}{l}\text { Packed Bed Flow } \\
\text { (rough surface) }\end{array}$ & 360 & 1 & 0 & 1 & 8 \\
\hline Achien'Jach & Packed Bed Flow & 320 & 1 & 20 & 0.4 & 1.75 \\
\hline
\end{tabular}

For laminar pipe flow, the pressure drop can be shown to be proportional to the product of mass flux and viscosity. For turbulent pipe flow, the pressure drop is proportional to the mass flux raised to the 1.8 power times the viscosity raised to the 0.2 power. A key to the flow stability issue is the temperature dependence of the viscosity appearing in this correlation; for a gas, viscosity increases with increasing temperature. Similar pressure drop dependencies for flow in packed beds can also be derived; however, it is instructive to demonstrate these dependencies graphically, as follows.

To investigate Equation (10), a SAFSIM input model of a single flow channel was prepared. The channel is assumed to be $1 \mathrm{~cm}$ long and to contain a packed bed with a uniform porosity of $\mathbf{0 . 4}$. The bed is comprised of spherical particles having a diameter of $400 \mu \mathrm{m}$. The channel has a rectangular cross section, $1 \mathrm{~cm}$ by $1 \mathrm{~cm}$, resulting in a superficial flow area of $10^{-4} \mathrm{~m}^{2}$. An exit pressure of $7.58 \mathrm{MPa}$ and an inlet hydrogen gas temperature of $125 \mathrm{~K}$ are also assumed for the calculations of this section. The exterior of the channel is assumed to be insulated. The Ergun equation for the friction factor 
correlation was selected because it is a well known correlation for flow in packed beds. Also, the Achenbach correlation for heat transfer coefficient is used. It should be noted that the following calculations could have been performed for flow in a pipe with similar results; a channel with a packed bed was selected because it is relevant to the particle bed element calculations of this document.

For simplicity, constant values of specific heat $\left(1.5 \cdot 10^{4} \mathrm{~J} / \mathrm{kg}-\mathrm{K}\right)$ and thermal conductivity $(0.2 \mathrm{~W} / \mathrm{m}-\mathrm{K})$ are assumed for the hydrogen gas. Also, the effective bed conductivity of $2 \mathrm{~W} / \mathrm{m}-\mathrm{K}$ is assumed to be independent of temperature. The temperature dependence of gas viscosity is approximated by the following equation:

$$
\mu=2 \cdot 10^{-7} \cdot T^{2 / 3}
$$

where

$\mu$ is the viscosity in Pa.s, and

$T$ is the gas temperature in $\mathrm{K}$.

It should be noted that SAFSIM is simultaneously solving mechanical [approximated by Equation (10)] and thermal energy equations to provide the solution to a total energy equation. The thermal energy equation requires that the energy generated equal the energy added to the gas during steady state. The temperature-independent gas and bed properties are used only for the calculations of this section. The use of these simplified gas and bed properties allows an analytical solution of the mechanical and thermal energy equations for comparison to SAFSIM results; agreement is very good. Documentation of this and other SAFSIM benchmark calculations is in progress.

Figure 9 provides the steady-state channel pressure drop as a function of superficial mass flux for three different bed power densities (power density is uniform within the bed). For the case with no internal power generation, the curve indicates, as expected, that the pressure drop decreases to zero as the mass flux decreases to zero. Ilowever, if there is power generation within the channel, a minimum value of pressure drop occurs. The mass flux at which this ininimum occurs is referred to as the critical mass flux. (The portion of the curve with negative slope is usually associated with laminar flow in which pressure drop is dominated by viscous effects. The portion of the curve with positive slope is associated with turbulent flow in which pressure drop is dominated by inertial effects.) The critical mass flux increases as the power density increases. The critical mass flux value, as will become clear as this explanation progresses, governs the flow stability. The lower its value, the more stable a flow system will be.

The fact that the minimum mass flux for a channel with no power generation is zero suggests that adding a flow resistance to a power-generating channel will reduce the critical mass flux of the channel. Figure 10 shows the pressure drop for the channel in which a cold frit was added to the entrance of the packed bed. The bed has a power

page - - ₹ó 
density of $2.5 \mathrm{MW} / \mathrm{L}$ but the cold frit has no internal power generation. The cold frit was modeled as a packed bed with additional resistance in the form of added $l / d$. As expected, the larger the cold frit resistance, the smaller the critical mass flux. Also of significance is the increase in the slope of the curve to the right of the critical mass flux. This increase in slope also helps to increase the flow stability of the system. This is because any given change in pressure drop requires a smaller change in mass flux compared to a channel with a lesser pressure drop-mass flux slope.

So far, only a single channel has been studied. But it takes more than one channel for a flow stability problem to arise if the mass flow rate is specified as a boundary condition. Further, it is necessary that the multiple channels have different pressure drop characteristics. Figure 11 shows the pressure drop curves for a channel with porosity of 0.4 and for another identical channel except the porosity has been decreased to 0.38 . The lower porosity channel is more restrictive to flow and has a slightly higher critical mass flux value. The chosen porosity values are arbitrary. The pressure drop characteristics of a channel could also be changed by changing the particle diameter, the channel length, the power density, or by the introduction of a localized flow blockage.

A new SAFSIM input model was created with two parallel-flow channels (no cold frit); the entrance to the two channels has twice the superficial flow area as a single channel. If the channels are identical, and nothing happens to change the pressure drop characteristics of the channels (such as the occurrence of a local flow blockage), then no redistribution of flow occurs, independent of power density and mass flux. The flow simply splits evenly between the channels. If the pressure drop characteristics of the two channels are different, a redistribution of flow between the two channels will occur. To investigate this, the porosity of one channel was set to 0.4 and the other to 0.38 in the twochannel input model. (The analyses to follow could have been performed by changing the power density, particle diameter, or length of one of the channels with analogous results.)

Figure 12 shows how the pressure drop curves for the two channels can be used graphically to determine the redistribution of flow. For the two-channel system, two conditions must be satisfied: (1) the pressure drop across both channels must be identical because they are connected to the same inlet and outlet reservoirs, and (2) the sum of the two channel mass flow rates must equal the total mass flow rate (conservation of mass). For a total mass flow rate of $3.7 \cdot 10^{-4} \mathrm{~kg} / \mathrm{s}$, these two conditions are met if the mass flux in the 0.38 porosity channel is $1.2 \mathrm{~kg} / \mathrm{m}^{2}-\mathrm{s}$ (a flow rate of $1.2 \cdot 10^{-4} \mathrm{~kg} / \mathrm{s}$ ) and the mass flux in the 0.4 porosity channel is $2.5 \mathrm{~kg} / \mathrm{m}^{2}$-s (a flow rate of $2.5 \cdot 10^{-4} \mathrm{~kg} / \mathrm{s}$ ). If the total mass flow rate is greater than $3.7 \cdot 10^{-4} \mathrm{~kg} / \mathrm{s}$, the different pressure drop characteristics of the two channels dictates a different, but stable, flow split. If the flow rate is decreased below $3.7 \cdot 10^{-4} \mathrm{~kg} / \mathrm{s}$, an instability is initiated.

The instability can be explained simplisticly as follows. When the flow is laminar (the negative slope region of the characteristic curve), a decrease in flow rate results in an increase in temperature. This increases the gas viscosity which in turn increases the flow 
resistance. Thus, less flow goes to this channel and more flow goes to the other less restrictive channel which decreases in temperature. As a result, the 0.38 porosity channel becomes even more restrictive to flow while the 0.4 porosity channel becomes less restrictive. This positive feedback response continues with the net result being that the 0.38 porosity channel is starved of flow and the bed temperatures increase until melting. This is the phenomenon sometimes referred to as laminar or viscosity-driven flow instability.

- Instability: an unbounded flow redistribution that results in flow starvation and excessive temperatures in one or more channels of a multichannel flow systern.

Figure 13 shows the ratio of the mass flux in the two channels as a function of the inlet mass flux (the sum of the two channel's mass fluxes). This figure demonstrates how the ratio rapidly increases as the inlet mass flux decreases. What's important to understand is the temperature response that occurs in the two channels. If the flow decreases in the channel, the temperature must increase. The temperature response of the two channels is provided in Figure 14. An increase in gas temperature increases the gas viscosity, which increases the channel flow resistance and drives the flow redistribution. Therefore, it is important to maintain the mass flux above the critical mass flux of the most restrictive channel. The critical mass flux is a good measure of the flow instability threshold.

Even if the mass flux remains above the critical value, the resulting flow distribution may be such that the maximum-allowed temperature is exceeded in a channel. In addition to flow instability, the flow maldistributions that occur in multiple channel systems is also of great concern. Any power producing system with multiple flow channels should be designed to minimize flow maldistributions in order to make optimurn use of the coolant and to reduce the possibility of flow instability due to inherent geometry perturbations (such as porosity or power variations). This topic is pursued further in Sections $\mathbf{4}$ and 5.

Maldistribution: an unfavorable, but stable, flow redistribution that results in clevated temperatures in one or more channels of a multichannel flow system.

It is important to note that the results presented so far are applicable only to the assumed 1-crn long channels without a cold frit. Every different channel has a different pressure drop characteristic and therefore has a different critical mass flux and flow redistribution response.

In the two-channel system addressed so far, the two channels are assumed to communicate only at the common inlet and outlet plenums of the channels. This simplifies the analysis by allowing 1-D flow and conduction calculations. In actuality, the two packed bed channels can communicate axially, i.e., gas can flow and heat can conduct axially between the two channels. It will now be shown that using a 1-D analysis is a very good and a conservative approximation for the two-channel problem. 
Figure 15 shows the calculated pressure distributions in the two different-porosity channels (radial flow is from right to left). The radial and axial pressure gradients are plotted in Figure 16. As is evident, the radial gradients are much larger than the axial gradient. Thus flow is predominately in the radial direction and 1-D in nature. There is very little axial flow because there is very little driving pressure potential in that direction.

The temperature distributions for the two channels are provided in Figure 17 and the temperature gradients are shown in Figure 18. The axial temperature gradients are of the same order of magnitude as the radial gradients, which indicates that axial conduction may be significant. Although cumbersome, it is possible to perform 2-D conduction with SAFSIM. The two-channel model was modified to include axial conduction between the two channels, and the bed surface temperature distribution results are shown in Figure 19. As expected, the addition of axial conduction decreases the difference in temperature between the two channels. In fact, inclusion of axial conduction serves to increase the stability of the system. Thus further reductions in flow can be made before flow instability occurs. However, the flow can be reduced only by about $2 \%$ compared to the no-axial conduction case. Thus neglecting axial conduction is conservative with respect to predicting flow stability and reinforces the use of the 1-D modeling assumption. Also, calculations using a 2-D computer program $\left(\mathrm{F}^{2} \mathrm{D}^{19}\right)$ demonstrate similar conclusions regarding the conservativeness of 1-D calculations. Similar conclusions are also documented in Reference 16 in which multidimensional calculations are compared to 1-D calculations.

As mentioned earlier, a constant value was used for the bed conductivity. The selected value of $2 \mathrm{~W} / \mathrm{m}-\mathrm{K}$ is representative of the value at about $2700 \mathrm{~K}$, based on Equation (2) of the previous section. At $1500 \mathrm{~K}$, the value would be reduced to about $0.34 \mathrm{~W} / \mathrm{m}-\mathrm{K}$. Thus the effect of axial conduction is even less significant than in the two-channel problem just described, and further justifies neglecting it for these engineering analyses.

It will be demonstrated in a later section that modeling the flow in a particle bed element with multiple parallel 1-D axial levels is a very good approximation for many flow situations of interest. Like the two-channel problem, this is because the pressure gradients are predominately in the radial direction, especially if the resistance of the cold frit is large compared to that of the bed, and because axial conduction is small. Also, in the presense of flowing coolant, heat transfer due to convection is much larger than heat transfer by conduction in the bed.

Because the critical mass flux is a convenient measure of flow stability, it is useful to plot the critical mass flux as a function of power density. This is done in Figure 20 for the 0.4 porosity channel. Operation of the two-channel system to the left of the curve can be interpreted as stable tlow conditions. As long as the mass flux falls on this side, flow instabilities will not develop. Another useful curve is shown in Figure 21. This shows the temperature ratio as a function of power density for the 0.4 porosity channel. The temperature ratio is the ratio of the channel gas temperature difference to the channel inlet temperature. Operation of the two-channel system to the left of this curve can be 
considered to be unstable. This figure implies that increasing the inlet gas temperature increases the flow stability.

It is important to recognize that these curves do not apply directly to the stability of a particle bed element. Every different fuel element design will have a different stability map. Whether or not introduction of a local flow perturbation (such as a local flow blockage or change in power density) will initiate flow instability depends on how much the local perturbation changes the pressure drop characteristics relative to the unperturbed part of the fuel element. Also, for low enough flow rates, instabilities can occur even if no additional flow perturbation is introduced because the elements pressure drop characteristics are not uniform over its entire length. Thus, there are "built-in" perturbations for the initiation of instability. As will be discussed later, it is desirable to eliminate these built-in perturbations in the element design.

A fuel element stability map could be generated by dividing the fuel element into several axial levels and then calculating the pressure drop characteristic curve for each level. The level with the largest critical mass flux can be assumed to be the limiting channel for stability. Such calculations were performed for the conical fuel element design and the resulting stability map is presented and explained in Section 5.2. In this section, the concept of an acceptability map is also introduced. An acceptability map addresses the issue of flow maldistributions (when unacceptable temperatures occur) in addition to flow stability.

The analysis so far has been based on steady-state calculations. It is important to understand that flow instabilities and maldistributions do not occur instantaneously. A transient calculation was performed in which the mass flow rate was ramped down in $5 \mathrm{~s}$ to a value $1 \%$ below the minimum value required for stable operation. A plot of the flow rate in the two channels as a function of time is provided in Figure 22. Figure 23 shows the bed surface temperature at the channel exits for the transient. The flow redistribution between channels develops slowly and a temperature excursion does not begin until about $80 \mathrm{~s}$. This delay is important to note because it means that a particle bed reactor, or any reactor, can be operated in the unstable regime for a certain length of time if necessary.

... the flow instability/

maldistribution problem is

not particular to particle bed systems but instead is a phenomenon common to any and all gas flow systems ... The length of time : reactor can be operated in the unstable regime depends primarily on its power density and its heat capacity.

Again, it is important to remember that the flow instability/maldistribution problem is not particular to particle bed systems but instead is a phenomenon common to any and all gas flow systems with multiple channels and internal power generation. Also, stability can be enhanced by adding resistance to the channels and by designing the channels to have as similar pressure drop characteristics as possible.

page -- 24 


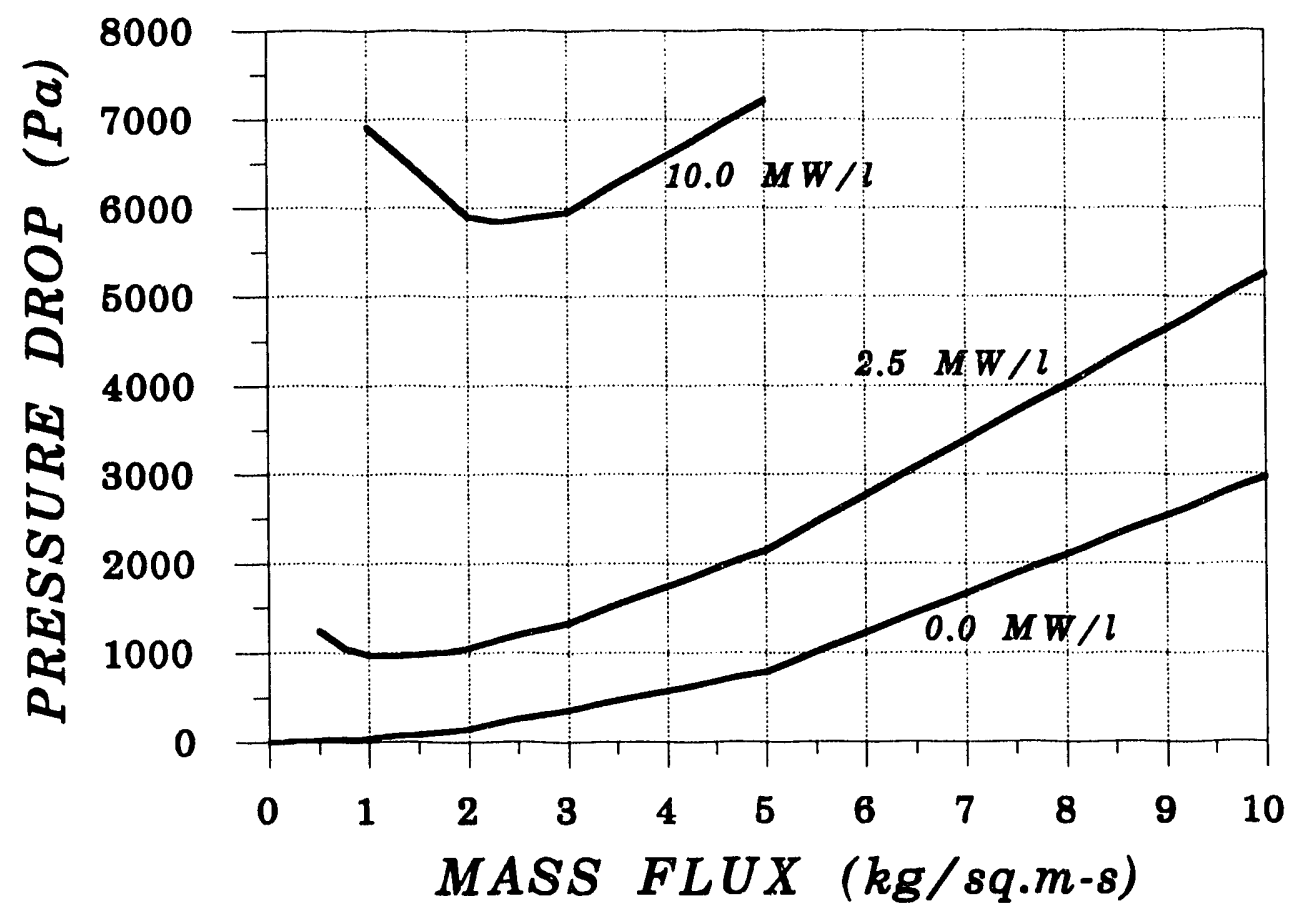

Figure 9. Channel Pressure Drop Characteristic Curves

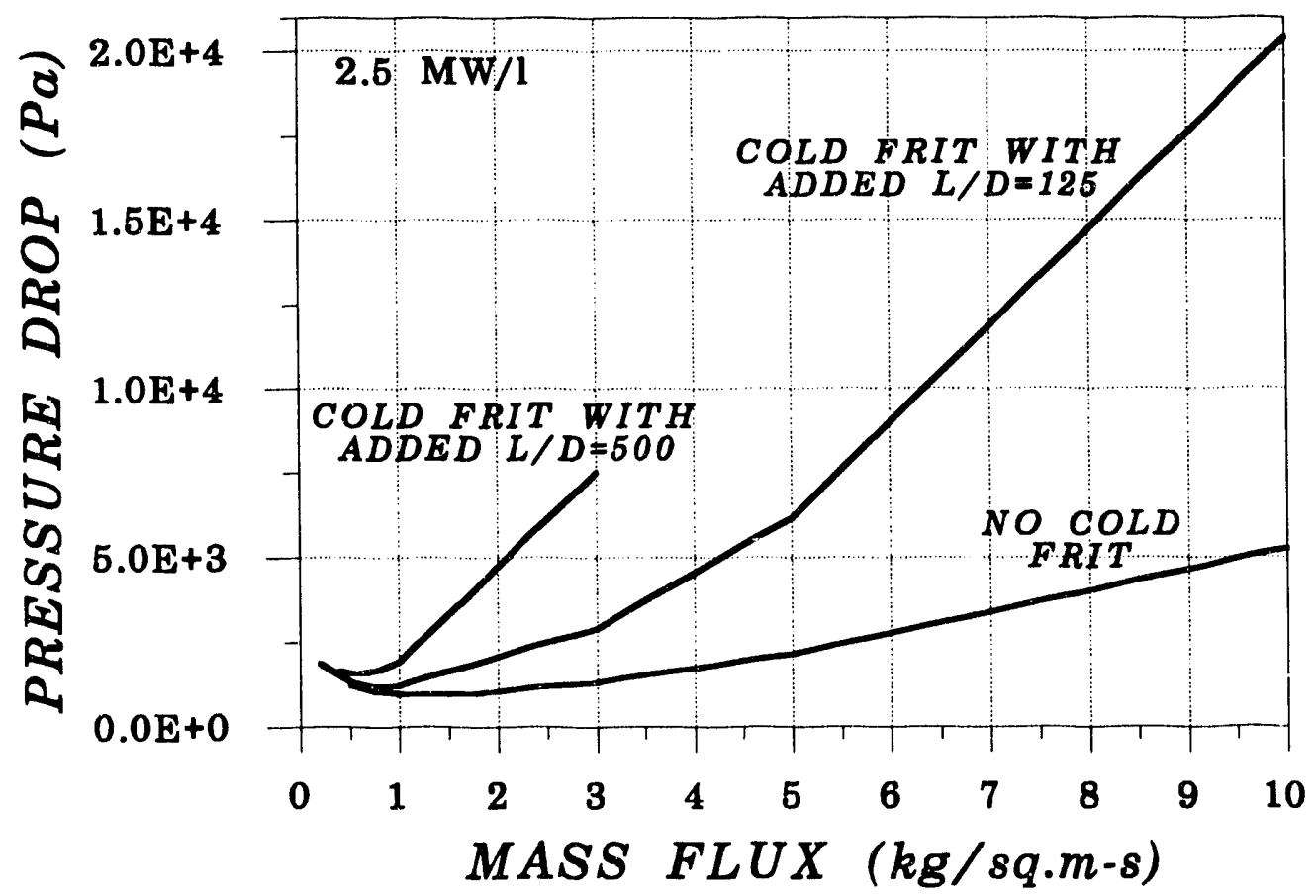

Figure 10. Pressure Drop Characteristic Curves With an Added Cold Frit 


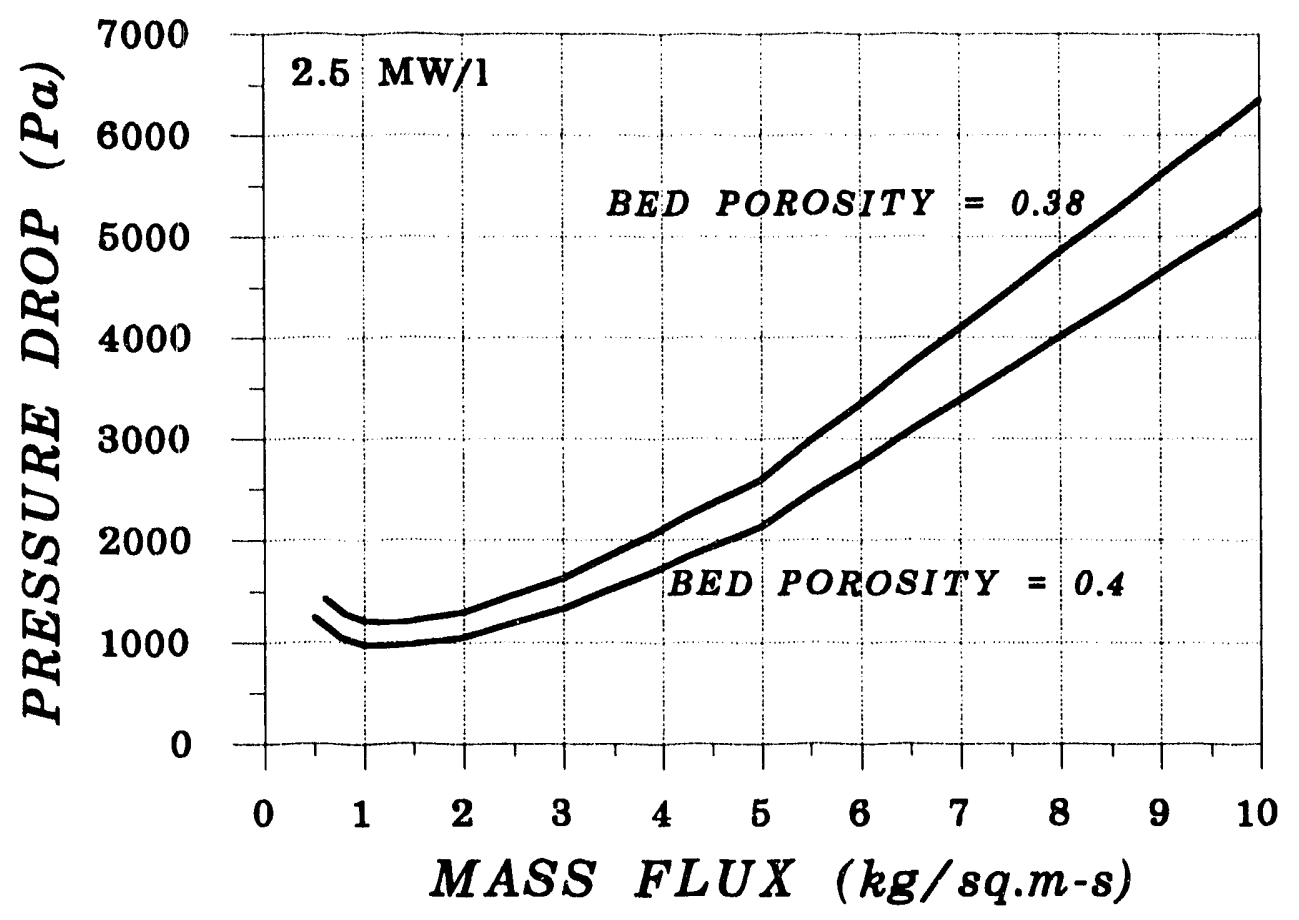

Figure 11. Pressure Drop Characteristic Curves for Two Different Channels

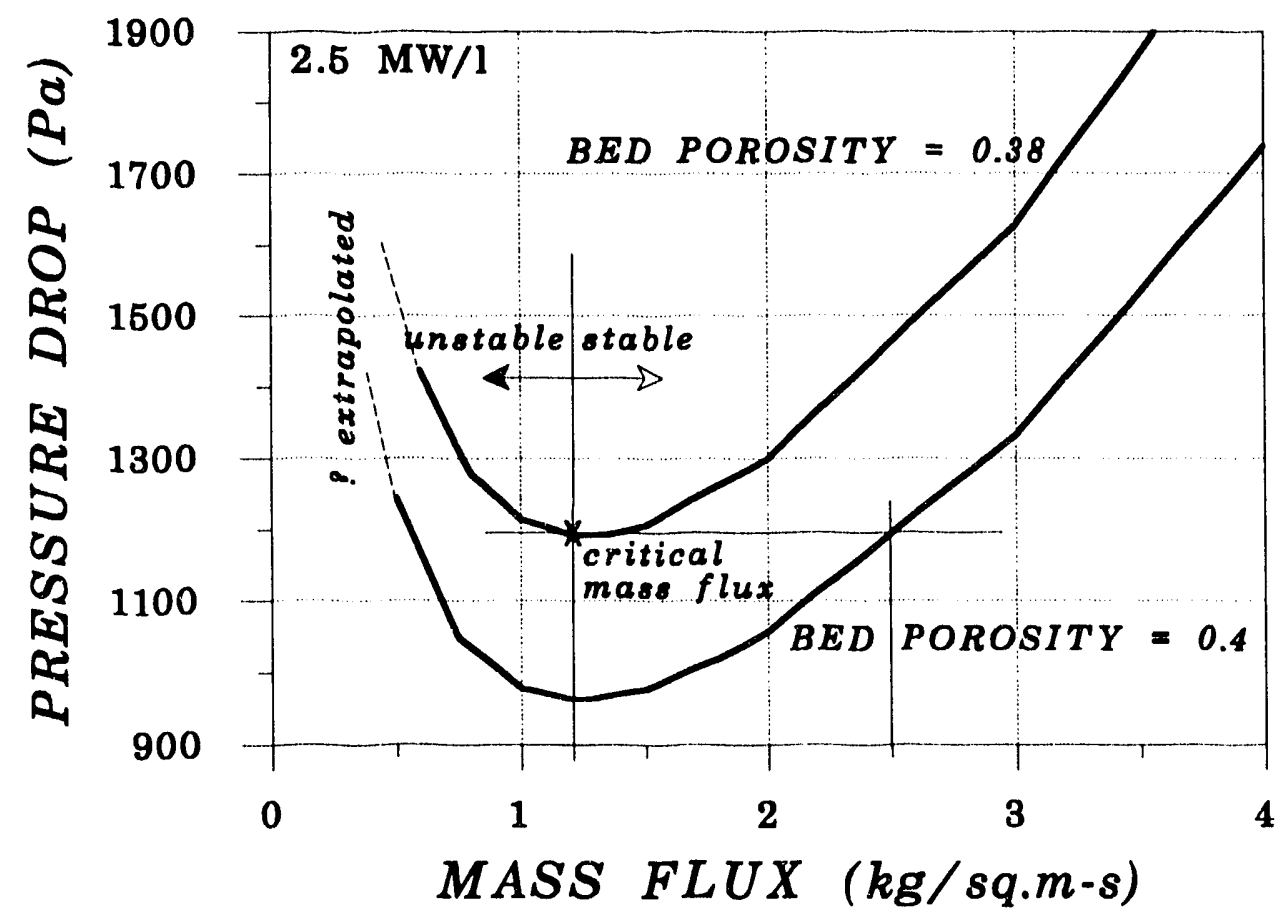

Figure 12. Graphical Solution of Two-Channel Flow Redistribution 


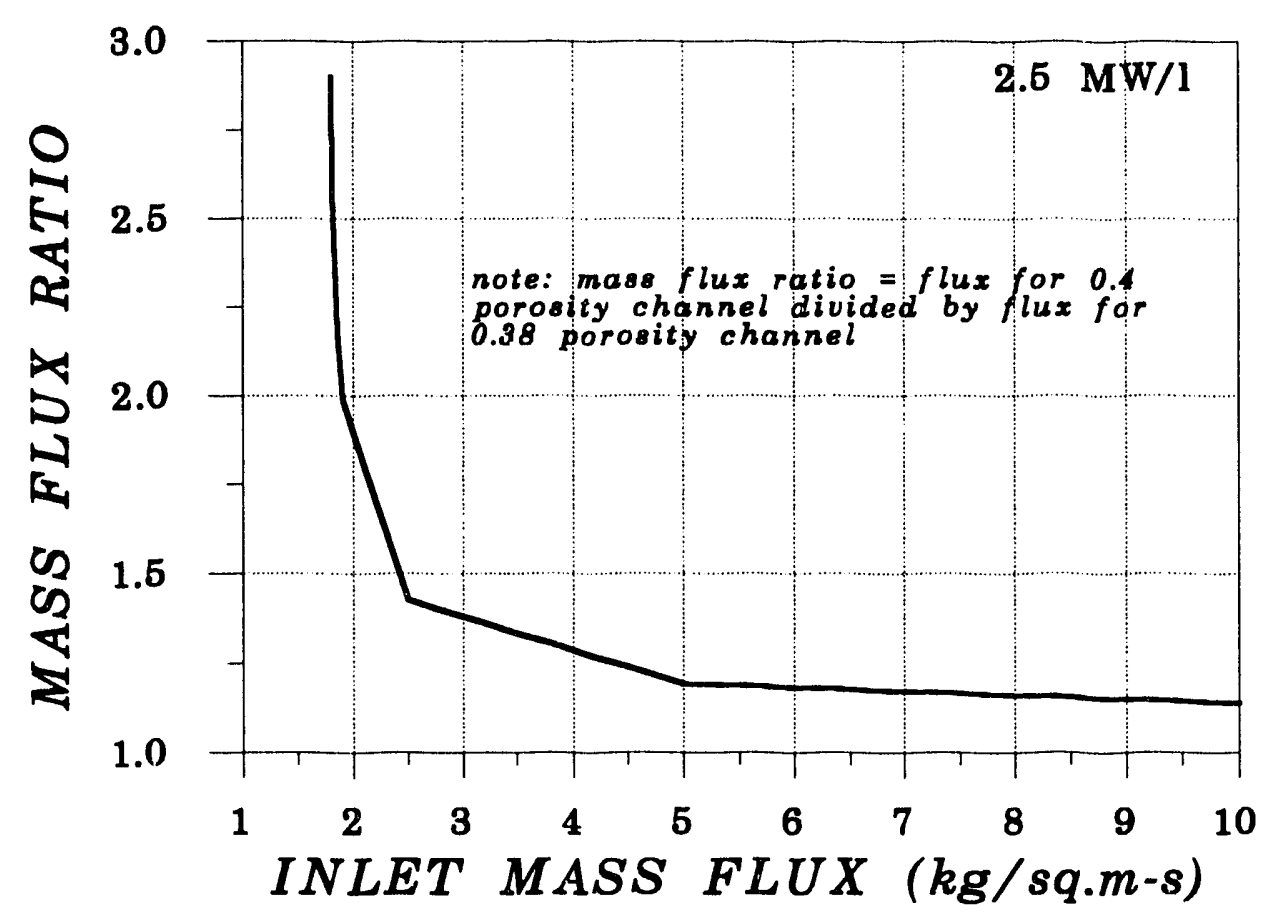

Figure 13. Mass Flux Ratio for a Two-Channel Flow System

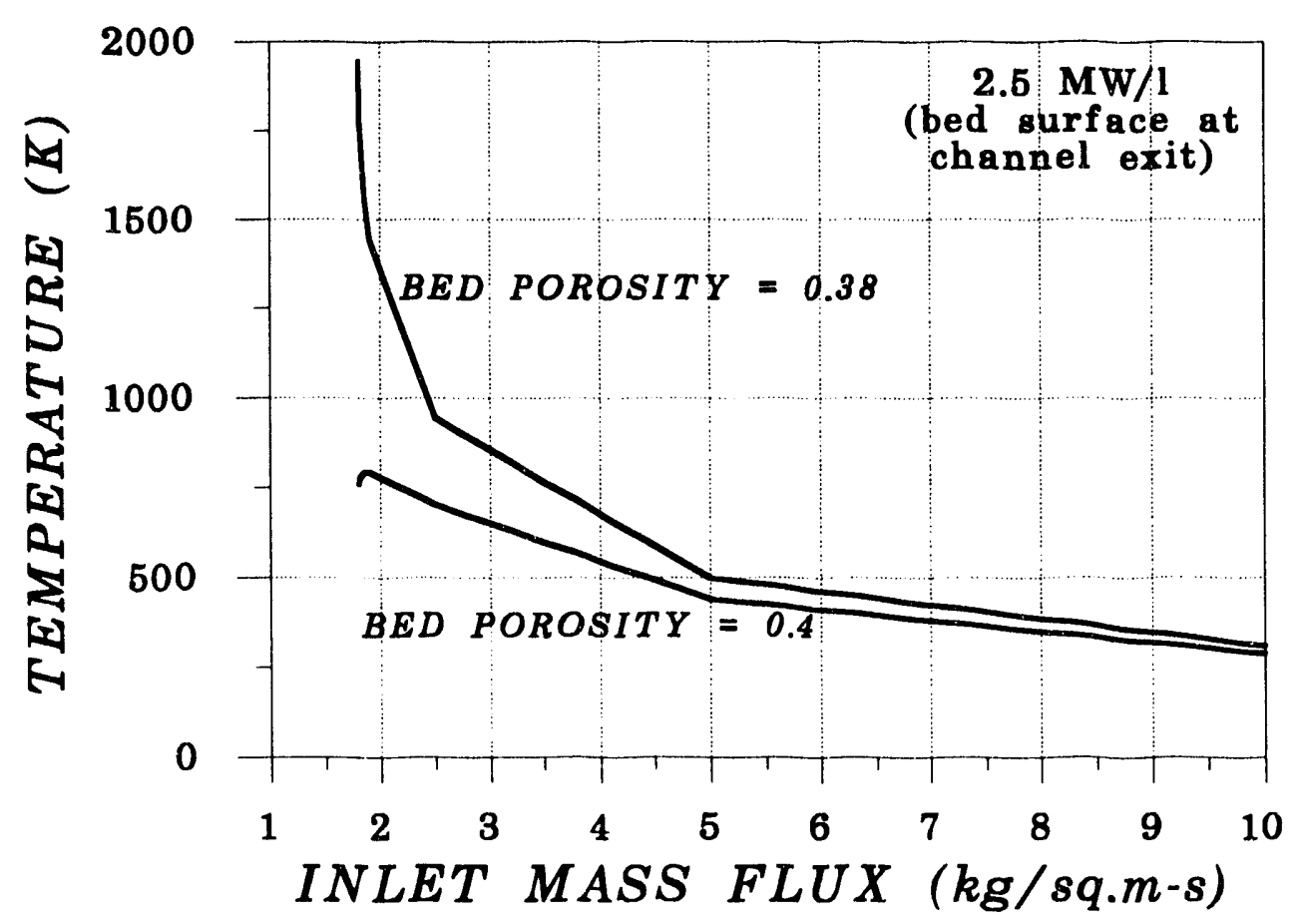

Figure 14. Temperature Response for a Two-Channel Flow Systern 


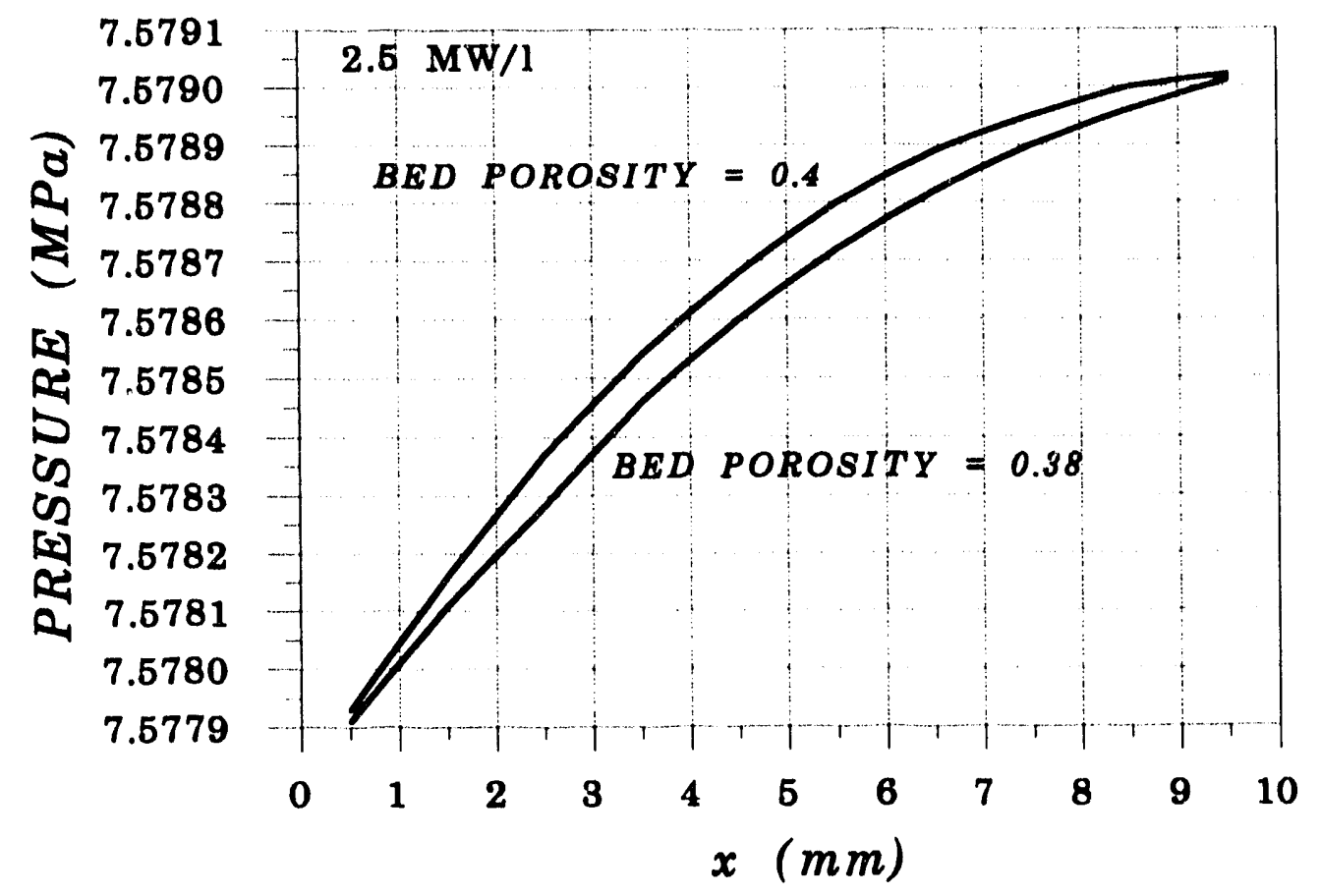

Figure 15. Pressure Distributions in the Two Channels

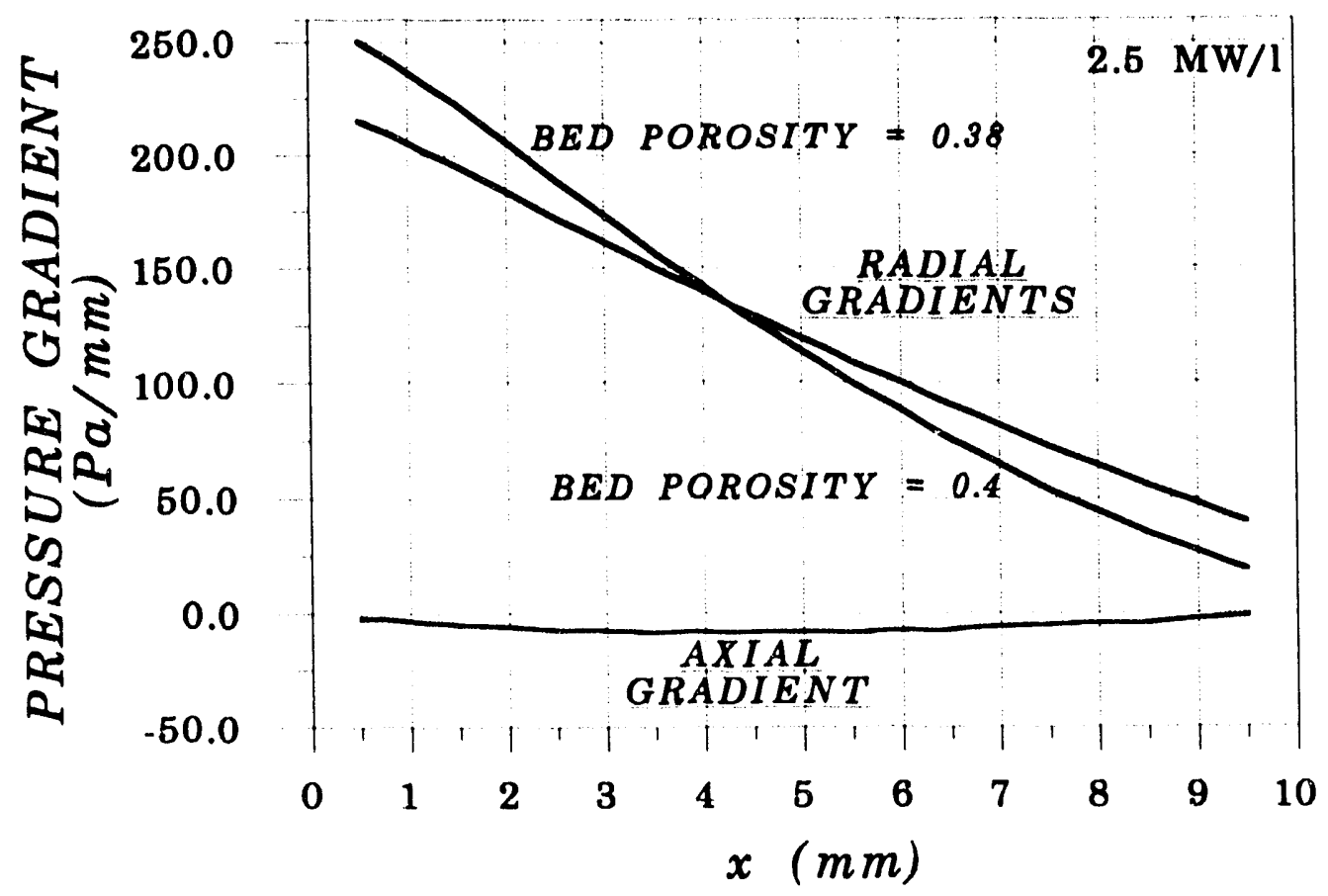

Figure 16. Pressure Gradients in the Two Channels 


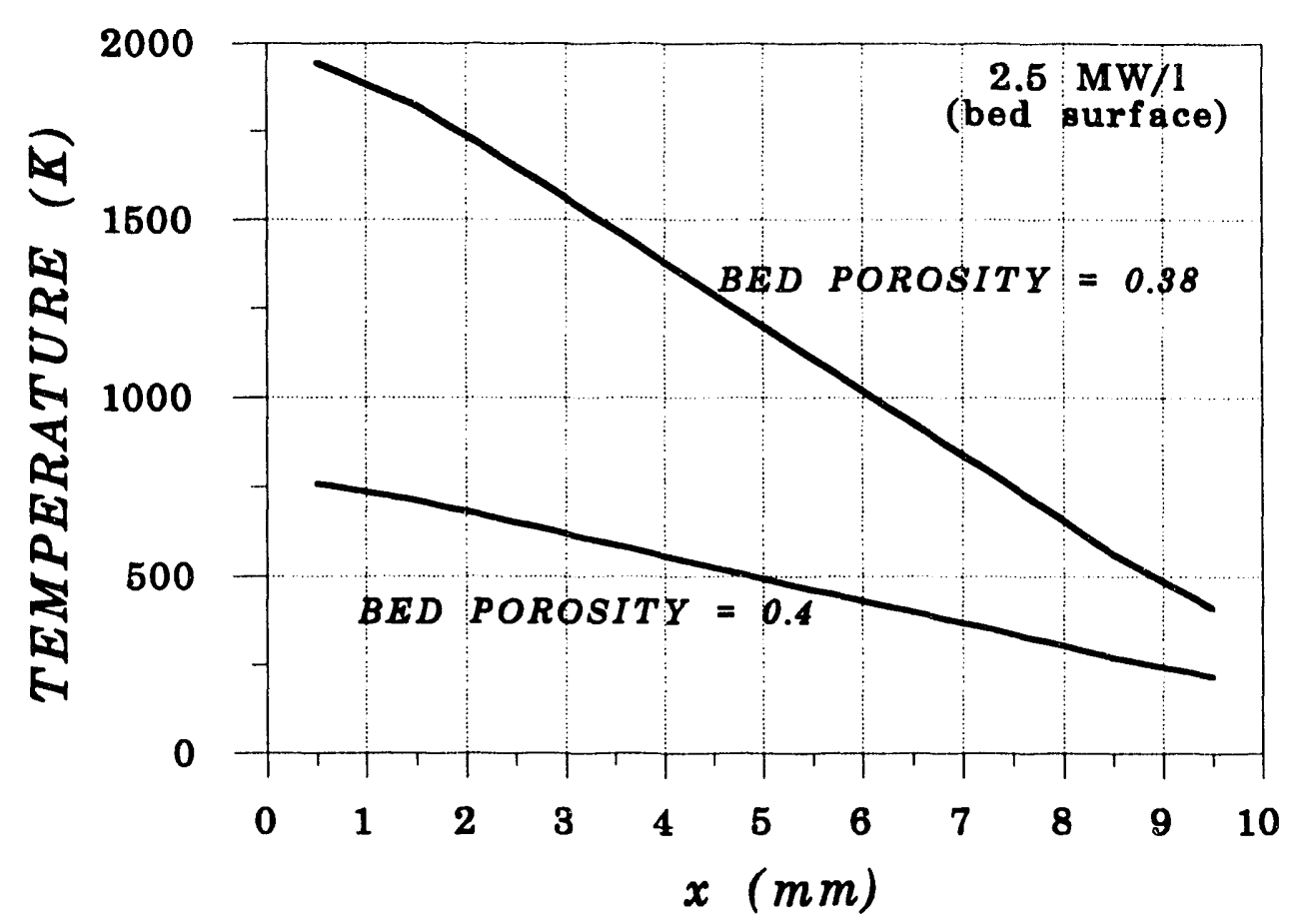

Figure 17. Temperature Distributions in the Two Channels

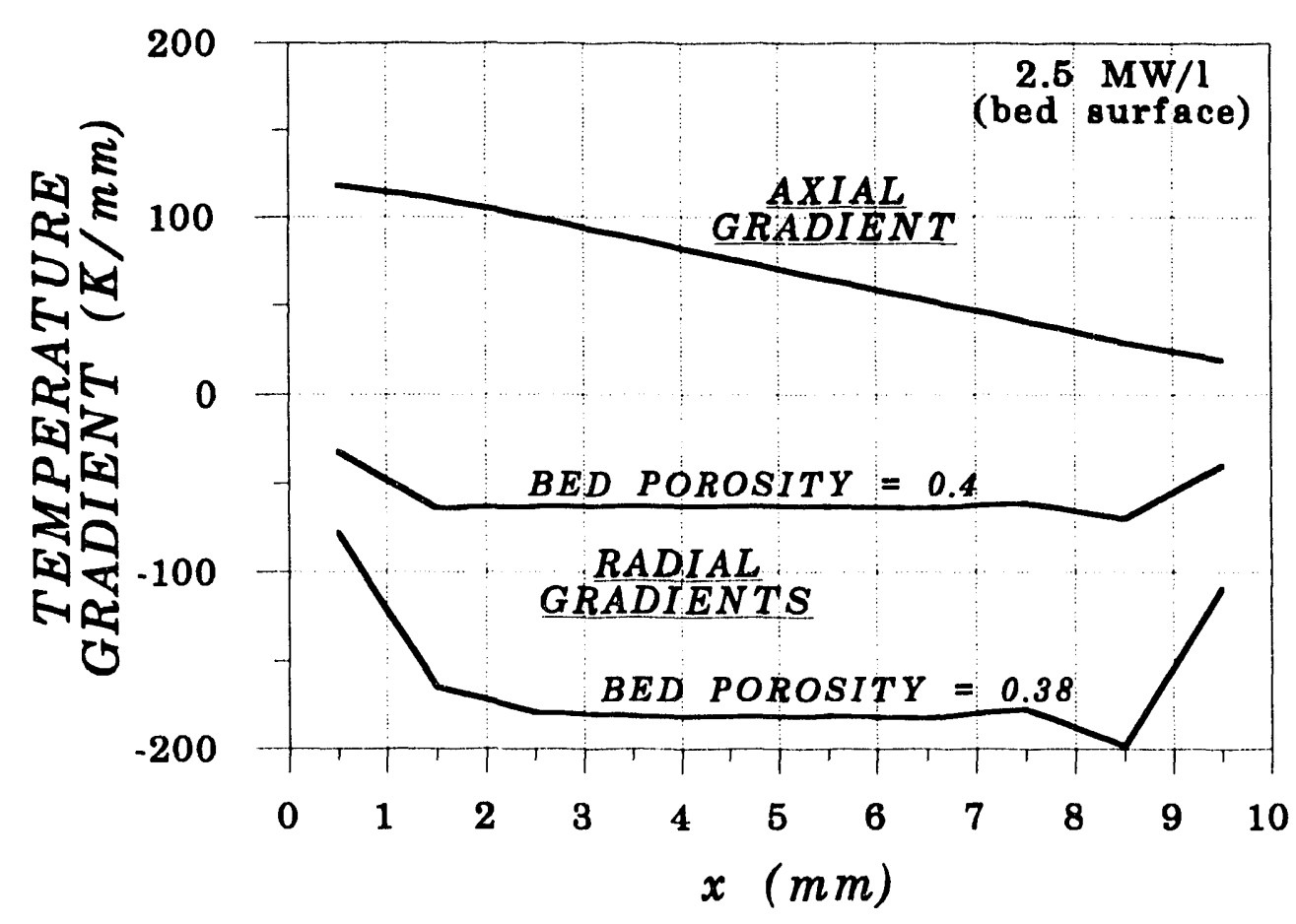

Figure 18. Temperature Gradients in the Two Channels 


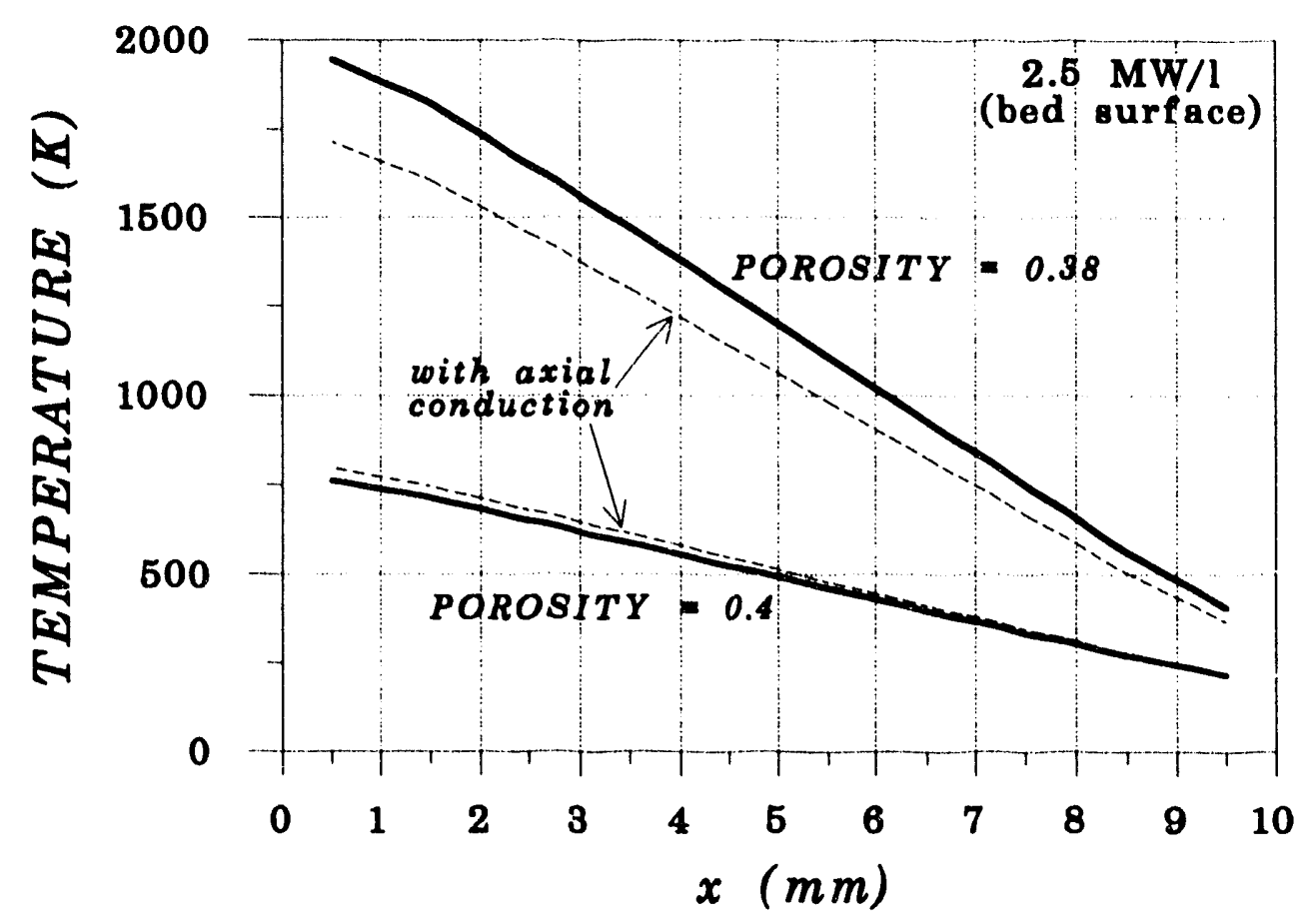

Figure 19. Temperature Distributions With Axial Conduction Included

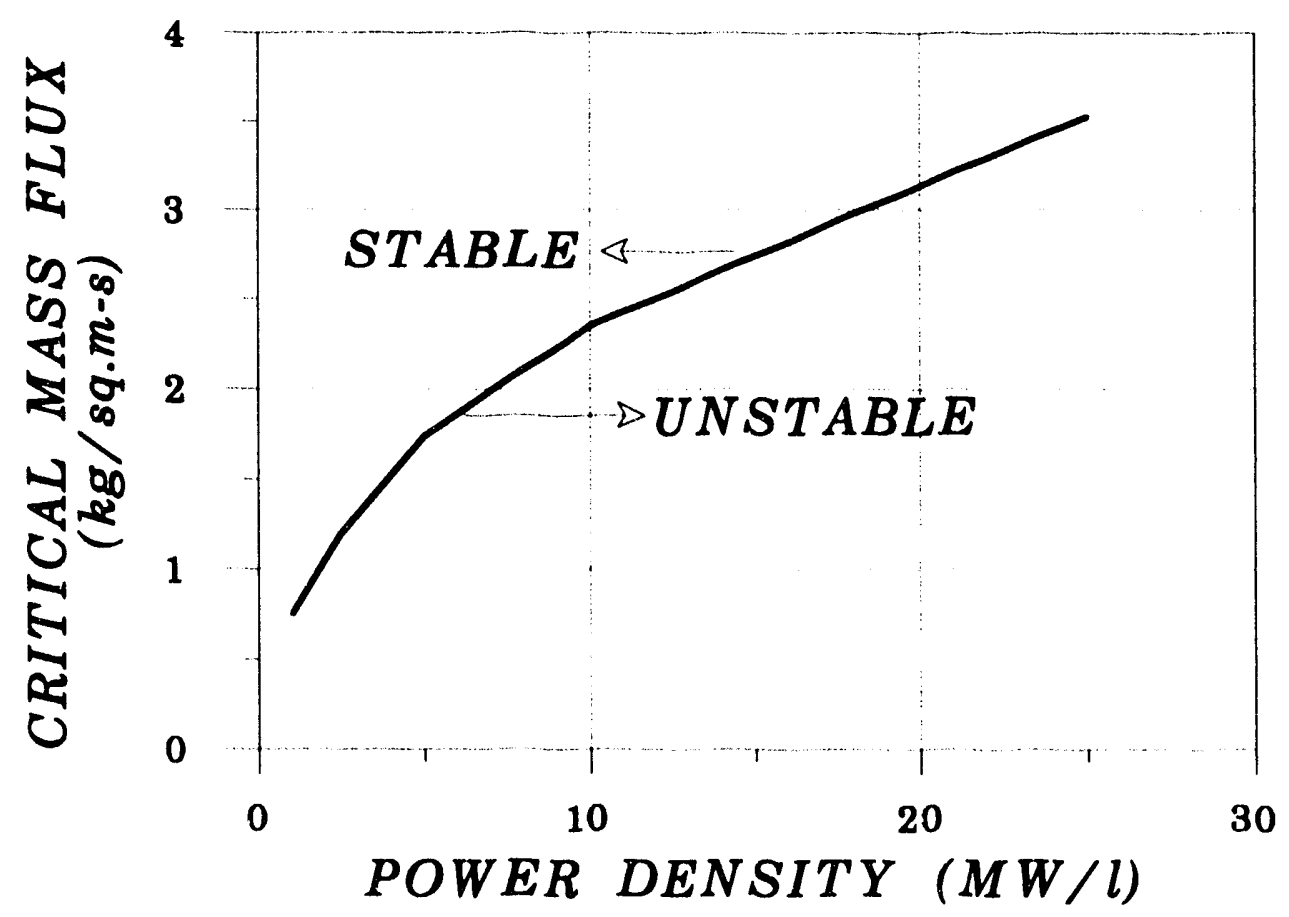

Figure 20. Critical Mass Flux Stability Regimes ('Two-Channel System) 


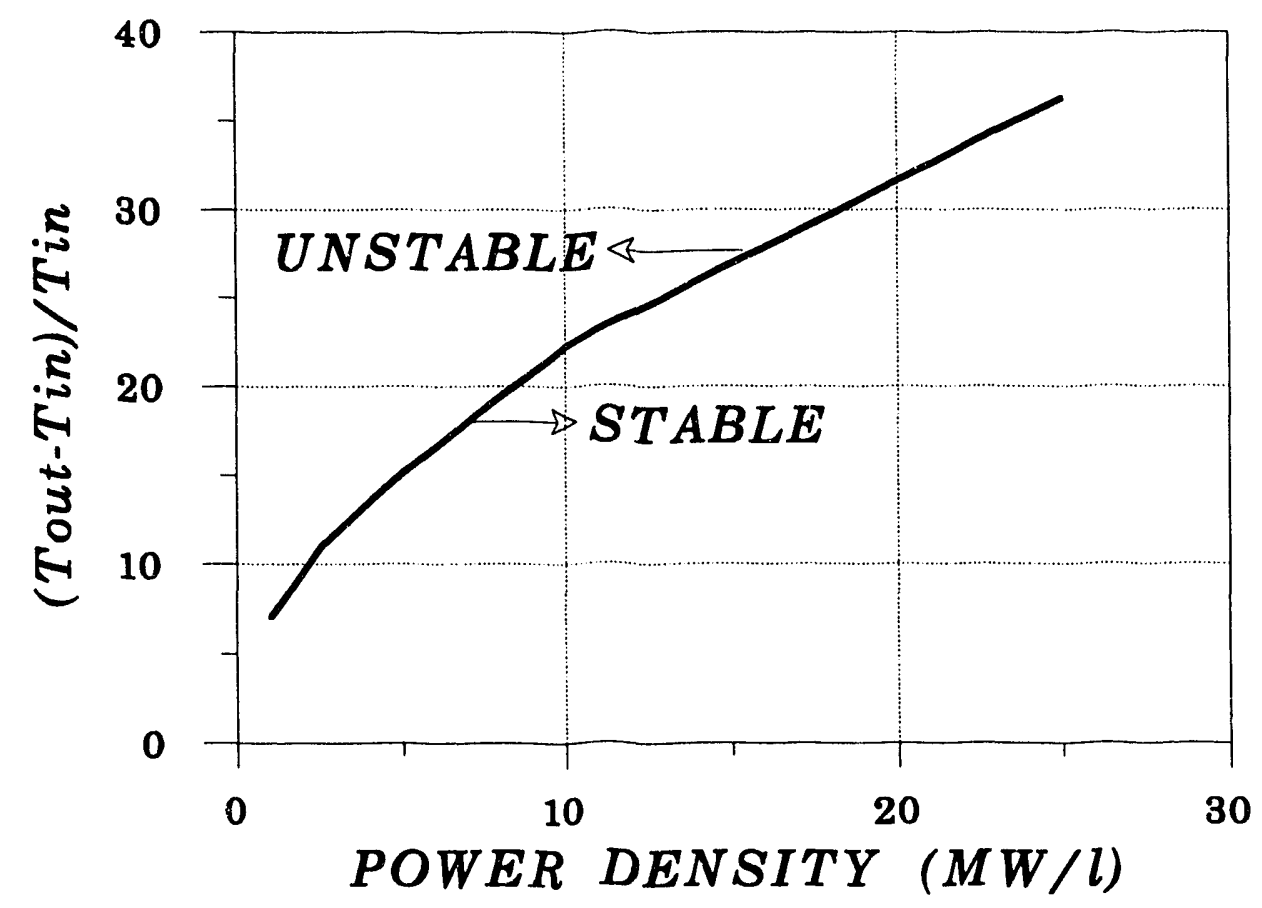

Figure 21. Temperature Ratio Stability Regimes (Two-Channel System)

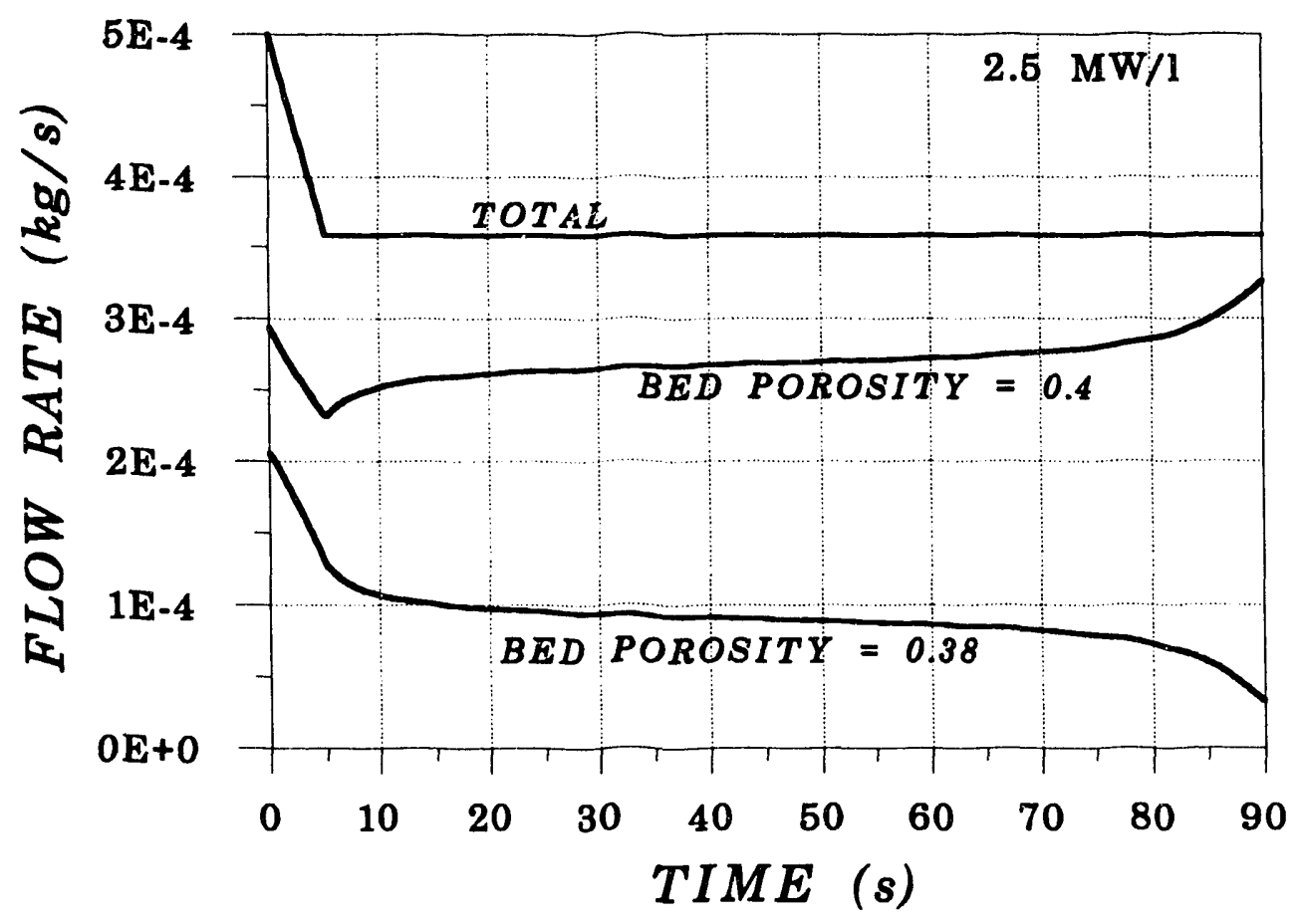

Figure 22. Mass Flow Rate for a Deliberate Flow Redistribution Transient (Two-Channel System) 


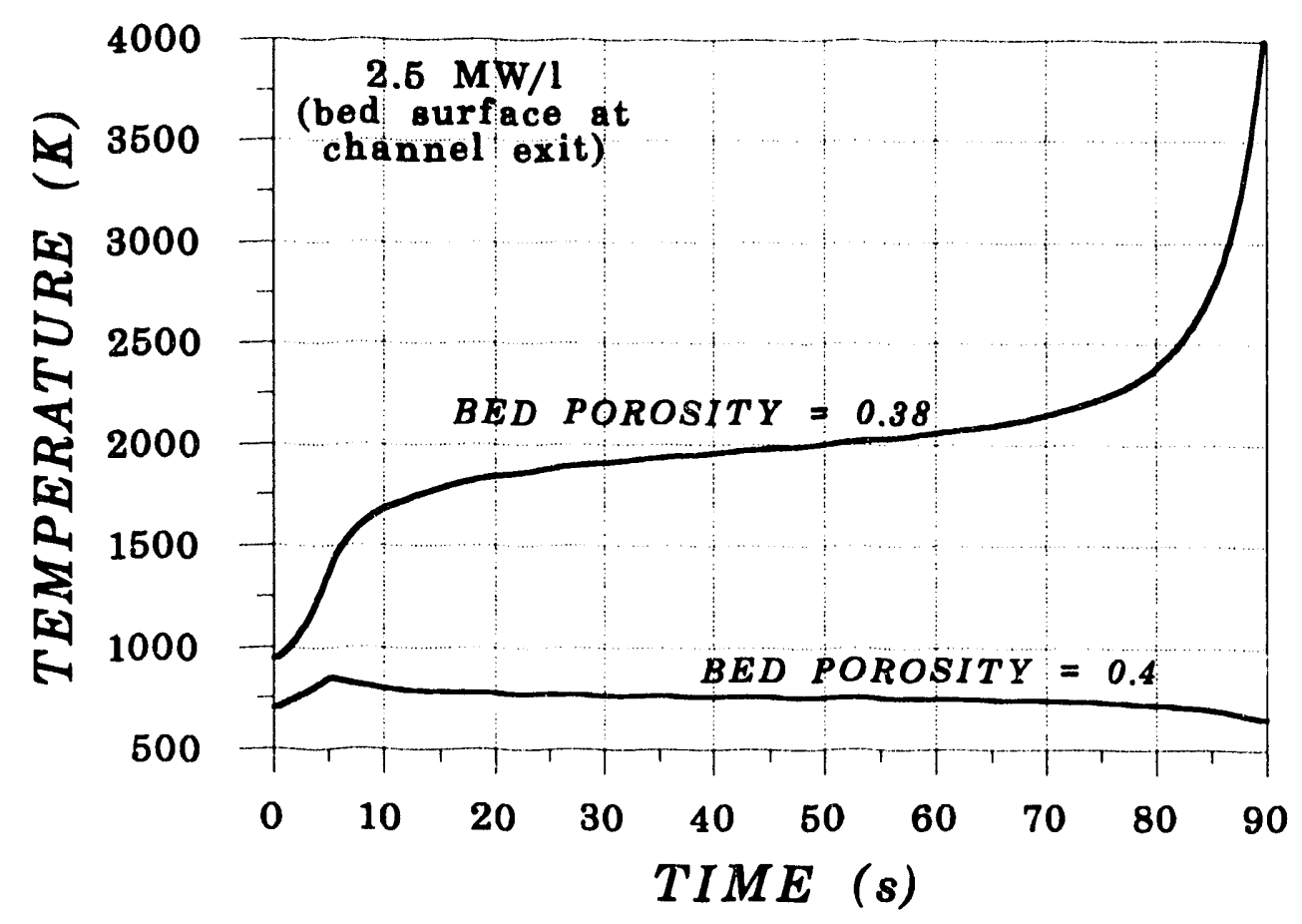

Figure 23. Bed Temperature for a Flow Redistribution Transient (Two-Channel System) 


\subsection{Sready-State Results}

SAFSIM calculations were performed using the input models described in Section 2 to invrstigate the steady-state performance of a particle bed fuel element. Steady-state conditions, especially decay power radionuclide concentrations, may not be reached for short-duration propulsive space reactor operations. However, steady-state calculations provide useful information about the re: or performance and are, in general, easier to understand than transient calculations. Two sets of steady-state calculations are addressed: Base Case and Ser.sitivity. The base case calculations are based on best-estimate assumptions regarding ine geometry and physics of a particle bed fuel element. These cases serve as a reference to which the sensitivity cases are compared. Sensitivity calculations were performed to investigate the sensitivity of the fuel element performance to different modcling assumptions.

\subsection{Base Case Analyses}

The base case analyses are ivided into two sections: Full Thrust and Reduced Thrust Operation. Full thrust refers to operation of the fuel element at full design power. Because the relctionship between thrust and power is essentially linear, the two terms can be used interchangeably. The thrust term is used here to remind the reader that the analuse address the operation of a reactor designed for propulsion and that choked flow in a nozzle controls the reactor pressure. The reduced thrust calculations address the flow maldistributions and instabilities that may occur when the fuel element is operated at a power below which the cold frit axial resistance profile was optimized.

\subsubsection{Full Thrust Operation}

Figure 24 shows the calculated particle centerpoint temperature axial profile along with the particle surface and coolant temperature axial profiles at the exit of the bed. (A relative axial position of zero references the bottom of the fuel element and the bed exit is defined as the column of bed finite elements adjacent to the hot frit. The temperature values are associated with the centroid of the finite elements, not the bed exit nodes.) As was mentioned in Section 2, the resistance of the cold frit was determined such that the particle centerpoint temperature axial profile at the exit of the bed is uniform at full power. A maximum centerpoint ternperature of $3275 \mathrm{~K}$ corresponds to the full power design point. Many SAFSIM calculations were performed to iteratively determine the axial resistance profile. Due to the highly nonlinear dependence of the cold frit resistance to the particle centerpoint temperature, a perfectly uniform centerpoint temperature rrolile was ‘ot achieved. However, the profile was considered good enough for purposes of this study. Because the total temperature drop across each particle is different (the power density of each particle depends on its location in the bed), the particle surface and coolant temperature axial profiles are not uniform. Tailoring of the cold frit resistance based on achieving a uniform particle centerpoint temperature profile minimizes the ainount of coolant required to conl the element during full power operation. 
It is werth pointing out that tailoring the cold frit resistance profile at full power conditions may not be optimum when specific missions are considered. The full power assumption is used for lack of detailed mission studies to indicate otherwise.

Figure 25 shows the resulting coolant mass flux distribution at the entrance of the cold frit. The mass flux decreases somewhat toward the top of the element. Figure 26 shows the radial temperature distributions of the bed surface and the coolant at the top and bottom of the element. The film drop (bed surface temperature minus the coolant temperature) decreases as the coolant flows radially inward because the power density decreases and because the heat transfer coefficient increases as the coolant temperature increases. The Reynolds and Prandtl numbers decrease in the direction of flow but the coolant conductivity increases, accounting for the increasing heat transfer coefficient.

The axial coolant temperature distribution in the inlet plenum is provided in Figure 27. Recall from Section 2 that the element entrance coolant temperature is $200 \mathrm{~K}$. The coolant temperature has increased to about $250 \mathrm{~K}$ at the bottom of the inlet plenum due to heat transfer from both the inoderator and the cold frit. This figure also shows the temperature of the cold frit at the inner and outer radial locations. About a 30-K temperature increase across the cold frit is predicted. The axial pressure profiles in the inlet and outlet plenums are shown in Figure 28. Note that the two profiles are nearly parallel. The pressure profile at the bed entrance (the inside radius of the cold frit) is also shown in this figure and demonstrates that most of the element pressure drop occurs across the high-resistance cold frit.

The output from SAFSIM for the full thrust, steady-state calculation is provided in Appendix C. This information is included to provide the interested reader with all the performance data provided by a SAFSIM simulation of a particle bed element and to demonstrate the enormous amount of information required to characterize the fluid mechanic and conduction heat transfer response. 


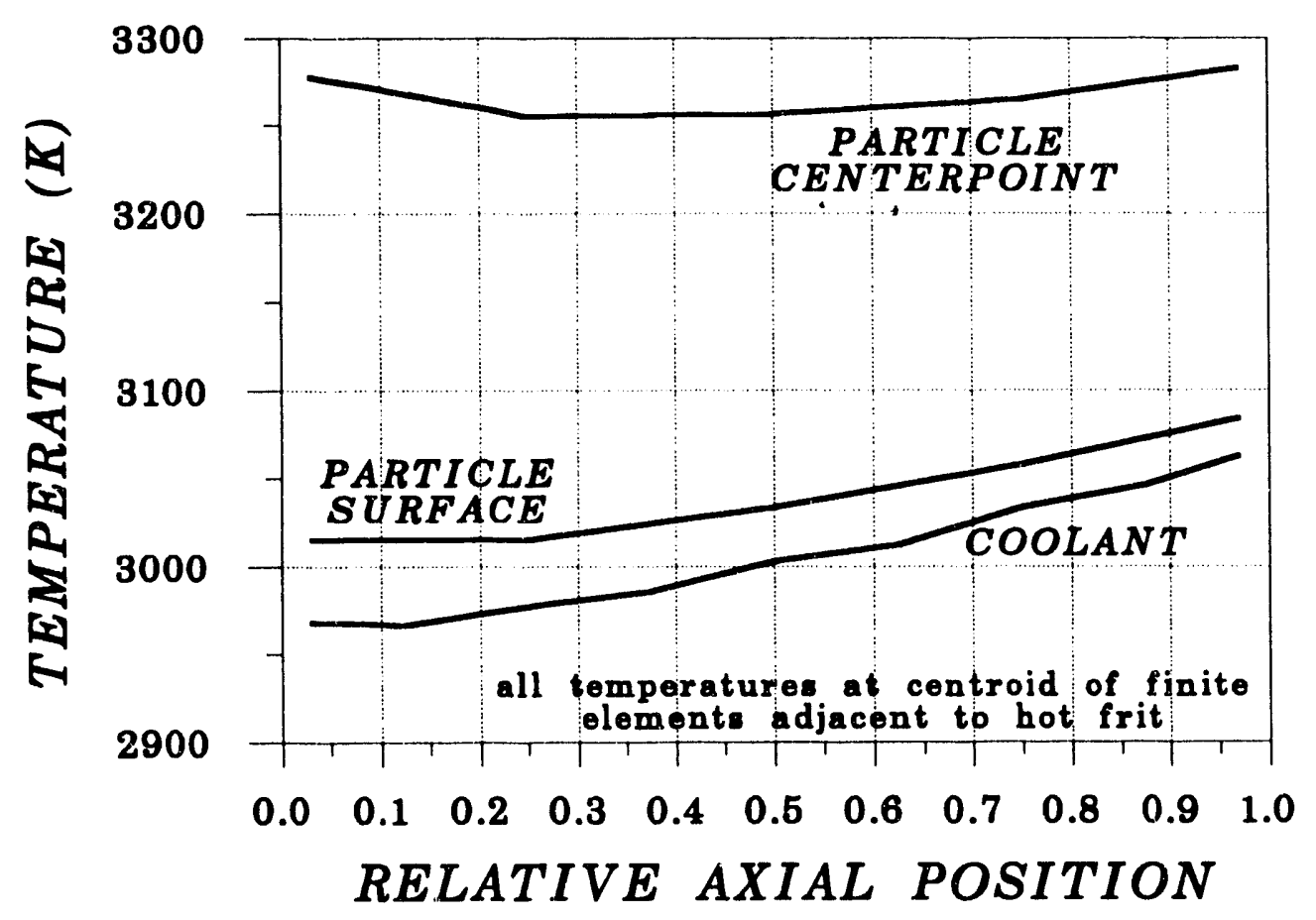

Figure 24. Axial Temperature Profiles in the Fuel Element at Full Thrust

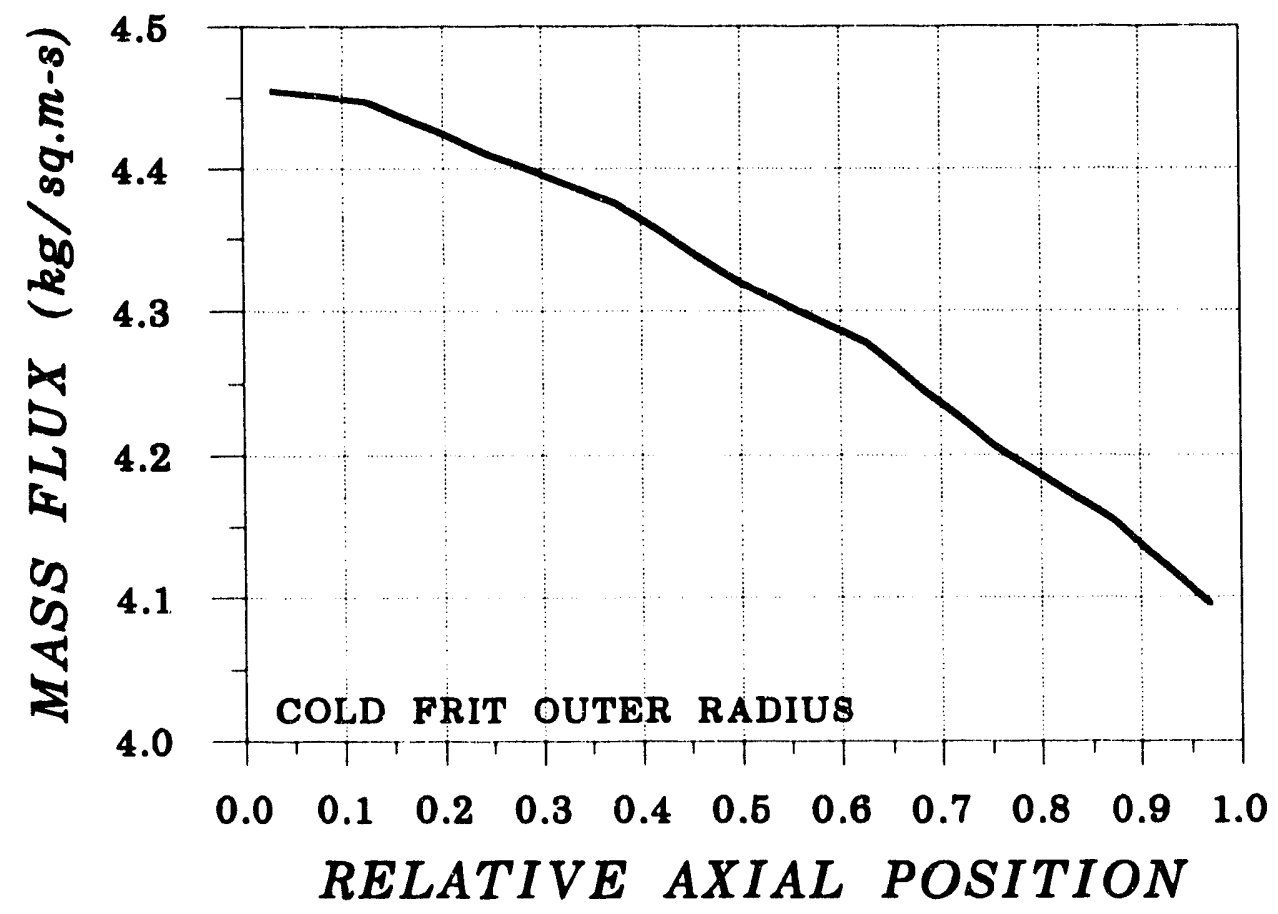

Figure 25. Axial Mass Flux Distribution at Full Thrust 


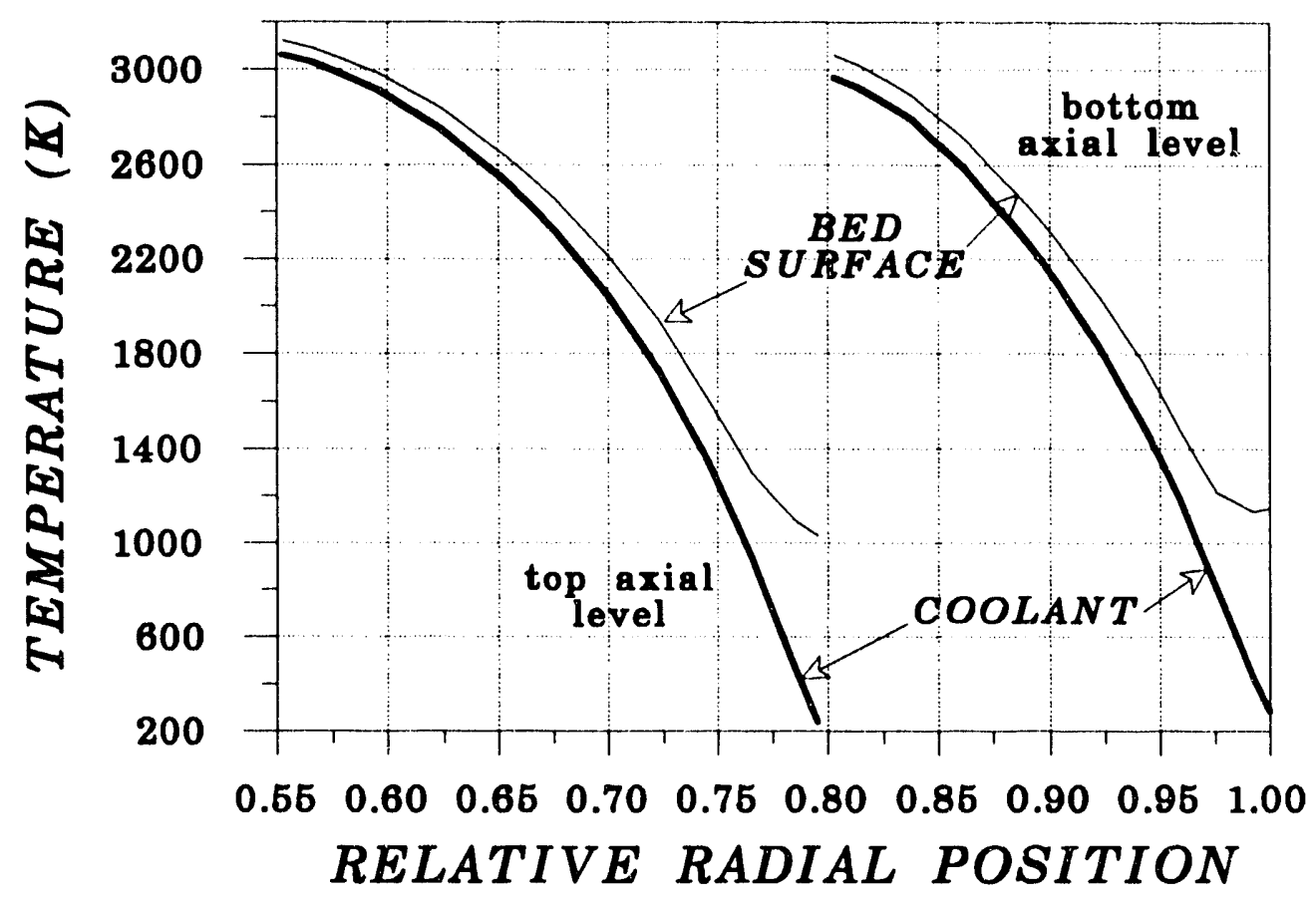

Figure 26. Radial Temperature Distributions at Full Thrust

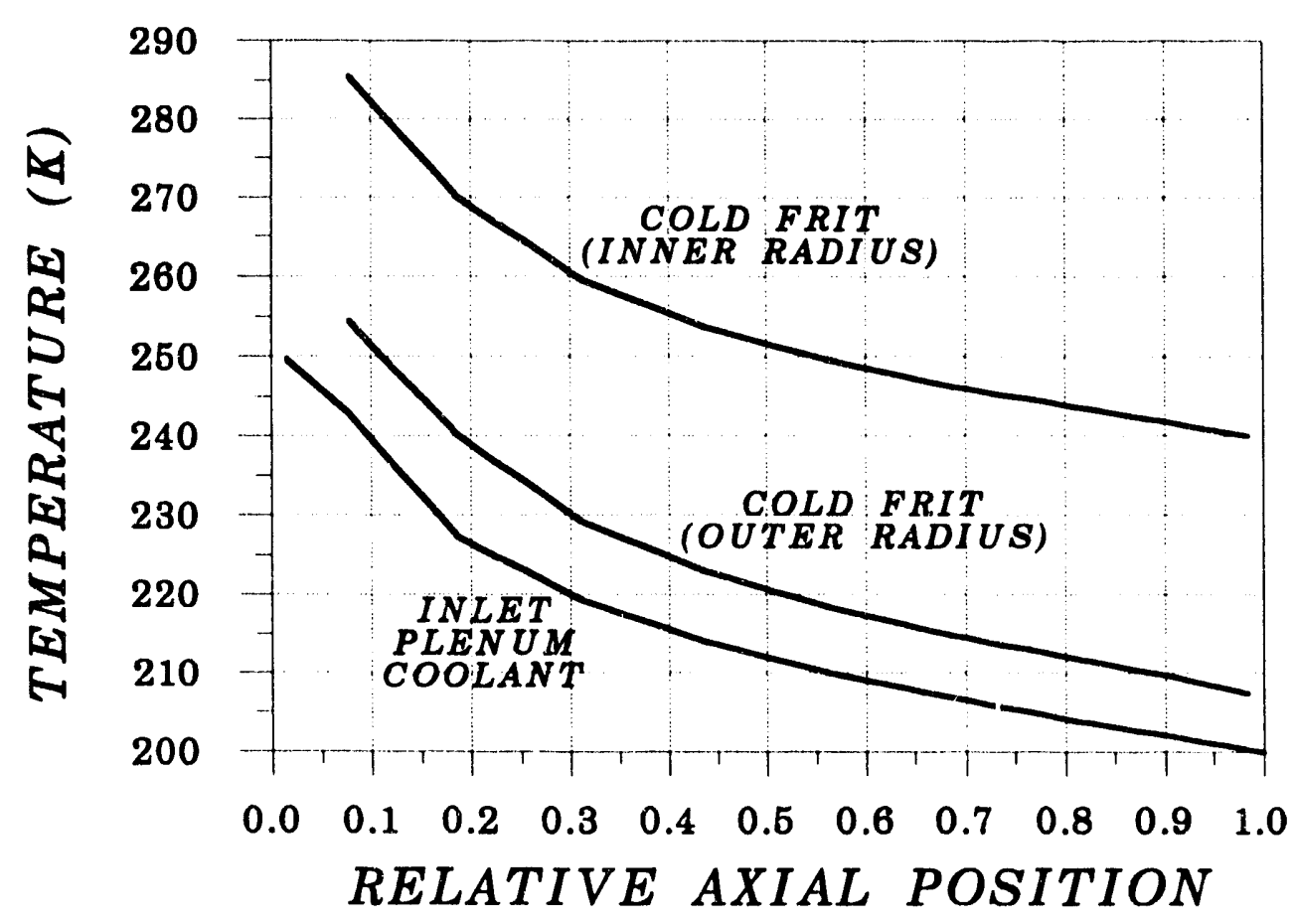

Figure 27. Axial Temperature Profiles in the Inlet Plenum and Cold Frit 


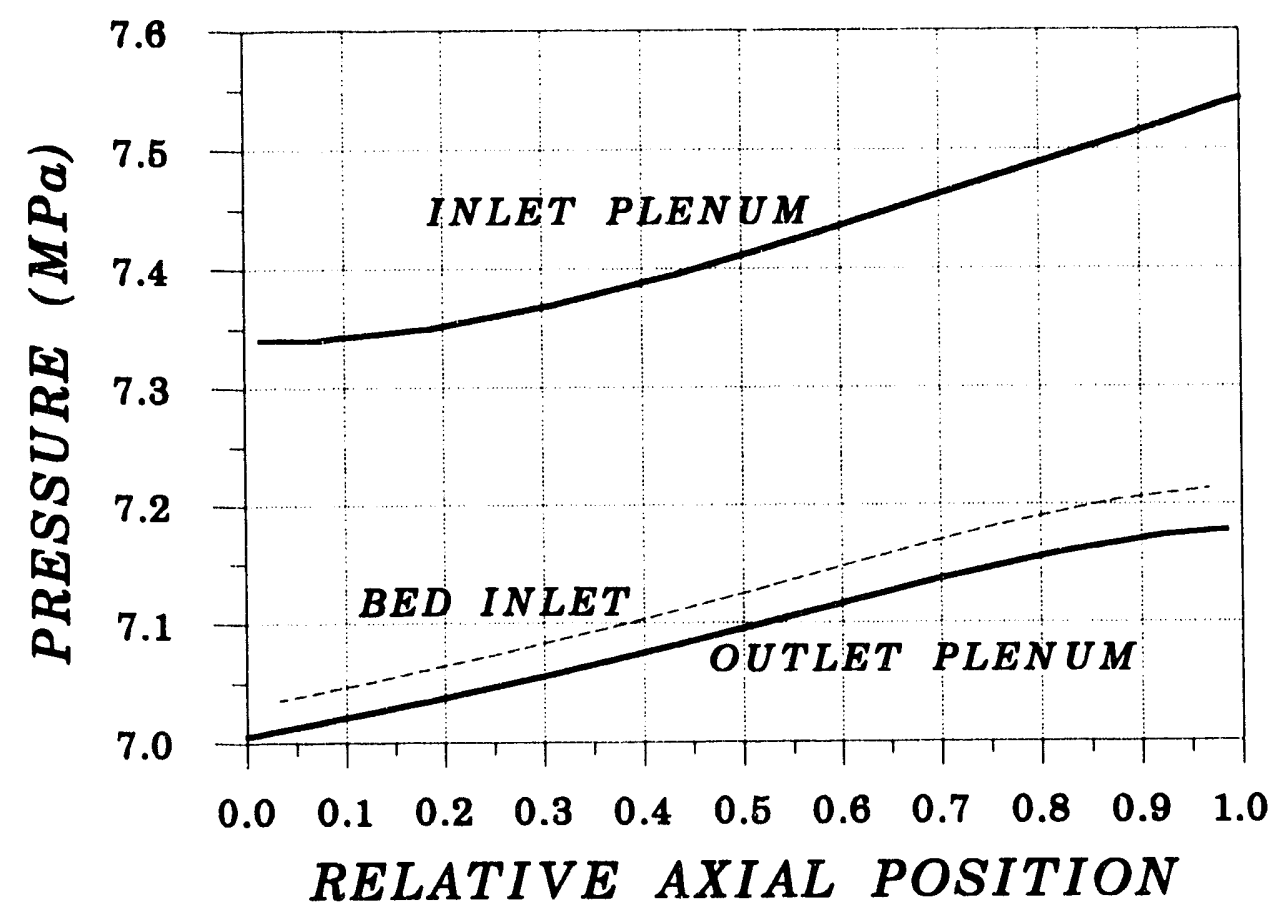

Figure 28. Axial Pressure Profiles in the Inlet and Outlet Plenums

\subsubsection{Reduced Thrust Operation}

As previously mentioned, the axial resistance profile of the cold frit was tailored to provide a uniform particle centerpoint temperature distribution at the exit of the fuel bed at full power. Due to the nonlinear relationship between pressure drop and flow rate, operation of the fuel element at reduced power (thrust) results in nonoptimum use of the coolant. The nonoptimurn use of coolant occurs because the flow redistributes within the element such that the particle centerpoint temperature axial profile is no longer uniform. This flow maldistribution in the element requires an increase in mass flow rate above what would be required if no maldistribution occurred. Because most missions will require operation of the reactor at reduced thrust for some period of time, it is advantageous to design the fuel element such that the flow maldistributions at reduced thrust are kept small.

Many factors contribute to the flow maldistribution problem: nonuniform power distributions, nonuniform porosity distributions, dynamic pressure effects in the inlet and outlet plenums, transpiration drag effects, heating of the inlet plenum coolant by the moderator, and heat transfer to the cold frit by radiation and coolant conduction, to name just a few. Some of these factors are addressed in this section and in the sensitivity analyses of Section 4.2 .

Figure 29 shows the axial pressure profiles in the inlet and outlet plenums at a thrust ratio of 0.05 , for the conical element design. A thrust ratio of 0.05 means that the element 
is operating at $5 \%$ of the full thrust design value. Contrary to the base case (Figure 28), the two profiles are no longer parallel due to flow maldistribution.

The flow maldistributions at reduced thrust are best shown by plotting the particle centerpoint temperature axial profiles. Figure 30 shows the profiles for $1.0,0.5,0.2,0.05$, and 0.025 thrust ratio cases. As intended, the profile is relatively flat at a thrust ratio of 1.0. As the thrust ratio decreases, the profiles become less and less uniform. Except for the 0.025 thrust ratio case, the flow rate at reduced thrust was determined iteratively such that a maximum centerpoint temperature of $3275 \mathrm{~K}$ was achieved. At a thrust ratio of 0.025 , it was not possible to maintain the $3275 \mathrm{~K}$ maximum temperature because of the constraint to maintain the flow rate in the stable regime. As a result, the maximum centerpoint temperature is below $3275 \mathrm{~K}$. The normalized mass flux at the bed entrance is provided in Figure 31 for the 1.0, 0.35, 0.1, and 0.025 thrust ratio cases. Each curve was normalized to its maximum value to facilitate comparison to the other curves. This figure demonstrates that the coolant distribution is shifting such that more flow is going to the lower elevations of the element as the thrust ratio decreases.

One of the factors affecting the redistribution of flow is the transpiration drag in the inlet and outlet plenums. The friction factor ratio in the inlet plenum for 1.0 and 0.35 thrust ratio cases is provided in Figure 32. The friction factor ratio is the ratio of the friction factor with transpiration drag to the friction factor if transpiration drag were not present. The effect of transpiration drag in the inlet plenum is to increase the frictional pressure drop (and the heat transfer coefficient). The increase is greater at the bottom of the inlet plenum than at the top. Also, the reduction of the friction factor with decreasing thrust ratio is greater at the bottom of the element. The friction factor ratio in the outlet plenum is shown if Figure 33. The effect of transpiration drag in the outlet plenum is to decrease the frictional pressure drop due to a thickening of the boundary layer. Lower thrust ratios result in less decrease in pressure drop, especially at the bottom of the element. The nonlinearity of transpiration drag contributes to the flow maldistributions that occur at reduced thrust. The element designer can take advantage of these nonlinearities to partially compensate for other nonlinearities. Many more parametric calculations are required to investigate this possibility.

Figure 34 shows the calculated temperature distribution within a fuel particle. The fuel particle is located in the upper axial level, in the finite element adjacent to the hot frit. The temperature gradient in the particle at full thrust is much larger than at reduced thrust. The large gradient associated with the particular particle design of this study accounts for the interesting result revealed in the next figure (Figure 35).

Figure 35 shows the coolant temperature at the exit of the fuel element (referred to as the chamber temperature) as a function of the thrust ratio. Recall that the mass flow rate was adjusted to maintain the centerpoint temperature of all particles at or below the maximum value of $3275 \mathrm{~K}$. Two competing effects occur as the thrust ratio is decreased:

page -- 38 
(1) Flow maldistribution within the fuel element at reduced thrust levels requires a mass flow rate greater than would be required based on perfect power-to-flow matching. The mass flow rate for perfect power-to-flow matching was determined by dividing the thermal power deposited in the element and moderator by the product of the coolant constant-pressure specific heat and the element coolant temperature difference at full power. (This neglects potential and kinetic energy, which account for about $0.6 \%$ of the total energy at full power.) The element coolant temperature difference is the chamber temperature minus the fuel element entrance coolant temperature. At full power conditions this difference is $2800 \mathrm{~K}$ $(3000 \mathrm{~K}-200 \mathrm{~K})$.

(2) Reduced temperature gradients in the fuel particles at reduced thrust allows a reduction in the mass flow rate required to maintain the maximum centerpoint temperature of $3275 \mathrm{~K}$. Keep in mind that the flow rate is adjusted based on the centerpoint temperature, not the surface or coolant temperature.

At thrust ratios down to about 0.2 , the reduced temperature gradient effect dominates; thus the mass flow rate is less than what would be required for perfect power-to-flow matching. As a result, the chamber temperature increases above the full power value. Below a thrust ratio of 0.2 , the flow maldistribution effect dominates and it is necessary to overcool the fuel element to prevent exceeding the maximum centerpoint temperature. This fuel element overcooling results in a reduction in chamber temperature as the thrust ratio is decreased further. This effect would be reduced for particles with less thermal resistance.

A measure of the fuel element performance at reduced thrust is the specific impulse ratio. This is the ratio of the specific impulse at full thrust to the impulse at reduced thrust. This ratio is presented in Figure 36. Specific impulse is proportional to the square root of chamber temperature. Due to the increase in chamber temperature, there is a small increase in the specific impulse ratio at thrust ratios down to about 0.2 . This means that there is no degradation of performance for this particular element design for thrust ratios greater than 0.2 . However, at a thrust ratio of 0.025 , the specific impulse ratio is degraded to about 0.7 due to the decrease in chamber temperature.

Figure 37 shows pressure at the element entrance, element exit (chamber), and nozzle throat as a function of thrust ratio. Also shown is an estimate of the effluent treatment system (ETS) backpressure for a proposed ground test facility for testing advanced nuclear fuel elements. This estimate is taken from Reference 20. The relationship between pressure and thrust ratio is approximately linear. The figure also indicates that particle bed fuel elesnents could be tested at thrust ratios down to about 0.1 before choked flow at the nozzle throat is lost in the referenced ETS design.

Keep in mind that the figures presented here are for one hypothetical design and that optimizations are possible. 


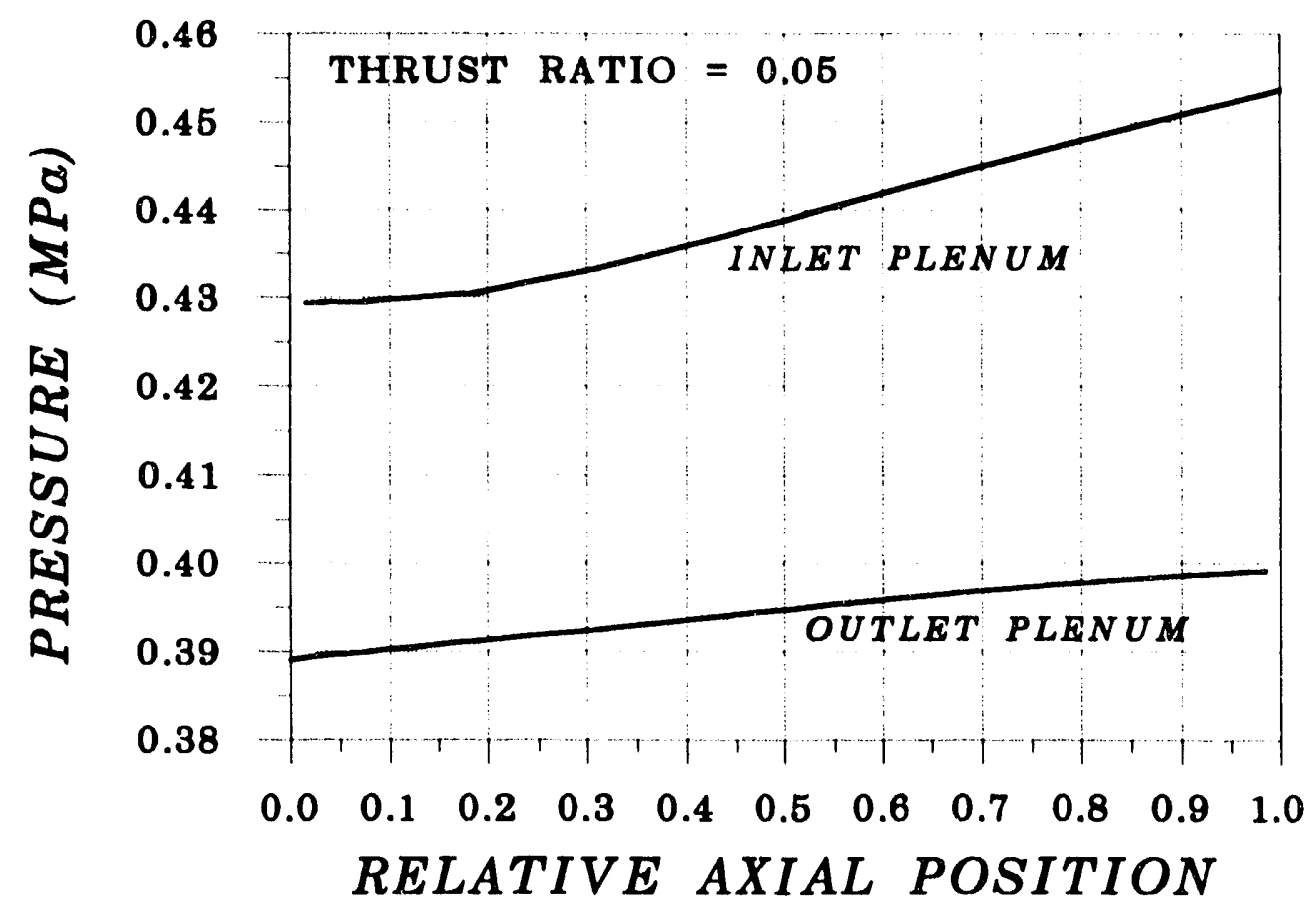

Figure 29. Axial Pressure Profiles in the Inlet and Outlet Plenums at 0.05 Thrust Ratio

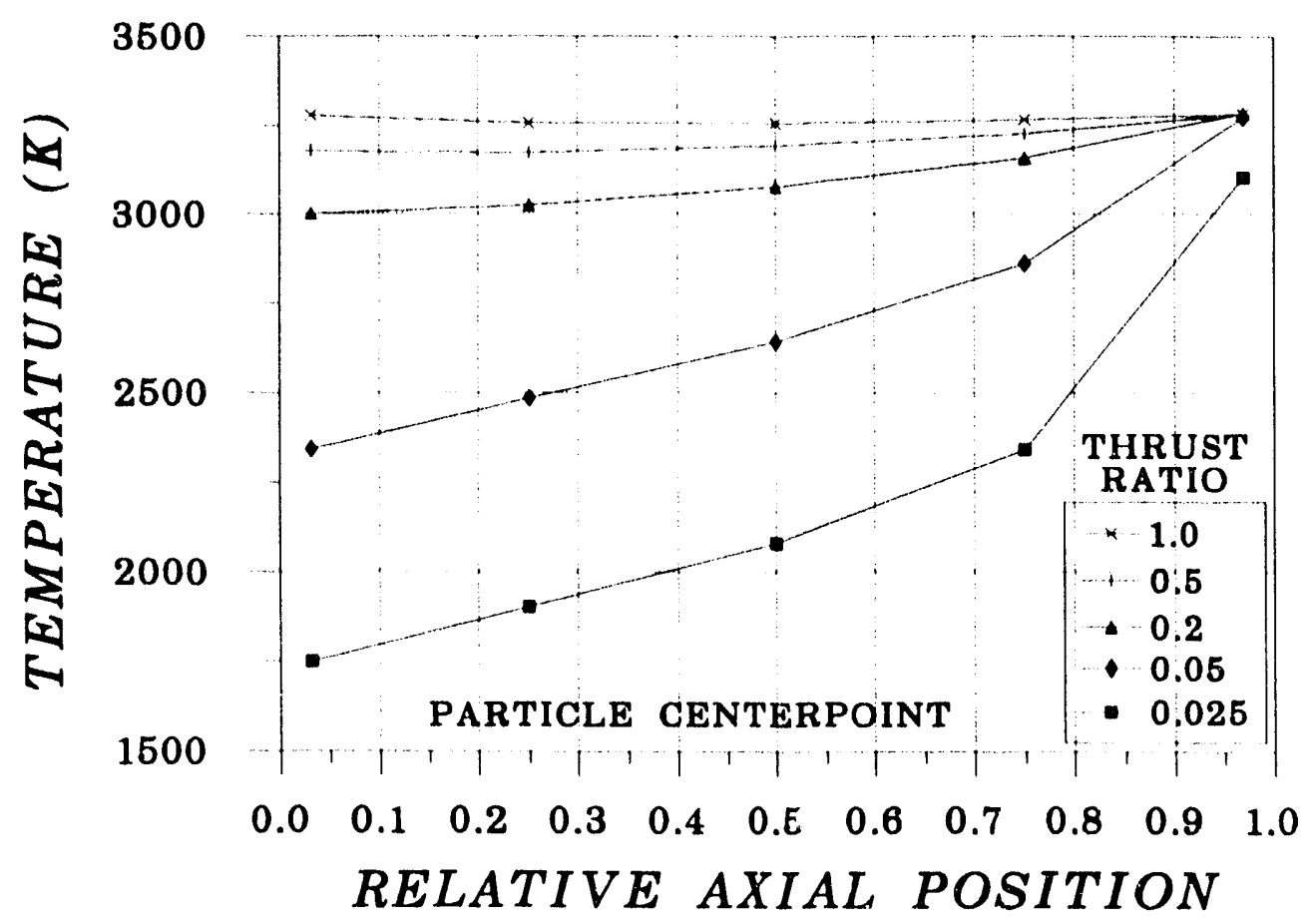

Figure 30. Particle Centerpoint Temperature Profiles at Reduced Thrust 


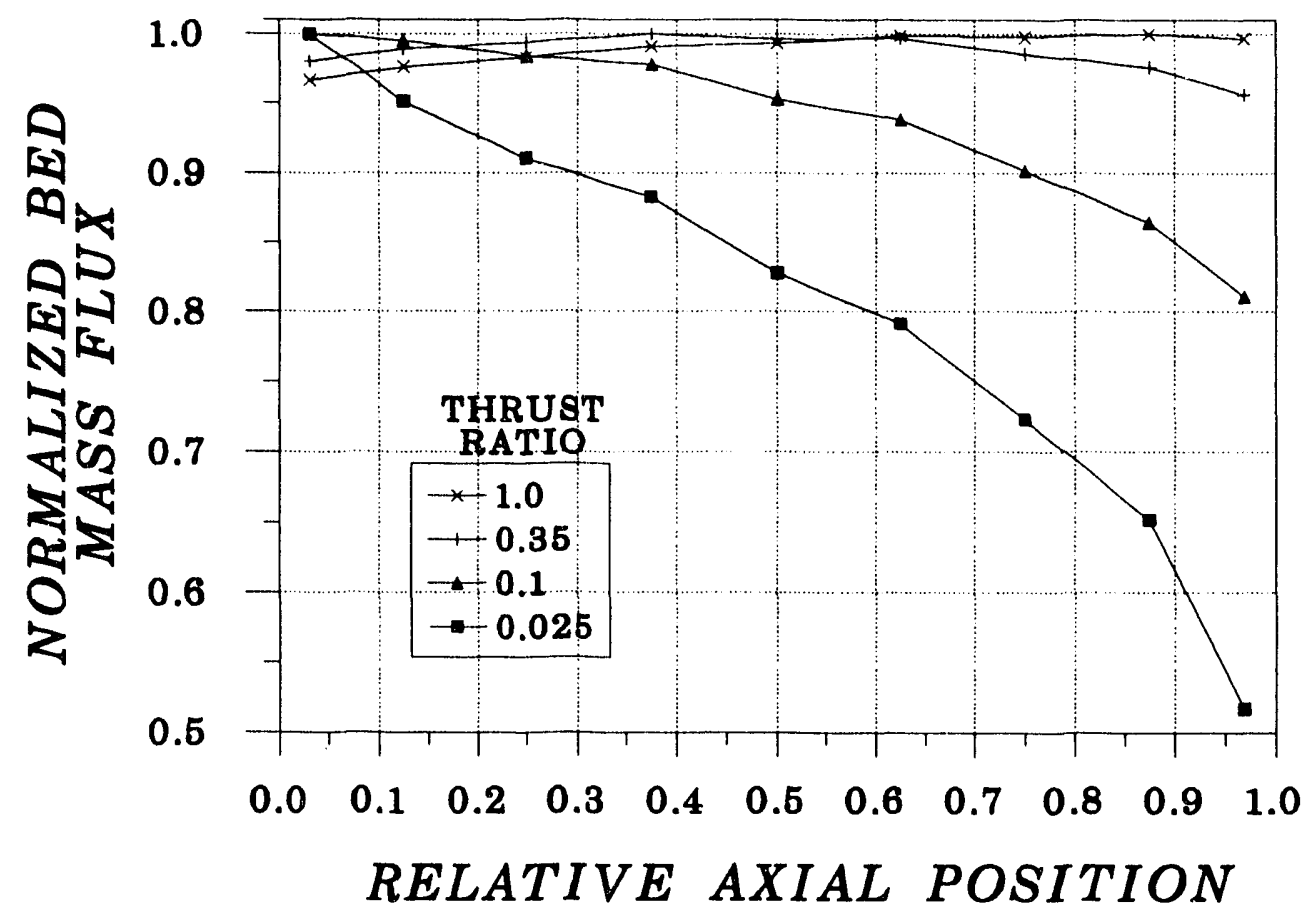

Figure 31. Normalized Mass Flux Profiles at Reduced Thrust

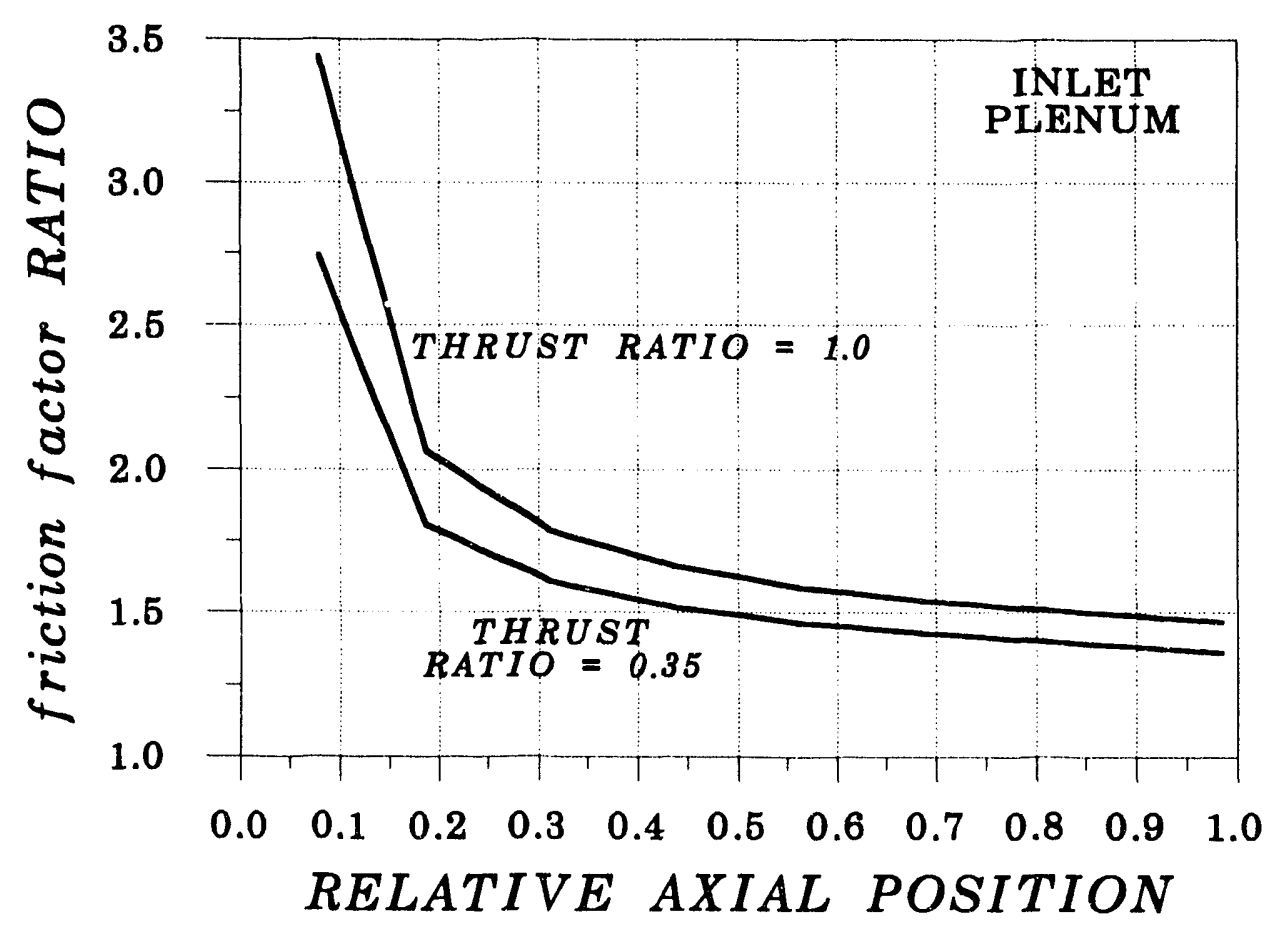

Figure 32. Friction Factor Ratio Profiles in the Inlet Plenum at Full and Reduced Thrust 


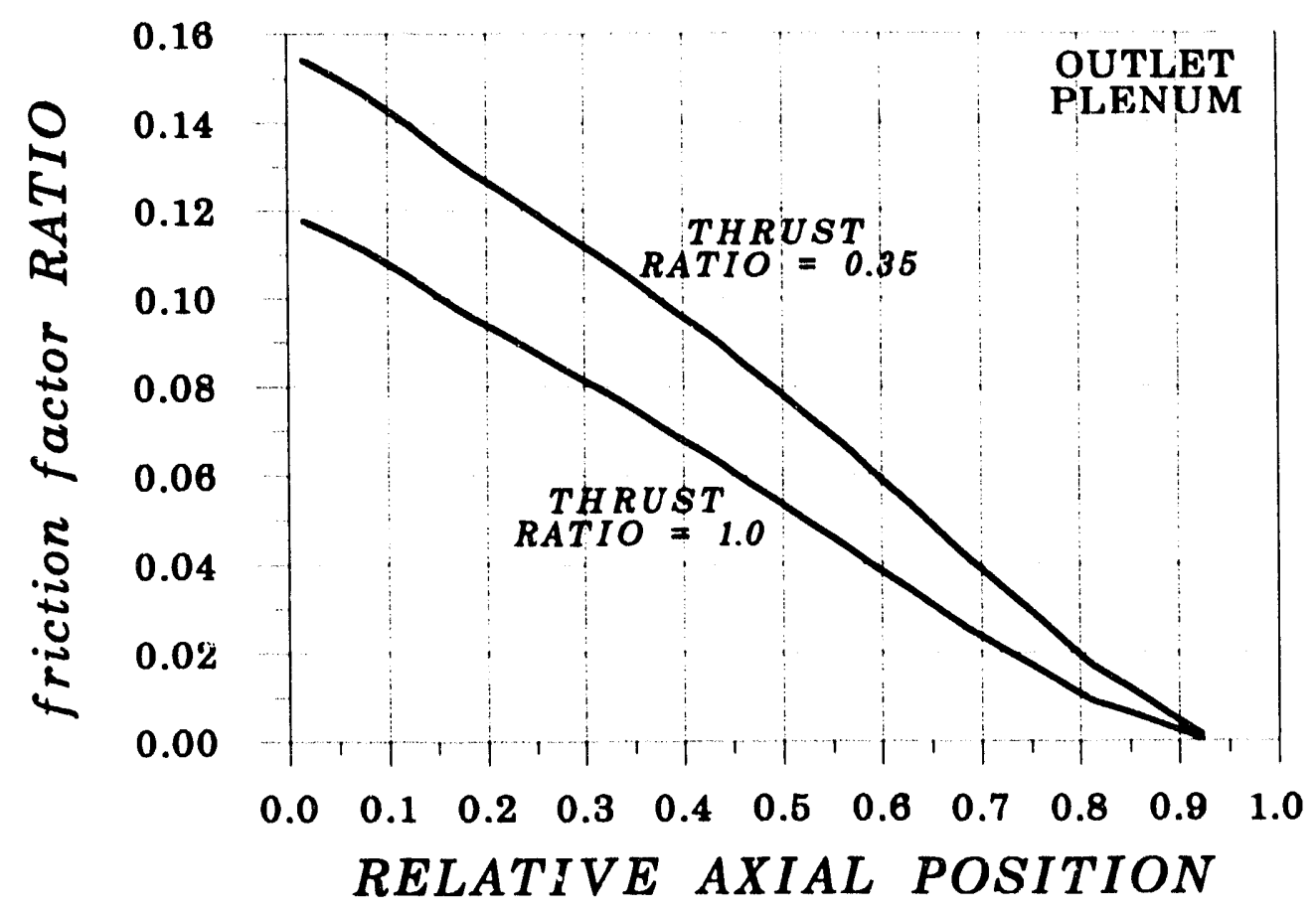

Figure 33. Friction Factor Ratio Profiles in the Outlet Plenum at Full and Reduced Thrust

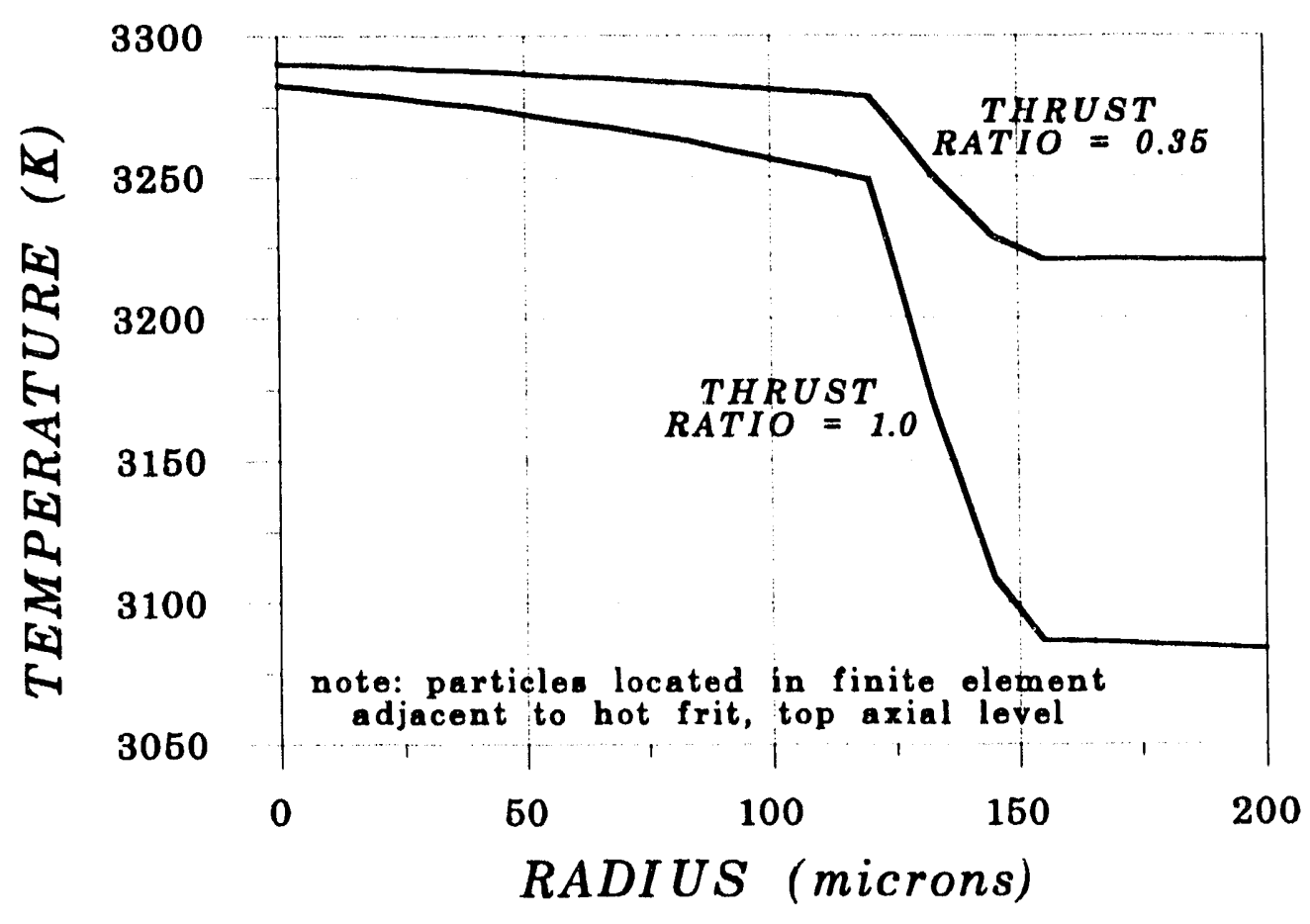

Figure 34. Radial Temperature Distribution in a Fuel Particle 


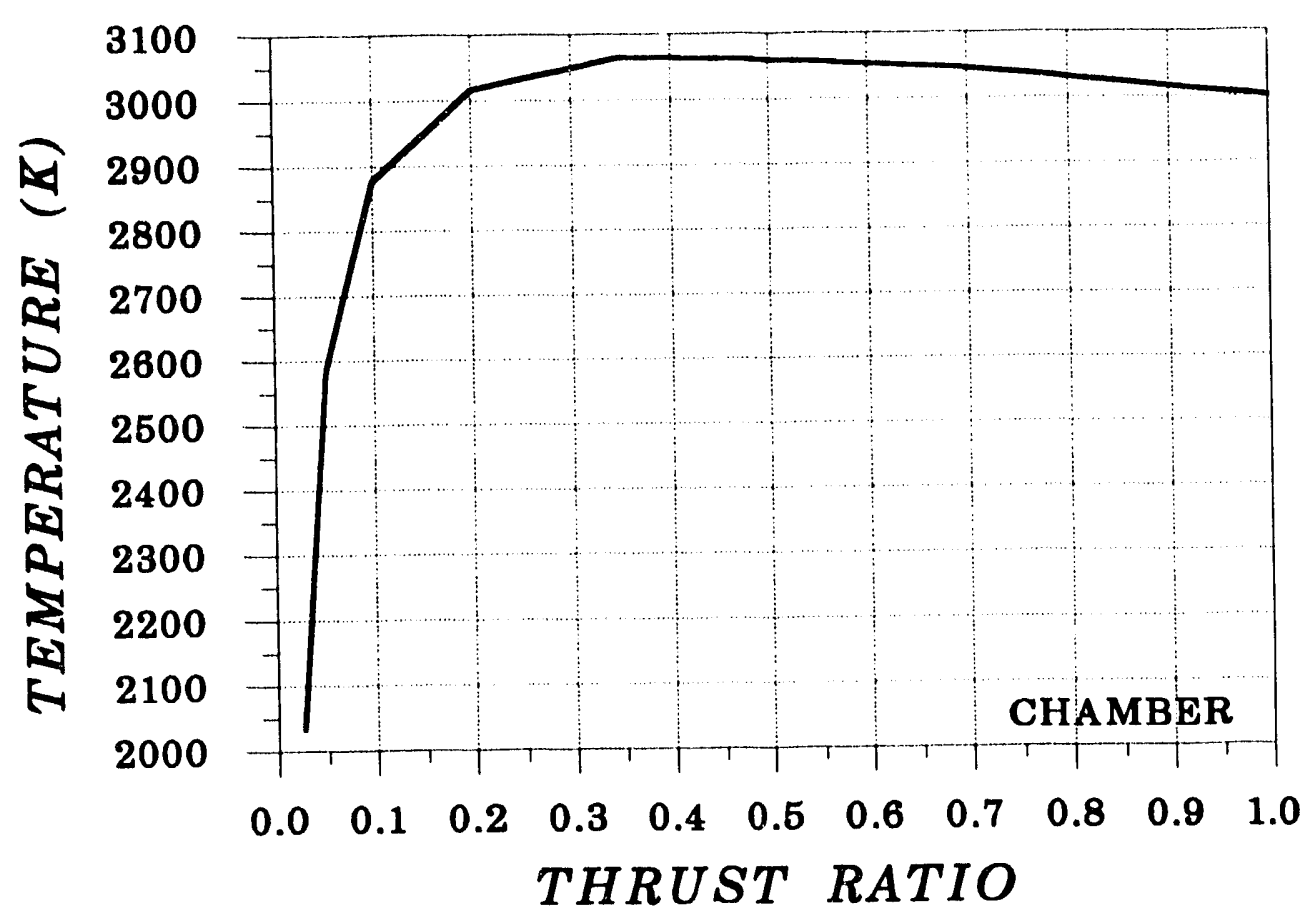

Figure 35. Chamber Temperature as a Function of Thrust Ratio

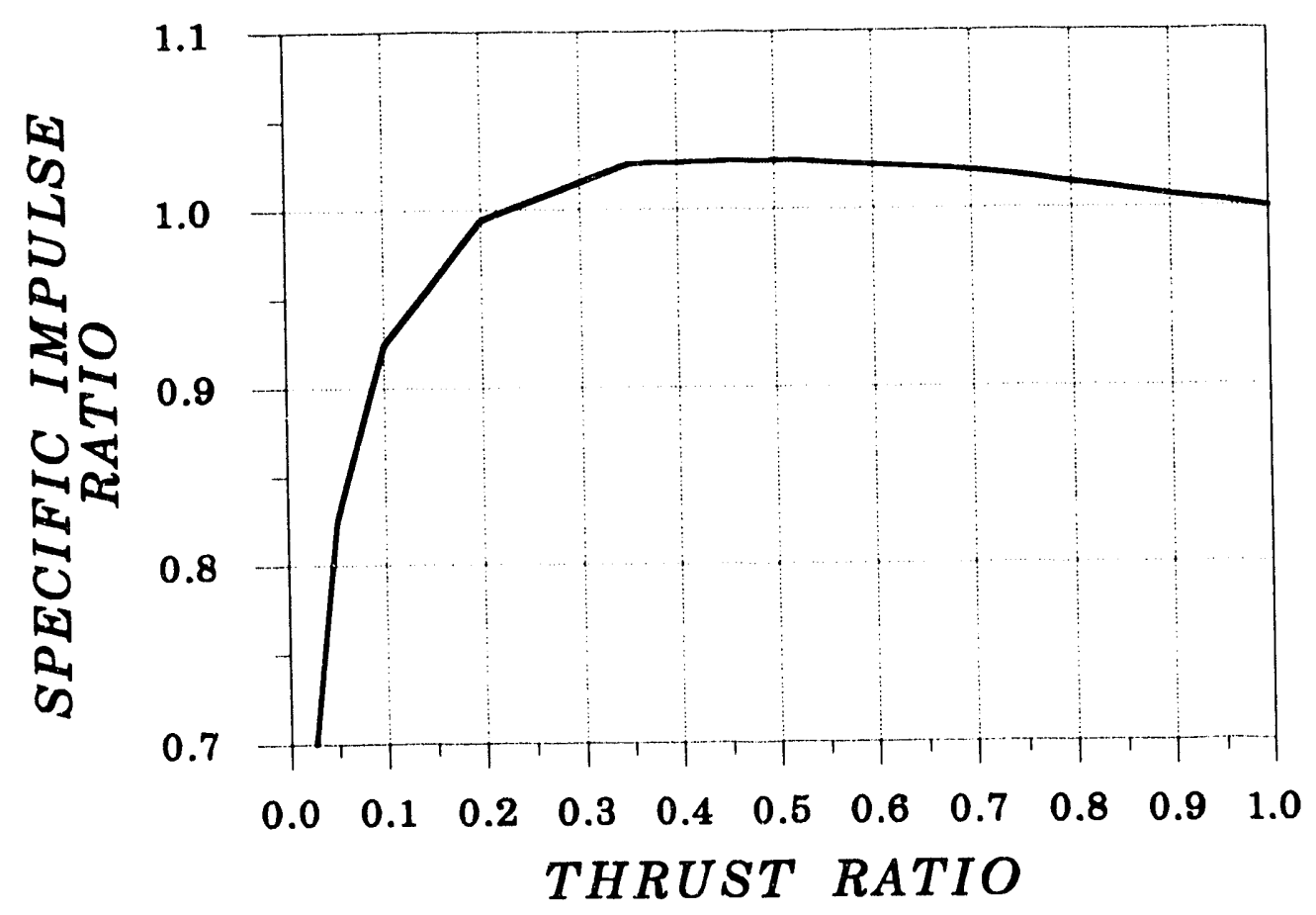

Figure 36. Specific Impulse Ratio as a Function of Thrust Ratio 


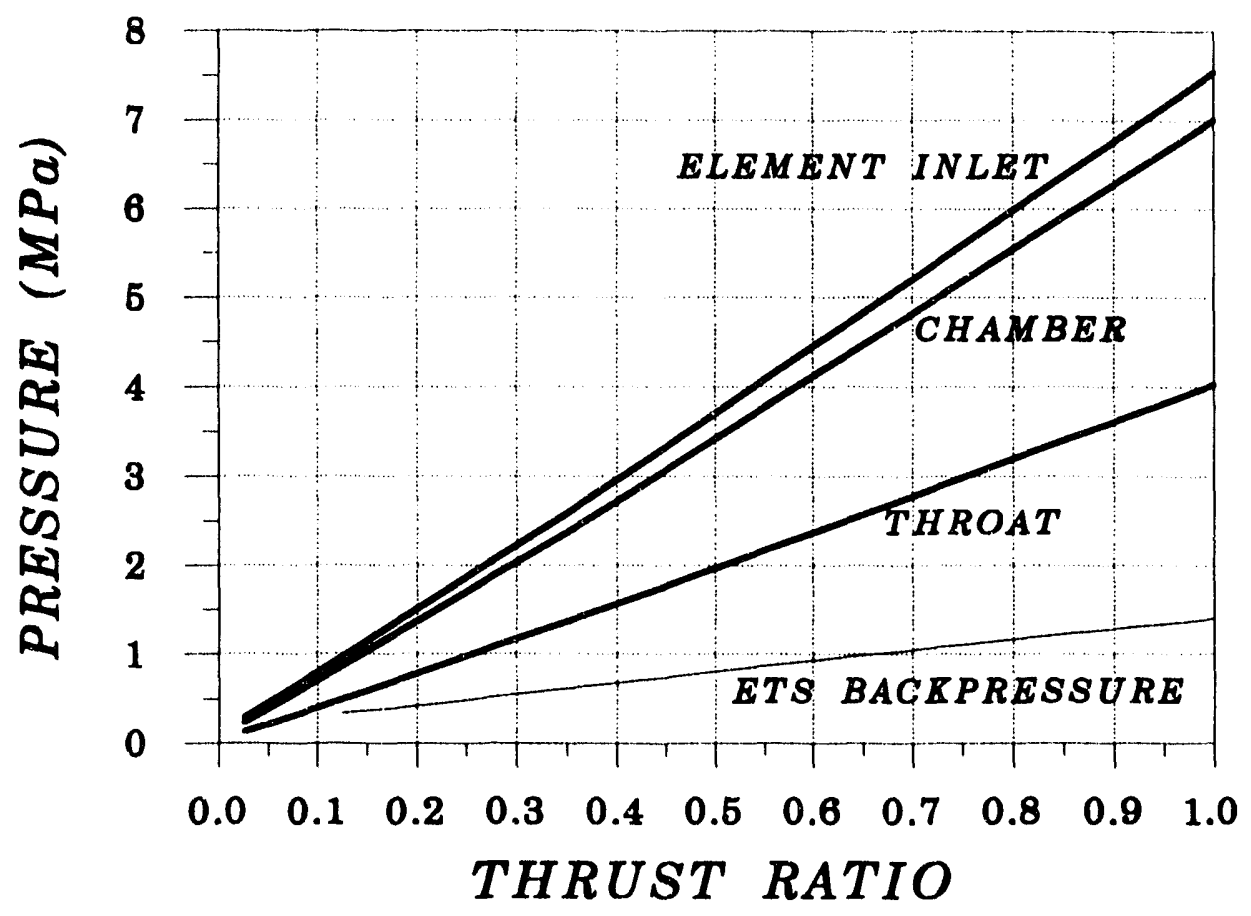

Figure 37. Pressure Response at Reduced Thrust

\subsection{Sensitivity Analyses}

The base case analyses of Section 4.1 are based on specific assumptions regarding the geometry and physics of a particle bed fuel element. Ilowever, there is a lot of uncertainty associated with the modeling of a fucl element that can affect the interpretation of the results. Fortunately, computer simulation allows the analyst the ability to alter physics in order to understand the sensitivity of the results to a particular assumption. For example, the pressure drop associated with transpiration drag can be "turned off;" this is a luxury not available to the experimentalist. Because the user has complete control of the input models for SAFSIM, the analyst can perform "what-if analyses" to improve understanding of performance and to provide insight as to where additional experimental work should be focused. The calculations in the following sections address some of the uncertainties associated with the fluid mechanics and heat transfer simulations of a particle bed fuel element.

Recall that $l / d$ was added to the cold frit to tailor the resistance profile of the element. The added $l / d$ for the full thrust base case and for the cases where moderator heat addition and transpiration flow losses are turned off is provided in Figure 38. This figure is included to highlight the sensitivity of the cold frit resistance profile to the proper modeling of the fuel element. If transpiration drag is not included in the modeling of a particle bed fuel element, the computed results will be greatly in error, at least for the assumed conical element design used in these calculations. This result also implies that 
the element designer can take advantage of the flow characteristics of the fuel element to produce an element that performs well at all thrust levels. The key is to obtain sufficient understanding of the element flow characteristics, which is the basis for the SAFSIM simulations described in this document.

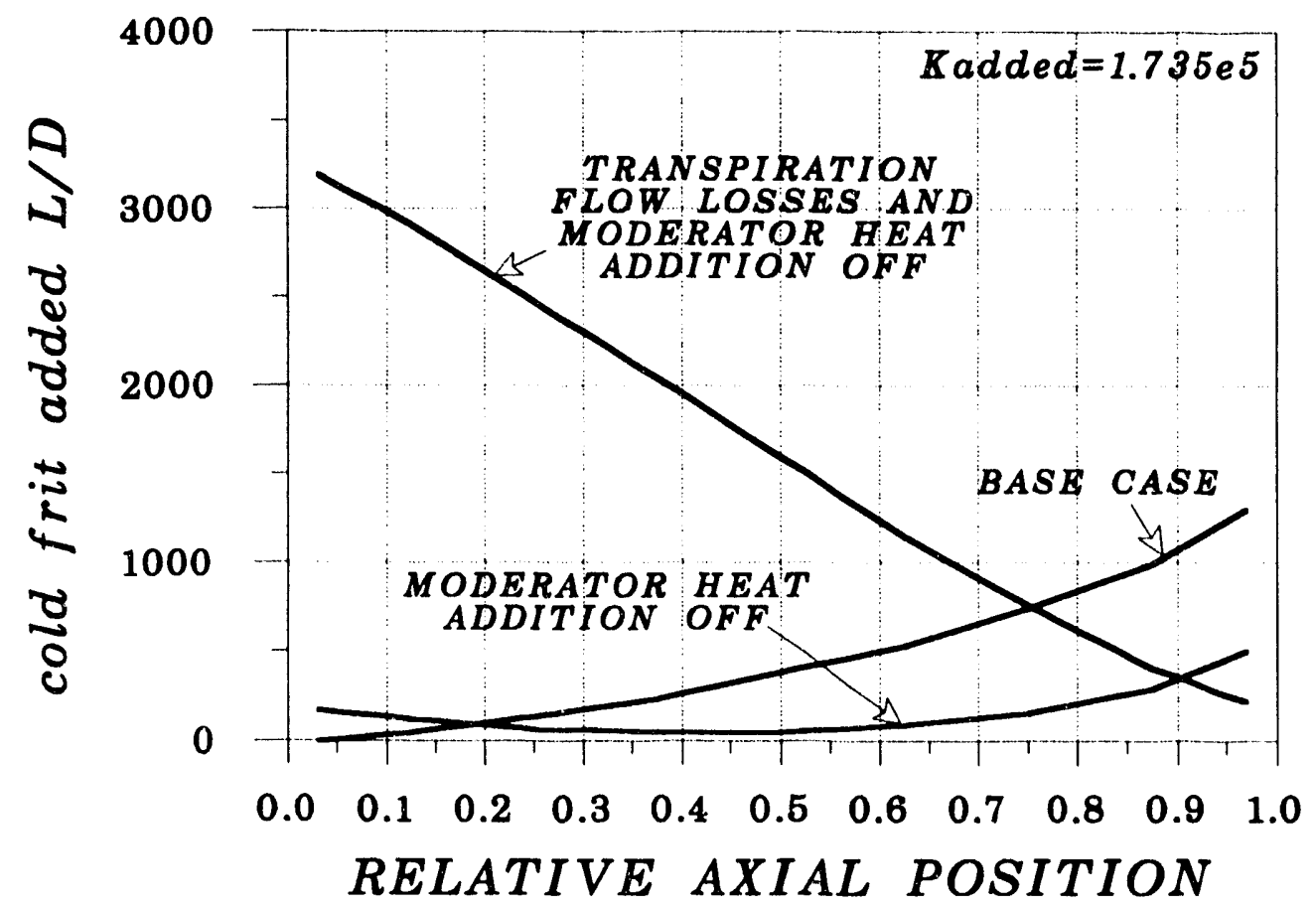

Figure 38. Effect of Modeling Assumptions on Calculated Cold Frit $l / d$

\subsubsection{Transpiration Drag}

A convenient way to demonstrate the sensitivity of modeling assumptions to the calculated results is to show the particle centerpoint axial temperature profiles at the bed exit for the different modeling assumptions. Figure 39 shows the centerpoint profile for the base case and for the cases in which transpiration drag was turned off in the inlet and outlet plenums. Although the influence of transpiration drag on the wall friction in the outlet plenum has some influence, the transpiration drag in the inlet plenum strongly affects the results. Because transpiration drag is a function of the axial-to-radial velocity ratio, modifying the width of the inlet and outlet plenums allows the designer to influence the transpiration drag effects. For example, a large increase of the inlet plenum gap can negate the effect of transpiration drag on the friction factor in the inlet plenum.

Transpiration drag in the inlet and outlet plenums proved to have significant effect on the flow distribution within the fuel element. Because SAFSIM relies on empirical correlations for transpiration drag, these analyses indicate that perhaps experimental or multidimensional computational work is required to validate the correlations for fuel element conditions. 


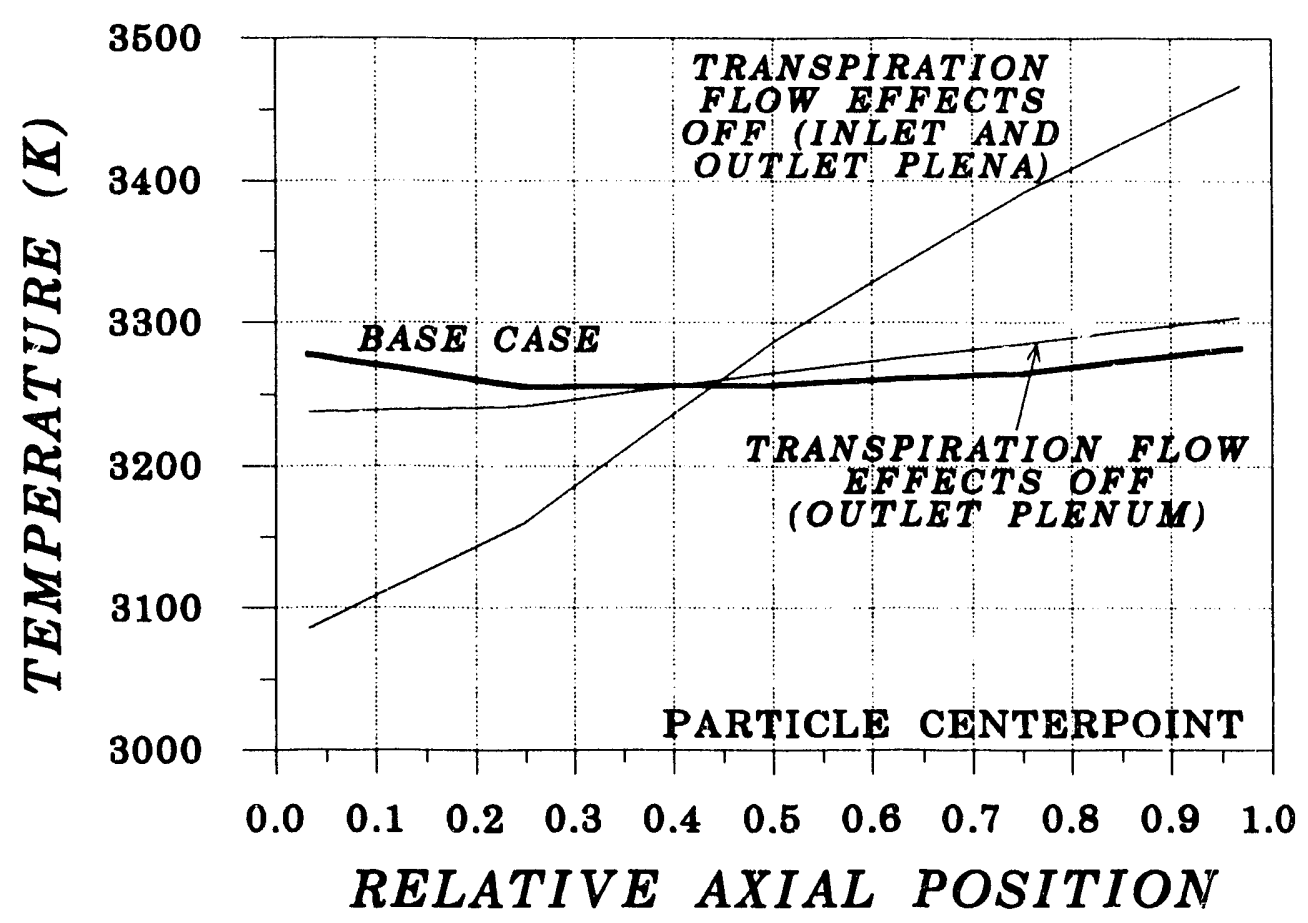

Figure 39. Effect of Transpiration Drag on the Particle Centerpoint Temperature Profile

\subsubsection{Moderator Heat Addition}

As coolant flows down the inlet plenum, it picks up heat from the moderator material surrounding the fuel element. Because viscosity (and therefore flow resistance) is a function of temperature, this heating influences the flow distribution through the element. Figure 40 shows the centerpoint temperature axial profile for a case in which moderator heat addition was turned off, compared to the base case. The effect is fairly strong. Moderator heating of coolant is also important during decay heat removal transients because the fraction of total power deposited in the moderator, relative to the fuel, is continually increasing. Like the transpiration drag phenomena, the element designer has some control over the amount of heat added to the coolant by the moderator. For example, coolant flow paths can be configured internal to the moderator such that most of the heat is removed from the moderator before the coolant enters the inlet plenum. Also, it may be desirable to have the coolant enter at the bottom of the element instead of at the top. Again, these options should be considered in the design of the element with respect to minimizing flow maldistributions. 


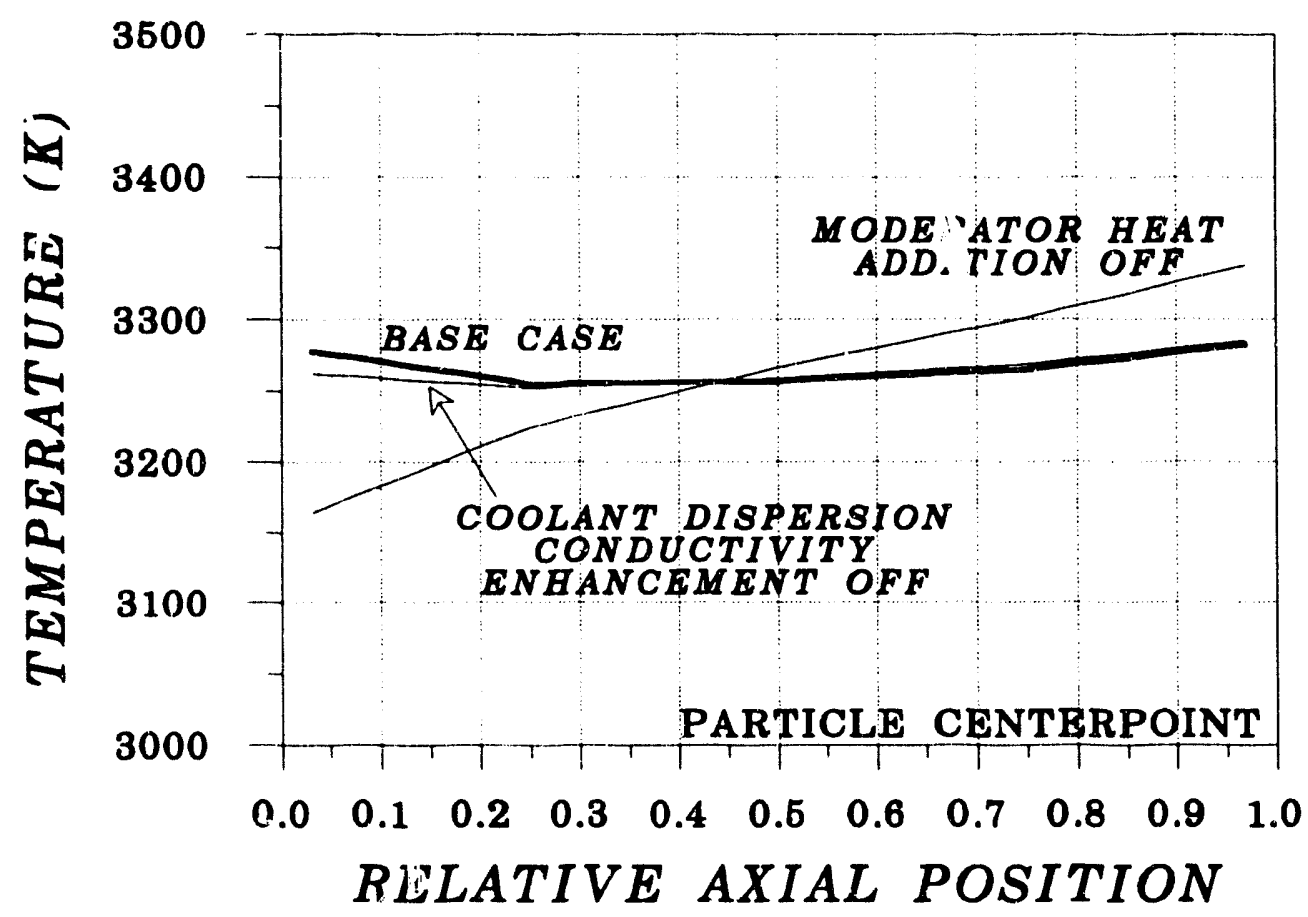

Figure 40. The Effect of Moderator Heat Addition and Coolant Dispersion Conductivity Enhancement on the Particle Centerpoint Temperature Profile

\subsubsection{Coolant Dispersion Conductivity Enhancement}

Figure 40 also shows the effect of coolant dispersion conductivity enhancement on the calculated particle centerpoint temperature profile. As is discussed in Section 2, conduction is enhanced in a coolant flowing through a porous media due to dispersion effects as the coolant takes its tortuous path over and between the particles. The conductivity enhancement is predicted by an empirical relationship as was provided in Equation (7). The form of this equation is fairly common, but different researchers report different values for the coefficient, $\phi$. Also, this correlation has no direct dependence on porosity, which varies within the fuel bed near the frits. SAFSIM allows the analyst to specify this coefficient for each porous media finite element. For the base case, a coefficient of 0.2 was arbitrarily selected for the bed and cold frit finite elements. The figure shows that conductivity enhancement does not strongly affect the particle centerpoint temperature profile.

Figure 41 shows the predicted radial coolant temperature distribution in the top axial level for two cases: no enhancernent and full enhancement in the fuel bed. Full enhancement refers to a dispersion coeffit ent of 0.5 , the maximum value reported by any researcher. As expected, the effect of conduction enhancement is to flatten the profile; however, the effect is very small. However, Figure 42 shows the large effect of conductivity enhancement on the cold frit temperature. The inner surface of the cold frit 
for the base case (coefficient of 0.2 ) increases in temperature by about $27 \mathrm{~K}$ compared to the case in which enhancement is turned off. Using a coefficient of 0.5 results in an increase of about $65 \mathrm{~K}$. As currently modeled (because of lack of data to indicate otherwise), the pressure drop across the cold frit does not depend directly on cold frit temperature. (Indirectly, the pressure drop is affected by changes in the coolant temperature.) Because thermal expansion of the cold frit might lead to such a direct depencence, conductivity enhancement could have a significant impact on fuel element performance. These results indicate that experimental work is required to characterize the cold frit pressure drop as a function of temperature. If a strong dependence is found, additional experimental work would be warranted to validate the conductivity enhancement correlation.

It should be noted that at the low power densities typical of decay heat, coolant conductivity is somewhat more important because the ratio of heat transfer by advection to heat transfer by conduction decreases. Thus the temperature profile of Figure 41 is further flattened and the cold frit temperatures increase more, compared to the full power base case results. Thus coolant conductivity enhancement has the potential to significantly affect the element performance. As mentioned previously, the appropriateness of the enhancement correlation, especially for regions near the cold frit, should be investigated. Further parametric calculations should address this issue.

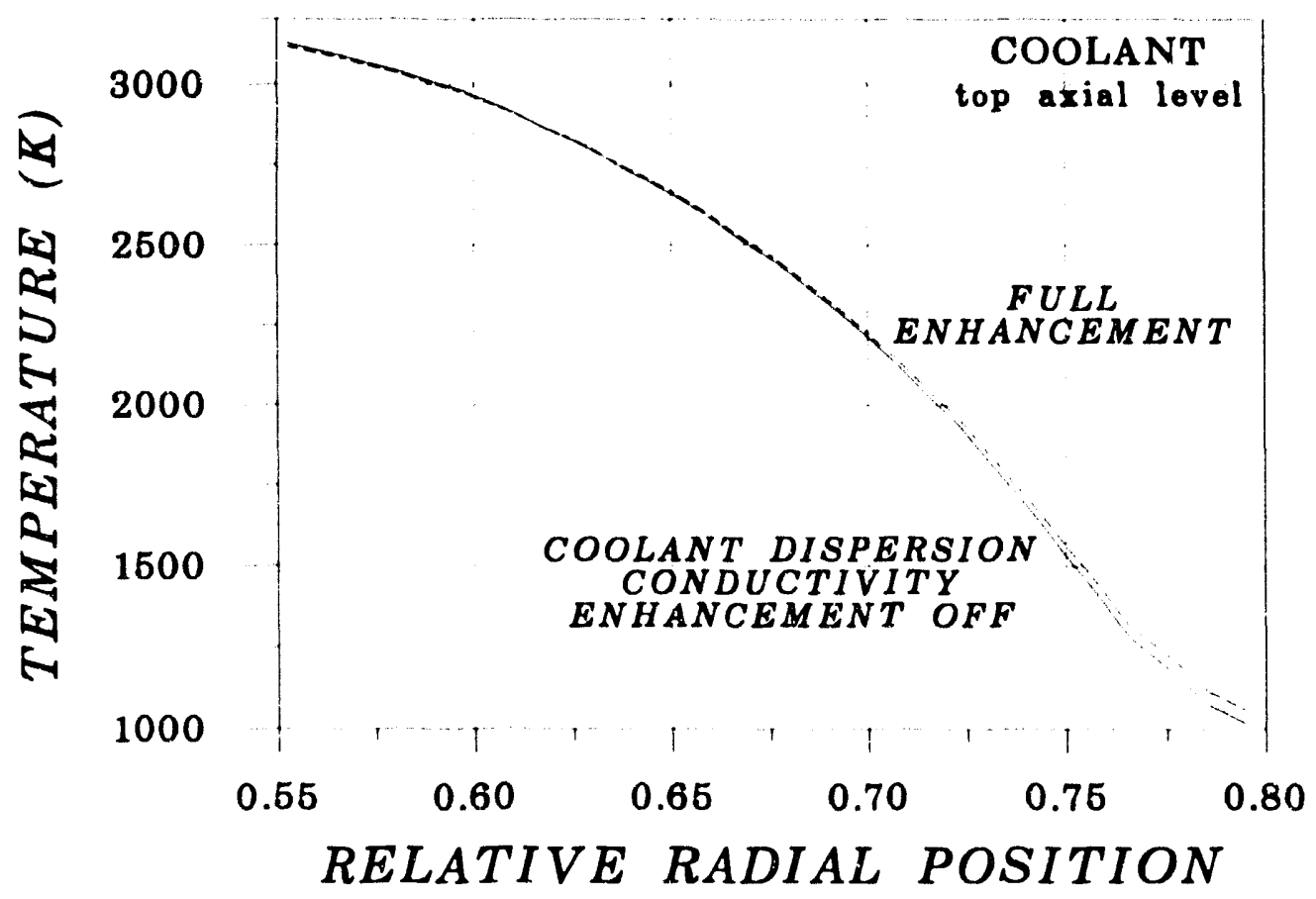

Figure 4l. Fffect of Coolant Dispersion Conductivity Enhancenent on the Coolant Radial Temperature Profile (Base Case Conditions) 


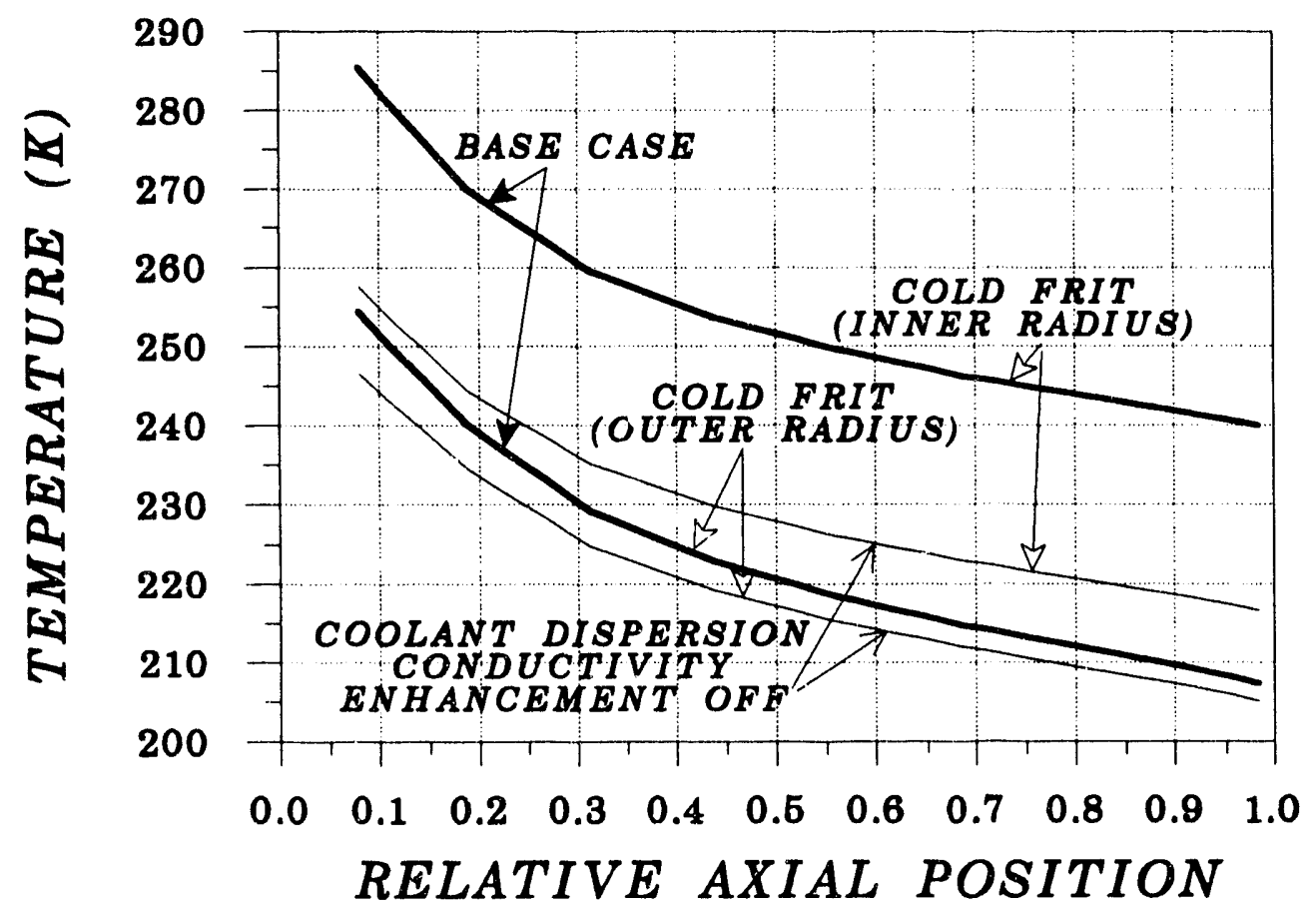

Figure 42. Effect of Coolant Dispersion Conductivity Enhancement on the Cold Frit Axial Temperature Profile

\subsubsection{Thermal Radiation Heat Transfer from Bed to Cold Frit}

The SAFSIM input model is configured such that heat can travel from the bed to the cold frit by conduction through the coolant and by thermal radiation. The base case calculation was repeated with radiation heat transfer from the bed to the cold frit turned off. The cold frit temperature changed by less than $1 \mathrm{~K}$ and the particle centerpoint temperature at the bed exit exhibited essentially no change at all. The temperatures at the cold frit-bed interface are simply too low for effective radiative heat transfer.

\subsubsection{Bed Friction Factor Correlation}

As mentioned in the input model description, the Achenbach correlation for friction factor in the bed is used for the base case. This case was repeated using the Ergun correlation instead. Because the pressure drop in the element is dominated by the cold frit, changes to the bed pressure drop are negligible. Using the Ergun equation resulted in an insignificant change in the centerpoint temperature profile (Figure 43).

\subsubsection{Element Entrance Coolant Temperature}

As was discussed in Section 4.2.2, the coolant temperature distribution in the inlet plenum affects the flow distribution through the element. During operation of the fuel 
element, the coolant temperature at the entrance of the fucl element will change during startup and shutdown, which will also affect the flow distribution. To determine the sensitivity of the flow distribution to coolant entrance temperature changes, a parametric case was run with the entrance temperature increased from $200 \mathrm{~K}$ (the base case value) to $300 \mathrm{~K}$. The flow rate was decreased such that the coolant exit temperature was the same as the full power base case. Figure 43 shows the effect of this change on the particle centerpoint temperature profile. The effect is not insignificant and indicates that element designers must consider the coolant entrance temperature when determining the cold frit axial resistance profile. Also, it may be possible to decrease the flow maldistributions within the fuel element during decay heat removal operation by altering the coolant entrance temperature. This can be accomplished by changing the flow path through the reactor (reflectors, shields, vessel walls, moderator, and other structure requiring cooling). Increasing the coolant temperature at the entrance to the element also improves the flow stability of the fuel element, as is discussed in Section 3.

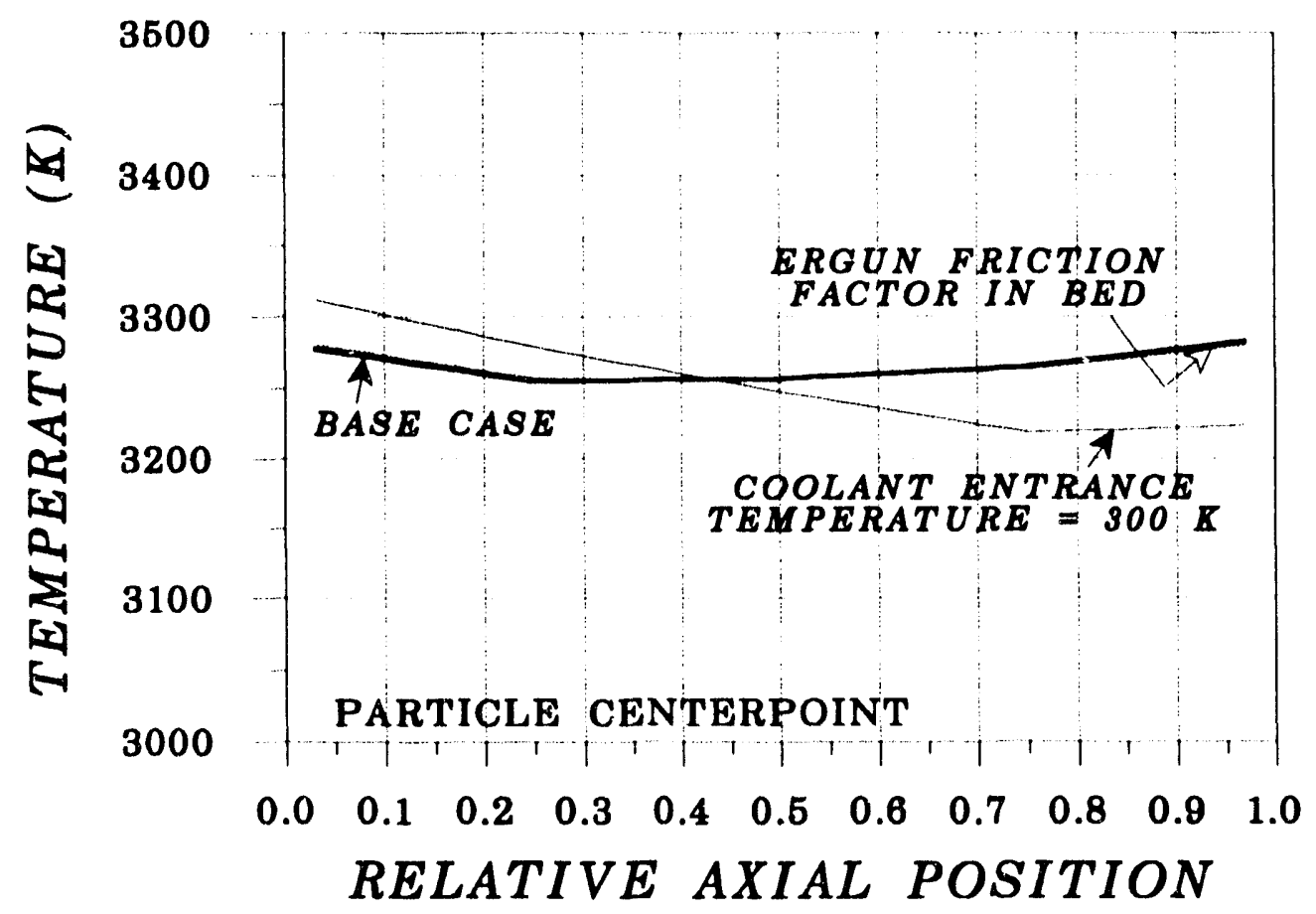

Figure 43. Effect of Coolant Entrance Temperature on the Particle Centerpoint Temperature Profile

\subsubsection{Helium Coolant}

A ground test facility to test advanced fuel elements may rely on different coolants during decay heat removal operation because of possible limited supplies of cryogenic hydrogen. A possible alternate coolant would be helium because chemical interaction with the reactor materials would be limited. Parametric cases were run in which the hydrogen 
coolant was replaced with helium coolant to investigate the effect on flow distribution. Because of the reduced specific heat of helium compared to hydrogen, it was necessary to increase the flow rates by a factor of about 3.4. Figure 44 shows the particle centerpoint temperature profile for the helium coolant simulation compared to the hydrogen coolant simulation for the 0.1 thrust ratio base case. Fortunately, the effect is not very large because the viscosities of helium and hydrogen are similar; however, the effect should probably be considered once a detailed, optimized fuel element design is created.

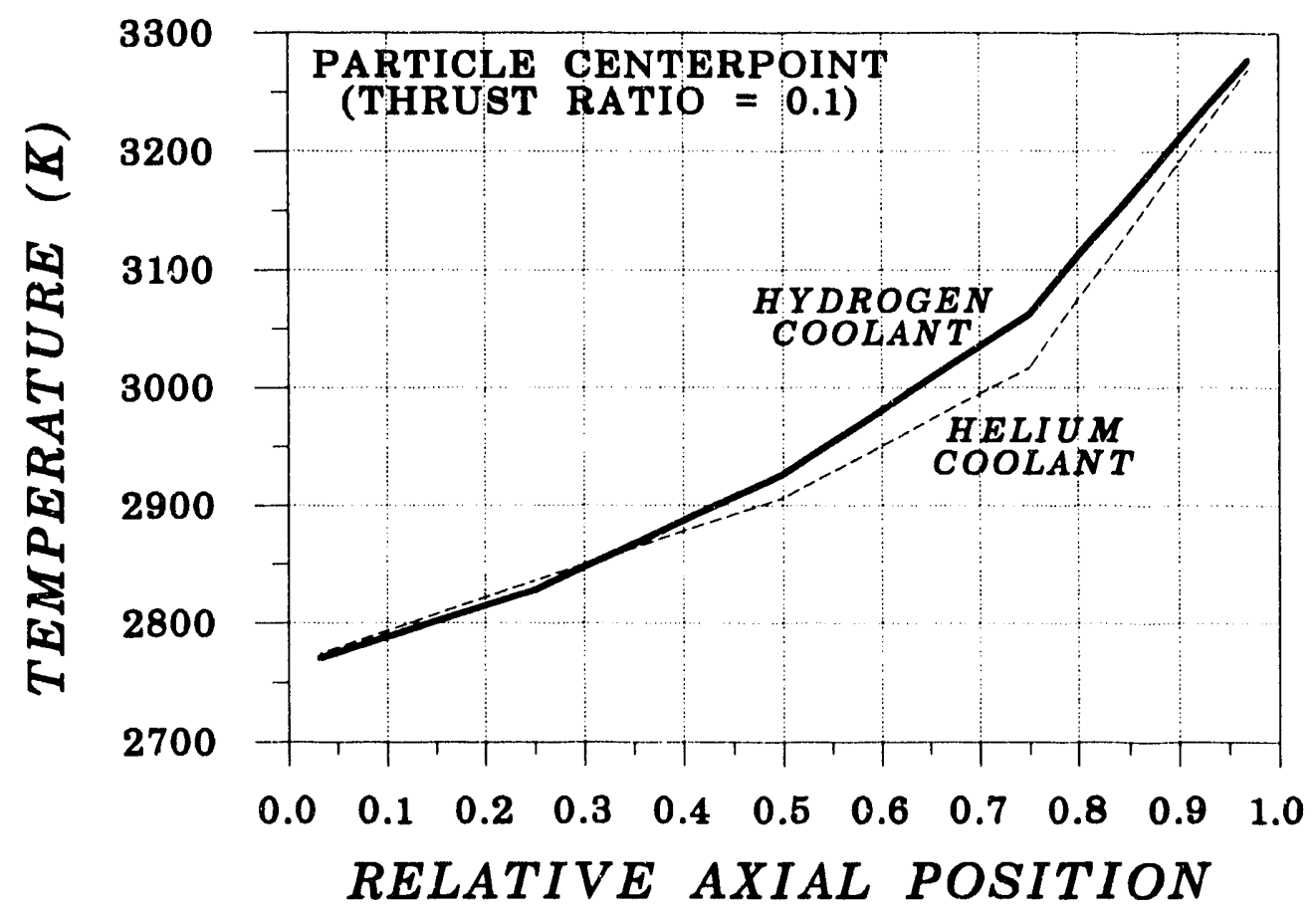

Figure 44. Effect of Using Helium Coolant on the Particle Centerpoint Temperature Profile (0.1 Thrust Ratio)

\subsubsection{Cylindrical Element Design}

A steady-state parametric case was performed to investigate the impact of using a cylindrical element instead of a conical element design. A cylindrical element would probably be easier to manufacture and assemble. Like the conical element design, the axial resistance profile of the cold frit was determined to provide a uniform particle centerpoint temperature distribution at the exit of the bed at full power. Figure 45 compares the cold frit added $l / d$ for the two different element designs. The two resistance profiles are entircly different indicating the sensitivity of the cold frit resistance profile to the element geometry. The profiles also indicate that an optimum geometry probably exists somewhere between the two designs. Ideally, it would be desirable to formulate a geometry 
that requires a relatively flat resistance profile. This would simplify cold frit manufacture and help to minimize the flow maldistribution problem at reduced thrust operation.

The particle centerpoint temperature profiles are shown in Figure 46 for the 1.0, 0.5, and 0.2 thrust ratio cases, for the cylindrical element design. Comparing these curves to those for the conical element design (Figure 30) shows that the shape of the curves are

... a geometry possibly exists

that can eliminate the flow malwith reduced thrust and decay heat removal operation. distribution problem associated different. As the thrust ratio decreases, the flow redistributes toward the top of the element in the cylindrical element design and toward the bottom in the conical element design. This disparity in the flow distribution performance of the two element designs is actually encouraging because it indicates that a geometry possibly exists that can eliminate the flow
with reduced thrust and decay heat removal operation.

Figure 47 shows the specific impulse ratio as a function of thrust ratio for the two element designs. As expected and desired, the conical element design is superior at all thrust ratios.

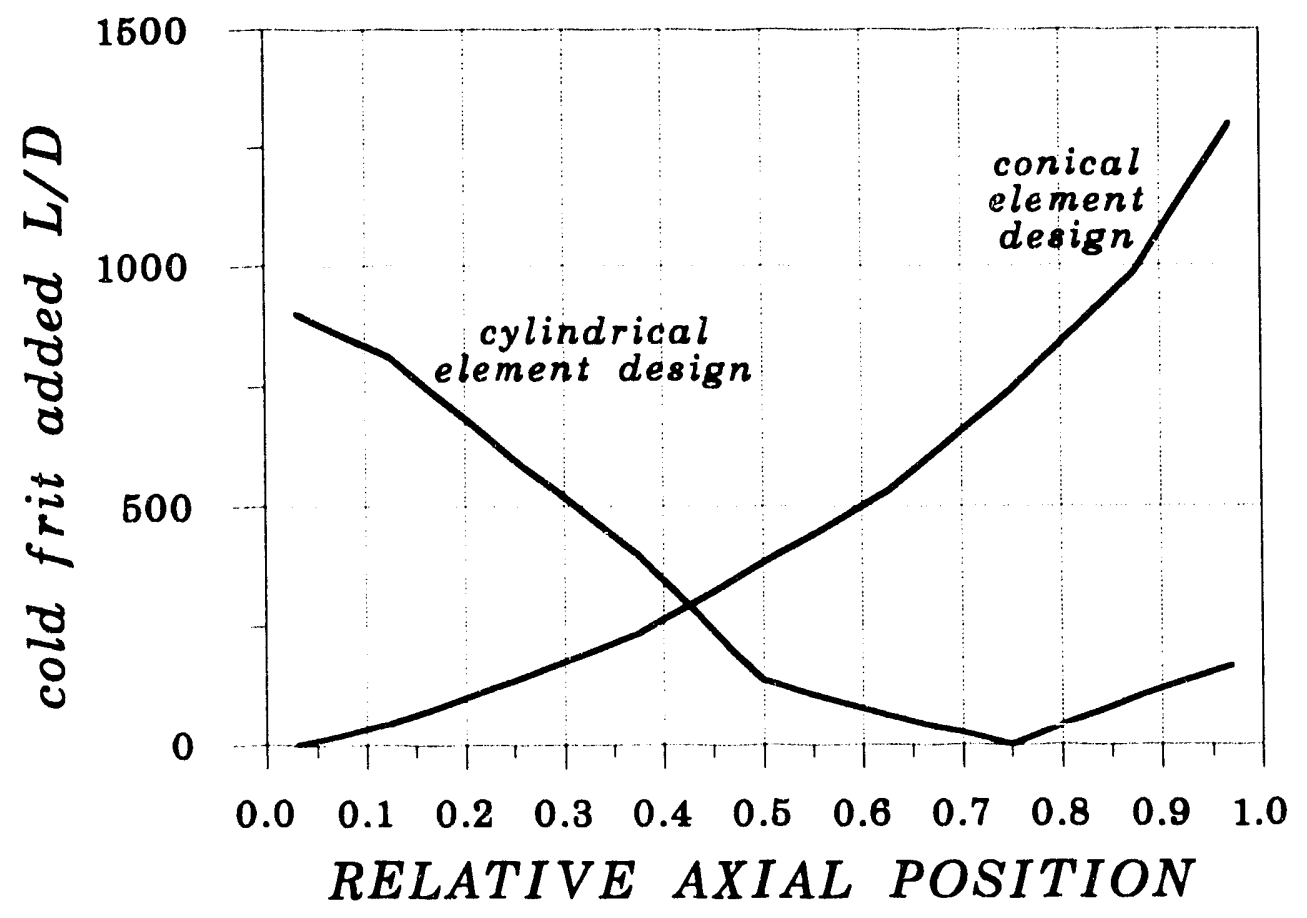

Figure 45. Comparison of Cold Frit Axial Resistance Profiles for the Conical and Cylindrical Element Designs 


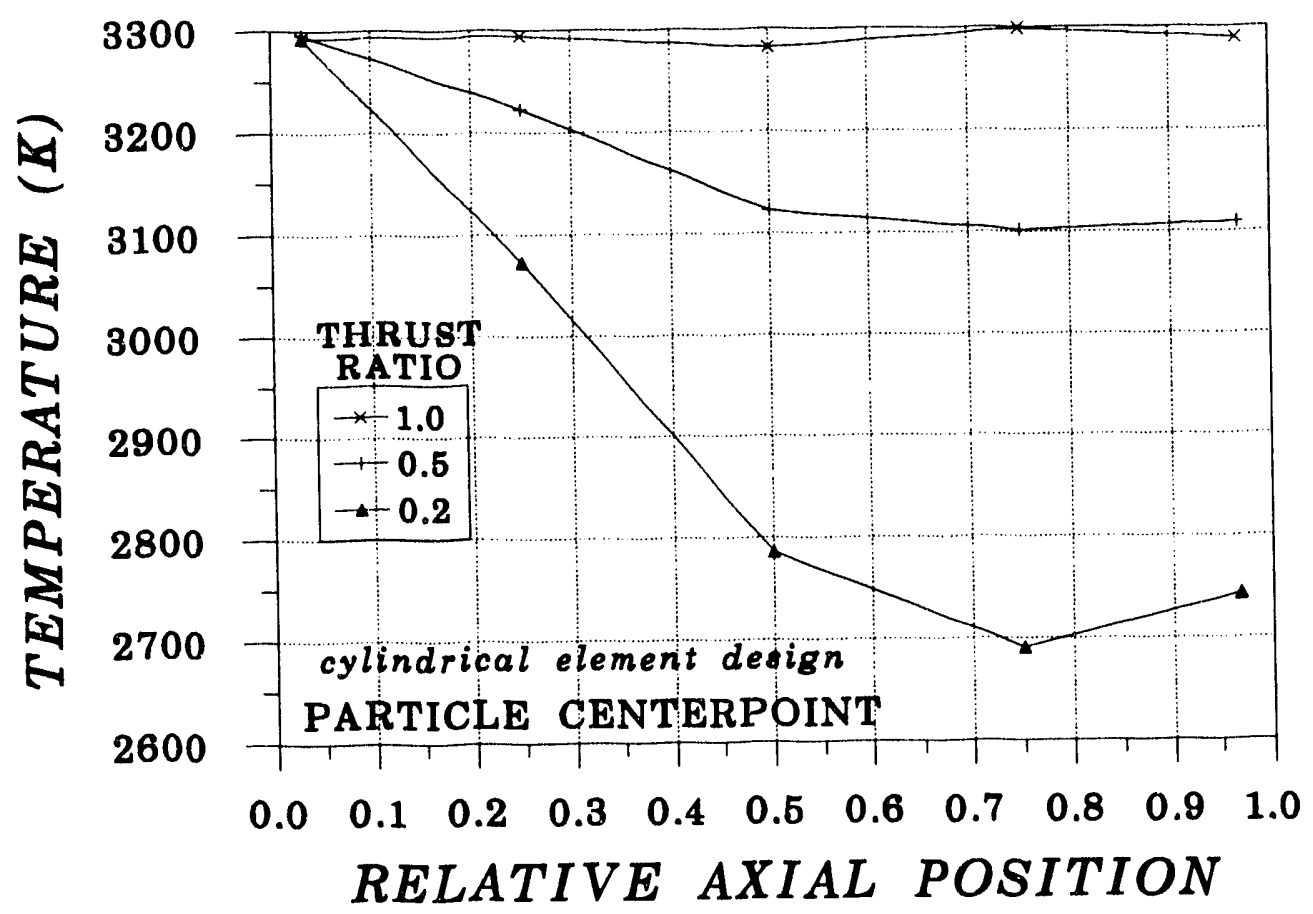

Figure 46. Particle Centerpoint Temperature Profiles at Reduced Thrust for the Cylindrical Element Design

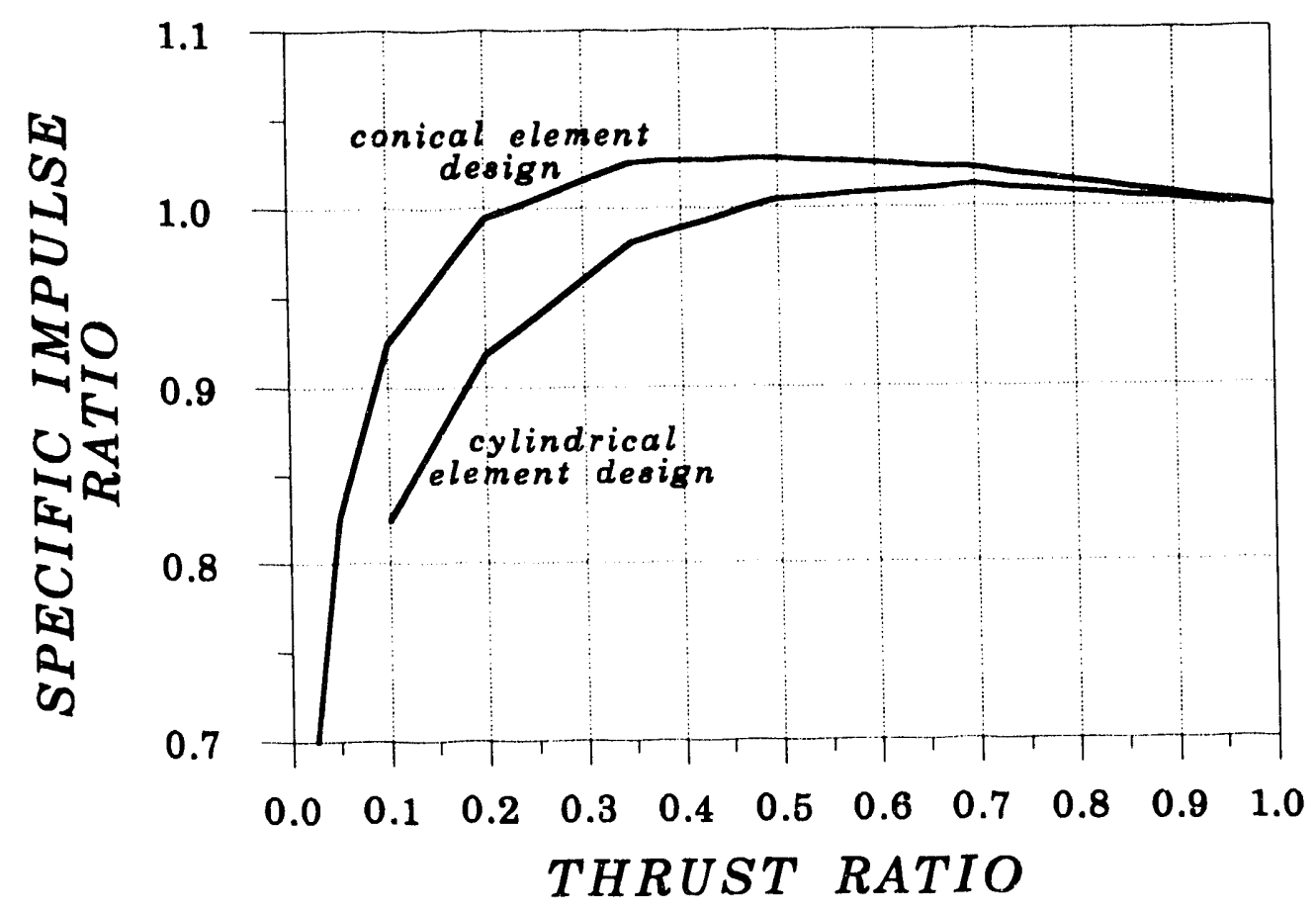

Figure 47. Comparison of Specific Impulse Ratio for the Conical and Cylindrical Designs 


\subsection{Transient Results}

The next three subsections address the transient response of a particle bed element following reactor shutdown. The first transient is referred to as the base case transient and demonstrates the performance of the element during decay heat removal. The next transient addresses the flow maldistributions that occur due to an assumed element flow perturbation. The last transient demonstrates the use of pulse cooling during decay heat removal. All transients are initiated from full power steady-state conditions. Thus the equilibrium radionuclide concentrations maximize the decay power; this is conservative with respect to determining coolant requirements. Reactor shutdown is initiated at time zero by the rotation of control drums to introduce $\$ 10$ of negative reactivity in $1 \mathrm{~s}$.

\subsection{Decay Heat Removal}

Figure 48 shows the time dependency of the power deposited in the fuel element and moderator. Recall that not all of the generated power is deposited in the element and moderator; some of the power is deposited in other structures such as reflectors, shields, vessel walls, etc. This figure shows that the power has decreased to $10 \%$ of its full power value at $1 \mathrm{~s}$ and to $5 \%$ by about $14 \mathrm{~s}$.

Based on the results of Section 4.1.2, a table of required mass flow rate as a function of power in the fuel element and moderator was generated. This information is provided in Table 2. This table was used to supply the time-dependent mass flow rate boundary condition at the entrance to the fuel element. Although the mass flow rates in this table are based on steady-state calculations, using them insures that the temperature limits of the fuel are not exceeded during the transient due to flow maldistribution or instability.

Table 2. Transient Mass Flow Rate Boundary Condition

\begin{tabular}{|c|c|c|}
\hline Power $(\mathbf{M W})$ & $\begin{array}{c}\text { Relative } \\
\text { Power }\end{array}$ & $\begin{array}{c}\text { Mass Flow Rate } \\
(\mathbf{k g} / \mathbf{s})\end{array}$ \\
\hline 0.622 & 0.020 & 0.025410 \\
\hline 0.7903 & 0.025 & 0.027443 \\
\hline 1.581 & 0.050 & 0.040051 \\
\hline 3.161 & 0.100 & 0.068837 \\
\hline 6.32 & 0.200 & 0.12851 \\
\hline 11.06 & 0.350 & 0.21981 \\
\hline 15.81 & 0.500 & 0.31570 \\
\hline 22.13 & 0.700 & 0.44669 \\
\hline 26.76 & 0.850 & 0.57500 \\
\hline 30.00 & 0.950 & 0.62000 \\
\hline 31.61 & 1.000 & 0.65497 \\
\hline
\end{tabular}

page -- 54 
The coolant temperature at the top of the outlet plenum, at the element exit, and at the nozzle throat is provided in Figure 49. An element flow rate based on power-to-flow matching would result in an element exit coolant temperature of $3000 \mathrm{~K}$ at all times. Maintaining the flow at or below this ideal flow rate minimizes coolant flow requirements and maximizes specific impulse performance. However, due to the flow maldistributions that occur at reduced power, the required flow rate exceeds the ideal flow rate and results in overcooling of the fuel element. This overcooling is demonstrated by the decreasing coolant temperatures. Recall that performance degradation for this particular element design occurs at thrust ratios below about 0.2, as was discussed in Section 4.1.2. Because the power has dropped to $10 \%$ by $1 \mathrm{~s}$, performance degradation, as indicated by the overcooling, occurs over most of the transient.

Figure 50 shows the time-dependent centerpoint temperature response for particles at the top, central, and bottom axial levels of the bed. The particles are located in the finite elements adjacent to the hot frit. Again, because of the overcooling necessitated by flow maldistribution, the temperatures are decreasing with time.

The pressure response of the element is shown in Figure 51 on a semilogarithmic plot. The pressure drop across the element decreases very fast during the first few seconds of the transient and then slowly continues to decrease. The pressure at the element exit has decreased from its initial value of $7 \mathrm{MPa}$ to about $0.2 \mathrm{MPa}$ at $180 \mathrm{~s}$. With the assumed backpressure of $0.1 \mathrm{MPa}$, the flow remains choked at all times.

Figures 52 and 53 show the bed surface temperature response for the top and bottom axial levels, respectively. The ten curves correspond ' he ten radial finite elements in the bed. The temperatures at the top axial level initially increase while the temperatures at the bottom axial level initially decrease. This indicates that most of the flow redistribution within the fuel element occurs within the first second of the transient; this is consistent with the degraded steady-state performance predicted when the thrust ratio drops below 0.2 . After $1 \mathrm{~s}$, the temperatures at the top of the element are decreasing at a slightly higher rate than those at the bottom of the element.

Figure 54 shows the radial distribution of the bed surface temperature for the top and bottom axial levels. At time zero (steady state), the maximum temperatures at the two locations are approximately equal because of ho: the cold frit axial resistance profile was determined. Due to the flow redistributions within the element, the radial profiles at $60 \mathrm{~s}$ are very different.

The effect of flow maldistribution within the element can be quantified by the specific impulse ratio as shown in Figure 55. At $180 \mathrm{~s}$, the specific impulse ratio has decreased to about 0.64 , indicating inefficient use of the coolant. Figure 56 shows the required and ideal mass flow rates for the fuel element as a function of time. The ideal flow rate is based on perfect power-to-flow matching. The difference between the two curves increases with time. A useful measure of fuel element flow maldistribution and instability is provided by the mass flow rate correction factor. This factor is defined as the ratio of the 
required mass flow rate to the ideal mass flow. The required mass flow rate is that necessary to prevent excessive fuel temperatures or flow instability. Figure 57 shows the mass flow rate correction factor for the decay heat removal base case transient. Although the correction factor is increasing with time, fortunately, the slope of the curve is decreasing with time.

Figure 58 shows the mass flow rate correction factor as a function of relative power in the fuel element and moderator. Below a relative power of about 0.05 ( $5 \%$ of full power), the correction factor begins to increase very fast. At a relative power of $0.02(2 \%)$, the correction factor equals about 2.1. This curve will not continue to increase indefinitely, however, because as the power continues to decrease, a large fraction of the heat will be radiated away from the element or conducted out through end fittings. Eventually, flow can be terminated. A multidimensional conduction heat transfer analysis of the entire reactor is required to determine the power level at which these heat transfer mechanisms begin to dominate. SAFSIM is not the appropriate tool for such an analysis. (This is the primary reason why the SAFSIM calculations were not extended beyond $180 \mathrm{~s}$.)

One of the goals of the fuel element designer is to minimize the mass flow rate correction factor. This factor (determined as a function of power for an element design) can be used to characterize the fuel element flow maldistribution performance. An element design with a low correction factor is also less susceptible to flow instabilities that may arise due to inherent geometric perturbations. It appears that significant improvements can be made to the conical element design with respect to the mass flow rate correction factor. Also, the information required to determine the correction factor can be used to generate flow "acceptability" maps. These maps are similar to stability maps but instead indicate the mass flux-power density regirnes where the resulting fuel ternperatures are acceptable. Such maps are provided in the next section.

One final figure (Figure 59) is included in this section to demonstrate the appropriateness of the 1-D network modeling assumption. This figure shows pressure profiles in the cold frit, bed, and hot frit as a function of the relative axial and radial positions. (The pressure values were assigned to the centroid of the finite elements.) These are the pressure profiles that exist at $20 \mathrm{~s}$ when the flow maldistribution in the fuel element is quite severe. As this figure shows, the pressure variation is greater in the radial direction than in the axial direction. Also, because the fuel element height is over one hundred times greater than the average bed thickness, it is clear that the radial pressure gradients are much greater than the axial pressure gradients. Based on the calculated gradients, the axial flow rates would be less than $1 \%$ of the radial flow rates. Because of the small axial pressure gradients, the driving potential for flow is predominantly in the radial direction and 1-D in nature.

As mentioned in the Introduction (Section 1), the initial objective of the work presented in this document was to obtain an estimate of decay hoat removal coolant requirements for a ground test facility. Thus, based on the results for the conical element non- 
optimized design, simple equations were developed to make such an estimate. As is evident from the parametric analyses, such an estimate is strongly dependent on fuel element design and modeling assumptions. Therefore, the equations for estimating coolant requirements, presented in this section, should be considered in this context.

Table 3 provides a summary of mass flow rate correction factors as a function of element/moderator power and transient time. Two additional steady-state calculations were performed, one at $1 \%$ and the other at $0.1 \%$ power, to provide late-time data points. A $1 \%$ power level is reached at approximately $8200 \mathrm{~s}$ while it takes approximately one day to reach the $0.1 \%$ level. For the $1 \%$ power case, the chamber temperature is reduced to $1277 \mathrm{~K}$ and flow in the nozzle is unchoked (the throat Mach number is 0.75 ).

The $0.1 \%$ power case must be viewed with skepticism because of the probable influence of thermal radiation heat transfer to the environment and conduction through end fittings, as has been discussed. Also, at the very low flow rates required for this power level, heat transfer by conduction in the bed and coolant becomes very significant with respect to convection. This alters the temperature profiles in the bed. Further complications arise because the flow in the inlet and outlet plenums is in either the laminar or transition regimes (for friction factors and heat transfer coefficients) due to the low Reynolds numbers. Consequently, the flow distribution in the element is reversed compared to the other cases. The fuel hot spots now occur at the bottom of the element instead of at the top. Also, the required mass flow rate is based on preventing excessive temperatures in the cold frit as opposed to the bed. Future work should address the fuel element performance at very low flow rates in detail using multidimensional flow and heat transfer computer programs. SAFSIM is not the appropriate tool for such work.

Table 3. Mass Flow Rate Correction Factors

\begin{tabular}{|c|c|c|c|}
\hline Time (s) & Power (MW) & Relative Power & Correction Factor \\
\hline 1 & 3.413 & 0.10797 & 1.0420 \\
\hline 5 & 2.298 & 0.07270 & 1.1161 \\
\hline 10 & 1.798 & 0.05688 & 1.1817 \\
\hline 20 & 1.382 & 0.04372 & 1.2885 \\
\hline 60 & 0.8807 & 0.02786 & 1.5837 \\
\hline 120 & 0.6683 & 0.02114 & 1.8769 \\
\hline 180 & 0.5785 & 0.01830 & 2.0957 \\
\hline 8200 & 0.3161 & 0.01000 & 2.9942 \\
\hline$\sim 1$ day & 0.03161 & 0.00100 & 5.97 \\
\hline
\end{tabular}

The mass flow rate correction factor can be used in the following equation to estimate coolant requirements as a function of power and decay cooling time: 


$$
m_{I}=\int_{t_{1}}^{t_{2}} \chi(t) \dot{m}_{i}(t) d t=\int_{t_{1}}^{t_{2}} \frac{\chi(t) q(t)}{\bar{c}_{p} \Delta T} d t
$$

where

$m_{I}$ is the integrated mass flow rate (total coolant mass),

$t_{1}$ and $t_{2}$ are the beginning and end times for integration,

$\chi(t)$ is the mass flow rate correction factor as a function of time, $t$,

$\dot{m}_{i}$ is the ideal mass flow rate (based on power-to-flow matching),

$q(t)$ is the reactor power as a function of time,

$\bar{c}_{p}$ is the average specific heat of the coolant, and

$\Delta T$ is the change in temperature of the coolant from element entrance to exit.

The advantage of putting the equation in this form is that analysts can substitute their own expressions for $q(t), \bar{c}_{p}$, and $\Delta T$ for different decay power profiles, coolant types, and coolant temperature changes, respectively. In the calculations of this document, $\bar{c}_{p}$ for the hydrogen coolant is approximately $1.72 \cdot 10^{4} \mathrm{~J} / \mathrm{kg}-\mathrm{K}$ and $\Delta T$ is $2800 \mathrm{~K}$.

The value for the mass flow rate correction factor, $\chi(t)$, can be obtained from approximate curve fits of the calculated data; these curve fits are provided in the following table for different time ranges.

Table 4. Correlations for Mass Flow Rate Correction Factor as a Function of Time

\begin{tabular}{|c|c|l|}
\hline Time Range & Correlation for $\chi(t)$ & \multicolumn{1}{c|}{ Comments } \\
\hline 0 to $200 \mathrm{~s}$ & $1.0659+9.8255 \cdot 10^{-3} t-2.4089 \cdot 10^{-5} t^{2}$ & based on calculations to $180 \mathrm{~s}$ \\
\hline 0 to $200 \mathrm{~s}$ & $\begin{array}{c}0.99663+0.007805 t-3.8411 \cdot 10^{-4} t^{1.5} \\
+1.9513 \cdot 10^{-8} t^{3}+0.03787 t^{0.5}\end{array}$ & $\begin{array}{l}\text { more accurate fit, but also } \\
\text { more complicated }\end{array}$ \\
\hline 200 to $10,000 \mathrm{~s}$ & $\begin{array}{c}1.9796+1.0204 \cdot 10^{-4} t \\
\text { based on straight line fit } \\
\text { between } 180 \mathrm{~s} \text { and } 8200 \mathrm{~s}\end{array}$ \\
\hline 1 to $10,000 \mathrm{~s}$ & $\begin{array}{c}0.51964+0.27310 \ln t+0.61225 / t \\
-0.08885 / t^{2}\end{array}$ & $\begin{array}{l}\text { reasonable fit of calculated } \\
\text { data points up to } 8200 \mathrm{~s}\end{array}$ \\
\hline$>10,000 \mathrm{~s}$ & 3.5 & engineering judgment \\
\hline
\end{tabular}

Again, these correlations really only apply to the assumed conical element design. An optimized design will have lower values for the correction factor. Thus, these correlations can be considered to a provide a conservative estimate of coolant requirements. Because conduction through end fittings and thermal radiation heat transfer become significant at late times, it is doubtful that the correction factor will continue to increase with time beyond $10,000 \mathrm{~s}$. Therefore, a constant value of 3.5 was selected for the correction factor 
for times greater than $10,000 \mathrm{~s}$. This correction factor is just a guess; investigations with detailed multidimensional tools are needed to determine correction factors at late times.

For convenience, curve fits of $q(t)$ are provided in Table 5. These curve fits are based on values calculated by SAFSIM's reactor dynamics solution module assuming equilibrium radionuclide concentrations at time zero (i.e. infinite full power run time). The power, $q(t)$, is in units of watts, and $t$ is the time after reactor shutdown in $s$.

Table 5. Correlations for Power as a Function of Time

\begin{tabular}{|c|c|l|}
\hline Time Range & Correlation for $\boldsymbol{q}(\boldsymbol{t})$ & \multicolumn{1}{|c|}{ Comments } \\
\hline 0 to $200 \mathrm{~s}$ & $\ln q(t)=\frac{\left(17.253+23.753 t+0.321 t^{2}\right)}{\left(1+1.6455 t+0.0250 t^{2}\right)}$ & $\begin{array}{l}\text { approximate curve fit, small } \\
\text { errors for } t \text { less than } ~ 2 \mathrm{~s}\end{array}$ \\
\hline 200 to $10,000 \mathrm{~s}$ & $5.8439 \cdot 10^{5}-32.718 t$ & $\begin{array}{l}\text { based on straight line fit } \\
\text { between } 180 \mathrm{~s} \text { and } 8200 \mathrm{~s}\end{array}$ \\
\hline 10,000 to $\sim 100,000 \mathrm{~s}$ & $3.4142 \cdot 10^{5}-3.1 t$ & $\begin{array}{l}\text { based on straight line fit } \\
\text { between } 8200 \mathrm{~s} \text { and } 100,000 \mathrm{~s}\end{array}$ \\
\hline
\end{tabular}

*straight line fit overestimates power and is therefore conservative for coolant inventory estimates

Table 6 presents the hydrogen coolant inventories required for decay heat removal. The inventories are based on the correlations of Tables 4 and 5, along with Equation (13). The $\mathrm{kg} / \mathrm{MW}$ column is determined by dividing the coolant inventory for a single element by the element steady-state power level of $31.61 \mathrm{MW}$. This column of numbers can be used to approximately scale the inventories for different power level reactors. For example, a $250 \mathrm{MW}$ reactor requires $1,900 \mathrm{~kg}$ of hydrogen to remove decay heat for $10,000 \mathrm{~s}$. The last column in the table is just the inventory per $\mathrm{MW}$ divided by the appropriate tirne interval. These calculated inventories do not include additional coolant that may be required to cool auxiliary structures.

Table 6. Coolant Inventories Required for Decay Heat Removal

\begin{tabular}{|c|c|c|c|}
\hline & \multicolumn{3}{|c|}{ Coolant Inventory } \\
\hline Time Range & (kg/element) & (kg/MW) & (kg/MW/s) \\
\hline 0 to $200 \mathrm{~s}$ & 5.06 & 0.16 & 0.000800 \\
\hline 200 to $10,000 \mathrm{~s}$ & 235.2 & 7.44 & 0.000759 \\
\hline 10,000 to $100,000 \mathrm{~s}$ & 2229.1 & 70.52 & 0.000784 \\
\hline 0 to $100,000 \mathrm{~s}$ & 2469.3 & 78.12 & 0.000781 \\
\hline
\end{tabular}

For decay power profiles that are significantly different than that predicted by SAFSIM, the correlations for $\chi(t)$ are not appropriate. In such instances, the mass flow rate correction factor should be applied as a function of relative power where the relative power is a function of time. Thus, Equation (13) can be rewritten as follows: 


$$
m_{I}=\int_{t_{1}}^{t_{2}} \frac{\chi(\eta(t)) q(t)}{\bar{c}_{p} \Delta T} d t
$$

where

$$
\eta(t) \text { is the relative power } q(t) / q(0) \text {. }
$$

Equation (15) then provides a curve fit of $\chi(\eta)$ for $\eta$ between 0.01 and 1.0. For values of $\eta$ less than 0.01 , a constant value of 3.5 is suggested for the mass flow rate correction factor.

$$
\chi(\eta)=0.988648+0.0034 / \eta+4.7605 \cdot 10^{-4} / \eta^{2}-3.095 \cdot 10^{-6 /} / \eta^{3}
$$

The use of Equation (14) in conjunction with Equation (15) allows analysts to supply their own correlations for $q(t)$, accounting for different full power run times if desired.

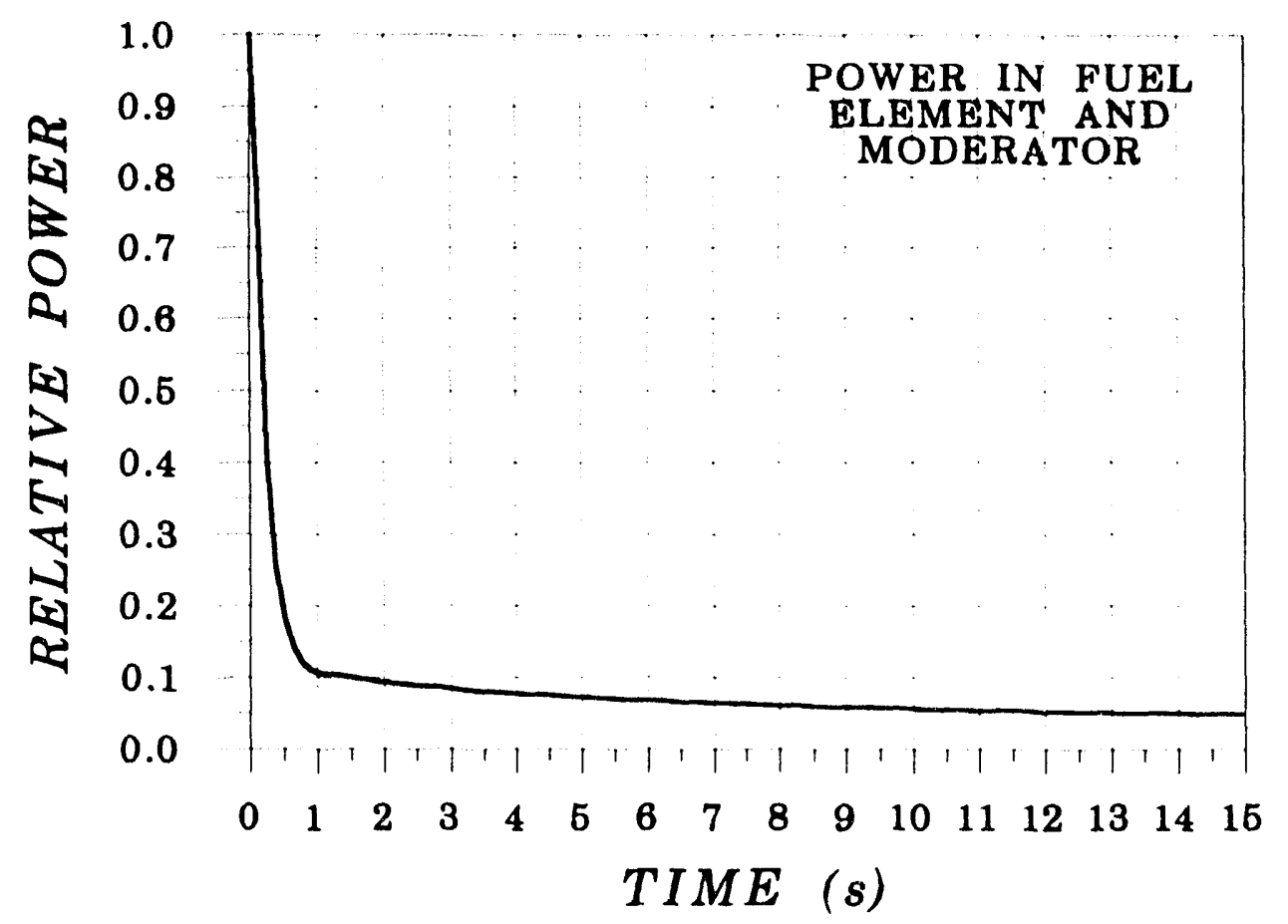

Figure 48. Relative Power Deposited in the Fuel Element and Moderator Versus Time 


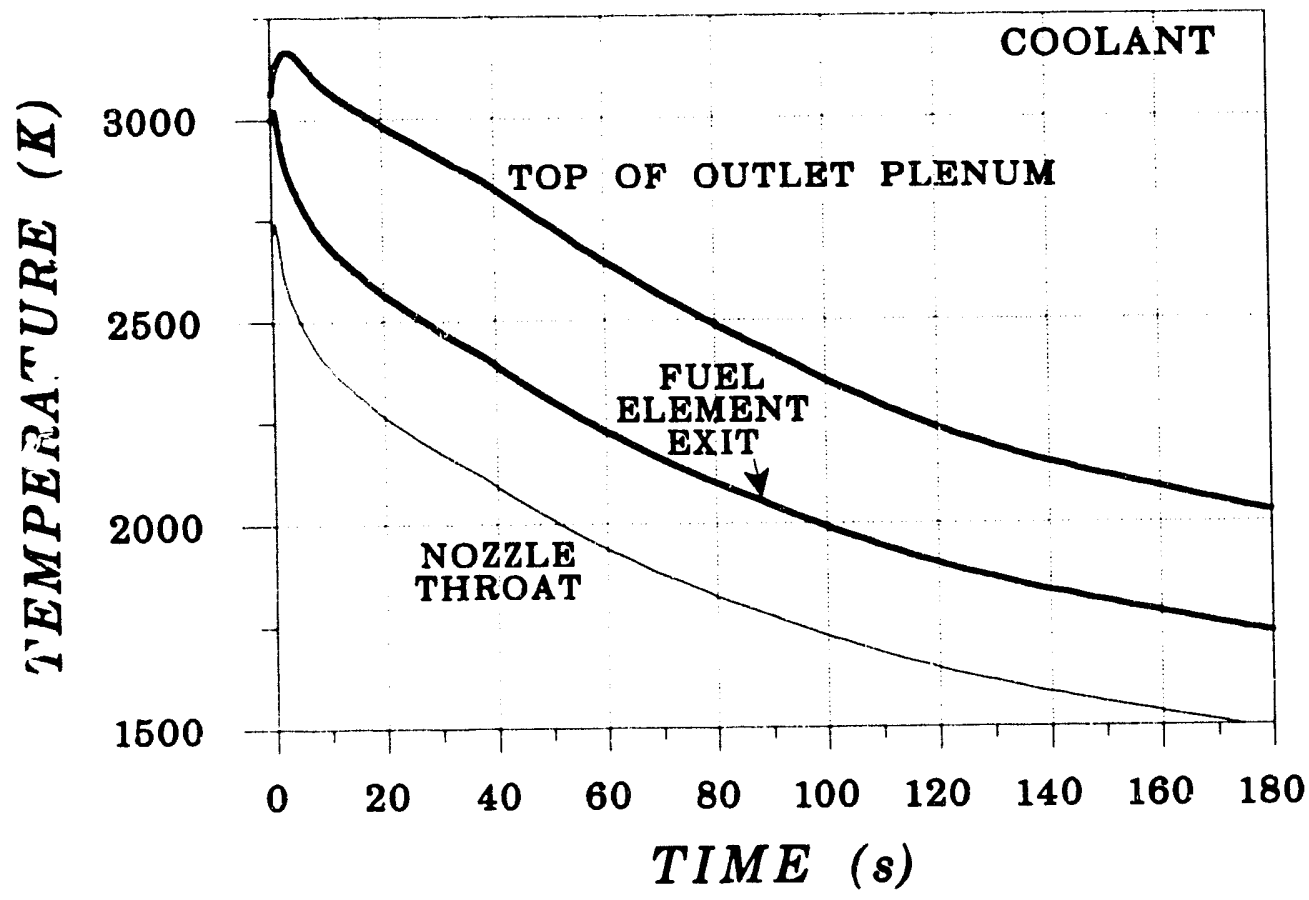

Figure 49. Time-Dependent Conlant Temperature Response

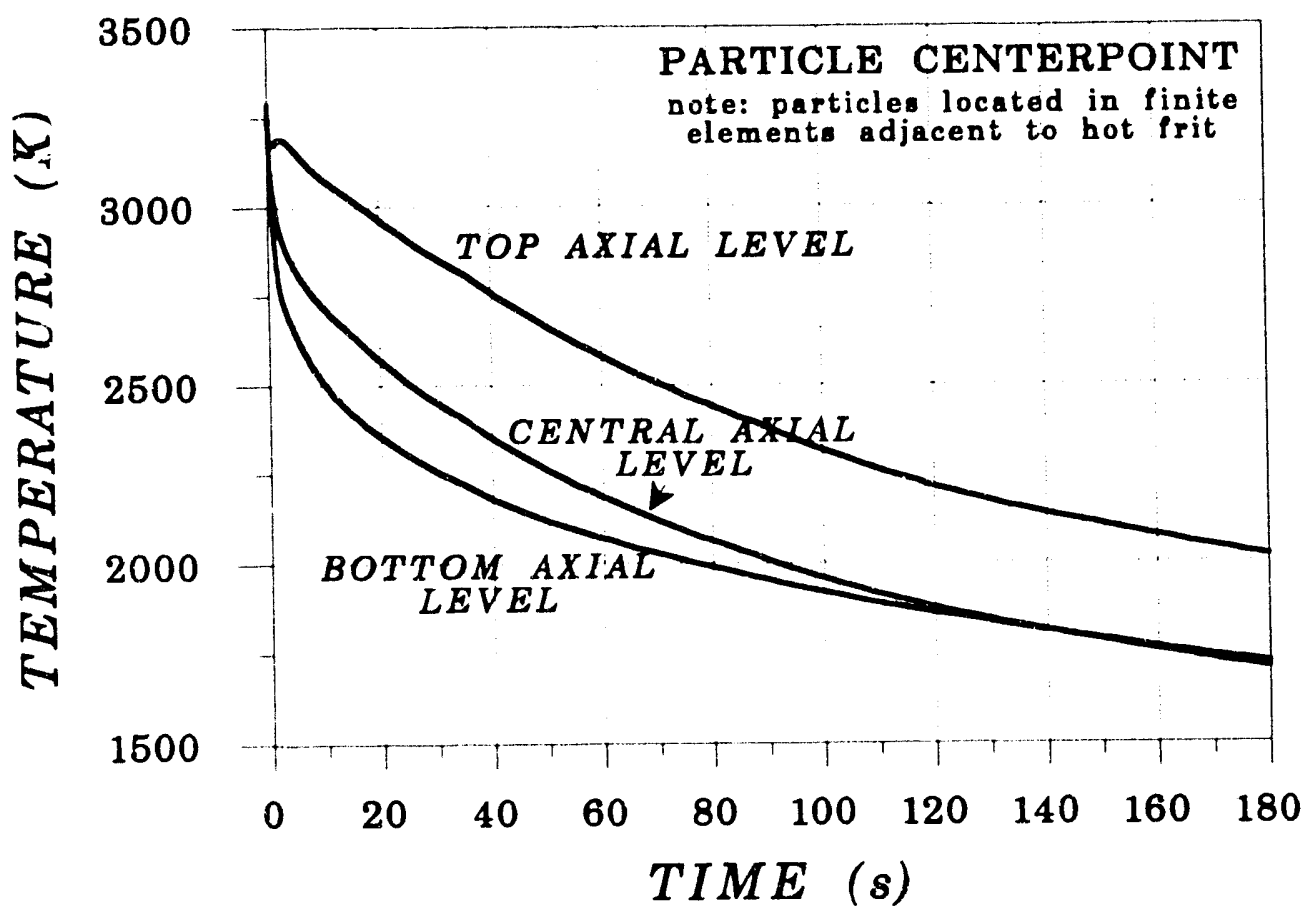

Figure 50. Time-Dependent Particle Centerpoint Temperature Response 


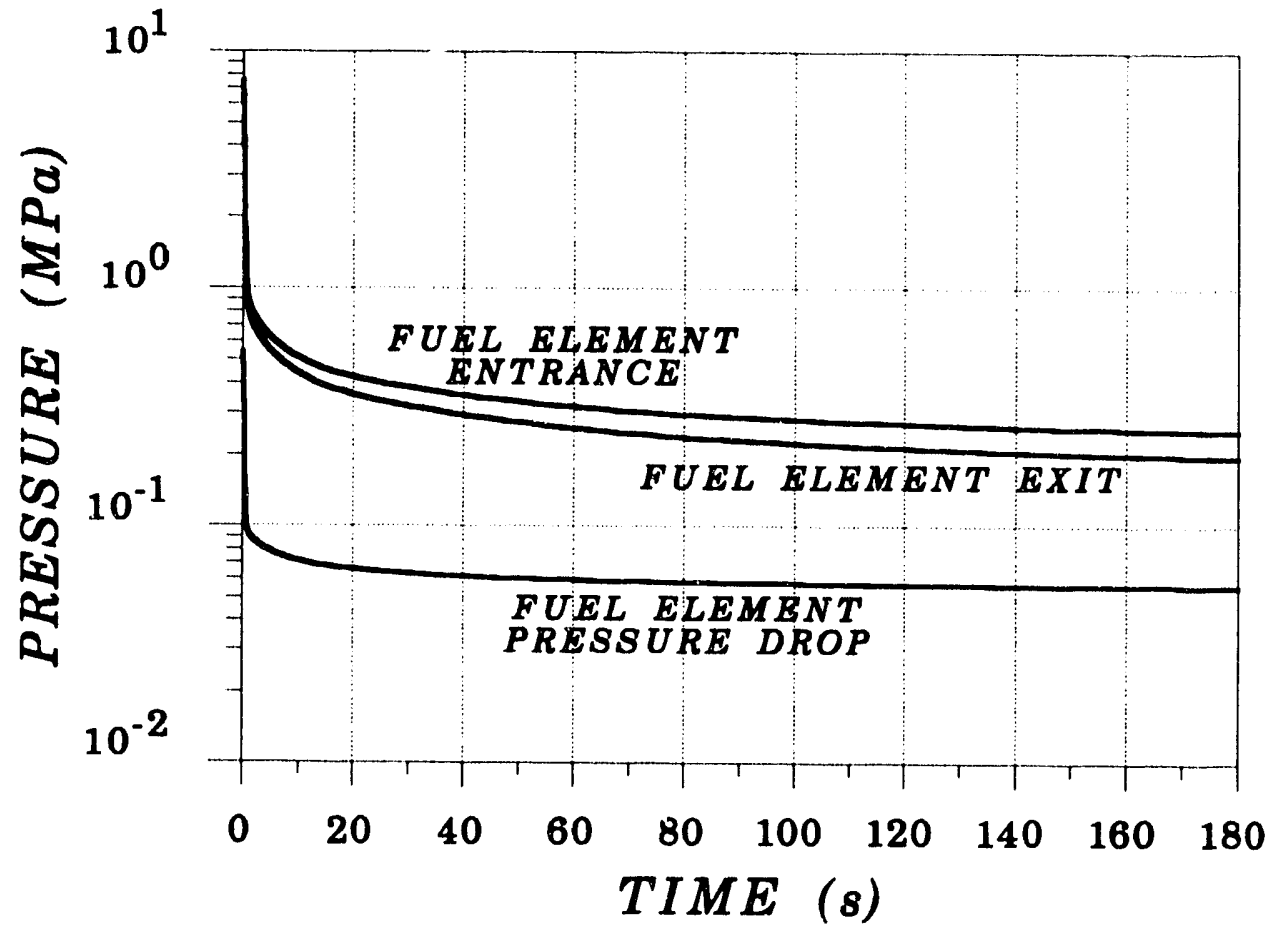

Figure 51. Fuel Element Pressure Response Versus Time

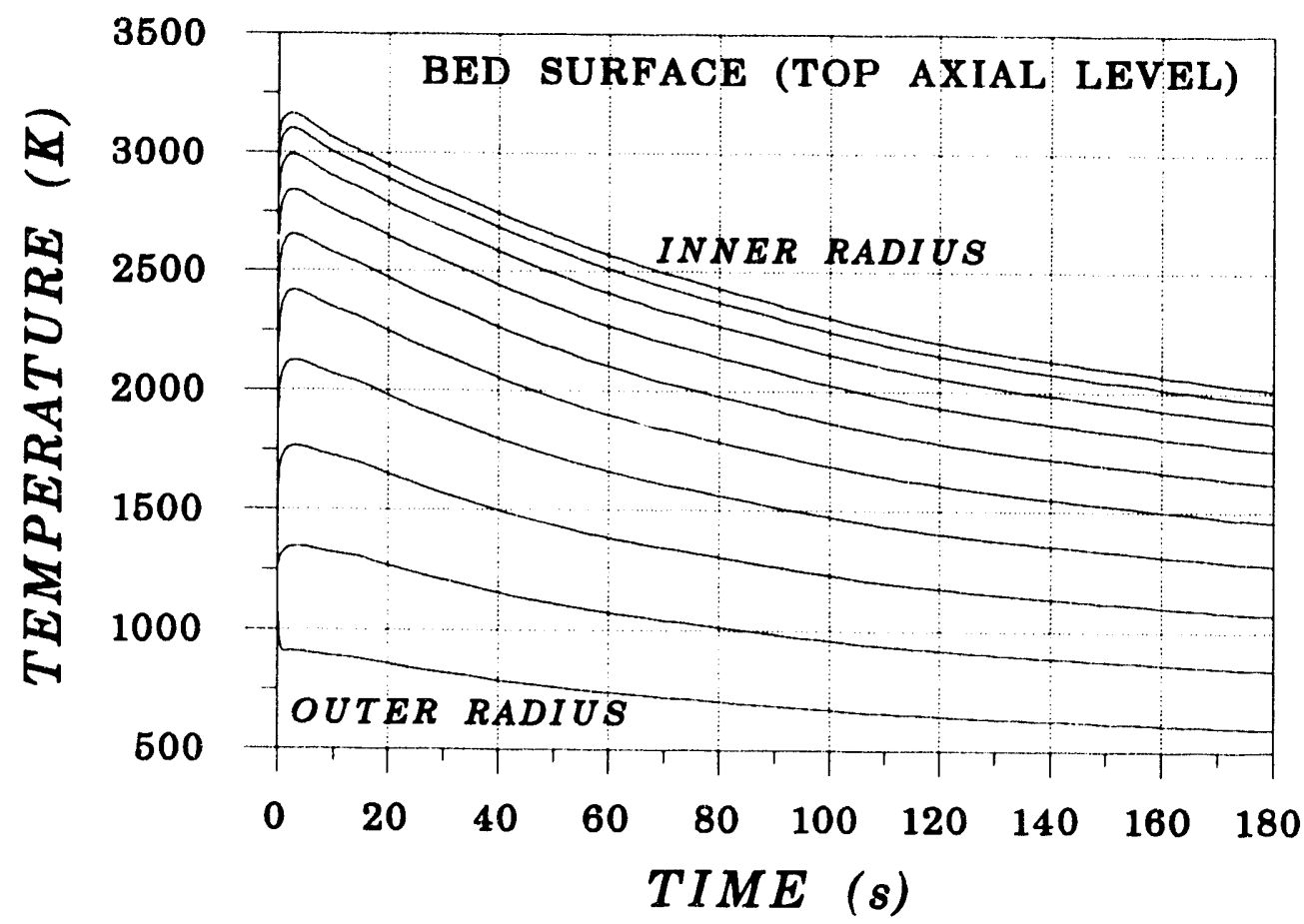

Figure 52. Time-Dependent Bed Surface Temperature Response (top axial bed level) 


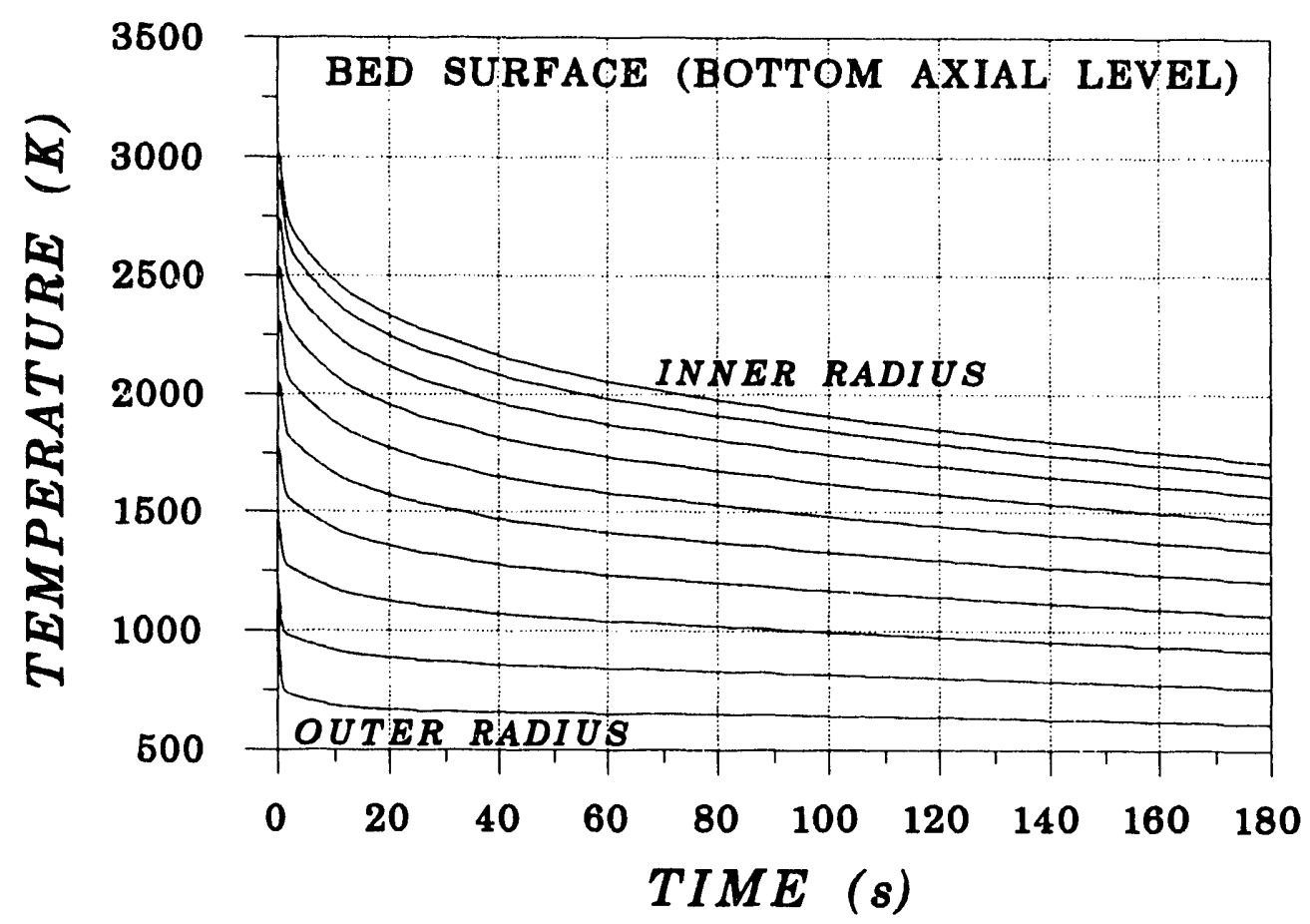

Figure 53. Time-Dependent Bed Surface Temperature Response (bottom axial bed level)

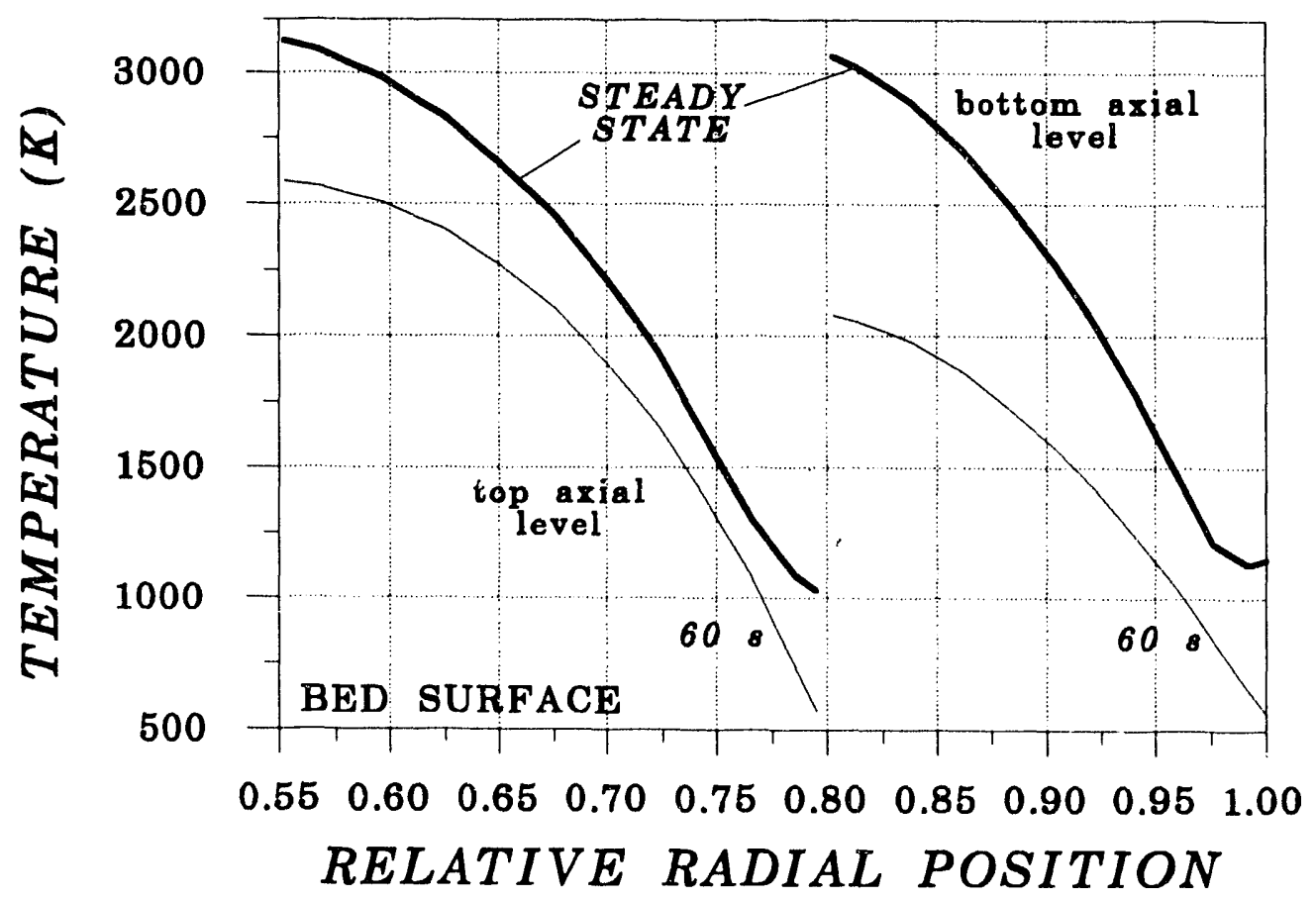

Figure 54. Bed Surface Temperature Radial Profiles 


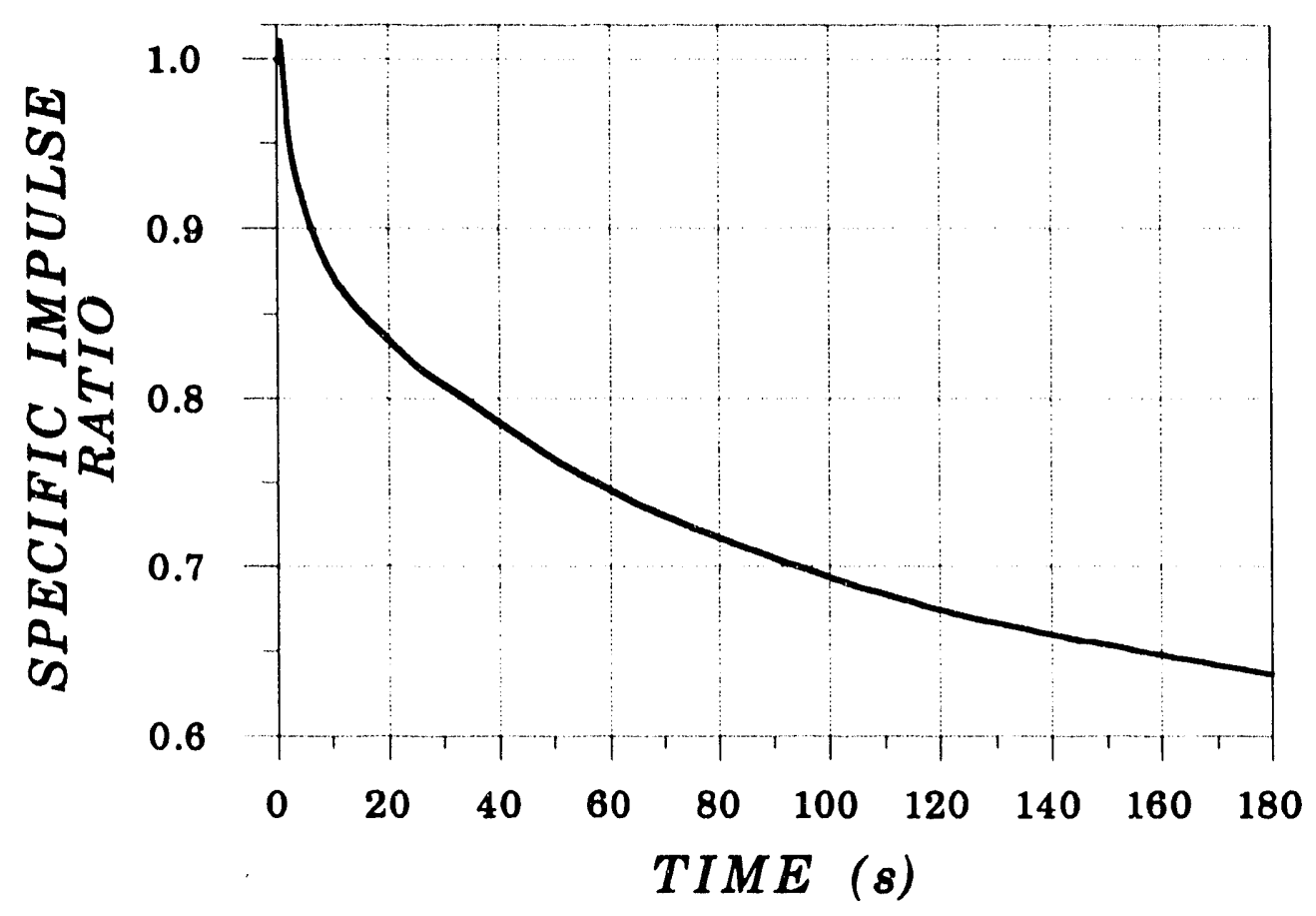

Figure 55. Specific Impulse Ratio Versus Time (Base Case Transient)

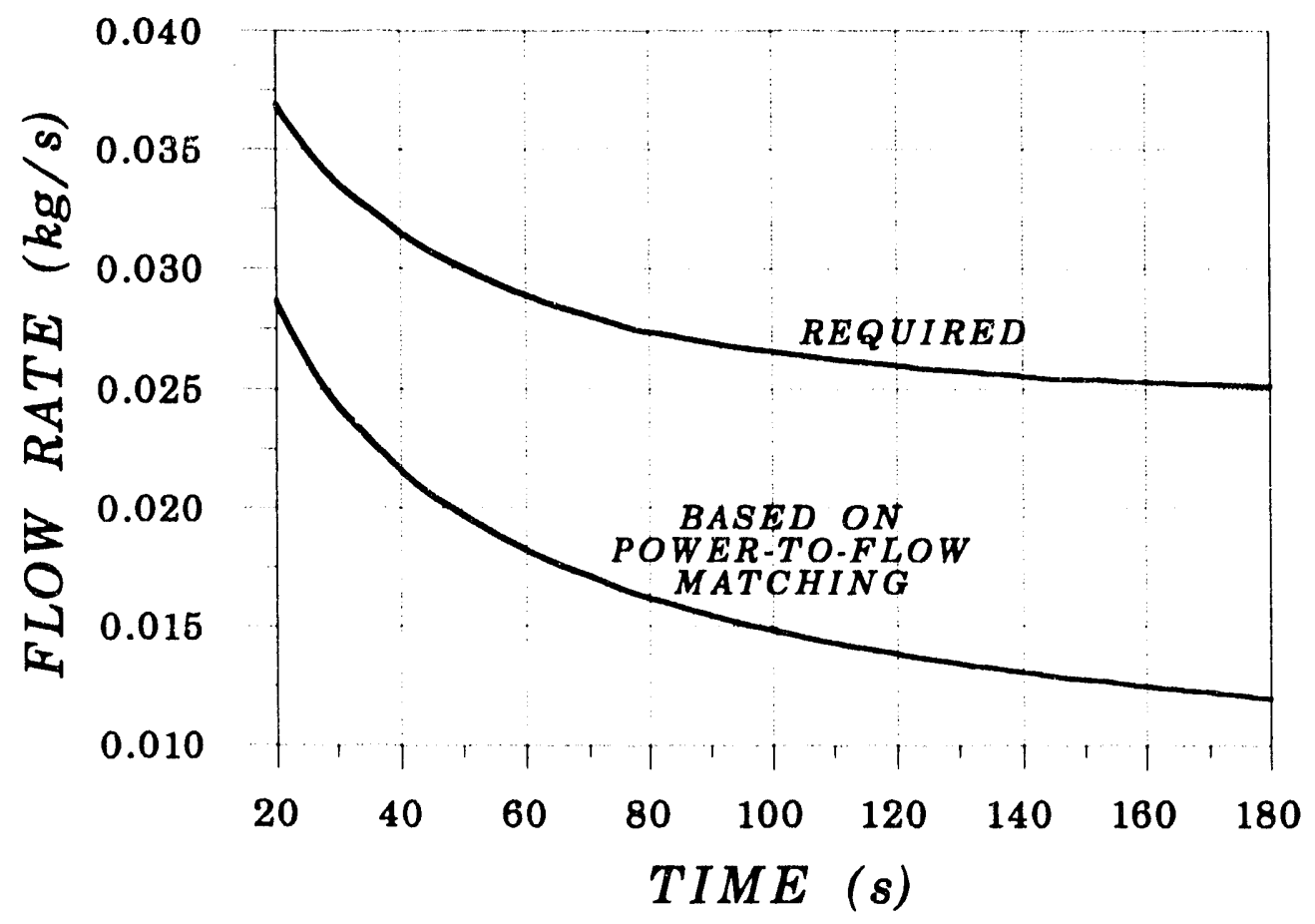

Figure 56. Required and Ideal Base Case Transient Flow Rates 


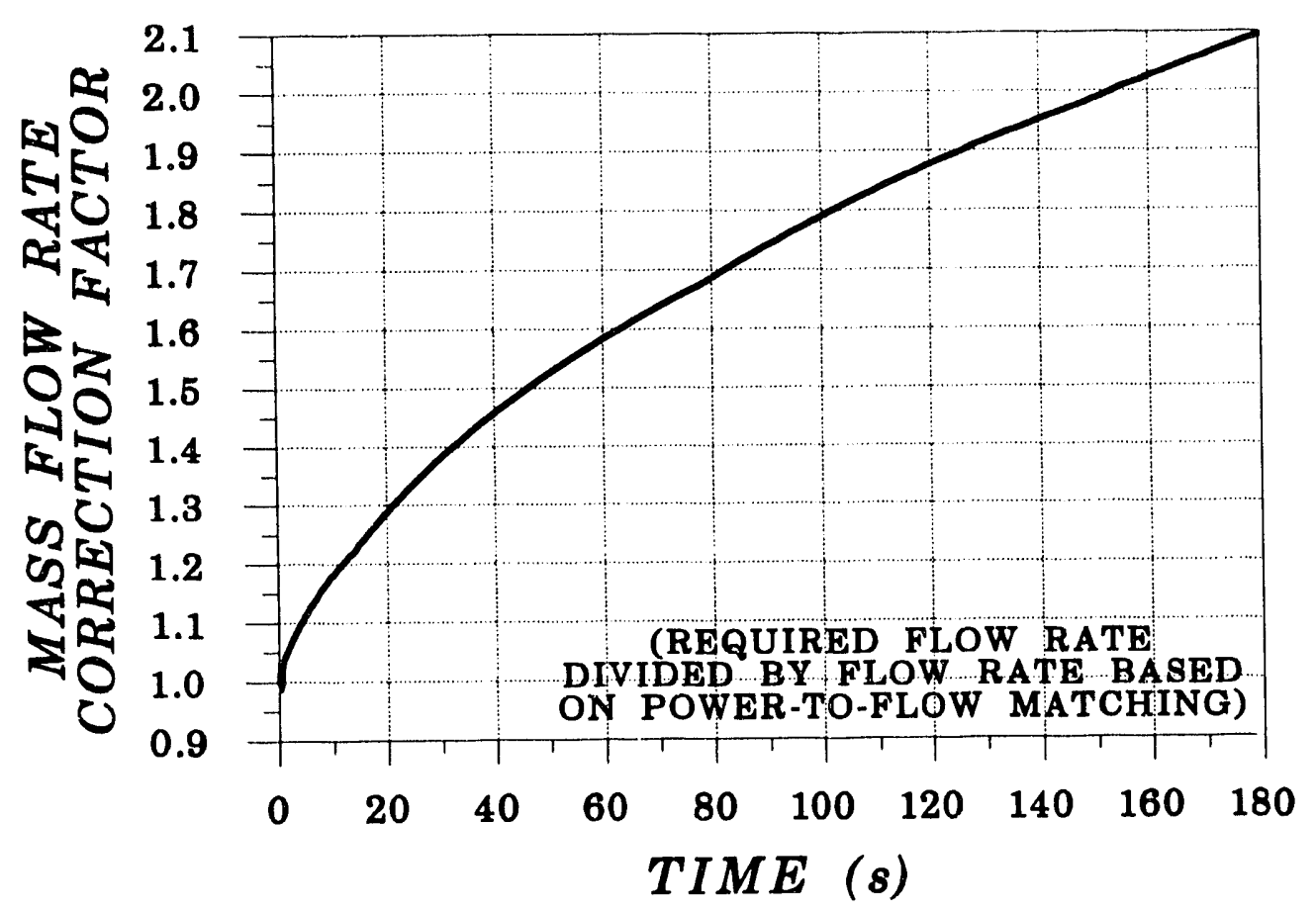

Figure 57. Mass Flow Rate Correction Factor Versus Time (Base Case Transient)

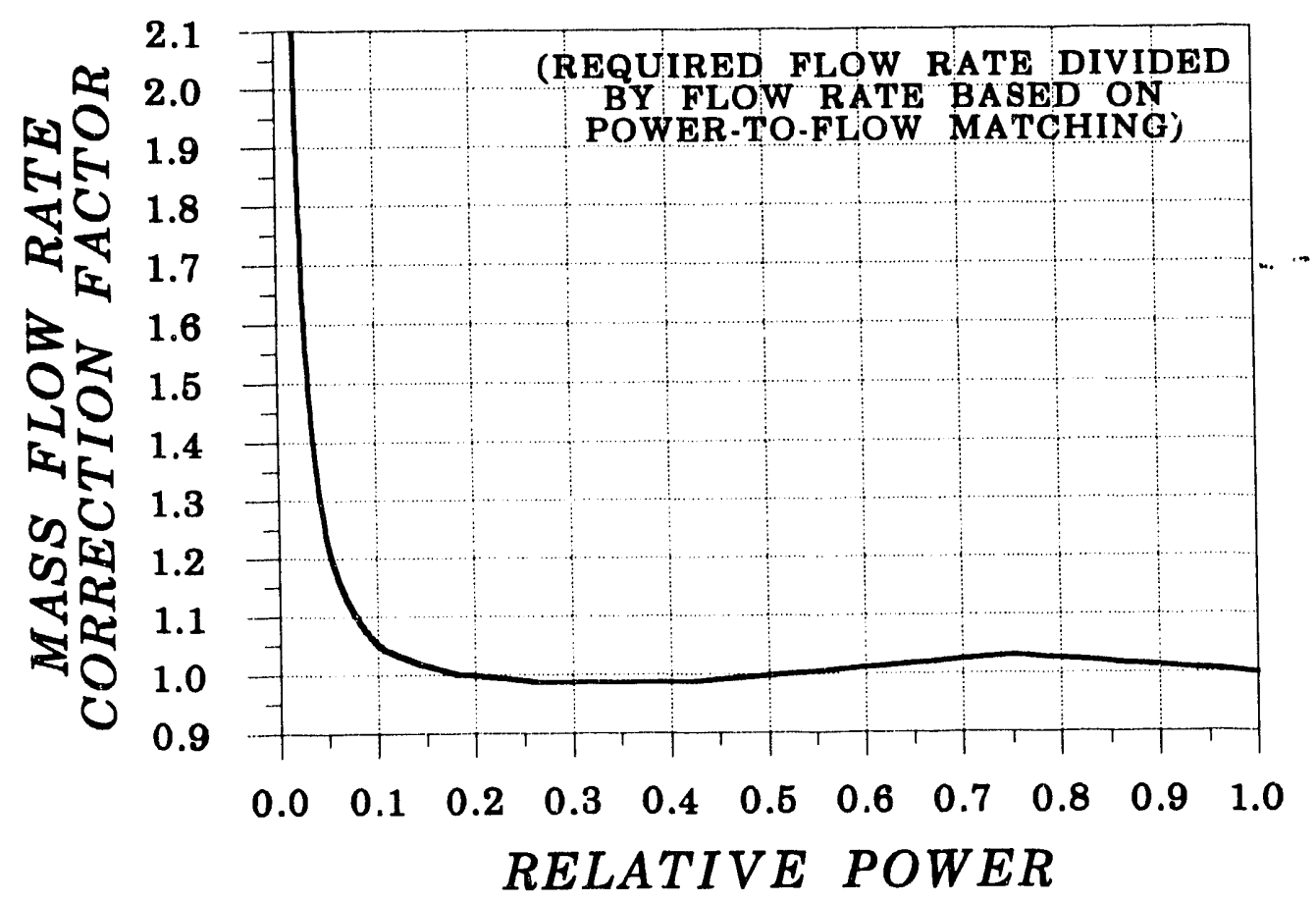

Figure 58. Mass Flow Rate Correction Factor Versus Relative Power (Base Case) 


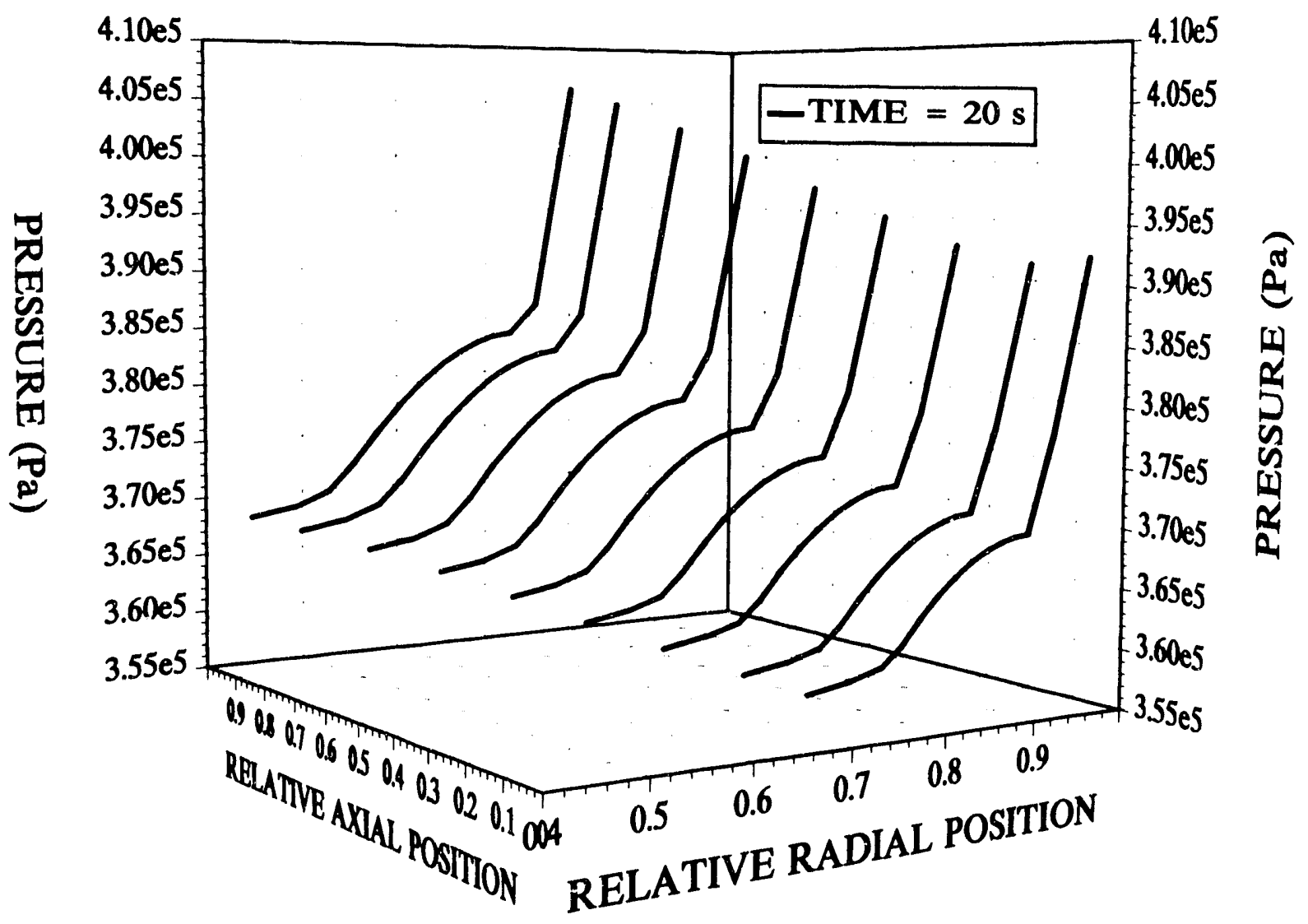

Figure 59. Pressure Profiles in Cold Frit, Bed, and Hot Frit at $20 \mathrm{~s}$

\subsection{Fuel Element Flow Perturbation}

It is often assumed that a flow instability occurs only if some kind of element perturbation is introduced, such as a local flow blockage or a local power density variation within the fuel bed. However, the conical element design already has several inherent perturbations that lead to flow maldistributions at reduced thrust and that may lead to initiation of a flow instability. For example, the variation of bed thickness, power, and porosity with axial position along with the dynamic pressure and transpiration flow losses in the inlet and outlet plenums all serve as "built-in" element perturbations. As mentioned previously, a goal of element designers is to reduce these built-in perturbations or to make them self compensating.

The section concerning flow stability (Section 3) contains a discussion of the flow redistributions that occur between parallel heated channels with different pressure drop characteristics. As mentioned in that section, the fuel element can be assumed to consist 
of multiple, parallel heated channels connected between the inlet and outlet plenums. Thus each axial level in the input model of the fuel element represents a heated channel. Due to the built-in element perturbations, each channel (or axial level) has a different pressure drop characteristic. Therefore, any decrease in the element flow rate below the required mass flow rate results in unacceptable conditions. (Recall that the required flow rate is defined as the mass flow rate required to prevent excessive particle temperatures or initiation of flow instability due to built-in geometry perturbations.) Section 4 deals with the flow maldistributions that occur at reduced thrust operation during steady state. The current section addresses the fuel element transient response to a postulated element flow perturbation.

This flow perturbation transient is identical to the decay heat removal base case transient from 0 to $20 \mathrm{~s}$. Starting at $20 \mathrm{~s}$, the entrance mass flow rate is assumed to drop from the required value to the ideal value (for perfect power-to-flow matching) over a $1 \mathrm{~s}$ interval and then held constant. This represents a 23\% decrease in mass flow rate. (The desired and ideal mass flow rates were determined in the reduced thrust calculations described in Section 4.1.2.) As will be demonstrated, this deliberate global flow perturbation to the fuel element is sufficiently large that flow instability is initiated and unacceptable fuel temperatures occur.

At this point, it is convenient and hopefully enlightening to explain the flow "acceptability" maps alluded to in the section on flow stability (Section 3). Recall that a flow stability map is generated by plotting the critical mass flux as a function of power density. An acceptability map is generated by plotting the required mass flux (the required mass flow rate divided by the cold frit outer superficial flow area) as a function of the average fuel element power density. Thus the required mass flux is the mass flux required to prevent excessive particle temperatures or initiation of flow instability due to built-in geometry perturbations. The acceptability map is therefore more comprehensive than a stability map because it indicates the region where operation is prohibited not only by stability considerations but also by fuel temperature limit considerations.

The acceptability map for the nonoptimum conical fuel element is presented in Figure 60 ; the required mass flux is represented by the thick line. Fuel element operation in the region to the left of this line is acceptable but operation to the right of the line is unacceptable with respect to fuel temperatures. For example, operation at an average power density of $20 \mathrm{MW} / \mathrm{L}$ with a cold frit mass flux of less than $2.1 \mathrm{~kg} / \mathrm{m}^{2}$-s results in particle centerpoint temperatures in excess of the maximum-allowed value of $3275 \mathrm{~K}$.

Two other curves are shown on Figure 60. These curves represent the stability maps for the conical element with a cold frit and with a no-added resistance cold frit. The noadded resistance cold frit curve is included for comparison to demonst ate the significant improvement in stability performance offered by the inclusion of a high resistance cold frit. At approximately $1 \mathrm{MW} / \mathrm{L}$ (a relative power of about 0.025 ), the acceptability and the two stability curves all converge. 
The stability curves were generated by calculating the pressure drop characteristic curves for various element power densities in order to determine the critical mass fluxes (the minimum point on the curves). This is the same process described in Section 3 except now the geometry is that of the most restrictive channel (level nine) of the conical element model. Thus this stability map is based on the actual conical geometry of the cold frit, fuel bed, and hot frit, accounting for the radially varying power density and porosity. Temperature-dependent properties for the bed and coolant are also used to allow a bestestimate prediction of the stability map. The critical mass flux is plotted in Figure 60 as a function of the average element power density and not the average power density of level nine. These two power densities differ due to the nonuniform axial power profile imposed by the conical geometry. For this design, the average level-nine power density is about $90 \%$ of the average fuel element power density. Either the average level-nine or fuel element power density could be used to generate the stability map; the element power density is used because it provides a more convenient reference point.

For completeness, the stability and acceptability maps in terms of the temperature ratio are included in Figure 61. Recall from Section 3 that the temperature ratio is the difference between the coolant inlet and outlet temperatures divided by the inlet temperature. The inlet and outlet temperatures of the fuel element (and not of level nine) are used in this figure. The acceptability and stability maps illustrate that a stable operating point may not be an acceptable operating point with respect to temperature limits. The acceptability maps are related directly to the mass flow rate correction factor. Modifications to the fuel element geometry to reduce the correction factor at all power levels will also reduce the unacceptable performance region. The desire is to modify the design so that the acceptability and stability curves are coincident. The stability limits can be decreased by increasing the resistance of the cold frit or by increasing the coolant inlet temperature.

Figure 62 highlights the acceptability and stability curves for average power densities less than $5 \mathrm{MW} / \mathrm{L}$. Also included on this figure is the mass flux trace corresponding to the flow perturbation transient. As dictated by the imposed flow boundary condition, the mass flux follows the acceptability curve down to a power density of about $1.75 \mathrm{MW} / \mathrm{L}$ which occurs at $20 \mathrm{~s}$. The mass flux then dips just below the stability curve at $21 \mathrm{~s}$ and remains there until about $45 \mathrm{~s}$ when the power density is $1.36 \mathrm{MW} / \mathrm{L}$. The mass flux again intercepts the acceptability curve at a power density of about $1.11 \mathrm{MW} / \mathrm{L}$ at $60 \mathrm{~s}$. Based on this figure, a flow instability induced by the built-in element perturbations and the reduced flow should initiate at $21 \mathrm{~s}$. Recovery from the instability should begin sometime after $45 \mathrm{~s}$ and acceptable temperatures should return sometime after $60 \mathrm{~s}$. (Recall that the acceptability and stability curves are based on steady-state calculations.) The following results indicate that this indeed is the predicted response for the flow perturbation transient. This helps to demonstrate the appropriateness of using acceptability maps to avoid unacceptable and unstable conditions during operation. Because these maps are based on 1-D calculations, they are known to be conservative and thus their use provides a built-in margin of safety.

page -- 68 
Figure 63 presents the particle centerpoint temperature for four different particles. Three of the particles are located in the finite elements adjacent to the hot frit (top, central, and bottom axial levels) and one of the particles is located in the finite element adjacent to the cold frit (top axial level). Starting at $20 \mathrm{~s}$, the temperature of all the particles increases. Due to flow redistribution occurring within the fuel element, the temperature of the particles in the central and bottom axial levels begins to decrease at about $25 \mathrm{~s}$ while the temperature of the particles in the top axial level continues to increase. At around $45 \mathrm{~s}$, the temperature of the particle adjacent to the hot frit in the top axial level peaks. However, the maximum-allowed particle centerpoint temperature of $3275 \mathrm{~K}$ is exceeded at about $35 \mathrm{~s}$. The temperature of the particle adjacent to the cold frit, which has a higher power density, continues to increase and doesn't peak until around $60 \mathrm{~s}$ at the unacceptable temperature of $3850 \mathrm{~K}$. Though not shown, after $60 \mathrm{~s}$ the temperatures return to normal.

The significance of the temperature response shown in Figure 63 is that during an off normal event, the particles adjacent to the hot frit are not necessarily the hottest particles. As was presented in Figure 4, the power density of the particles increases as the radius increases. If temporarily starved of flow, the higher power density particles increase in temperature at a higher rate. The resulting skewed temperature profiles affect the flow redistributions that are occurring as time progresses. These calculated transient flow redistributions are different than if they had been determined assuming steady-state conditions. The next two figures are included to help clarify the calculated transient response.

Figures 64 and 65 show the bed surface temperature transient response for the bottom and top axial levels of the fuel element. The ten curves on each figure correspond to the ten radial finite elements in the bed. The flow redistribution during the transient is such that the bottom axial level temperatures are decreasing after $25 \mathrm{~s}$. However, the temperatures in the top axial level are increasing and the temperatures of the particles closer to the cold frit are increasing faster.

Figure 66 shows the radial bed surface temperature variations at $0,20,40$, and $60 \mathrm{~s}$ for the top and bottom axial levels. This figures illustrates the complex response of the bed temperatures during the transient. Due to the radial and axial variations of power along with the flow redistributions occurring within the element, different parts of the bed have entirely different temperature responses. This figure also shows that the maximum temperature of over $4000 \mathrm{~K}$ occurs about one-third of the way in from the cold frit in the top axial level. The calculation indicates that during an off normal event, the maximum particle temperatures can occur at a location other than the bed exit. It is recognized that this transient was allowed to progress beyond the time when fuel melting occurs. The selection of the flow rate boundary condition was based on achieving this result. This was done because it is instructional with respect to the complex performance of a fuel element during a transient and because it demonstrates the usefulness of stability maps. 
Figure 67 shows the coolant temperature distribution in the outlet plenum as a function of time. (Temperature values are assigned to the centroid of the finite elements.) The peak coolant temperature of about $3160 \mathrm{~K}$ occurs at the top of the outlet plenum at approximately $42 \mathrm{~s}$. At this time, the coolant temperature at the exit of the fuel element is about $2600 \mathrm{~K}$. Monitoring the coolant temperature in the outlet plenum does not provide experimentalists with a clear indication of the margin by which the bed has exceeded maximum-allowed limits. However, the increasing values of coolant temperature throughout the outlet plenum, beginning shortly after the initiation of the flow perturbation, indicate that something undesirable is in progress. This early indication provides time for corrective response. For this transient, about $10 \mathrm{~s}$ would be available for restoration of coolant flow before some of the particles exceed their maximum-allowed temperatures.

As an aside, if a local flow blockage were introduced into the fuel element, coolant mixing in the outlet plenum would preclude any indications of excessive bed temperatures. This, of course, is true of any reactor because it is impractical to monitor the temperature of every individual flow channel unless some type of thermal imaging system can be nonintrusively implemented.

Two final figures are included in this section to help the reader better visualize the complicated temperature profiles occurring in the element. Figure 68 shows the axial and radial variations of surface temperature for the cold frit, bed, and hot frit at $20 \mathrm{~s}$ (before the global flow perturbation is initiated). Flow maldistribution accounts for the lower temperatures in the lower axial levels. Figure 69 shows the axial and radial temperature profiles at $60 \mathrm{~s}$. This figure clearly shows the unfavorable temperature response within the element.

It is important to remember that the flow perturbation transient response is for a hypothetical, nonoptimized fuel element design. Other element designs will surely have a different response. Also, the imposed 23\% reduction in element flow is rather large; smaller reductions in flow rate can be accommodated by the element without particle melting. The flow reduction limit can be determined by further parametric calculations. This should be explored after a more optimized element design has been created.

Three major points are demonstrated by this element flow perturbation transient there is a significant time lag between initiation of a flow perturbation event and the occurrence of fuel melting calculation: (1) acceptability maps characterize both the flow maldistribution and instability regions of operation and can be used to guide operations, (2) during an off normal transient, the inaximum fuel temperature can occur at a location other than the bed exit, and (3) during decay heat removal, there is a significant time lag between initiation of a flow perturbation event and the occurrence of fuel melting. 


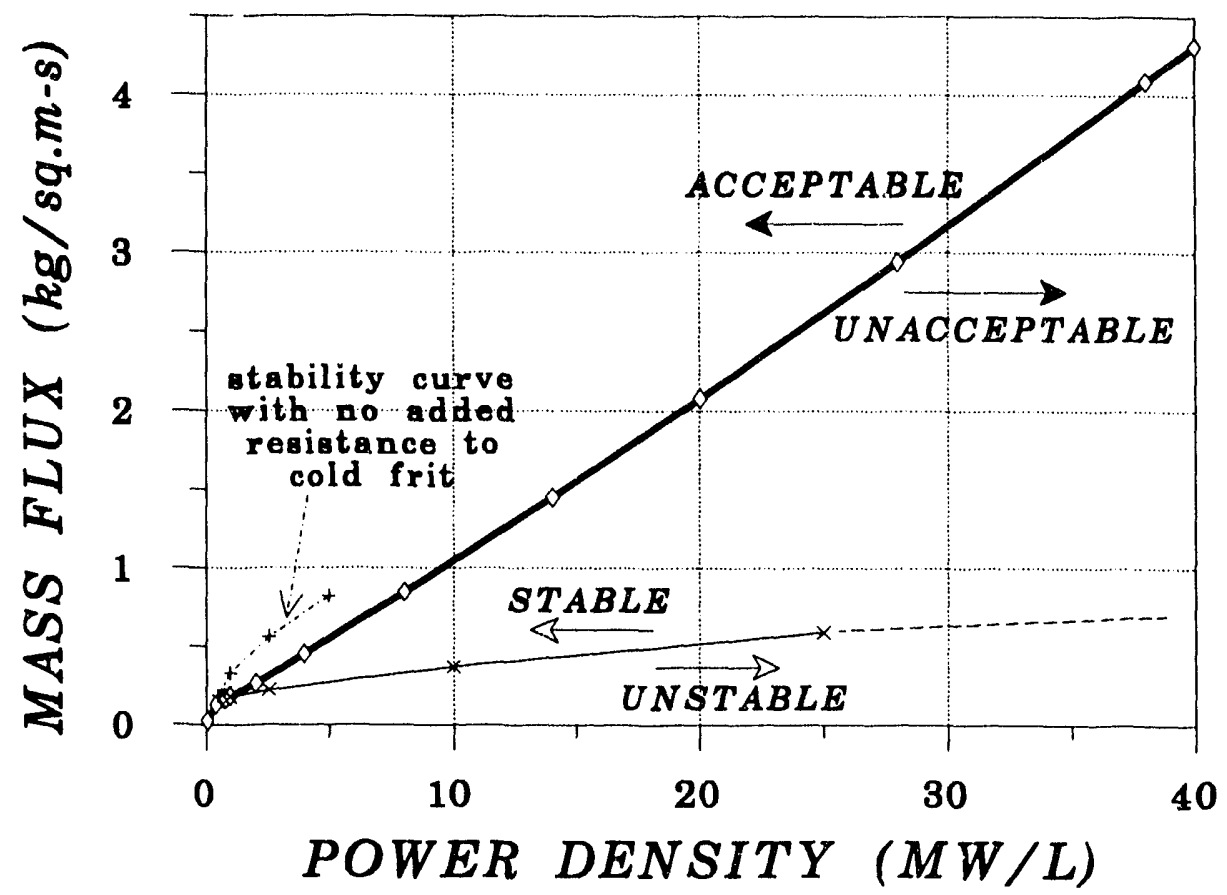

Figure 60. Mass Flux Acceptability and Stability Maps for the Conical Element

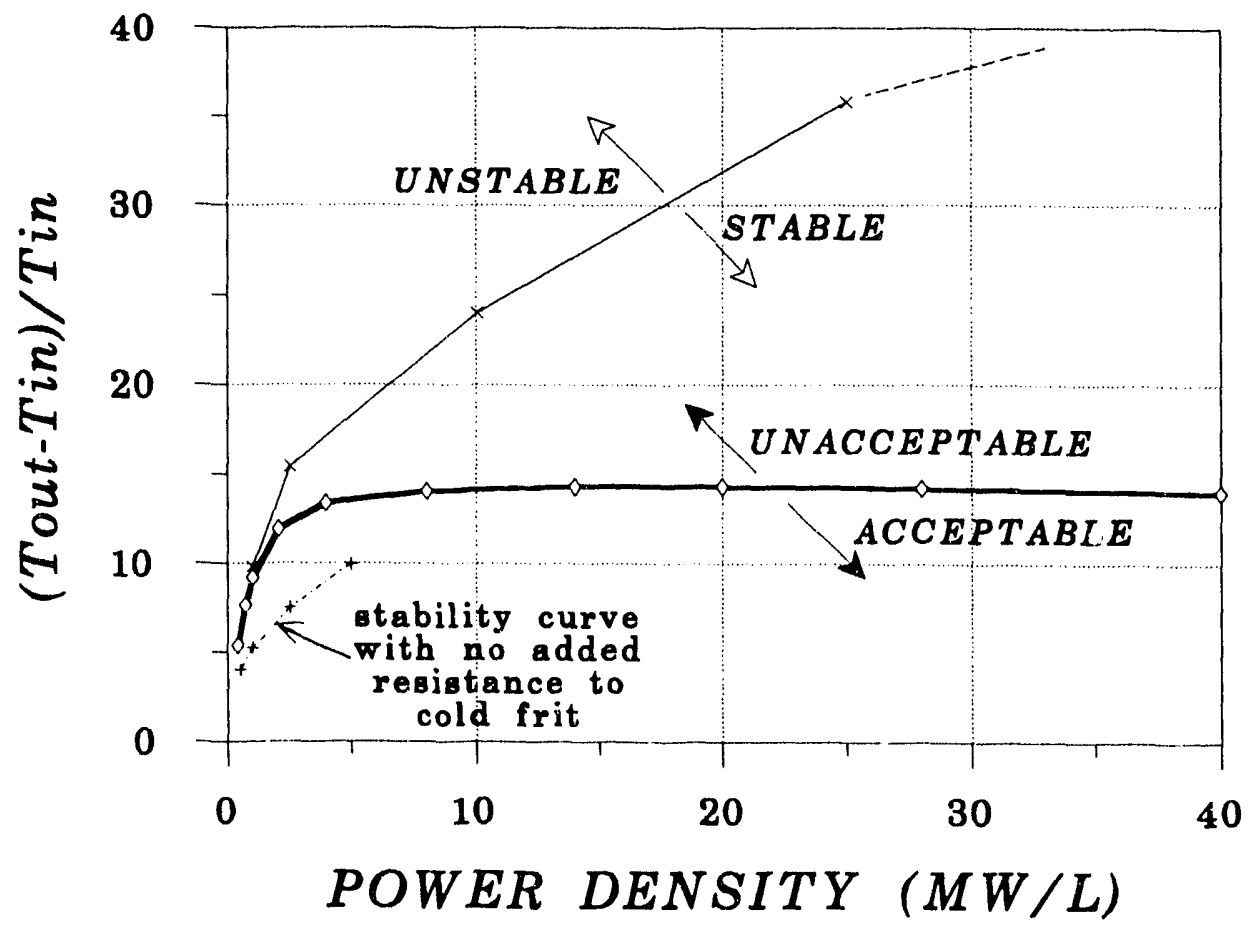

Figure 61. Temperature Ratio Acceptability and Stability Maps for the Conical Element 


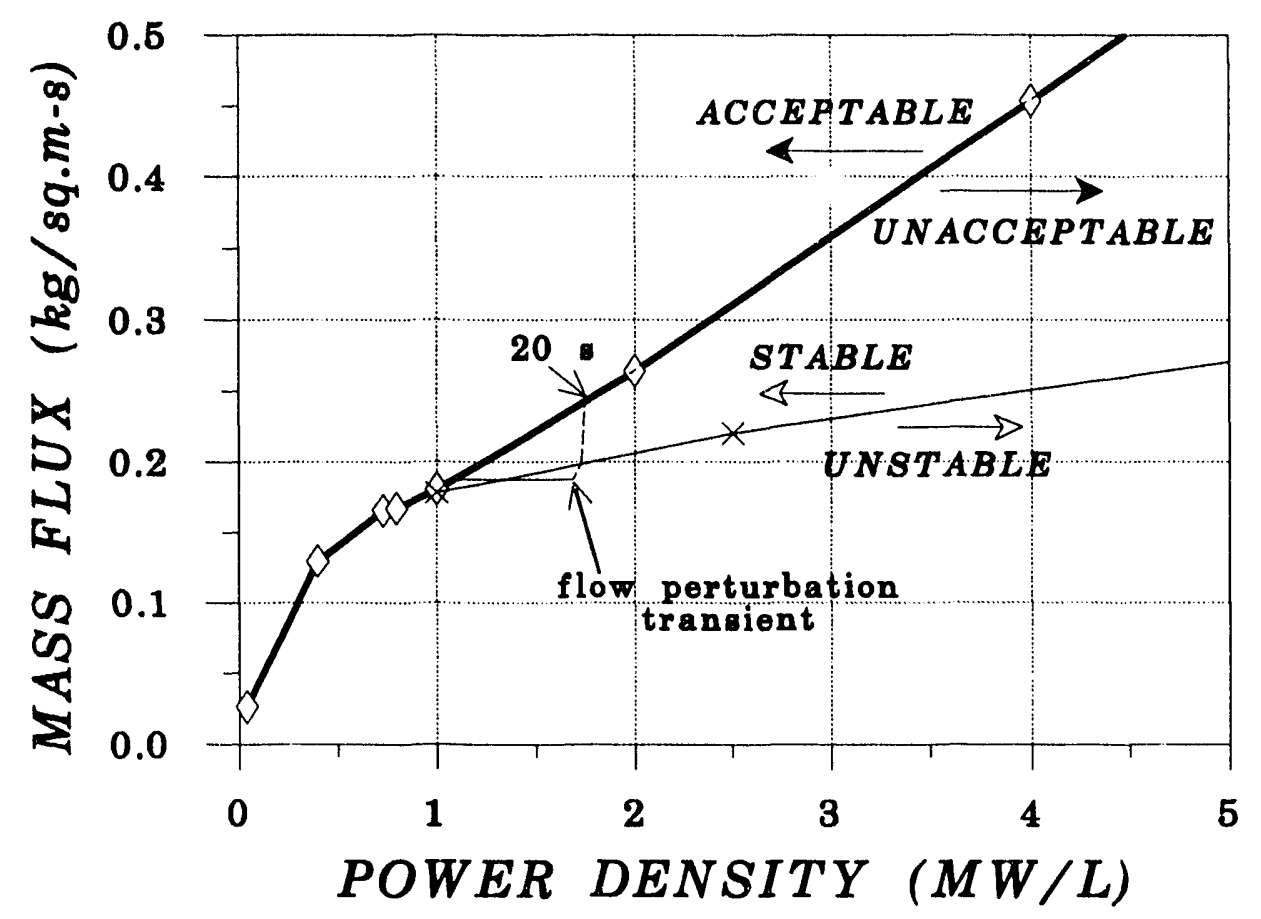

Figure 62. Imposed Flow Perturbation Mass Flux With the Acceptability and Stability Maps of the Conical Element

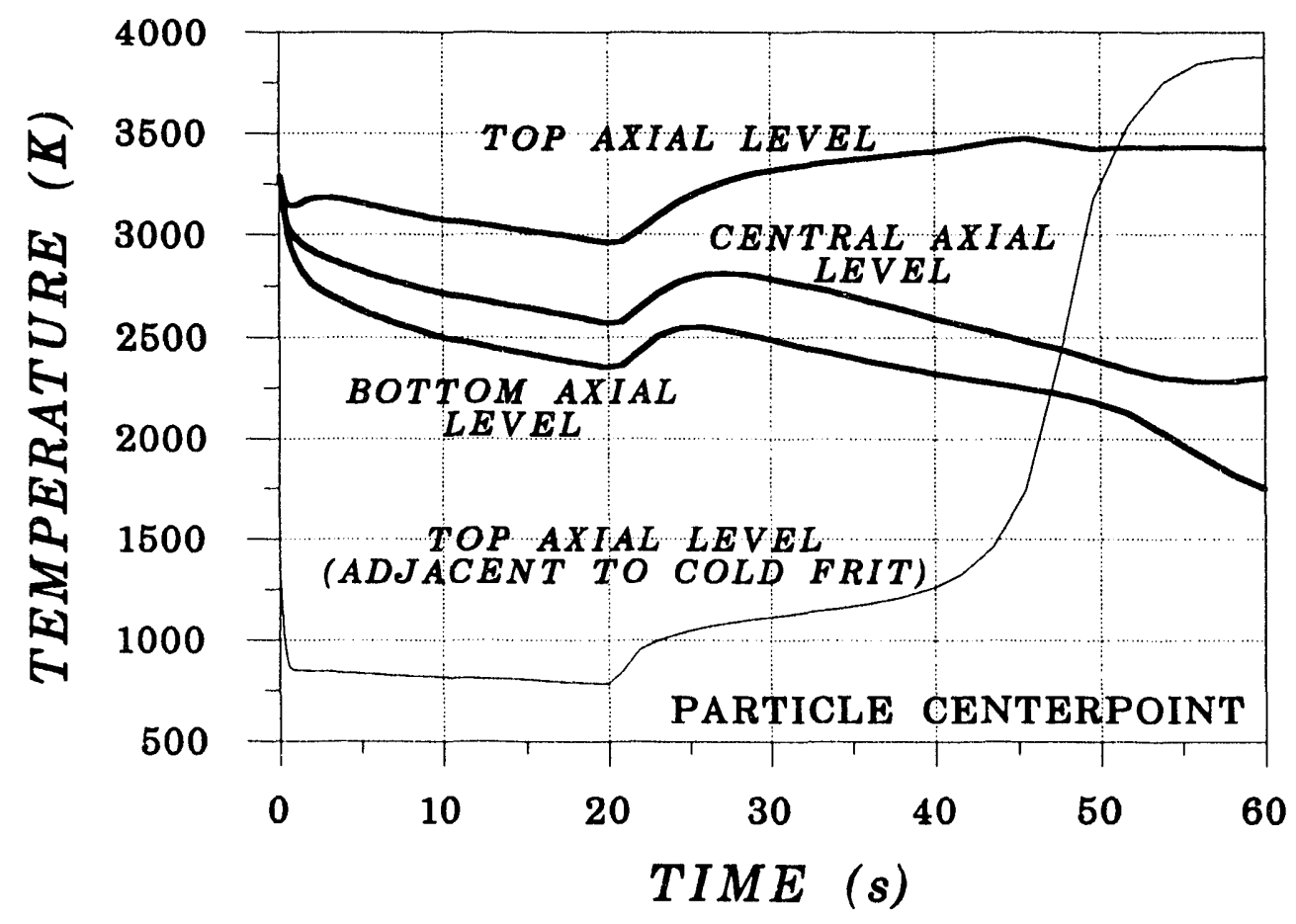

Figure 63. Particle Centerpoint Temperature for the Flow Perturbation Transient 


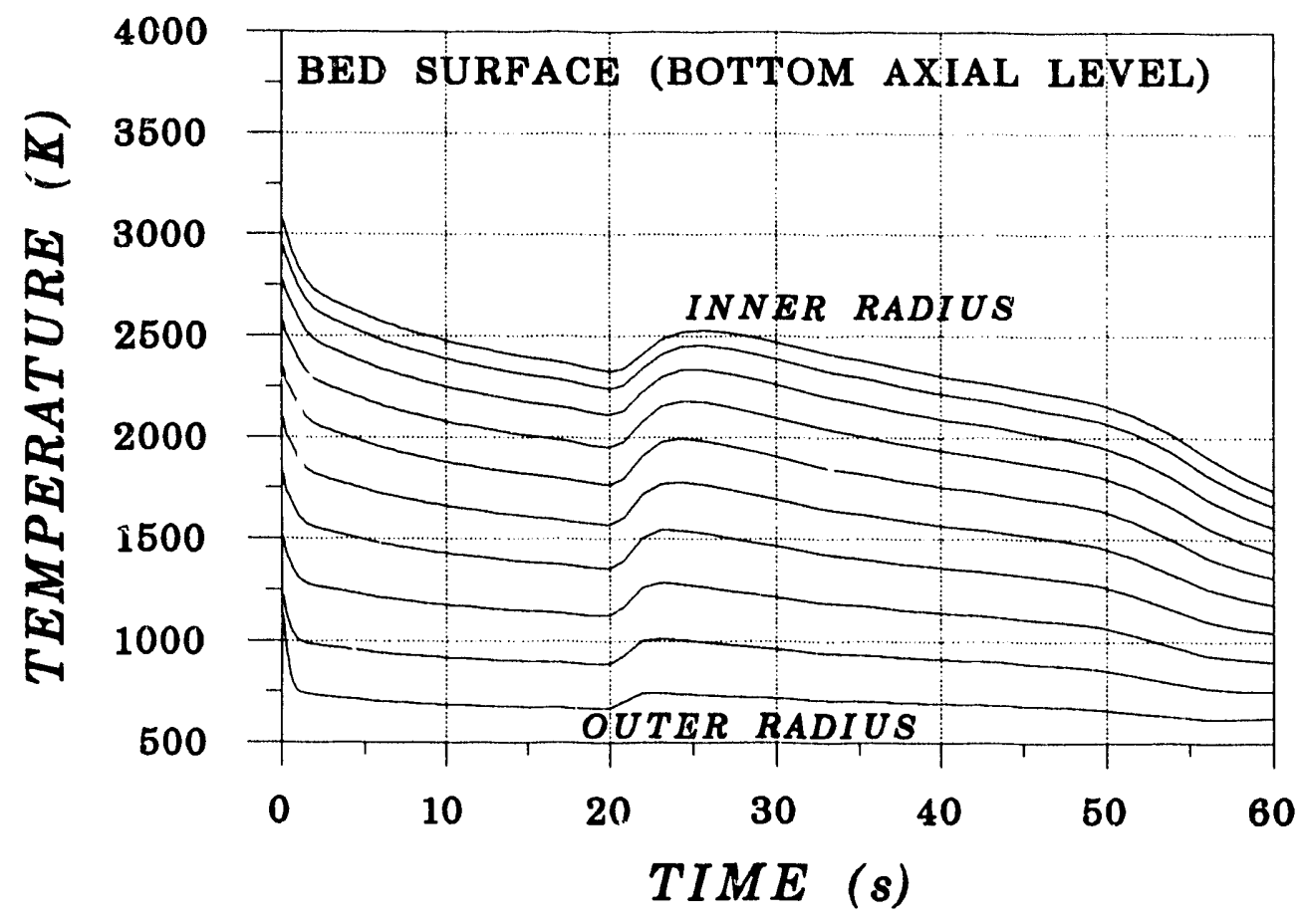

Figure 64. Bed Surface Temperature for the Flow Perturbation Transient (bottom level)

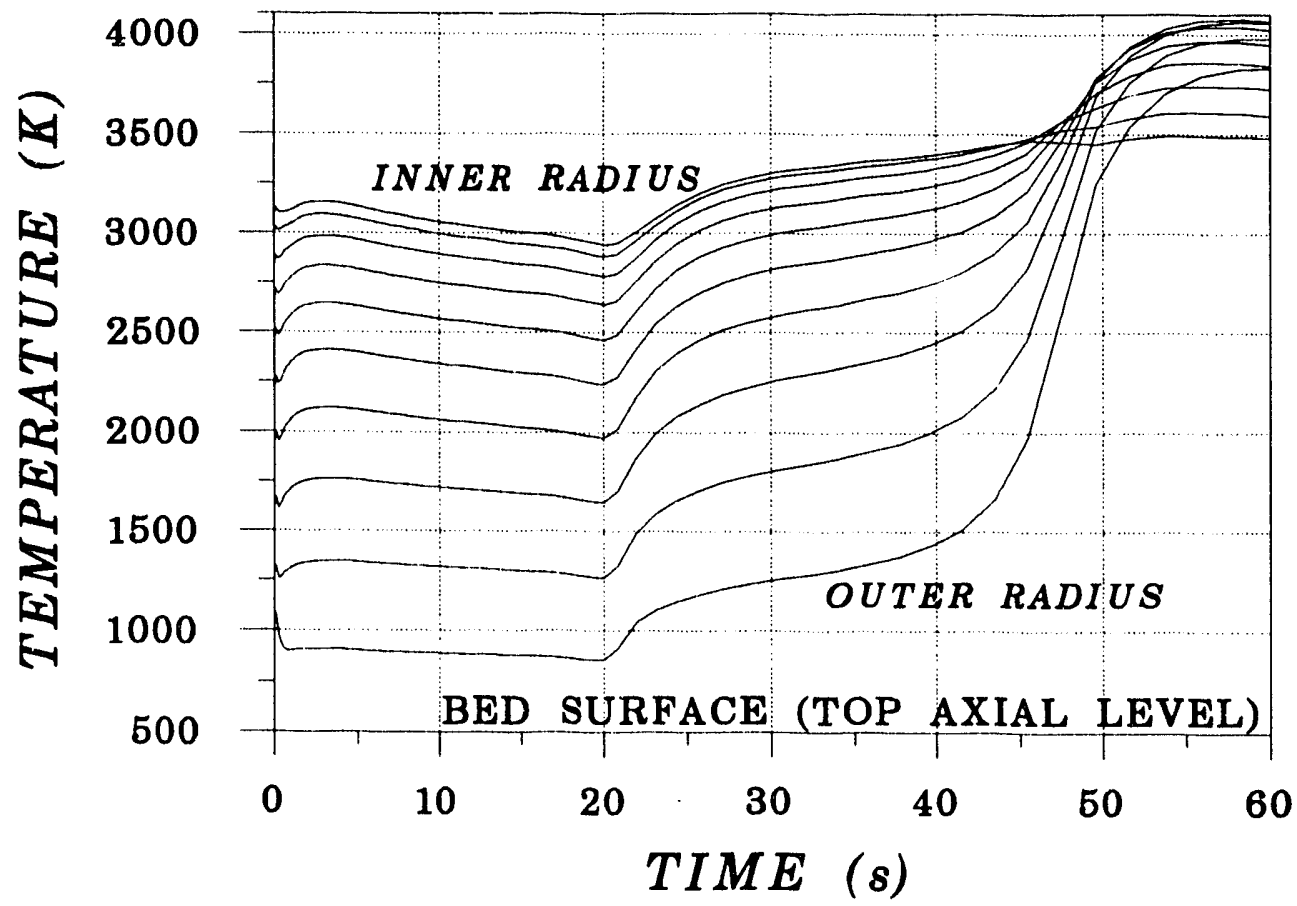

Figure 65. Bed Surface Temperature for the Flow Perturbation Transient (top level) 


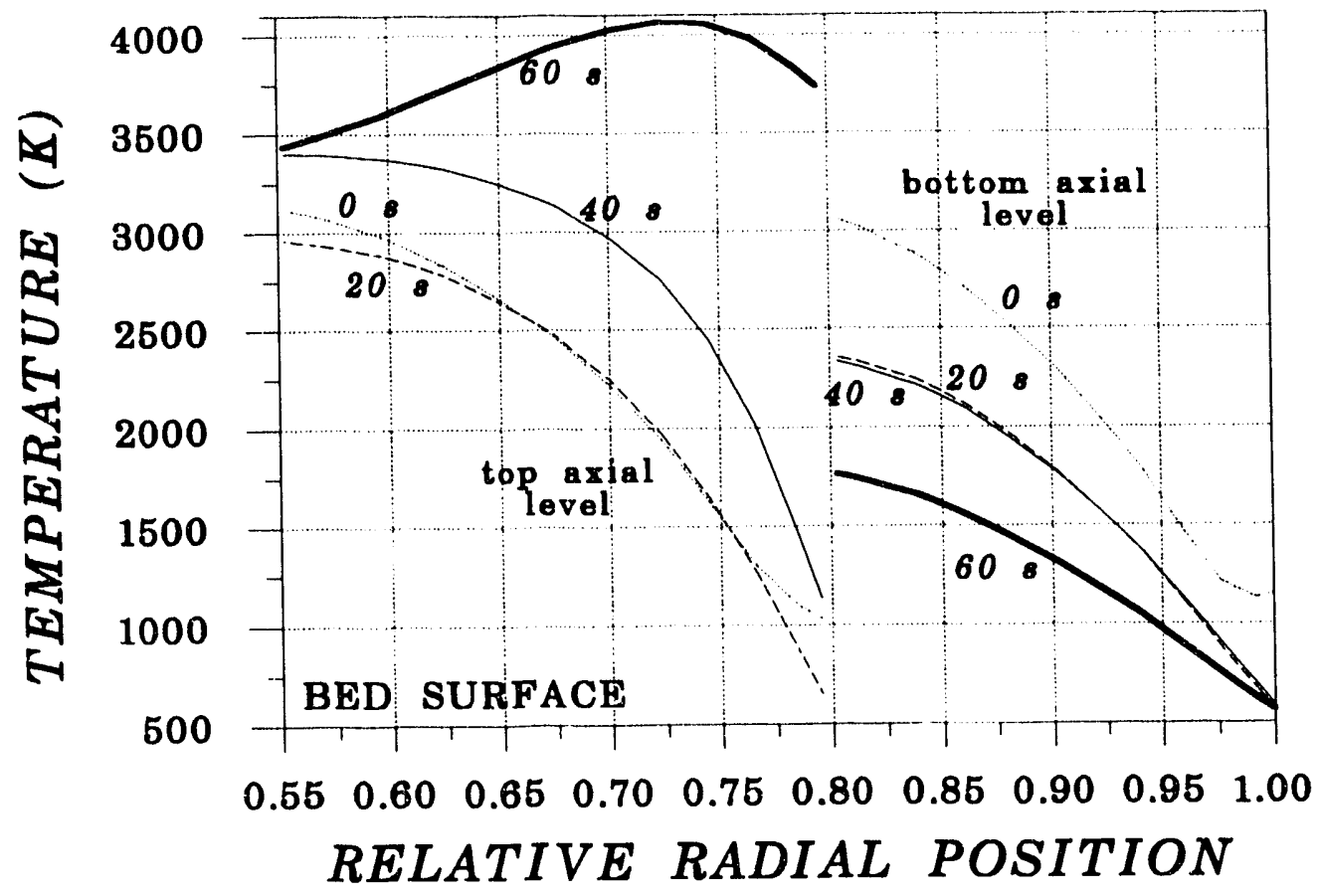

Figure 66. Bed Surface Radial Temperature Profiles (Flow Perturbation Transient)

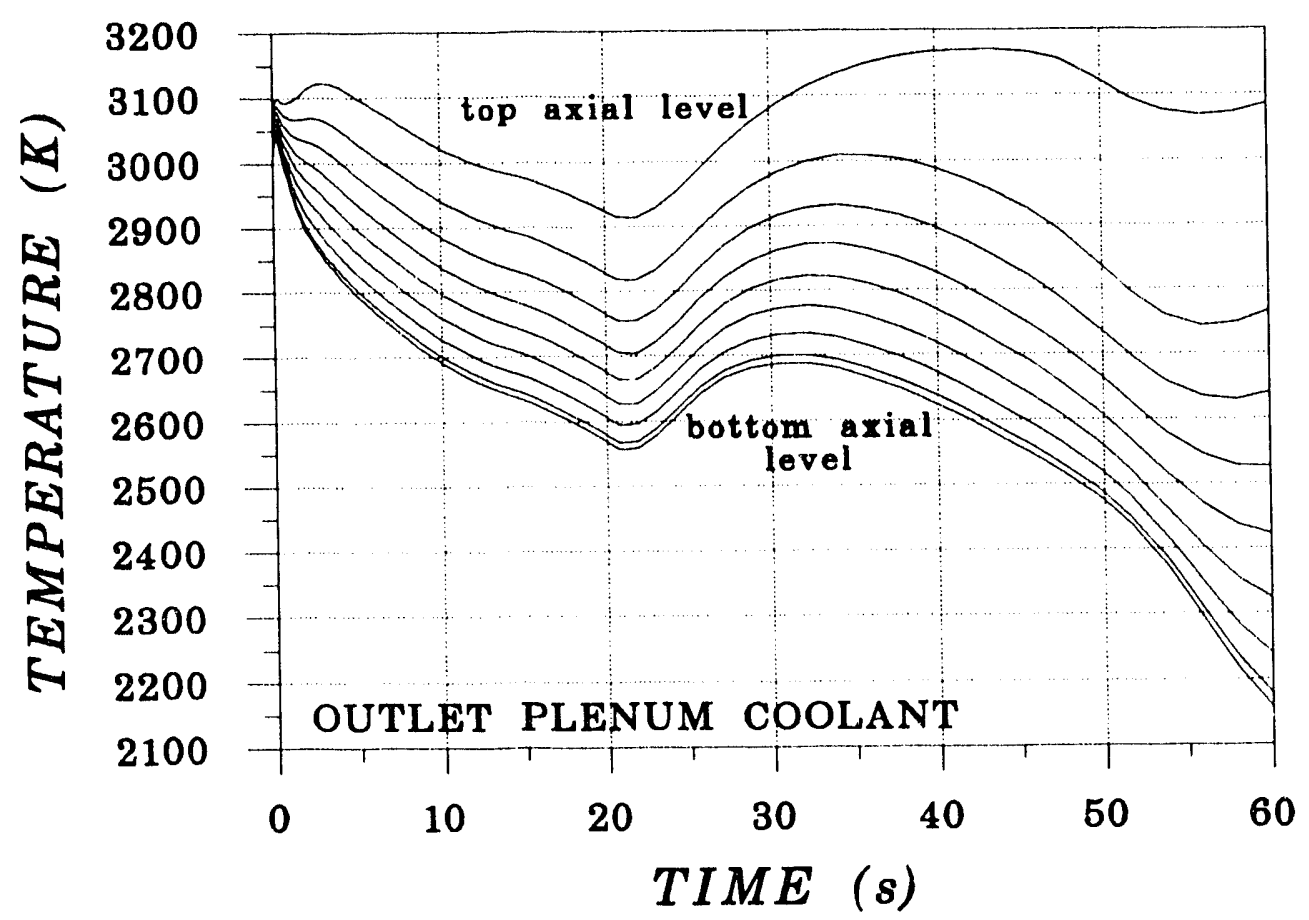

Figure 67. Outlet Plenum Coolant Temperature Response (Flow Perturbation Transient) 


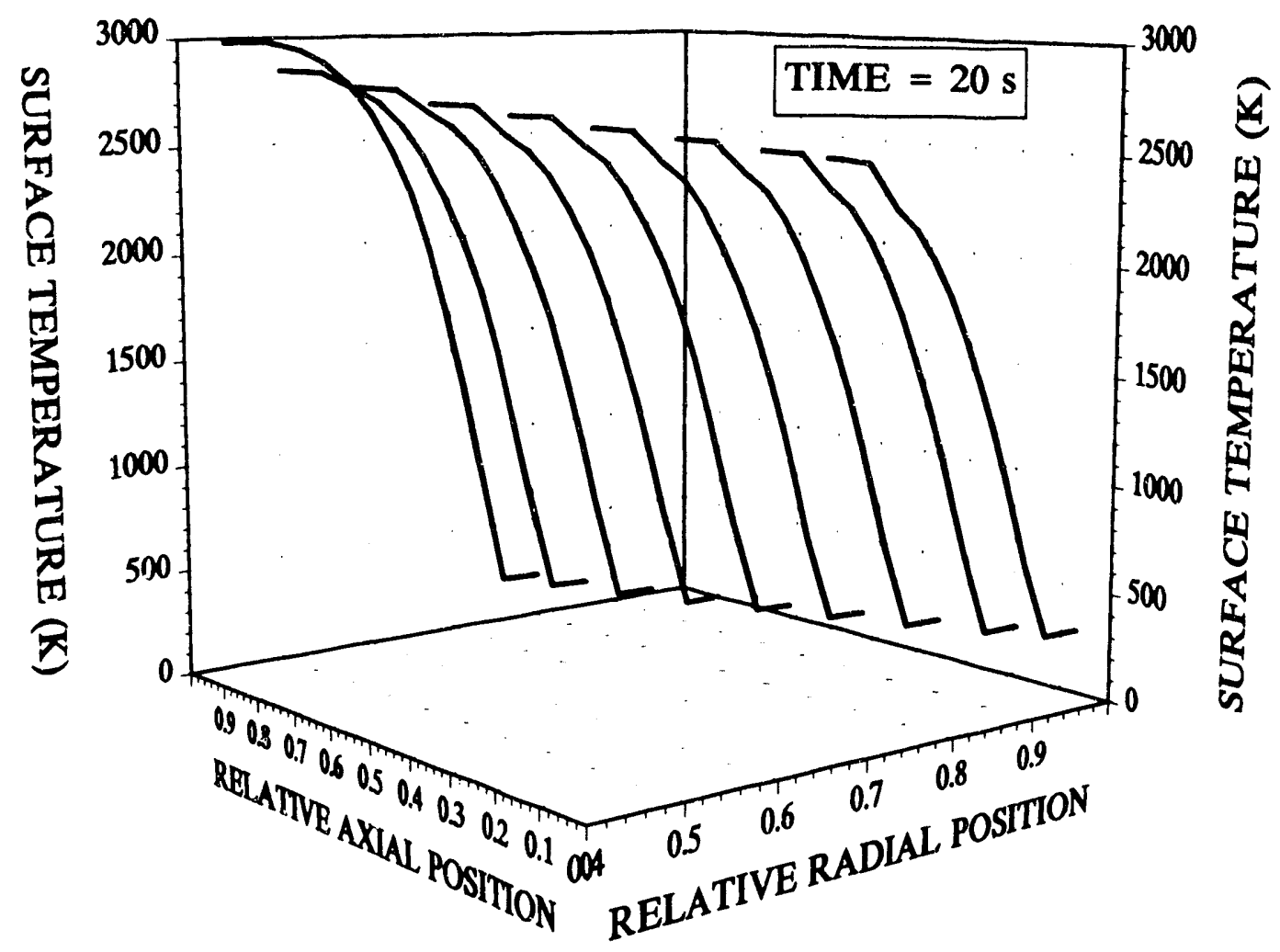

Figure 68. Surface Temperature Axial and Radial Profiles at $20 \mathrm{~s}$ (Flow Perturbation)

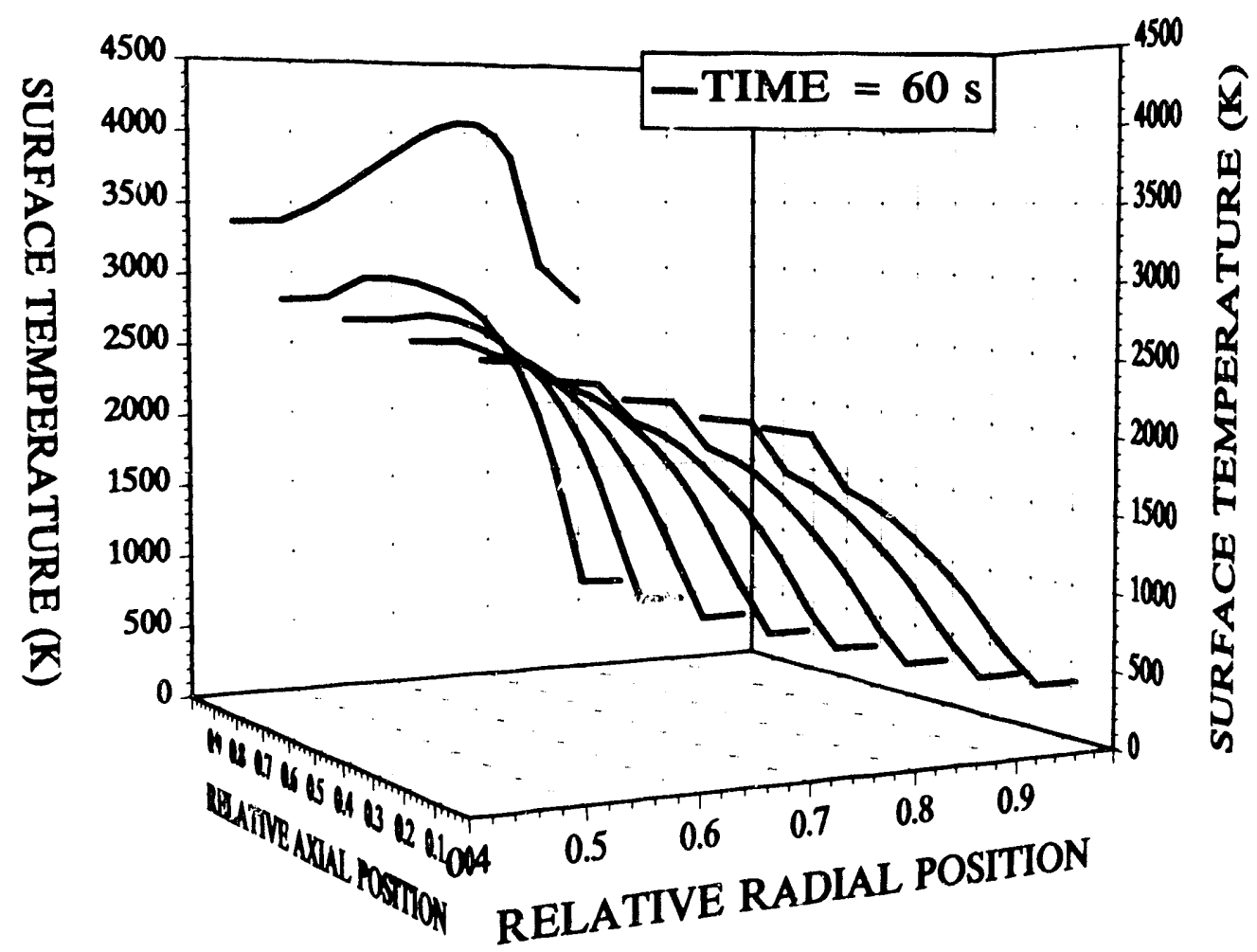

Figure 69. Surface Temperature Axial and Radial Profiles at $60 \mathrm{~s}$ (Flow Perturbation) 


\subsection{Pulse Cooling}

The final transient addresses the flow and heat transfer performance of the particle bed fuel element during pulse cooling. Pulse cooling is one possible strategy to avoid flow instabilities associated with low flow rates following reactor shutdown. In this mode of cooling, the flow is cycled on and off. During the on part of the cycle, a high flow rate is used to preclude flow instability. At low power levels, the heating rate of the fuel is low enough that lack of coolant can be tolerated for some period of time. The SAFSIM calculations described in this section demonstrate the feasibility of pulse cooling. It should be kept in mind that the results apply to the single conical element design described throughout this document. As has been mentioned repeatedly throughout this document, it appears very likely that a different element design can significantly improve fuel element performance at reduced power.

As was mentioned in Section 5.1 (the base case decay heat removal transient), the SAFSIM transient calculations were not advanced very far in time because it is believed that multidimensional conduction and thermal radiation heat transfer mechanisms from the fuel element to the reactor and environment become significant at low power; this issue needs to be addressed using a multidimensional conduction analysis of the entire reactor. Therefore, these SAFSIM calculations address only the early-time response of the fuel element, when the decay power is still about $2 \%$ to $4 \%$ of full power. Much can be learned by these early time calculations.

Before the pulse cnoling transient could be performed, it was necessary to formulate an algorithm for controlling the flow pulses. An algorithm was formulated to provide coolant at either the required mass flow rate or the ideal mass flow rate, depending on the maximum $\mathrm{F}$ rticle centerpoint temperature found anywhere in the bed. (The required and ideal flow rates are defined in Section 5.1. Keep in mind, however, that the required mass flow rate in a transient is different than that predicted by steady-state calculations because the temperature distribution within the bed is continually changing.) If the maximum temperature exceeds $3150 \mathrm{~K}$, then the flow is ramped up to the required mass flow rate, corresponding to the current power, at a rate of $0.1 \mathrm{~kg} / \mathrm{s}^{2}$. When the maximum temperature drops below $2950 \mathrm{~K}$, the flow is ramped down to the ideal flow rate, again at a rate of $0.1 \mathrm{~kg} / \mathrm{s}^{2}$. (The upper and lower temperature limits were determined by trial and error.) The mass flow rate was not reduced to zero because, at this early time, the heating rate of the particle without forced convection is very large and would necessitate rapid flow rate pulses to prevent melting.

The algorithm just described was found to prevent particle centerpoint temperatures from exceeding the maximum-allowed value of $3275 \mathrm{~K}$. However, it is probably impossible to implement this algorithm in an actual hardware system because there is no way of knowing the maximum temperature in the bed. Nevertheless, implementation of this ideal algorithm in the computer simulation provides insight into the fuel element's transient performance.

page -- 76 
Pulse cooling is initiated at $20 \mathrm{~s}$, when the power is below the $5 \%$ level. This is the time when flow instability due to built-in geometry perturbations starts to become an issue (see Sections 4.1.2 and 5.2). Figure 70 shows the particle centerpoint temperature response and demonstrates the ability of the control algorithm to keep the maximum particle centerpoint temperature at or below $3275 \mathrm{~K}$. For the conical fuel element design assumed in these analyses, the maximum temperature occurs in the top axial level. The temperatures in the remainder of the bed are decreasing, however, because flow maldistributions require overcooling of most of the bed in order to prevent excessive temperatures. The peak temperature of the particle in the top axial level, adjacent to the cold frit, is gradually increasing with time. Recall that particles closer to the cold frit have higher power densities than those near the hot frit.

Figures 71 and 72 are included to further demonstrate the predicted bed temperature response. Only the first $60 \mathrm{~s}$ of the $180 \mathrm{~s}$ transient is included to avoid cluttered figures. Figure 71 shows the bed surface temperature for the ten radial regions of the bottom axial level and Figure 72 shows the same for the top axial level. The temperatures at the bottom of the fuel element are gradually decreasing as flow redistributes to that location. As a result of this flow redistribution, the temperatures at the top of the elernent are slowly increasing. Note also that at all locations, the amplitude of each temperature pulse is slightly greater than the amplitude of the previous pulse.

As in the flow perturbation transient of the previous section, the different power densities of the various particles results in a different time-dependent response for each. As a result, each pulse leaves the fuel element with a temperature distribution that is less favorable with respect to flow redistribution (more about this later). To compensate for this, the required mass flow rate must continually increase to prevent excessive temperatures or flow instability. This effect is demonstrated by Figure 73, which shows the element mass flow rate as a function of time. The base case transient flow rate (no pulse cooling) is also included for comparison. The integrated flow rate for the pulse cooling case is about $10 \%$ greater than for the base case. Thus, even with this ideal control algorithm, pulse cooling is not advantageous early (with respect to minimizing coolant inventory) when the power is at about the $2 \%$ to $4 \%$ level. This may not be the case much later on because other heat transfer mechanisms (conduction through end fittings and thermal rauiation) affect the flow redistributions. Also, at very low flow rates, the transition from turbulent to laminar flow completely changes the flow redistributions, as discussed in Section 5.1. Thus the response to pulse cooling at late times will be entirely different than demonstrated here for early time performance.

Pulse cooling does, however, reduce the possibility of flow instability because the flow rate during the on part of the cycle is much greater than the minimum flow rate required for flow stability. Referring back to the base case decay heat removal transient (Section 5.1 ), the flow rate was maintained just slightly above the minimum. As was demonstrated in the flow perturbation transient (Section 5.2), any reduction below this minimum can rosult in fud molting. Thus, there is not a very large margin for error. Increasing the mass 
flow rate to provide a larger margin would increase the required coolant inventory just as implementation of pulse cooling does.

As was mentioned earlier, each flow pulse leaves the fuel element with a temperature distribution that is less favorable with respect to flow redistribution. Thus the temperature \begin{tabular}{l}
\hline A stability map generated \\
for steady-state conditions \\
may not be representative of \\
the fuel element during off \\
normal transient events. \\
\hline \hline
\end{tabular} distribution in the bed imposes an additional "built-in" perturbation. Hot channels are more flow restrictive than cold channels because of the relationship between pressure drop, viscosity, and temperature [see Section (3) and Equation (10)]. The implications of this are that flow stability maps of fuel elements (particle bed or otherwise) are history dependent. A stability map generated for steady-state conditions may not be representative of the fuel clement during off normal transient events.

A sequence of color plots (four plots per figure) is provided in the next three figures to aid in the visualization of the fuel element transient response. Each plot represents a "snapshot" from a color movie displaying the changing temperature distributions as time progresses. A color is assigned to each of the 145 fluid mechanics finite elements based on the coolant temperature. Thus, each snapshot depicts the entire fuel element and provides a representation of the results that is difficult to capture with standard plots.

Figure 74 contains coolant temperature snapshots at 0 (steady state), 5, 10, and $20 \mathrm{~s}$. These snapshots apply to all three decay heat removal transient calculations (base case, flow perturbation, and pulse cooling) and show the fuel element response before any kind of perturbation is introduced. At steady state, the coolant temperature distribution is fairly uniform as intended by design of the cold frit. The large temperature increase $(2800 \mathrm{~K})$ across the fuel bed is clearly depicted. The next three snapshots at 5,10 , and $20 \mathrm{~s}$ demonstrate the temperature distribution nonuniformity that is developing as the flow redistributes toward the bottom of the element. At $20 \mathrm{~s}$, the bottom portions of the fuel element are much cooler than the top portions. The hot spot occurs in the top axial level.

Figure 75 provides snapshots at $60.7,64.4,79.8$, and $84.1 \mathrm{~s}$ of the pulse cooling transient. These times were selected because they correspond to peaks and valleys of the flow pulses. At $60.7 \mathrm{~s}$, the mass flow rate is at a local maximum. Due to the thermal inertia of the system, the coolant temperature throughout the fuel element is also at a local maximum, but just beginning to decrease. At the end of one flow pulse cycle (64.4 s), the temperatures are at their local minimum, as is the flow rate. The two snapshots show the change in nonuniform temperature distributions. Because the lower regions of the fuel element are continually cooled with each pulse, they become less restrictive to flow. Because the coolant flow takes the path of least resistance, a larger fraction of the flow is diverted to the lower regions of the element with every successive flow pulse. This is why the required mass flow rate continues to increase during pulse cooling.

page -- 78 
The next two snapshots (at 79.8 and $84.1 \mathrm{~s}$ ) show: the coolant temperature distributions for a later flow pulse. These two snapshots also correspond to the peak and valley of a single pulse. As is evident, the lower regions of the fuel element continue to decrease in temperature. The maximum temperature in the top axial level remains constant due to the programmed action of the flow controller, as intended.

Figure 76 shows two more peak and valley snapshots much later in the transient. The coolant in the top axial level has not changed but the lower regions of the element are still cooling. The last two snapshots of this figure are a repeat of the previous two, but instead use a logarithmic scale to better illustrate the temperature gradients. The $50 \mathrm{~K}$ increase in coolant temperature in the inlet plenum from top to bottom is more apparent with this scale, as is the nonuniform temperature distribution in the bed.

Returning to the standard figure format, Figure 77 shows the chamber temperature for the pulse cooling and base case transients. After about $60 \mathrm{~s}$, the chamber temperature for the pulse cooling case is lower than that for the base case. This again demonstrates the increasing flow rate required to prevent excessive fuel temperatures.

The final two figures (Figures 78 and 79) show, respectively, the pressure at the exit of the element (chamber pressure) and at the nozzle throat. The base case response is included for comparison. For these calculations, the backpressure is $0.1 \mathrm{MPa}$. In the pulse cooling transient, the pressure at the nozzle throat decreases to the backpressure at the valley of each flow pulse, starting at about $50 \mathrm{~s}$. Thus, the flow is no longer choked. It is also clear that in time unchoking will occur in the base case transient. A space-based reactor will have a zero backpressure. Thus unchoking will occur at a different flow rate. It is expected that the effect will be small and would not change the overall trend of this calculation. However, unchoking may have implications for a ground test facility employing an effluent treatment system. Such a system will impose its own timedependent backpressure on the reactor. Additional work can employ SAFSIM to model such a system coupled to the reactor to further investigate the system interactions.

These transient calculations of early-time pulse cooling of a fuel element emphasize the need for an optimized element design. An improved design, with respect to flow maldistribution, can greatly improve the element performance during pulse cooling or any off normal event. Also, the late-time response of the fuel element to pulse cooling will be very different and needs to be investigated using multidimensional computational tools. 


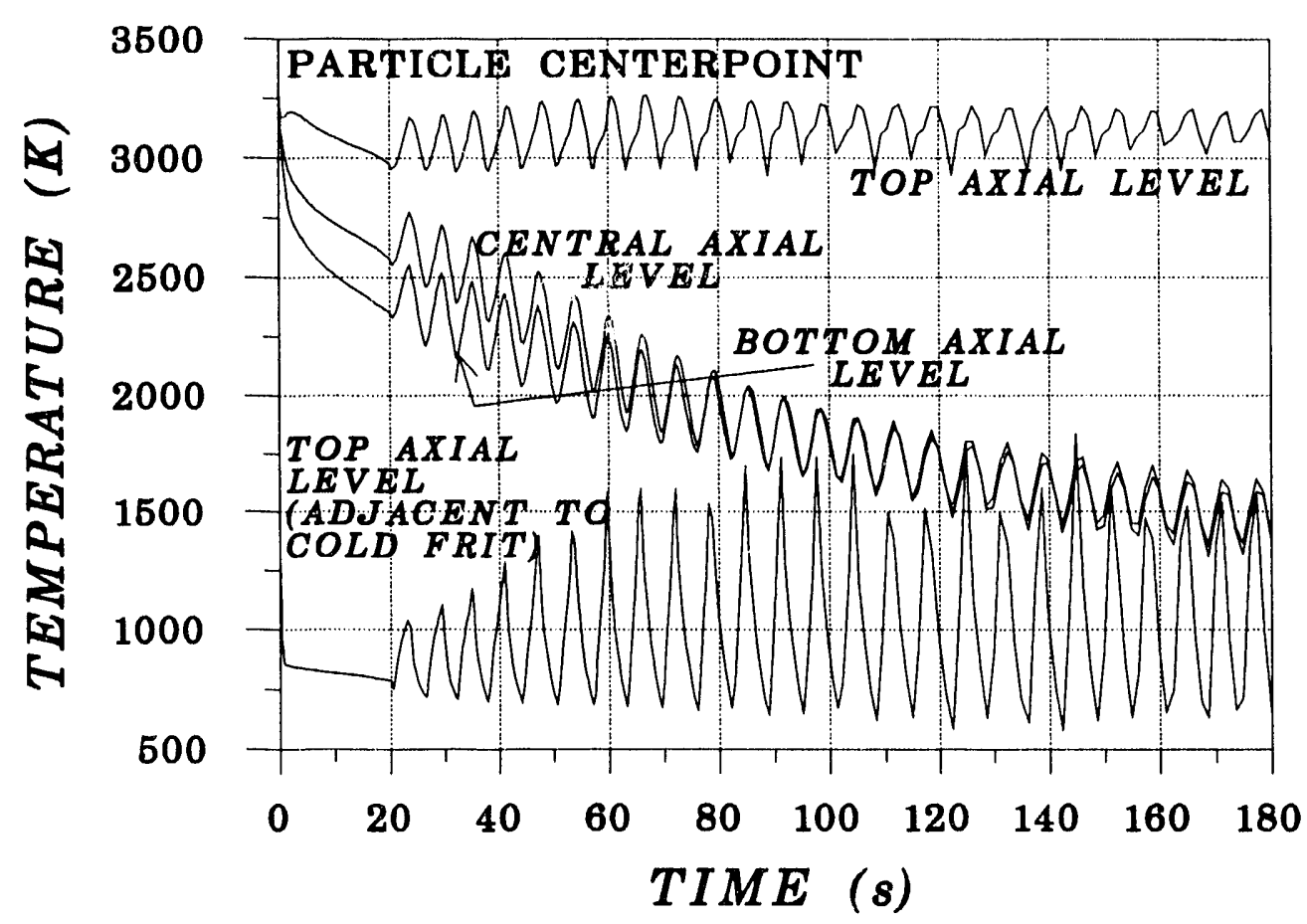

Figure 70. Particle Centerpoint Temperature Response to Pulse Cooling

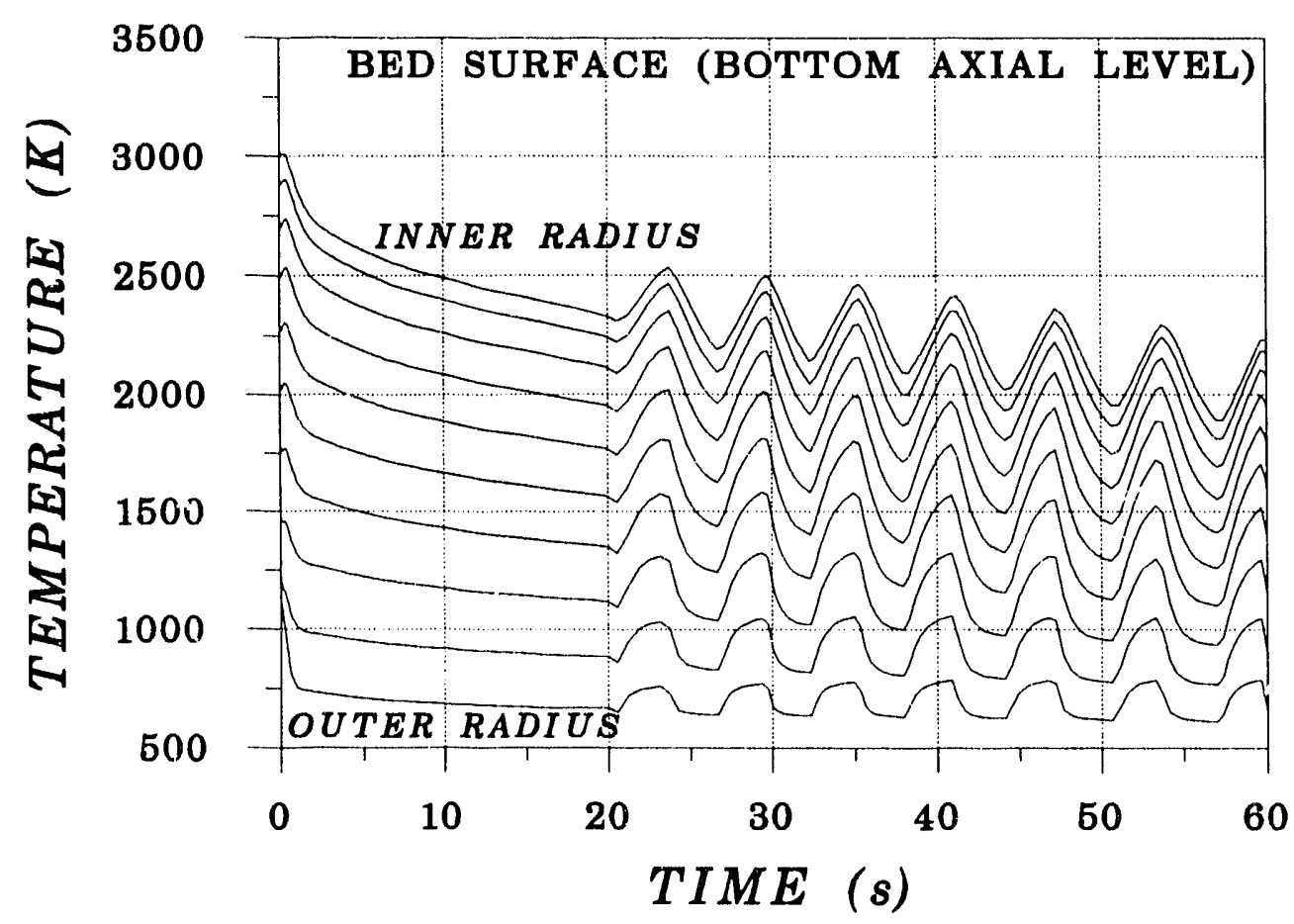

Figure 71. Bed Surface Temperature Response in Bottom Axial Level (Pulse Cooling) 


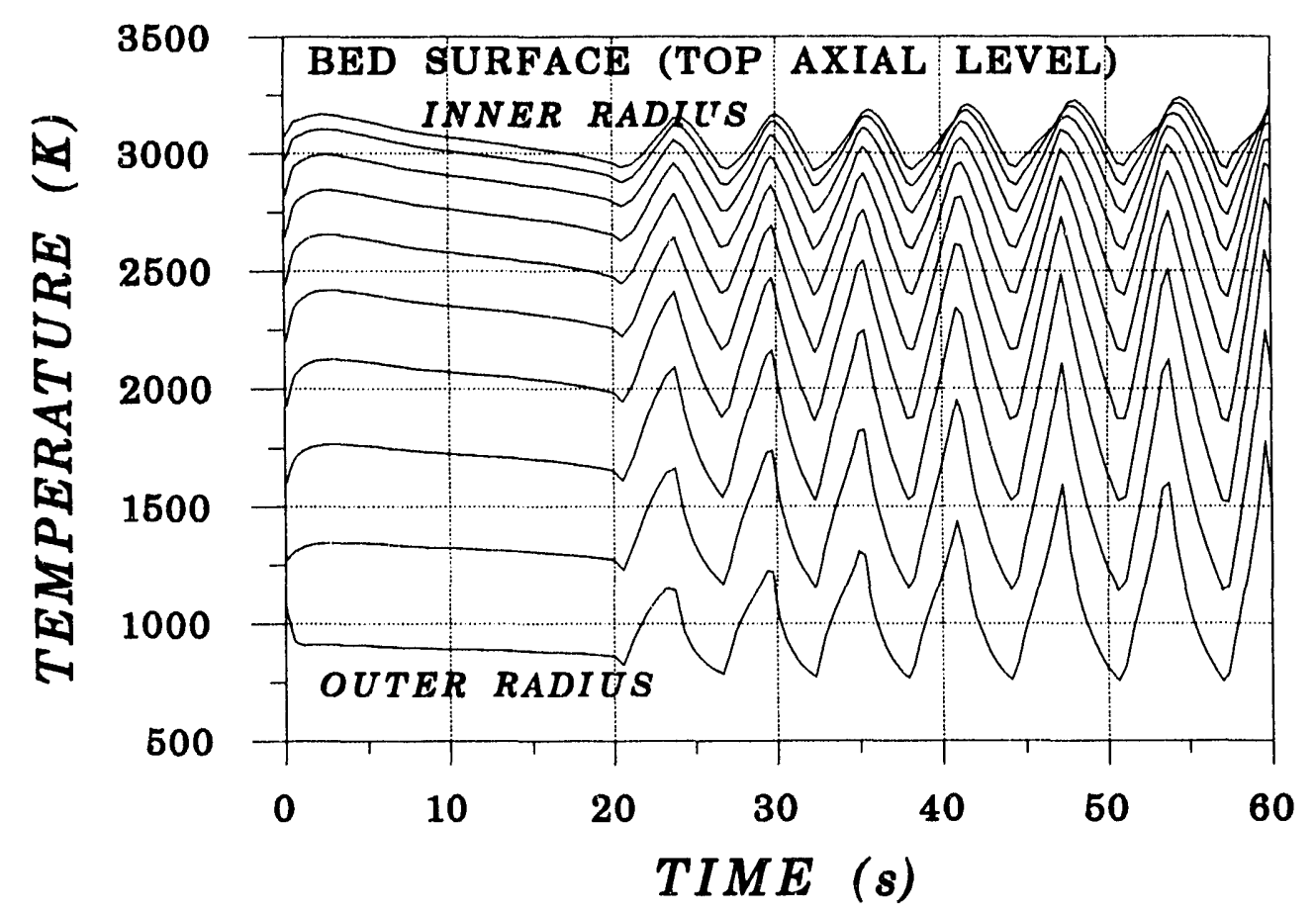

Figure 72. Bed Surface Temperature Response in Top Axial Level (Pulse Cooling)

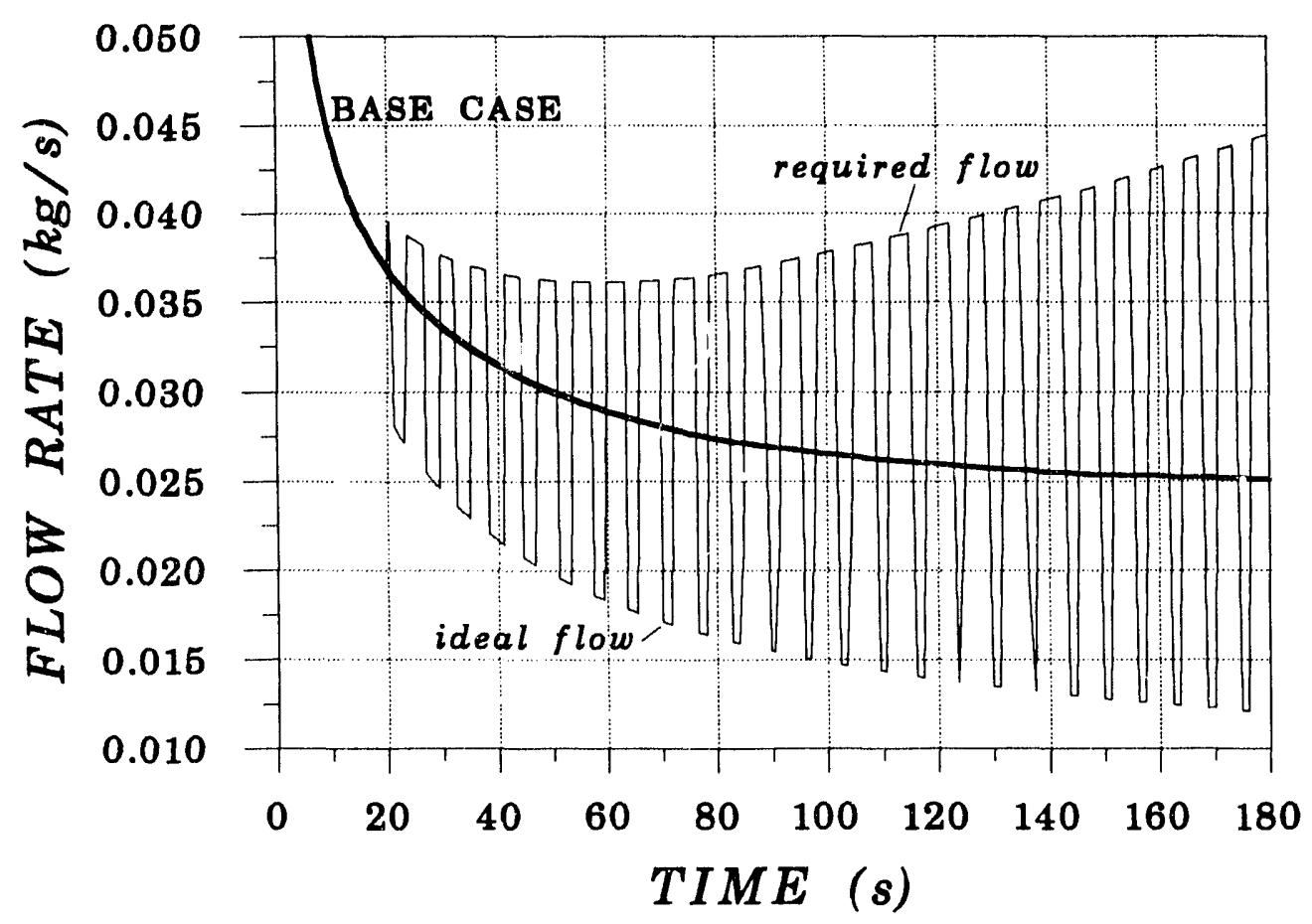

Figure 73. Pulse Cooling Required Mass Flow Rate 


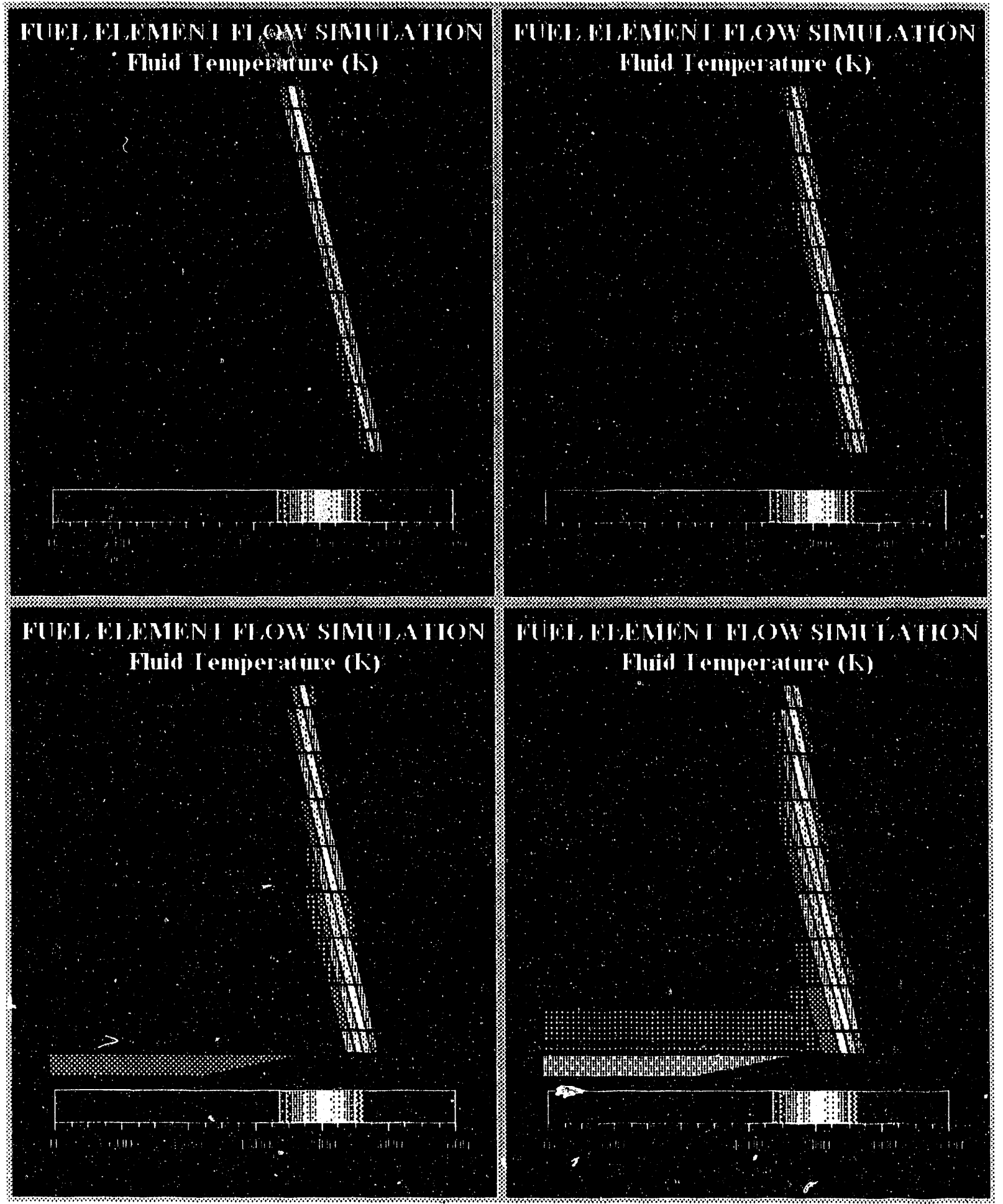

Figure 74. Coolant Temperature Color Snapshots at $0,5,10$, and $20 \mathrm{~s}$ 


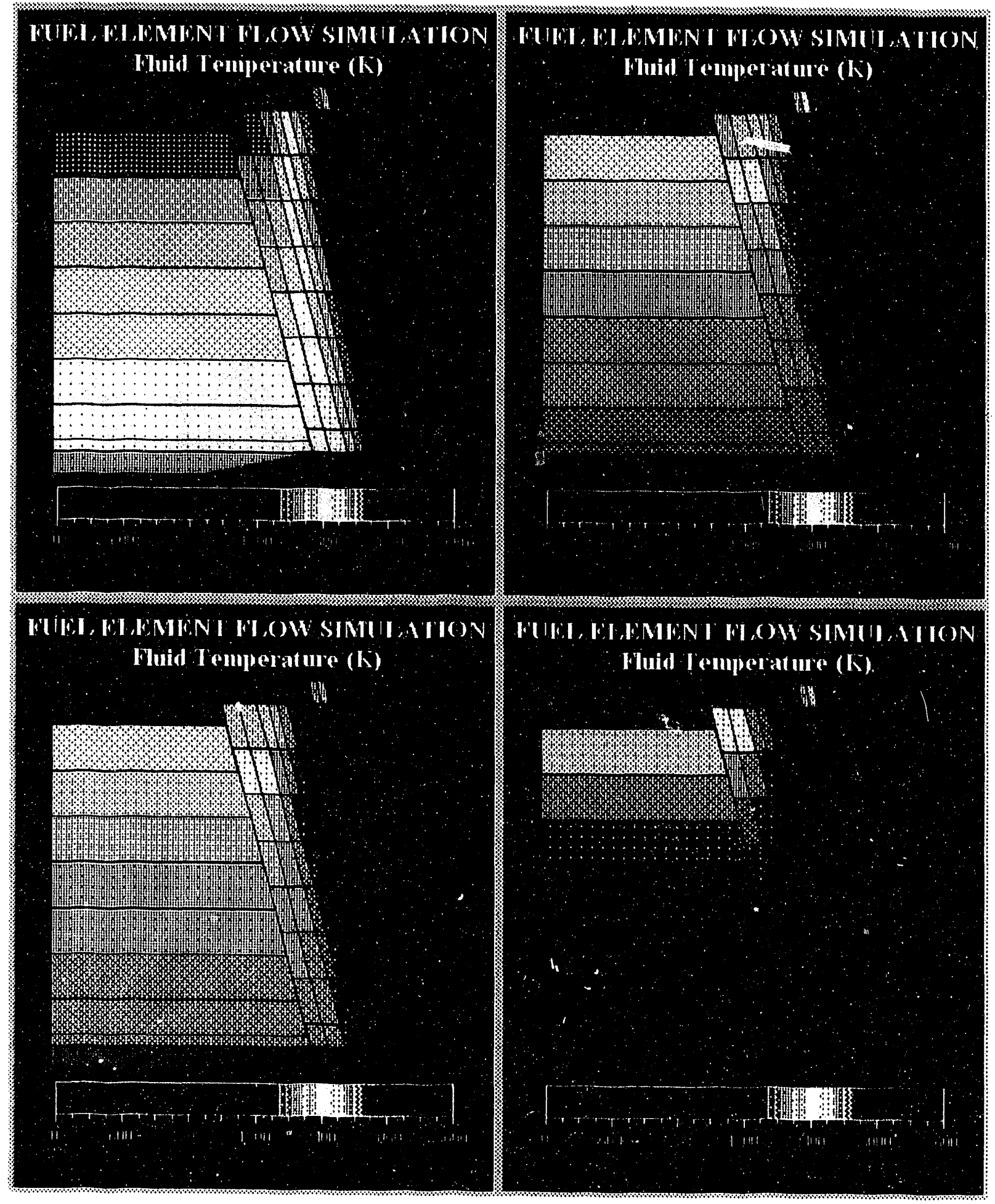

Figure 75. Coolant Temperature Color Snapshots at 60.7, 64.4, 79.8, and 84.1 s (Pulse Cooling) 


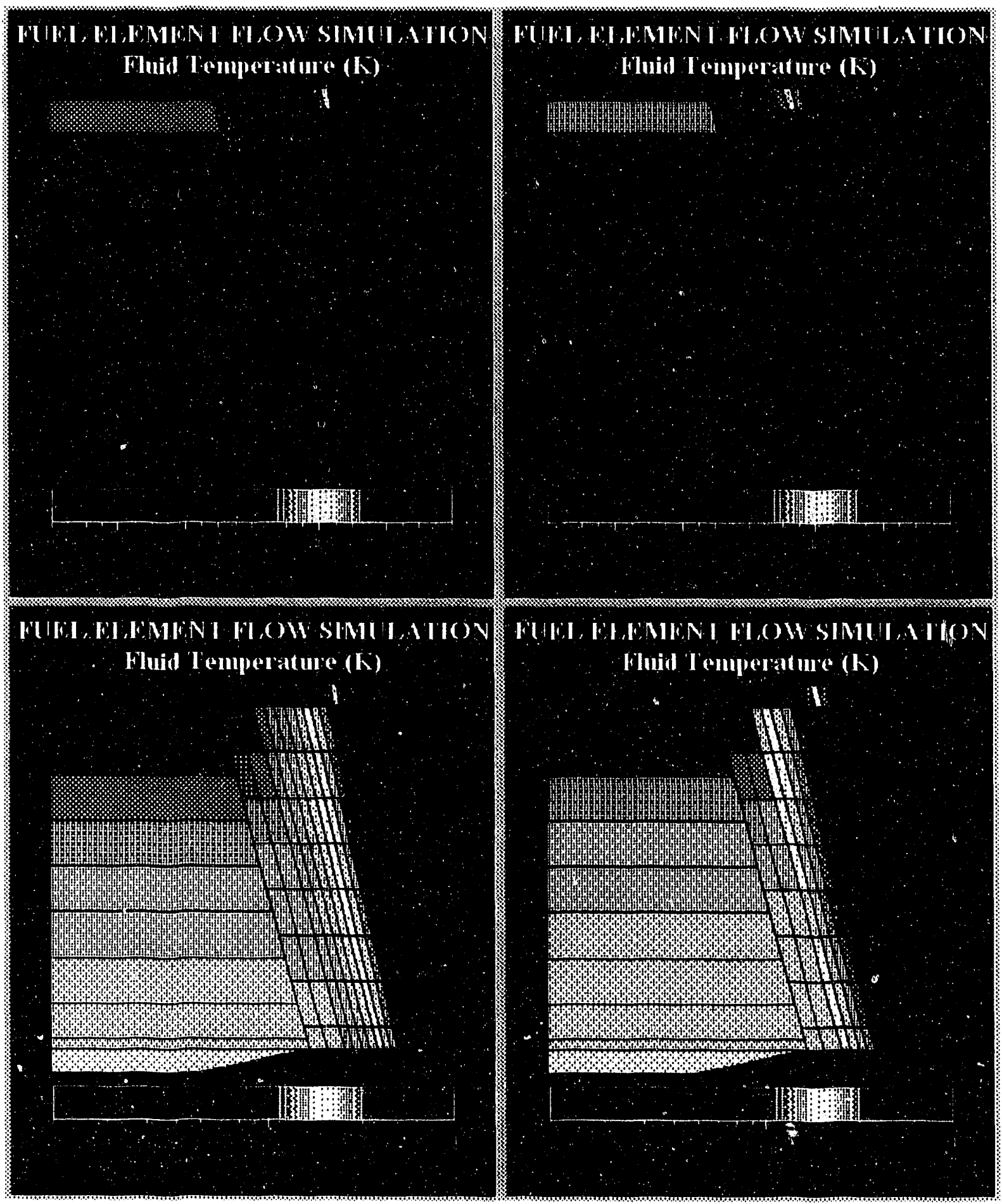

Figure 76. Coolant Temperature Color Snapshots at 171.1 and $174.9 \mathrm{~s}$ (linear and logarithmic scales, Pulse Cooling) 


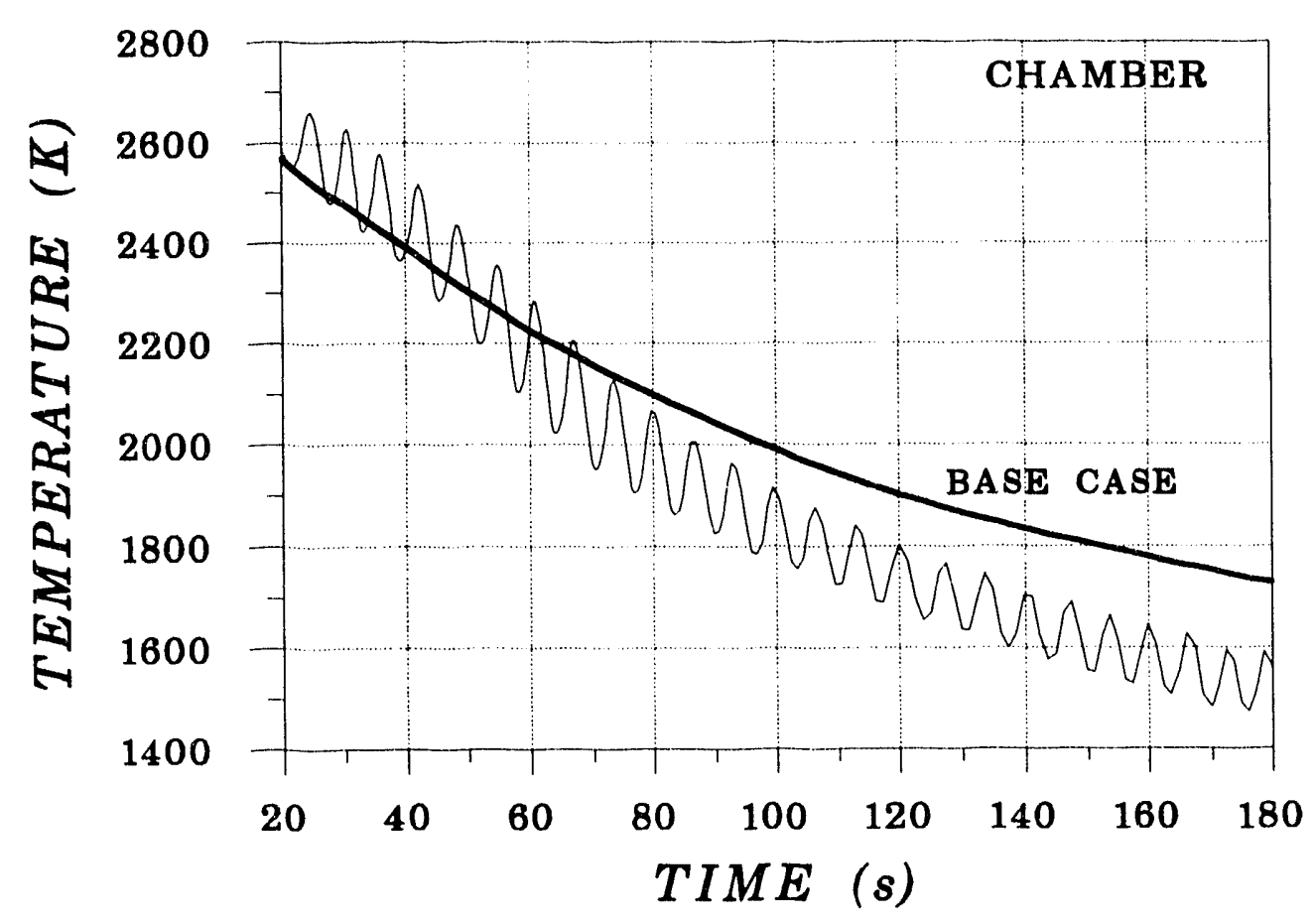

Figure 77. Chamber Temperature During Pulse Cooling

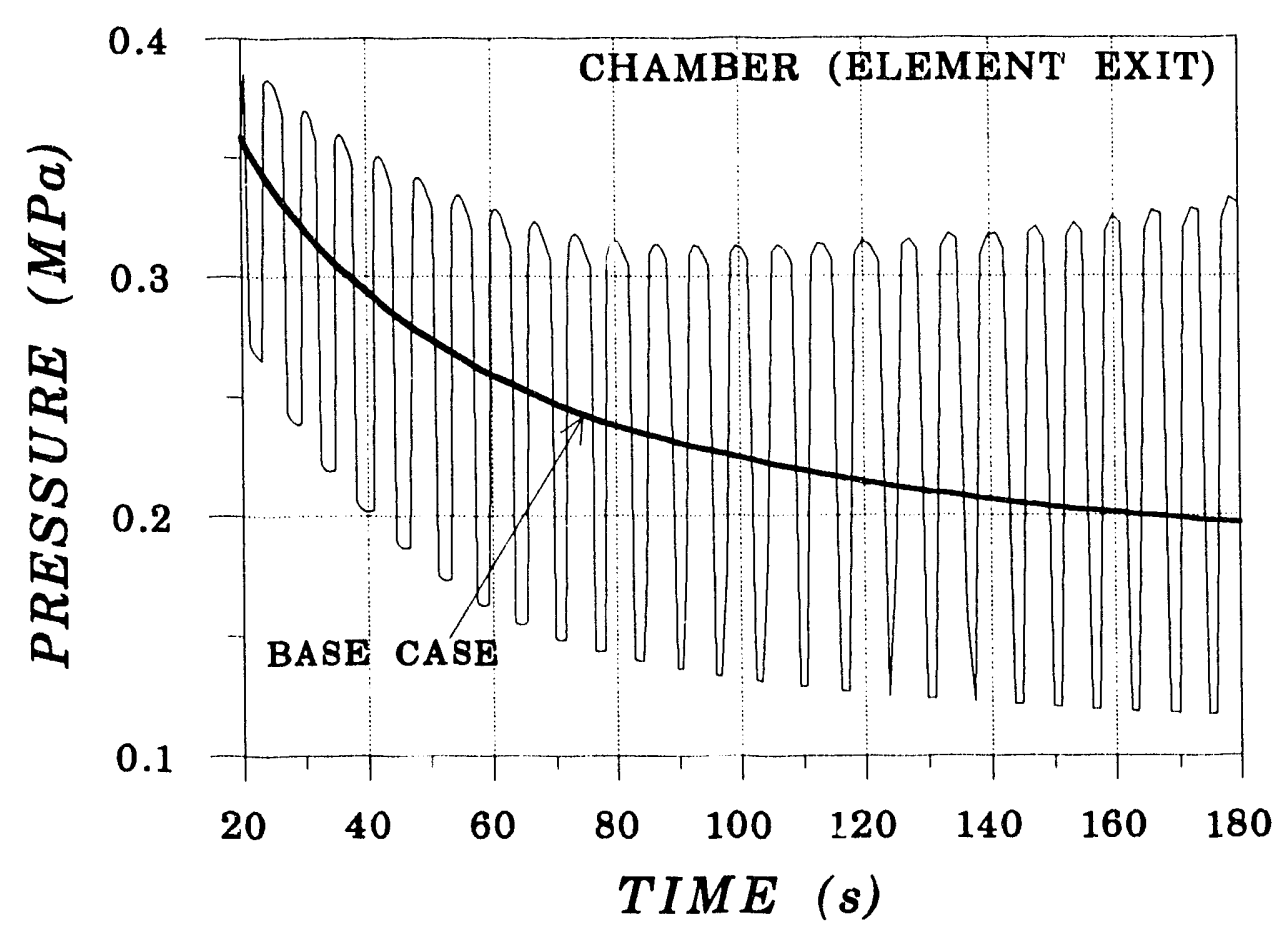

Figure 78. Chamber Pressure During Pulse Cooling 


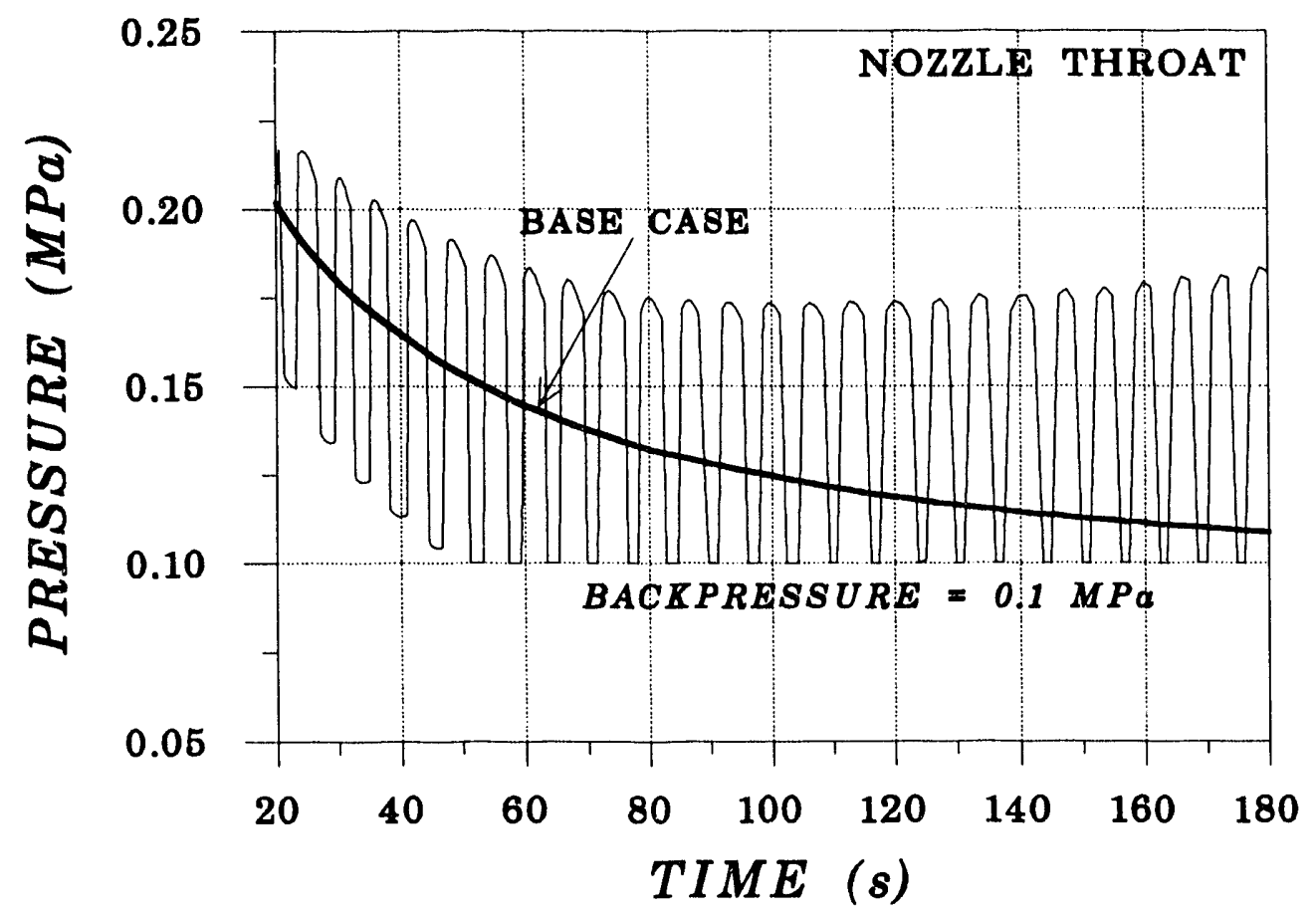

Figure 79. Pressure at the Nozzle Throat During Pulse Cooling

page -- 86 


\subsection{Summary, Observations, and Conclusions}

The particle bed reactor is an advanced nuclear reactor concept with tremendous potential for space propulsion applications. The realization of this potential requires a clear understanding of the fluid flow and heat transfer mechanisms governing its performance. To help acquire this understanding, parametric calculations were performed, using the SAFSIM computer program, to address some of the issues associated with operation of a particle bed fuel element. SAFSIM provides the quick and inexpensive calculational capability appropriate for parametric analysis of conceptual flow systems. This section provides a brief summary of the parametric calculations along with some comments and observations regarding the results. (Comments and observations are presented in italicized print.)

The initial objective of the SAFSIM calculations was to provide estimates of coolant requirements during decay heat removal for a proposed ground-based test facility. To perform such calculations required numerous modeling assumptions that strongly affect the fuel element performance. Therefore, many parametric calculations were performed to address the sensitivity of the results to these assumption. These parametric calculations contribute significantly to the understanding of fuel element performance and aid in the interpretation of the results.

To provide a simple tutorial on gas flow systems, the issue of stability in parallel heated channels was investigated first. A simple two-channel flow system was simulated. The discussion of results emphasizes three important points: (1) flow stability and flow maldistribution are related phenomena, (2) flow maldistributions in a fuel element are as much of a concern as flow instabilities, and (3) the flow instability/maldistribution problem is not particular to particle bed systems but instead is a phenomena common to any and all gas flow systems with heat addition. It is probably inappropriate to refer to flow maldistribution and instability as problems. Rather, they should be viewed as physics-based limitations that can be accounted for in the design and operation of the fuel element once they are characterized.

A set of steady-state calculations was performed next to investigate the flow maldistributions that occur during reduced thrust (power) operation. The cold frit axial resistance profile was tailored to provide an axially-uniform particle centerpoint temperature profile at the exit of the bed at full power. This tailoring results in optimum use of coolant at full power. Operation at reduced power results in a nonuniform temperature profile due to the nonlinear dependence of flow resistance on flow rate. Tailoring the resistance profile at full power may not be optimum when specific missions are considered. This should be addressed in mission and reactor design studies. For the nonoptimized conical fuel element design of these studies, the power can be reduced to about the $20 \%$ level with no degradation of element performance. Further reducions in power result in degraded performance due to flow maldistribution and instability constraints. The results 
of the parametric calculations indicate that simple fuel element d'sign changes may greatly improve performance at reduced power operation.

Sensitivity calculations were performed to investigate some of the many modeling assumptions, including transpiration drag losses, moderator heating, coolant dispersion conductivity enhancement, thermal radiation heat transfer from the bed to the cold frit, bed friction factor correlation, element entrance coolant temperature, coolant type, and element geometric design. Some of these assumptions were found to have a large impact on calculated results.

Transpiration drag in the inlet and outlet plenums was found to strongly influence flow performance. Not accounting for transpiration drag in the cold frit resistance profile tailoring results in an inefficient design with respect to coolant requirements and flow performance. The parametric calculations clearly indicate that further experimental and computational work is warranted to characterize the effects of transpiration drag for particle bed fuel elements. It appears possible that element designers can take advantage of transpiration drag effects to reduce flow maldistributions at low power levels.

The heating of the coolant in the inlet plenum by the moderator alters the flow distribution through the element. This heating must be accounted for in the element design, especially for decay power removal when the fraction of total power deposited in the moderator is large. Selection of moderator coolant paths and whether the flow enters at the top or bottom of the element can help reduce the coolant heating effects on flow maldistribution. Again, these effects can be used to advantage in the design of the fuel element.

The enhancement of coolant conductivity due to the dispersion effects of packed bed flow did not significantly change the particle centerpoint temperature. However, it was found to strongly affect the predicted cold frit temperature. If dimensional changes in the cold frit due to thermal expansion are found to affect the cold frit flow characteristics, the effect of conductivity enhancement would be large. Such dimensional change effects were not included in the SAFSIM input models due to lack of supporting data. Possible expansion effects should be explored by characterizing the cold frit flow resistance as a function of both flow rate and temperature. If the effects of expansion are found to be large, the enhancement of coolant conductivity should also be thoroughly investigated for the conditions of a particle bed clement.

Thermal radiation heat transfer from the bed to the cold frit, along with the choice of correlation for the bed friction factor, were found to be insignificant with respect to flow performance. The temperatures were too low at the bed entrance for significant thermal radiation heat transfer and the element pressure drop was dominated by the high resistance cold frit (by design).

A change in the temperature of the coolant at the entrance to the fuel element was found to affect the calculated flow distribution through the element. This is because coolant temperature affects viscosity which in turn affects fluw resistance. Changing page --88 
values of inlet temperature during a transient could therefore impact the peak fuel temperatures. The reactor coolant paths should be designed to minimize such changes whenever possible. Or, it may be possibie to use this effect to offset other phenomena affecting flow maldistribution.

Switching from hydrogen to helium coolant was found to result in small changes in the flow distribution through the element at reduced power. The changes are small enough that they should only be reconsidered after optimized fuel element designs have been created.

Employing a cylindrical instead of a conical element design had a large influence on the predicted flow distributions through the element. In fact, the flow distributions of the two designs were completely reversed. As power was decreased, flow shifted toward the bottom of the element for the conical design. But, flow shifted toward the top of the element for the cylindrical design. This disparity in flow performance indicates than an optimum geometry design exists that will minimize or even eliminate flow maldistributions at all power levels. Significant effort should be focused on finding such a design.

The sensitivity calculations indicate that many options are available to the fuel element designer to enhance flow performance at reduced power. For example, increasing the cold frit global resistance reduces flow maldistribution and instability at the expense of increased system pressure drop. Also, changing the inlet plenum gap width influences the transpiration drag pressure losses which in turn affects the flow distribution response. Table 7 summarizes the possible design features that can be changed, along with the factors influenced by that change, to achieve an optimized fuel element design.

Transient calculations were performed to study the fuel element performance during decay heat removal. The flow rate required to prevent excessive fuel temperatures or flow instability was found to be much larger than the ideal flow rate. The ideal flow rate is that flow that would maintain a constant exit coolant temperature if no flow maldistribution occurred. Therefore, estimates of coolant requirements must consider the mass flow rate penalty imposed by flow maldistribution and possible instability. This emphasizes the need to achieve an optimized fuel element geometry. Significant improvements in the element performance appear possible.

Introduction of a local flow blockage may lead to unacceptable flow distributions with respect to fuel temperature. Fuel elements contain "built-in" geometric perturbations that can also lead to unacceptable flow distributions or instability at reduced power operation. Such built-in perturbations include nonuniform power profiles and transpiration drag pressure losses. A reduction in flow rate can initiate such an unacceptable flow redistribution. However, the flow redistribution does not occur instantaneously but instead requires several seconds to develop. Thus it appears that the fuel element can be operated within the unstable or unacceptable flow regime for a certain length of time during startup and shutdown operations. This is particularly significant for startup operations 
because it greatly reduces the impact of flow instability on the startup control algorithm. Thus avoidance of the unstable regime during startup may not be necessary because the reactor may not be in that regime long enough for a problem to develop. Further investigations are required at the reactor system level to address this issue.

Table 7. Summary of Possible Design Changes

\begin{tabular}{|l|l|}
\hline \multicolumn{1}{|c|}{ Design Feature } & \multicolumn{1}{c|}{ Primary Influences } \\
\hline outlet plenum taper & $\begin{array}{l}\text { (1) axial power shape } \\
\text { (2) outlet plenum dynamic pressure } \\
\text { (3) transpiration flow pressure losses }\end{array}$ \\
\hline inlet plenum taper & $\begin{array}{l}\text { (1) axial power shape } \\
\text { (2) inlet plenum dynamic pressure } \\
\text { (3) transpiration flow pressure losses }\end{array}$ \\
\hline outlet plenum diameter & $\begin{array}{l}\text { (1) outlet plenum dynamic pressure } \\
\text { (2) transpiration flow pressure losses } \\
\text { (3) fuel element exit Mach number }\end{array}$ \\
\hline inlet plenum gap width & (1) inlet plenum dynamic pressure \\
& (2) transpiration flow pressure losses \\
\hline moderator coolant paths & fuel element entrance coolant temperature \\
\hline cold frit global flow & (1) system pressure drop \\
resistance & (2) maldistribution response \\
& (3) instability regime \\
\hline cold frit local flow resistance & maldistribution response \\
(axial resistance profile) & \\
\hline
\end{tabular}

Acceptability maps were generated for the conical element design. These maps indicate the mass flux-power density operation regimes that are acceptable with respect to fuel temperature limits in addition to stability criteria. Comparison to stability maps for the conical element illustrate that a stable operation regime may be unacceptable with respect to fuel temperature. Both acceptability and stability maps should be generated for all fuel element designs (particle bed, prismatic, or other); such maps are applicable only for the particular design and should not be used as generic maps representative of a given fuel element technology.

Pulse cocling during the early stages of decay heat removal (the first few minutes after shutdown) requires more coolant compared to cooling based on the flow rate required to prevent unacceptable temperatures or flow instability. However, the flow rate during the peak of the flow pulse is large enough to greatly reduce the possibility of flow instability. It was also found that flow stability maps generated for steady-state conditions may not be representative of the element during off-normal transient events. For example, in the pulse cooling transient, each pulse leaves the fuel element with a temperature distribution that is less favorable with respect to flow redistribution. Thus, flow stability and 
acceptability maps are history dependent. Using such steady-state maps may not be appropriate for some off normal transient events.

The statements regarding the built-in geometry perturbations and the historydependent flow stability maps are applicable not only to particle bed elements but to any kind of fuel element, including prismatic fuel elements. Every element type should be designed to minimize these effects. Also, to say one type of element is better than another with respect to flow stability is inappropriate. Any given element design can be changed to improve or degrade it's performance. Thus it is only appropriate to compare point designs for given applications.

Based on the SAFSIM calculations presented in this document, the following general conclusions are offered.

1. Predicted results are strongly dependent on some of the modeling assumptions; thus additional experimental and multidimensional calculational work is warranted and needed.

2. Flow maldistribution and flow instability are phenomena common to all gas flow systems with heat addition and can be minimized by proper design of the system.

3. The assumed conical element design can be operated down to about the $20 \%$ power level with no degradation of performance.

4. The effect of transpiration drag on wall friction in the plenums is significant but can be adjusted by modifying the element geometry.

5. The geometry of the fuel element (cylindrical or conical) strongly influences the fuel element flow performance. The conical design is superior and additional improvements appear possible.

6. Flow maldistribution within the fuel element is as much a concern as flow instability at low power levels.

7. The flow rate penalty associated with flow maldistribution at reduced power must be accounted for in estimates of decay heat removal coolant requirements.

8. "Built-in" geometric element perturbations exist in all element designs and affect the flow maldistribution and instability response. Element designers should strive to minimize such perturbations or make them self compensating.

9. Acceptability maps indicate the operation regimes that are prohibited not only by stability considerations but also by fuel temperature limit considerations.

10. Flow instability and maldistribution do not occur instantaneously but require several seconds to develop at decay power levels.

11. Flow stability and flow acceptability maps are history dependent and may not be appropriate for some off normal transient events. 
12. A 1-D network modeling approach is satisfactory for a wide range of flow and heat transfer problems of interest. Thus SAFSIM is a valuable engineering tool for performing quick and inexpensive parametric simulations addressing complex flow problems.

The work described in this document answers many questions regarding the fluid flow and heat transfer performance of a particle bed fuel element. However, as is common in parametric studies, many more questions have surfaced and remain to be answered. That is the nature of research. These analyses provide an indication of where additional work should be focused to enable realization of the very promising particle bed technology.

"Iron rusts from disuse, stagnant water loses its purity, and in cold weather becomes frozen; even so does inaction sap the vigors of the mind."

Leonardo Da Vinci 


\subsection{References}

1. Powel, J. R., and F. L. Horn, "High Power Density Reactors Based on Direct Cooled Particle Beds," in Space Nuclear Power Systems, M. S. El-Genk and M. D. Hoover, eds., (Malabar, Florida: Orbit Book Company, 1985).

2. Ludewig, Hans, James R. Powel, Otto W. Lazareth Jr., and Michael Todosow, "A Particle Bed Reactor Based NTP in the 112,500 N Thrust Class," in Proceedings of the 10 ${ }^{\text {h }}$ Symposium on Space Nuclear Power and Propulsion, CONF-930103, M. S. ElGenk and M. D. Hoover, eds., American Institute of Physics, New York, Conference Proceedings No. 271, 3: 1737 - 1742, January 1993.

3. Dobranich, Dean, "SAFSIM Input Manual -- A Computer Program for the Engineering Simulation of Flow Systems," Sandia National Laboratories, Albuquerque, NM, SAND92-0694, September 1992.

4. Koenig, D. R., "Experience Gained from the Space Nuclear Rocket Program (ROVER)," Los Alamos National Laboratory, Los Alamos, NM, LA-10062-4, May 1986.

5. Dobranich, D., "Heat Transfer and Thermal Stress Analyses of the Multilayered Spherical Fuel Particles of a Particle Bed Space Nuclear Reactor," Sandia National Laboratories, Albuquerque, NM, SAND90-1032, March 1991.

6. Sheppard, Susan J. and John E. McAllister, Jr., "Pressure Drop Correlation for Blowing Conditions in a Cylindrical Geometry," in Proceedings of Nuclear Technologies for Space Exploration Conference, August 1992, NTSE92, 2: 549 - 558.

7. Petukhov, B. S., "Heat Transfer and Friction in Turbulent Pipe Flow with Variable Physical Properties," in Advances in Heat Transfer, Vol. 6, New York, Academic Press, 1970 , p. 504.

8. Achenbach, E., "Heat Transfer and Pressure Drop of Pebble Beds Up to High Reynolds Number," in Proceedings of Seventh International Heat Transfer Conference, Munchen, Federal Republic of Germany, pp. 3 - 8, 1982.

9. Vafai, K., "Convective Flow and Heat Transfer in Variable Porosity Media," in 」. Fluid Mech., Vol. 147, pp. 233 - 259, 1984.

10. Schotte, William, "Thermal Conductivity of Packed Beds," in A.I.Ch.E. Journal, Vol. 6, No. 1, pp.63 - 67, March 1960.

11. Tuddenham, Read Stapley, "Thermal Hydraulic Analysis of a Packed Bed Reactor Fuel Element," Masters These, Massachusetts Institute of Technology, May 1989. 
12. Walkao, N. and S. Kaguei, Heat and Mass Transfer in Packed Beds, Gordon and Breach Science Publishers, 1982.

13. Keepin, G. R., The Physics of Nuclear Kinetics, Addison Wesley Publishers, 1965.

14. Proposed ANS Standard Decay Energy Release Rates Following Shutdown of Uranium-Fueled Thermal Reactors, ANS-5.1, 1971.

15. Black, David L., "Laminar Flow Instability in Nuclear Rockets," in Proceedings of the $\underline{10}^{\text {th }}$ Symposium on Space Nuclear Power and Propulsion, CONF-930103, M. S. ElGenk and M. D. Hoover, eds., American Institute of Physics, New York, Conference Proceedings No. 271, 3: 1535 - 1540, January 1993.

16. Witter, Jonathan K., David D. Lanning, and John E. Meyer, "Flow Stability Analysis of a Particle Bed Reactor Fuel Elernent," in Proceedings of the 10 hymposium on Space Nuclear Power and Propulsion, CONF-930103, M. S. El-Genk and M. D. Hoover, eds., American Institute of Physics, New York, Conference Proceedings No. 271, 3: 1541 - 1546, January 1993.

17. Ergun, S., "Fluid Flow Through Packed Columns," in Chem. Eng. Progress, Vol. 48, No. 2, pp. 89 - 94, 1952.

18. M. nnald, I. F., M. S. El-Sayed, K. Mow, and F. A. L. Dullien, "Flow through Por: 15 Media - the Ergun Equation Revisited," in Ind. Eng. Chem. Fundam., Vol. 18, No. 3, pp. 199 - 208, 1979.

19. Suo-Anttila, Ahti, "F2D: A Two Dimensional Compressible Gas Flow Code," in Proceedings of the 10 ${ }^{\text {th }}$ Symposium on Space Nuclear Power and Propulsion, CONF930103, M. S. El-Genk and M. D. Hoover, eds., American Institute of Physics, New York, Conference Proceedings No. 271, 3: 1673 - 1682, January 1993.

20. Beck, David F., et al., "Test Facilities for Evaluating Nuclear Thermal Propulsion Systems," in Proceedings of the 10 ${ }^{\text {w }}$ Symposium on Space Nuclear Power and Propulsion, CONF-930103, M. S. El-Genk and M. D. Hoover, eds., American Institute of Physics, New York, Conference Proceedings No. 271, 2: 1139 - 1148, January 1993.

page -- 94 


\section{Appendix A -- Coolant Properties}

\section{Para Hydrogen}

$$
\begin{gathered}
R=4124.2 \\
\mu=1.8541 \cdot 10^{-7} T^{0.68} \\
c_{p}=1.6274 \cdot 10^{4}-6.2496 T+6.8411 \cdot 10^{-3} T^{2}-1.8753 \cdot 10^{-6} T^{3} \quad \text { for } T<1500 \mathrm{~K} \\
c_{p}=-6.2935 \cdot 10^{3}+34.41 T-1.8140 \cdot 10^{-2} T^{2}+3.3939 \cdot 10^{-6} T^{3} \quad \text { for } T \geq 1500 \mathrm{~K} \\
k=6.2265 \cdot 10^{-2}+6.8021 \cdot 10^{-4} T-4.3262 \cdot 10^{-7} T^{2}+1.3360 \cdot 10^{-10} T^{3}
\end{gathered}
$$

\section{$\underline{\underline{\text { Helium }}}^{+}$}

$$
\begin{gathered}
R=2073.0 \\
\mu=4.459 \cdot 10^{-7} T^{0.666} \\
c_{p}=5192.6 \\
k=3.722 \cdot 10^{-2}+3.896 \cdot 10^{-4} T-7.450 \cdot 10^{-8} T^{2}+1.290 \cdot 10^{-11} T^{3}
\end{gathered}
$$

where

$R$ is the gas constant $(\mathrm{J} / \mathrm{kg}-\mathrm{K})$,

$T$ is the coolant temperature $(\mathrm{K})$,

$\mu$ is the dynamic viscosity (Pa-s),

$c_{p}$ is the constant pressure specific heat $(\mathrm{J} / \mathrm{kg}-\mathrm{K})$, and

$k$ is the coolant thermal conductivity $(\mathrm{W} / \mathrm{m}-\mathrm{K})$.

curve fits at 7 MPa based on NBS data: Roder, H. M., R. D. McCarty, and W. J. Hall, "Computer Programs for Thermodynamic and Transport Properties of Hydrogen

(Tabcode-II)," National Bureau of Standards, Tech. Note 625, October 1972.

$\downarrow$ Howel, John R., and Richard O. Buckius, Fundamentals of Engineering

Thermodynamics, McGraw-Hill Book Company, 1987. 


\section{Appendix B -- Execution-Time Statistics}

The following tables provide the execution times for selected SAFSIM calculations. All calculations were performed on a $25 \mathrm{MHertz} / 486$ personal computer. The input model contains 145 fluid mechanics (FM) finite elements (138 nodes) and 177 structure heat transfer finite elements $(211$ nodes), plus one nuclear reactor for reactor dynamics modeling.

Table B1. Steady-State Execution-Time Statistics

\begin{tabular}{|c|c|c|}
\hline Calculation & $\begin{array}{c}\text { Execution } \\
\text { Time (s) }\end{array}$ & $\begin{array}{c}\text { Execution Time per } \\
\text { FM Element (s) }\end{array}$ \\
\hline Thrust Ratio $=1.0$ & 17.1 & 0.1179 \\
\hline Thrust Ratio $=0.5$ & 22.2 & 0.1531 \\
\hline Thrust Ratio $=0.05$ & 59.4 & 0.4097 \\
\hline
\end{tabular}

Table B2. Transient Execution-Time Statistics

\begin{tabular}{|c|c|c|c|c|c|c|}
\hline Calculation & $\Delta \mathbf{t}_{\mathbf{s}}(\mathbf{s})$ & $\boldsymbol{\Delta} \mathbf{t}_{\mathbf{e}}(\mathbf{s})$ & $\mathbf{n}$ & $\begin{array}{c}\Delta \mathbf{t}_{\mathbf{e}} / \\
\boldsymbol{\Delta} \mathbf{t}_{\mathbf{s}}\end{array}$ & $\begin{array}{c}\Delta \mathbf{t}_{\mathbf{e}} / \# \mathbf{F M E} \\
(\mathbf{s})\end{array}$ & $\begin{array}{c}\Delta \mathbf{t}_{\mathbf{e}} / \# \mathbf{F M E} / \mathbf{n} \\
(\mathbf{s})\end{array}$ \\
\hline Base Case & 180 & 1727.5 & 3614 & 9.6 & 11.9 & 0.00330 \\
\hline Perturbation & 60 & 891.7 & 2196 & 14.9 & 6.1 & 0.00280 \\
\hline Pulse Cooling & 180 & 3359.9 & 7578 & 18.7 & 23.2 & 0.00306 \\
\hline
\end{tabular}

Table B2 Heading Definitions:

\begin{tabular}{cl}
\hline$\Delta \mathbf{t}_{\mathbf{s}}$ & simulation time \\
$\Delta \mathbf{t}_{\mathbf{e}}$ & execution time \\
$\mathbf{n}$ & number of system time steps \\
\#FME & number of fluid mechanics finite elements \\
\hline
\end{tabular}




\section{Appendix C -- Base Case Steady-State Output}

This appendix contains the printed output generated by SAFSIM for the steady-state full power base case. The output is divided into four sections: (1) fluid mechanics output, (2) structure heat transfer output, (3) reactor dynamics output, and (4) function and function-controlled variable output. SAFSIM allows the user to supply a name for each fluid mechanics finite element. The names are either of (cold frit), hf (hot frit), bed (fuel bed), or nozzle. The numbers following the $\mathrm{cf}, \mathrm{hf}$, and bed names indicate the radial region number and the axial level number. The inner-most radial region and the bottom axial level are numbered 1. Also, all the heat transfer structures are named for identification. All units are SI/mKs. Additional information concerning interpretation of the SAFSIM output can be found in Reference 3. Figure $\mathrm{Cl}$ provides the numbering scheme for the fluid mechanics finite elements.

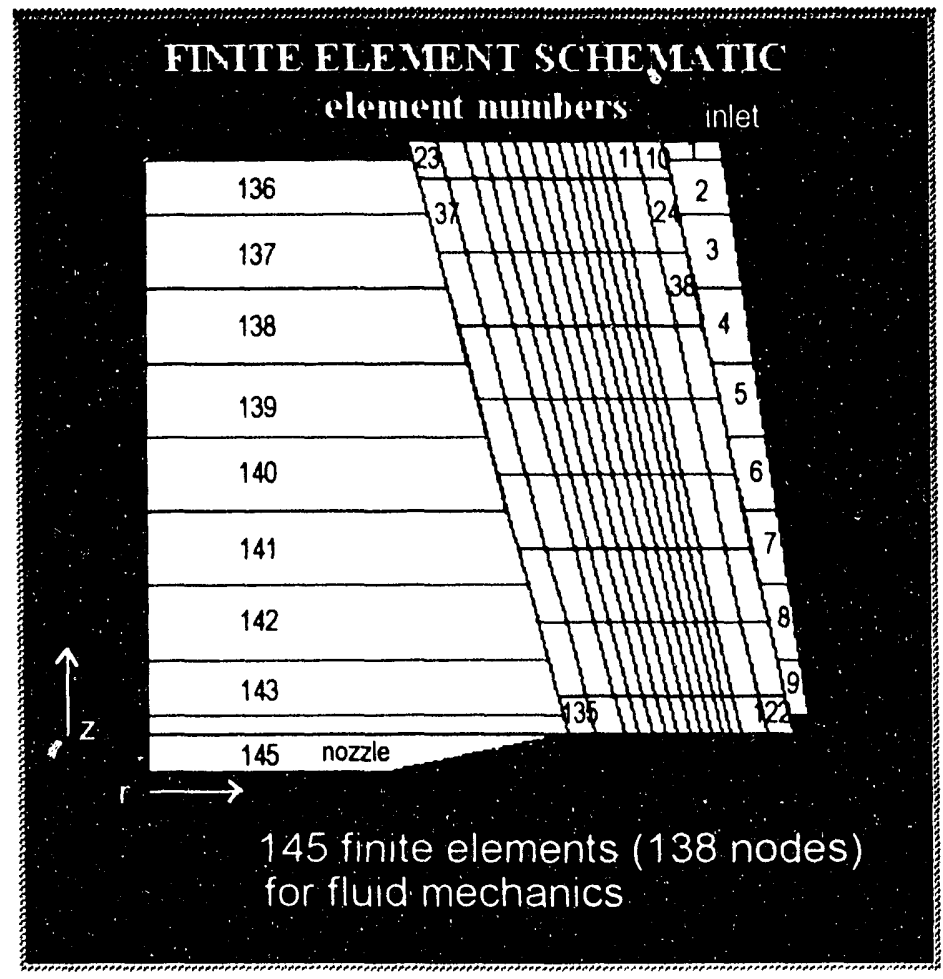

Figure C1. Fluid Mechanics Finite Element Schematic 
PROGRAM SAFSIM OUTPUT (FLUID MECHANICS):

SINGLE PBR CONICAL ELEMENT WITh 9 AXIAL LEVELS AND 14 RADIAL REGIONS

INVESTIGATE ELEMENT PERFORMANCE DURING DECAY COOLING

v.v.v.v.v.v.v.v.v.v.v.v.v.v.v.v.v.v.v.v.v.v.v.v.v.v.v.v.v.v.v.v.v.v.v.v.v.v.v.v.v.v.v.v.v.v.v.v.v.v.v.v.v.v.v.v.v.v.v.v.v.v.v.v. $\rightarrow \rightarrow$ SYSTEM TIME (s) $=0.00000$

TIME STEP

TIME STEP (s) $=5.0000 E-03<-$

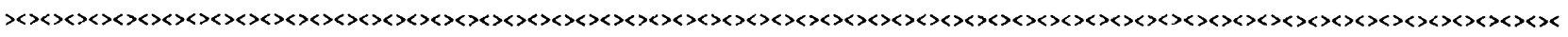

*. NETWORK * 1 NETWORK NAME: DETAILED PBR ELEMENT

STATIC SOLUTION

- TIME $(s)=0.00000$ SYSTEM TIME STEP $\quad 0$ SYSTEM TIME STEP $(s)=5.00008-03$

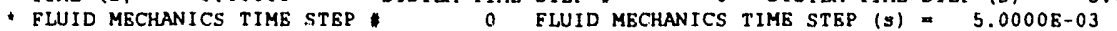

\begin{tabular}{|c|c|c|c|c|c|c|c|c|c|c|c|c|c|}
\hline 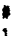 & \multirow{2}{*}{ NODE 1} & \multirow{2}{*}{$\begin{array}{c}\text { NODE } 2 \\
2\end{array}$} & \multicolumn{3}{|c|}{ NAME } & \multirow{2}{*}{$\begin{array}{c}P 1(\mathrm{~Pa}) \\
7.5718 \mathrm{~B}+06\end{array}$} & \multirow{2}{*}{$\begin{array}{c}\mathrm{P2}(\mathrm{Pa}) \\
7.5630 \mathrm{~B}+06\end{array}$} & \multirow{2}{*}{$\begin{array}{l}P 2-P 1 \quad(P a) \\
-8.3976 E+03\end{array}$} & & $\mathrm{~T} 2 \quad(\mathrm{~K})$ & $T 2-T 1 \quad(K)$ & kg/cub.m) & D2 (kg/cub.m) \\
\hline 1 & & & (IP, & & & & & & 200.000 & 200.691 & 0.691 & $9.1793 \mathrm{E}+00$ & $9.1376 \mathrm{E}+00$ \\
\hline 2 & 2 & 17 & (IP, & 8 & & $7.56305+06$ & $7.5375 E+06$ & $-2.5505 E+04$ & 200.691 & 202.833 & 2.142 & $9.1376 \mathrm{E}+00$ & $9.0106 \mathrm{~B}+00$ \\
\hline 3 & 17 & 32 & (IP, & 7 & & $7.5375 E+06$ & $7.5040 E+06$ & $-3.3503 E+04$ & 202.833 & 205.913 & 3.080 & $9.0106 \mathrm{E}+00$ & $8.83645+00$ \\
\hline 4 & 32 & 47 & (IP) & 6 & & $7.5040 \mathrm{~B}+06$ & $7.4707 E+06$ & $-3.3360 \mathrm{~B}+04$ & 205.913 & 209.421 & 3.508 & $8.8364 E+00$ & $8.6497 \mathrm{E}+00$ \\
\hline 5 & 47 & 62 & (IP, & 5 & & $7.4707 \mathrm{E}+06$ & $7.4385 E+06$ & $-3.2190 \mathrm{E}+04$ & 209.421 & 213.531 & 4.110 & $8.6497 \mathrm{~B}+00$ & $8.4467 E+00$ \\
\hline 6 & 62 & 77 & (IP, & 4 & & $7.43855+06$ & $7.40905+06$ & $-2.9467 E+04$ & 213.531 & 218.587 & 5.056 & $8.4467 E+00$ & $8.2186 \mathrm{E}+00$ \\
\hline 7 & 77 & 92 & (IP, & 3 & & $7.4090 \mathrm{E}+06$ & $7.3848 E+06$ & $-2.4273 E+04$ & 218.587 & 225.341 & 6.755 & $8.2186 E+00$ & $7.9462 \mathrm{E}+00$ \\
\hline 8 & 92 & 107 & (IP, & 2 & & $7.3848 \mathrm{E}+06$ & $7.36888+06$ & $-1.5982 E+01$ & 225.341 & 236.892 & 11.551 & $7.94625+00$ & $7.54238+00$ \\
\hline 9 & 107 & 122 & (IP, & 1 & & $7.3688 \mathrm{E}+06$ & $7.3667 \mathrm{~B}+06$ & $-2.0838 \mathrm{E}+03$ & 236.892 & 258.468 & 21.575 & $7.54238+00$ & $6.9108 \mathrm{E}+00$ \\
\hline 10 & 2 & 3 & $C F$, & 2, & 9 & $7.5630 \mathrm{E}+06$ & $7.3521 \mathrm{E}+06$ & $-2.1099 E+05$ & 200.691 & 229.095 & 28.404 & $9.1376 \mathrm{E}+00$ & $7.7814 \mathrm{E}+00$ \\
\hline 11 & 3 & 4 & CE, & 1, & 9 & $7.35215+06$ & $7.2144 E+06$ & $-1.3769 E+05$ & 229.095 & 275,358 & 46.263 & $7.78148+00$ & $635285+000$ \\
\hline 12 & 4 & 5 & BED, & 10 & 9 & $7.2114 \mathrm{E}+06$ & $7.2143 E+06$ & $-9.76118+01$ & 275.358 & 669.558 & 394.200 & $6.3528 B+00$ & $2.6126 B+00$ \\
\hline 13 & 5 & 6 & BED, & 9, & 9 & $7.2143 \mathrm{E}+06$ & $7.2135 B+06$ & $-7.7872 \mathrm{E}+02$ & 669.558 & 1146.674 & 477.116 & $2.6126 \mathrm{~B}+00$ & $1.5253 \mathrm{E}+00$ \\
\hline 14 & 6 & 7 & BED, & 8, & 9 & $7.2135 E+06$ & $7.2120 \mathrm{E}+06$ & $-1.4400 E+03$ & 1146.674 & 1524.347 & 377.673 & $1.5253 \mathrm{E}+00$ & $1.1472 B+00$ \\
\hline 15 & 7 & 8 & BED, & 7 , & 9 & $7.2120 \mathrm{~B}+06$ & $7.2099 \mathrm{E}+06$ & $-2.1474 \mathrm{E}+03$ & 1524.347 & 1864.709 & 340.362 & $1.1472 B+00$ & $9.3752 \mathrm{E}-01$ \\
\hline 16 & 8 & & & & & $20005+06$ & & & & & & & \\
\hline 17 & 9 & 10 & BED, & 0, & 9 & +06 & $7.2069 E+06$ & $-2.9546 \mathrm{E}+03$ & 1864.709 & 2158.782 & 294.073 & $9.3752 \mathrm{~B}-01$ & $8.0918 \mathrm{~B}-01$ \\
\hline 18 & 10 & 11 & BED, & & 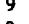 & $2069 B+06$ & $7.20315+06$ & $-3.8622 \mathrm{~B}+03$ & .782 & 686 & 253.904 & $8.0948 E-01$ & $90 \mathrm{E}-01$ \\
\hline 19 & 11 & 12 & $\begin{array}{l}\text { BED, } \\
\text { BED, }\end{array}$ & 4, & 9 & $.20318+06$ & $7.1982 \mathrm{E}+06$ & $-4.8753 E+03$ & 2412.686 & 2627.481 & 214.795 & 7.2 & $275-01$ \\
\hline 20 & 12 & 13 & $\begin{array}{l}\text { BED, } \\
\text { BED, }\end{array}$ & 3, & 9 & $.1982 \mathrm{E}+06$ & $7.1922 \mathrm{E}+06$ & $-6.0109 \mathrm{E}+03$ & 2627.481 & 2808.993 & 181.512 & $6.6427 \mathrm{E}-01$ & $6.2083 \mathrm{~B}-01$ \\
\hline & & & & 2, & 9 & $.1922 \mathrm{E}+06$ & $7.1850 \mathrm{E}+06$ & -7.24 & 2808.993 & 2959.911 & 150.918 & $38-01$ & BE-01 \\
\hline 21 & 13 & 14 & BED, & 1. & 9 & $7.1850 \mathrm{~B}+06$ & $7.1803 E+06$ & $-4.6456 \mathrm{E}+03$ & 2959.911 & 3055.599 & 95.688 & $5.8858 \mathrm{E}-01$ & $5.6978 \mathrm{E}-01$ \\
\hline 22 & 14 & ¿5 & HF, & 2, & 9 & $7.1803 B+06$ & $7.1796 \mathrm{E}+06$ & $-7.1652 \mathrm{~B}+02$ & 3055.599 & 3057.136 & 1.537 & $5.6978 \mathrm{~B}-01$ & $5.6944 \mathrm{~B}-01$ \\
\hline 23 & 15 & 16 & HF, & 1 , & 9 & $7.1796 \mathrm{~B}+06$ & $7.1788 \mathrm{E}+06$ & $-7.8708 E+02$ & 3057.136 & 3057.571 & 0.435 & $5.69446-01$ & $5.6930 \mathrm{E}-01$ \\
\hline 24 & 17 & 18 & CF, & 2, & 8 & $7.5375 E+06$ & $7.3460 \mathrm{E}+06$ & $-1.9152 \mathrm{E}+05$ & 202.833 & 230.822 & 27.989 & $9.0106 \mathrm{~B}+00$ & $7.7168 \mathrm{E}+00$ \\
\hline 25 & 18 & 19 & CF， & 1. & 8 & $7.3460 \mathrm{E}+06$ & $7.2041 \mathrm{E}+06$ & $-1.4189 E+05$ & 230.822 & 276.685 & 45.863 & $7.7168 \mathrm{E}+90$ & $6.3133 \mathrm{E}+00$ \\
\hline & & & & & & & & & & & & & \\
\hline $\begin{array}{l}\text { E) } \\
26\end{array}$ & DEE 1 & NODE 2 & & $M$ ME & & (Pa) & P2 (Pa) & $(\mathrm{Pa})$ & $\mathrm{T} \perp \quad(K)$ & T2 (K) & $\cdots$ & (b.m) & ub.ml \\
\hline 26 & 19 & 20 & $\mathrm{BED}$ & 10, & 8 & $.2041 E+06$ & $7.2040 \mathrm{~B}+06$ & $-9.2901 E+01$ & 276.685 & 655.775 & 379.090 & $6.3133 \mathrm{~B}+00$ & $2.6637 \mathrm{E}+00$ \\
\hline 27 & 20 & 21 & BED, & 9, & 8 & $7.2040 \mathrm{E}+06$ & $7.2033 \mathrm{E}+06$ & $-7.5208 \mathrm{~B}+02$ & 655.775 & 1123.902 & 468.127 & $2.6637 \mathrm{~B}+00$ & $1.55<0 \mathrm{E}+00$ \\
\hline 28 & 21 & 22 & BED, & 8. & 8 & $7.2033 \mathrm{E}+06$ & $7.20195+06$ & $-1.3967 E+03$ & 1123.902 & 1496.127 & 372.225 & $1.5540 \mathrm{E}+00$ & $1.1672 E+00$ \\
\hline 29 & 22 & 23 & $B E D$, & 7 , & 8 & $7.2019 E+06$ & $7.1998 \mathrm{E}+06$ & $-2.0830 E+03$ & 1496.127 & 1833.298 & 337.170 & $1.1672 \mathrm{E}+00$ & $9.5225 \mathrm{E}-01$ \\
\hline 30 & 23 & 24 & BED, & 6 , & 8 & $7.1998 E+06$ & $7.1969 E+06$ & $-2.8660 \mathrm{~B}+03$ & 1833.298 & 2126.584 & 293.286 & $9.5225 \mathrm{E}-01$ & $8.2059 \mathrm{E}-01$ \\
\hline & & & & & & & & & & & & & \\
\hline 31 & 24 & 25 & BED, & 5, & 8 & $8+06$ & $7.1932 \mathrm{E}+06$ & $-3.7480 \mathrm{~B}+03$ & 84 & 2382.055 & 255.471 & 8.2 & $0 E-01$ \\
\hline 32 & 25 & 26 & BED, & 4, & 8 & $7.1932 E+06$ & $7.1885 \mathrm{E}+06$ & $-4.73288+03$ & 2382.055 & 2600.018 & 217.963 & E- 01 & $8 \mathrm{BE}-01$ \\
\hline 33 & 26 & 27 & BED, & 3, & 8 & $7.1885 \mathrm{E}+06$ & $7.1826 \mathrm{E}+06$ & $-5.8338 \mathrm{E}+03$ & 2600.018 & 2785.409 & 185.391 & $6.7038 E-01$ & $6.2525 \mathrm{E}-01$ \\
\hline 34 & 27 & 28 & BED, & 2, & 8 & $7.18268+06$ & $7.1756 \mathrm{E}+06$ & $-7.01668+03$ & 2785.409 & 2940.175 & 154.767 & $6.2525 E-01$ & $5.9176 E-01$ \\
\hline 35 & 28 & 29 & $B E D$ & 1. & 8 & $7.1756 E+06$ & $7.1712 \mathrm{E}+06$ & $-4.37418+03$ & 2940.175 & 3038.082 & 97.907 & $5.9176 \mathrm{E}-01$ & $5.7234 \mathrm{E}-01$ \\
\hline 36 & & & $\mathrm{HF}$ & & & $1712 E+06$ & it 05 & & & & & & \\
\hline 37 & 30 & 31 & $\mathrm{HE}$, & 1 & 8 & +06 & $\begin{array}{l}5+06 \\
8+06\end{array}$ & -1.0 & 303 & 818 & 2.735 & 5. & -01 \\
\hline 38 & 32 & 33 & $C F$, & 2 & 7 & $7.5040 E+06$ & $\begin{array}{l}7.1698 E+06 \\
7.3275 E+06\end{array}$ & -7.70 & 304 & 730 & 4.912 & 1 & $9 E-01$ \\
\hline 39 & 33 & 34 & $\mathrm{CF}$ & 1, & 7 & $7.3275 E+06$ & $\begin{array}{l}7.3275 E+06 \\
7.1812 E+06\end{array}$ & $\begin{array}{l}-1.7650 E+05 \\
-1.4637 E+05\end{array}$ & 205.913 & 85 & 27.672 & 0 & 0 \\
\hline 40 & 34 & 35 & BED, & 10 & 7 & $7.1812 E+06$ & $\begin{array}{l}7.1812 \mathrm{E}+06 \\
7.1811 \mathrm{E}+06\end{array}$ & $\begin{array}{l}-1.4637 \mathrm{E}+0 \\
-8.6566 \mathrm{E}+0\end{array}$ & 233.585 & 279.165 & 45.581 & $7.6064 \mathrm{E}+00$ & $6.2373 E+00$ \\
\hline 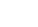 & & & & & & & $.1811 E+06$ & -8.6 & 279 & 641.262 & 362.097 & $6.2373 E+00$ & $2.7153 \mathrm{E}+00$ \\
\hline 41 & 35 & 36 & BED, & 9 , & 7 & $7.1811 \mathrm{E}+06$ & $7.1804 \mathrm{E}+06$ & $-7.1609 E+02$ & 262 & 1099.976 & 458.714 & $2.7153 \mathrm{E}+00$ & $8 E+00$ \\
\hline 42 & 36 & 37 & BED, & 8, & 7 & $7.1804 E+06$ & $7.1790 E+06$ & $25+03$ & 109 & .998 & 367.021 & +00 & $6 E+00$ \\
\hline 43 & 37 & 38 & BED, & 7 & 7 & $7.1790 \mathrm{E}+06$ & $7.1770 \mathrm{E}+06$ & $-1.9978 E+03$ & 1466.998 & 1801.542 & 334.544 & $1.1866 E+00$ & $9.6597 \mathrm{E}-01$ \\
\hline 44 & 38 & 39 & BED, & 6, & 7 & $7.1770 \mathrm{E}+06$ & $7.1743 \mathrm{E}+06$ & $-2.7494 E+03$ & 1801.542 & 2094.818 & 293.276 & $9.6597 \mathrm{E}-01$ & $8.3041 \mathrm{E}-01$ \\
\hline 45 & 39 & 40 & $B E D$ & 5 & 7 & $7.1743 E+06$ & $7.1707 E+06$ & $-3.5971 \mathrm{E}+03$ & 2094.818 & 2352.805 & 257.987 & $8.3041 \mathrm{E}-01$ & $7.3899 \mathrm{E}-01$ \\
\hline 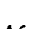 & & & & & & & & & & & & & \\
\hline 46 & 40 & 41 & BED, & 4 & 7 & $7.1707 E+06$ & $7.16618+06$ & -4.54 & & 0 & 05 & -01 & $E-01$ \\
\hline 47 & 41 & 42 & BED, & 3. & 7 & 7.16 & $5 E+06$ & $9 E+03$ & 010 & 366 & 190.357 & $E-01$ & $E-01$ \\
\hline 48 & 42 & 43 & BED, & 2, & 7 & $7.1605 E+06$ & $7.1538 \mathrm{E}+06$ & $-6.7128 \mathrm{E}+03$ & 2765.366 & 2924.944 & 159.578 & $6.2785 E-01$ & $5.9304 \mathrm{E}-01$ \\
\hline 49 & 43 & 44 & BED, & 1. & 7 & $7.1538 \mathrm{E}+06$ & $7.1498 E+06$ & $-4.0239 E+03$ & 2924.944 & 3025.461 & 100.517 & $5.9304 E-01$ & $5.7301 \mathrm{E}-01$ \\
\hline 50 & 44 & 45 & $H F$, & 2, & 7 & $7.1498 \mathrm{E}+06$ & $7.1491 E+06$ & $-6.8631 E+02$ & 3025.461 & 3029.258 & 3.797 & $5.7301 \mathrm{E}-01$ & $5.7224 \mathrm{E}-01$ \\
\hline ca & & & & & & & & & & & & & \\
\hline E. & NODE 1 & NODE 2 & & LME & & P1 (Pa) & $\mathrm{P2}$ (Pa) & $\mathrm{P} 2-\mathrm{P} 1 \quad \mathrm{~Pa})$ & (K) & (K) & T1 (K) & o.m) & ub.m) \\
\hline $\begin{array}{l}51 \\
52\end{array}$ & 45 & 46 & $\mathrm{HF}$, & 1. & 7 & $7.1491 E+06$ & $7.1484 E+06$ & $-7.5124 E+02$ & 3029.258 & 3037.576 & 8.318 & & $1 E-01$ \\
\hline 52 & 47 & 48 & $C F$ & 2, & 6 & $7.4707 \mathrm{E}+06$ & $7.3059 E+06$ & $\cdot 1.6477 \mathrm{~B}+05$ & 209.421 & 237.212 & 27.791 & $8.6497 \mathrm{E}+00$ & $7.4679 \mathrm{E}+00$ \\
\hline 53 & 48 & 49 & $\mathrm{CF}$, & 1, & 6 & $7.3059 E+06$ & $7.1539 E+06$ & $-1.5200 E+05$ & 237.212 & 281.728 & 44.516 & $7.4679 \mathrm{E}+00$ & $6.1571 \mathrm{E}+00$ \\
\hline 54 & 49 & 50 & BED, & 10, & 6 & $7.1539 \mathrm{E}+06$ & $7.1538 \mathrm{E}+06$ & $-8.0853 E+01$ & 281.728 & 626.297 & 344.569 & $6.1571 E+00$ & $2.7696 \mathrm{E}+00$ \\
\hline 55 & 50 & 51 & BED, & 9. & 6 & $7.1538 \mathrm{E}+06$ & $7.1531 E+06$ & $-6.8235 E+02$ & 626.297 & 1074.141 & 447.844 & $2.7696 \mathrm{E}+00$ & $1.6147 \mathrm{E}+00$ \\
\hline & & & & & & & & & & & & & \\
\hline 56 & 51 & $\$ 2$ & BED, & 8 & 6 & $7.1531 \mathrm{E}+06$ & $7.1519 E+06$ & -1.28 & & & 360.873 & 00 & $4 E+00$ \\
\hline 57 & 52 & 53 & BED, & 7 & 6 & $7.1519 E+06$ & $7.1499 E+06$ & $-1.9185 E+03$ & 1435.015 & 1765.953 & 330.939 & 1. $2084 \mathrm{E}+00$ & $9.8172 \mathrm{E}-01$ \\
\hline 58 & 53 & 54 & BED, & 6 , & 6 & $7.14998+06$ & $7.14738+06$ & $-2.6405 E+03$ & 1765.953 & 2058.220 & 292.267 & $9.8172 E-01$ & $8.4200 \mathrm{E}-01$ \\
\hline 59 & 54 & $5 s$ & BED, & 5, & 6 & $7.1473 E+06$ & $7.1438 \mathrm{E}+06$ & $-3.4564 E+03$ & 2058.220 & 2317.914 & 259.693 & $8.4200 E-01$ & $7.4730 E-01$ \\
\hline 60 & 55 & 56 & BED, & 4, & 6 & $7.1438 E+06$ & $7.1395 E+06$ & $-4 \cdot 3683 E+03$ & 2317.914 & 2543.889 & 225.975 & $7.4730 \mathrm{E}-01$ & $6.8050 \mathrm{E}-01$ \\
\hline
\end{tabular}

page -- 98 


\begin{tabular}{|c|c|c|c|c|c|c|}
\hline 61 & 56 & 57 & BED, & 3,6 & $7.1395 E+06$ & $7.1341 \mathrm{E}+06$ \\
\hline 62 & 57 & 58 & BED, & 2,6 & 7. $1341 \mathrm{~B}+06$ & $7.1277 \mathrm{~B}+06$ \\
\hline 63 & 58 & 59 & BED, & 1,6 & $7.12775+06$ & $7.1240 \mathrm{E}+06$ \\
\hline 64 & 59 & 60 & $\mathrm{HE}$, & 2,6 & $7.1240 \mathrm{E}+06$ & $7.1233 \mathrm{E} \uparrow 06$ \\
\hline 65 & 60 & 61 & $\mathrm{HF}$, & 1,6 & $7.1233 \mathrm{E}+06$ & $7.1225 \mathrm{E}+06$ \\
\hline : & & & & & & \\
\hline 66 & 62 & 63 & CE, & 2,5 & $7.4385 \mathrm{E}+06$ & $7.2822 \mathrm{E}+06$ \\
\hline 67 & 63 & 64 & $C F$, & 1,5 & 7. $2822 \mathrm{E}+06$ & $7.1258 \mathrm{~B}+06$ \\
\hline 68 & 64 & 65 & BED, & 10,5 & $7.1258 \mathrm{E}+06$ & $7.12578+06$ \\
\hline 69 & 65 & 66 & BED, & 9,5 & $7.1257 \mathrm{E}+06$ & $7.1251 \mathrm{E}+06$ \\
\hline 70 & 66 & 67 & BED, & 8,5 & $7.1251 \mathrm{E}+06$ & $7.1238 \mathrm{E}+06$ \\
\hline : & & & & & & \\
\hline 71 & 67 & 68 & BED, & 7,5 & $7.1238 \mathrm{E}+06$ & $7.1220 \mathrm{E}+06$ \\
\hline 72 & 68 & 69 & BED, & 6,5 & $7.1220 \mathrm{E}+06$ & $7.1195 E+06$ \\
\hline 73 & 69 & 70 & BED, & 5,5 & $7.1195 \mathrm{E}+06$ & $7.1161 E+06$ \\
\hline 74 & 70 & 71 & BED, & 4,5 & $7.1161 \mathrm{E}+06$ & $7.1119 \mathrm{E}+06$ \\
\hline 75 & 71 & 72 & BED, & 3,5 & $7.1119 \mathrm{E}+06$ & $7.1068 \mathrm{E}+06$ \\
\hline : & & & & & & \\
\hline E* 1 & NODE1 $N$ & NODE2 & NA & & P1 (Pa) & P2 (Pa) \\
\hline 76 & 72 & 73 & BED, & 2,5 & $7.1068 \mathrm{E}+06$ & $7.1006 \mathrm{E}+06$ \\
\hline 77 & 73 & 74 & BED, & 1,5 & $7.1006 \mathrm{E}+06$ & $7.0972 \mathrm{E}+06$ \\
\hline 78 & 74 & 75 & $\mathrm{HE}$, & 2,5 & $7.0972 \mathrm{E}+06$ & $7.0966 \mathrm{~B}+06$ \\
\hline 79 & 75 & 76 & $H E$, & 1,5 & $7.0966 \mathrm{~B}+06$ & $7.0959 \mathrm{E}+06$ \\
\hline 80 & 77 & 78 & CF, & 2,4 & $7.4090 \mathrm{E}+06$ & $7.2611 \mathrm{E}+06$ \\
\hline : & & & & & & \\
\hline 81 & 78 & 79 & CF, & 1,4 & $7.2611 \mathrm{E}+06$ & $7.0988 E+06$ \\
\hline 82 & 79 & 80 & BED, & $1.0,4$ & $7.0988 E+06$ & $7.0988 \mathrm{E}+06$ \\
\hline 83 & 80 & 81 & BED, & 9,4 & $7.09888 \mathrm{~B}+06$ & $7.0982 \mathrm{E}+06$ \\
\hline 84 & 81 & 82 & BED, & 8,9 & $7.0982 \mathrm{E}+06$ & $7.0970 \mathrm{E}+06$ \\
\hline 85 & 82 & 83 & BED, & 7,4 & $7.0970 \mathrm{E}+06$ & $7.0952 \mathrm{E}+06$ \\
\hline : & & & & & & \\
\hline 86 & 83 & 84 & BED, & 6,4 & $.0952 \mathrm{E}+06$ & $7.0928 \mathrm{E}+06$ \\
\hline 87 & 84 & 85 & BED, & 5,4 & $7.0928 \mathrm{E}+06$ & $7.0896 \mathrm{E}+06$ \\
\hline 88 & 85 & 86 & BED, & 4,4 & $.0896 \mathrm{E}+06$ & $7.0856 E+06$ \\
\hline 89 & 86 & 87 & BED, & 3,4 & $7.08568+06$ & $7.0806 \mathrm{E}+06$ \\
\hline 90 & 87 & 88 & BED, & 2,4 & $7.0806 \mathrm{E}+06$ & $7.0747 E+06$ \\
\hline$:$ & & & & & & \\
\hline 91 & 88 & 89 & BED, & 1,4 & $.0747 E+06$ & $7.07168+06$ \\
\hline 92 & 89 & 90 & $\mathrm{HF}$, & 2,4 & $7.0716 \mathrm{E}+06$ & $7.0710 \mathrm{E}+06$ \\
\hline 93 & 90 & 91 & $\mathrm{HF}$, & 1,4 & $.0710 E+06$ & $7.0703 E+06$ \\
\hline 94 & 92 & 93 & CE, & 2,3 & $7.3848 \mathrm{E}+06$ & $7.2415 E+06$ \\
\hline 95 & 93 & 94 & CF, & 1,3 & $7.2415 E+06$ & $7.0738 \mathrm{E}+06$ \\
\hline 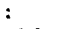 & & & & & & \\
\hline 96 & 94 & 95 & BED, & 10,3 & $.0738 \mathrm{E}+06$ & $7.0737 \mathrm{E}+06$ \\
\hline 97 & 95 & 96 & BED, & 9,3 & $.0737 E+06$ & $7.0731 \mathrm{E}+06$ \\
\hline 98 & 96 & 97 & BED, & 8,3 & $.0731 E+06$ & $7.0720 \mathrm{E}+06$ \\
\hline 99 & 97 & 98 & BED, & 7,3 & $.0720 E+06$ & $7.0703 E+06$ \\
\hline 100 & 98 & 99 & BED, & 6,3 & $7.0703 E+06$ & $7.0680 \mathrm{E}+06$ \\
\hline${ }^{\circ}$ & & & & & & \\
\hline E* & ODE1 & NODE2 & & AME & P1 $(\mathrm{Pa})$ & P2 (Pa) \\
\hline 101 & 99 & 100 & BED, & 5,3 & $.0680 E+06$ & $7.0649 E+06$ \\
\hline 102 & 100 & 101 & BED, & 4,3 & $7.0649 \mathrm{E}+06$ & $7.0611 \mathrm{E}+0 \mathrm{E}$ \\
\hline 103 & 101 & 102 & $B E D$ & 3,3 & $.0611 E+06$ & $7.0563 E+06$ \\
\hline 104 & 102 & 103 & BED, & 2,3 & $7.0563 E+06$ & $7.0507 \mathrm{E}+06$ \\
\hline 105 & 103 & 104 & BED, & 1,3 & $7.0507 E+06$ & $7.0479 \mathrm{E}+06$ \\
\hline$:$ & & & & & & \\
\hline 106 & 104 & 105 & $\mathrm{HF}$, & 2,3 & $.0479 E+06$ & $7.0472 E+06$ \\
\hline 107 & 105 & 106 & $H F$, & 1,3 & $.0472 B+06$ & $7.0466 \mathrm{E}+06$ \\
\hline 108 & 107 & 108 & $\mathrm{CE}$, & 2,2 & $7.3688 E+06$ & $7.2273 E+06$ \\
\hline 109 & 108 & 109 & $C F$ & 1,2 & $7.2273 \mathrm{E}+06$ & $7.0511 \mathrm{E}+06$ \\
\hline 110 & 109 & 110 & BED, & 10,2 & $7.0511 \mathrm{E}+06$ & $7.0511 \mathrm{E}+06$ \\
\hline : & & & & & & \\
\hline 111 & 110 & 111 & BED, & 9,2 & $.0511 \mathrm{E}+06$ & $7.0505 E+06$ \\
\hline 112 & 111 & 12 & BED, & 8,2 & $0505 E+06$ & $7.0494 E+06$ \\
\hline 113 & 112 & 113 & BED, & 7,2 & $.0494 \mathrm{E}+06$ & $7.0478 E+06$ \\
\hline 114 & 113 & 114 & BED, & 6 & $7.0478 E+06$ & $7.0456 E+06$ \\
\hline 115 & 114 & 115 & BED, & 5,2 & $7.0456 \mathrm{E}+06$ & $7.0427 \mathrm{E}+06$ \\
\hline$:$ & & & & & & \\
\hline 116 & 115 & 116 & BED, & 4, & $7.0427 \mathrm{E}+06$ & $7.0390 \mathrm{E}+06$ \\
\hline 117 & 116 & 117 & BED, & 3, & $8+06$ & $18+06$ \\
\hline 118 & 117 & 118 & BED, & 2,2 & $7.0344 E+06$ & $7.0290 \mathrm{E}+06$ \\
\hline 119 & 118 & 119 & BED， & 1, & $7.0290 \mathrm{E}+06$ & $7.0265 E+06$ \\
\hline 120 & 119 & 120 & $\mathrm{HF}$, & 2,2 & $7.0265 E+06$ & $7.0258 E+06$ \\
\hline$:$ & & & & & & \\
\hline 121 & 120 & 121 & $\mathrm{HF}$, & 1, & $E+06$ & $7.0251 E+06$ \\
\hline 122 & 122 & 23 & $\mathrm{CE}$, & 2, & $8+06$ & $E+06$ \\
\hline 123 & 123 & 124 & $C F$, & 1,1 & $7.2215 E+06$ & $7.0357 E+06$ \\
\hline 124 & 124 & 125 & BED, & 10,1 & $7.0357 E+06$ & $7.0357 \varepsilon+06$ \\
\hline 125 & 125 & 126 & BED, & 9,1 & $7.0357 E+06$ & $7.0352 \mathrm{E}+06$ \\
\hline : & & & & & & \\
\hline E* & NODE 1 & NODE2 & & AME & $(\mathrm{Pa})$ & $(P a)$ \\
\hline 126 & 126 & 127 & $B E D$ & 8 & $.0352 E+06$ & $7.0341 E+06$ \\
\hline 127 & 127 & 128 & BED, & 7 & $7.0341 E+06$ & $7.0325 E+06$ \\
\hline 128 & 128 & 129 & BED, & 6, & $7.0325 E+06$ & $7.0303 E+06$ \\
\hline 129 & 129 & 130 & BED, & 5,1 & $7.0303 E+06$ & $7.0275 E+06$ \\
\hline 130 & 130 & 131 & $B E D$ & 4, & $7.0275 E+06$ & $7.0239 E+06$ \\
\hline : & & & & & & \\
\hline 131 & 131 & 132 & BED, & 3, & $7.0239 E+06$ & $E+06$ \\
\hline 132 & 132 & 133 & BED, & 2 , & $17.0195 E+06$ & $7.0143 \mathrm{E}+06$ \\
\hline 133 & 133 & 134 & BED, & 1, & $7.0143 E+06$ & $7.0119 E+06$ \\
\hline 134 & 134 & 135 & HF, & 2,1 & $17.0119 E+06$ & $7.0113 E+06$ \\
\hline 135 & 135 & 136 & HF, & 1,1 & $7.0113 E+06$ & $7.0106 E+06$ \\
\hline
\end{tabular}




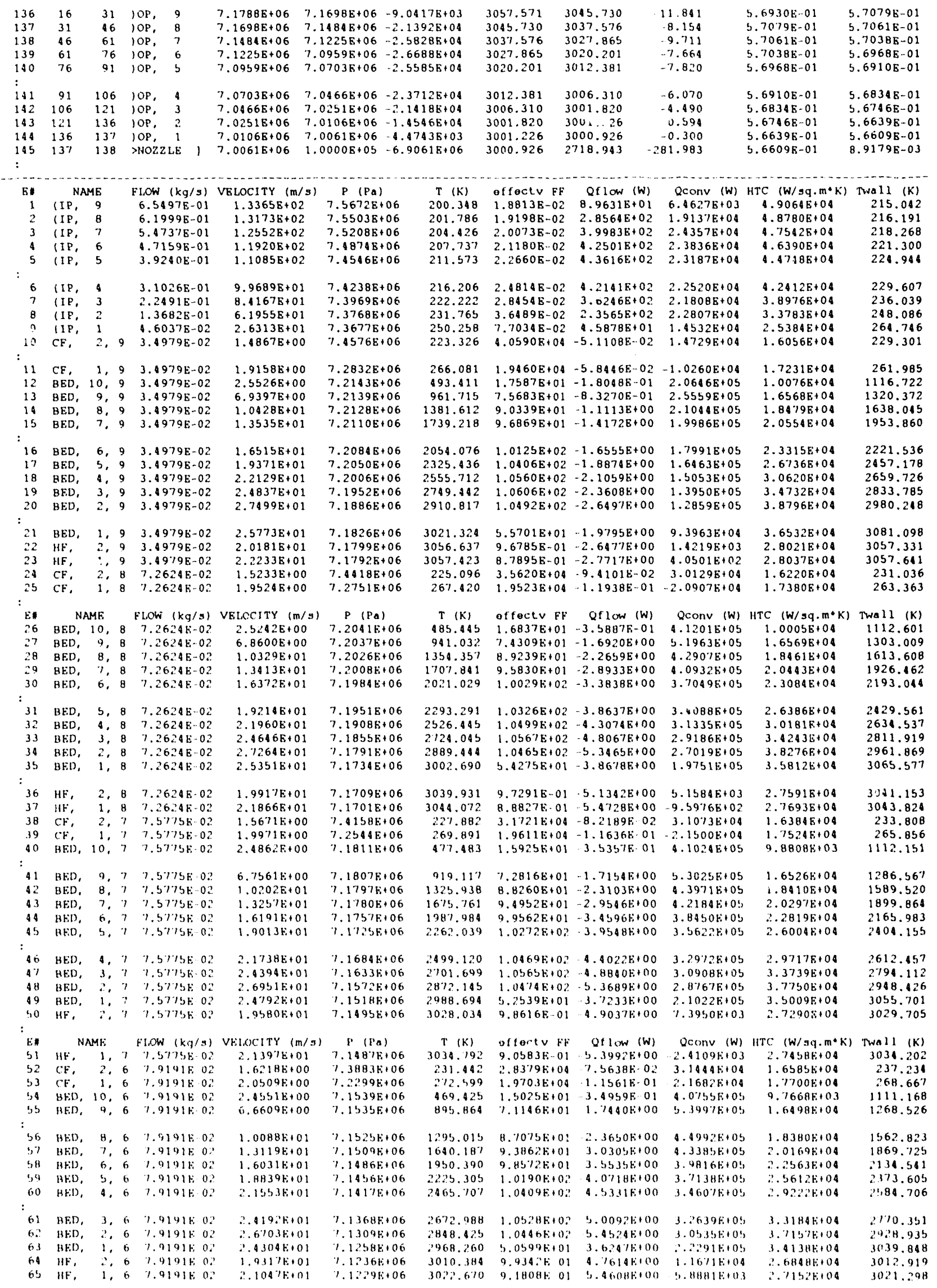




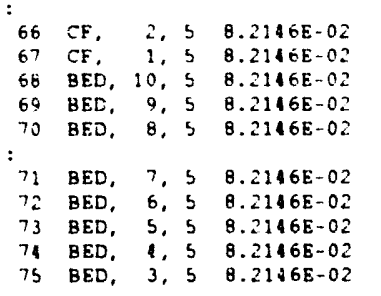

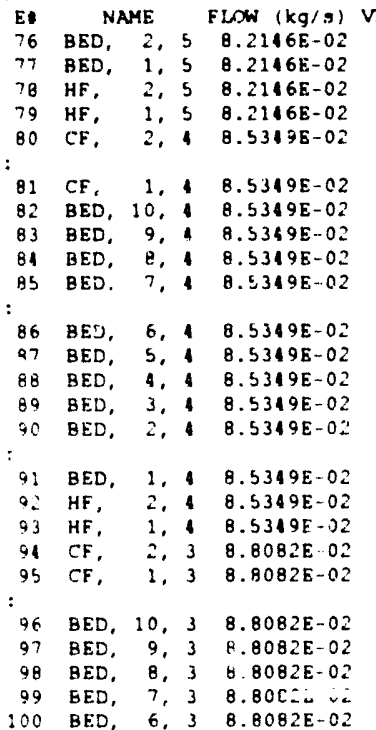

$\begin{array}{ll}1.6678 E+00 & 7.3603 E+06 \\ 2.1021 E+00 & 7.2010 E+06 \\ 2.1218 E+00 & 7.1257 E+06 \\ 6.5652 E+00 & 7.1251 E+06 \\ 9.9719 E+00 & 7.1211 E+06 \\ & \\ 1.2977 E+01 & 7.1229 E+06 \\ 1.5866 E+01 & 7.1207 E+06 \\ 1.8651 E+01 & 7.1178 E+06 \\ 2.1352 E+01 & 7.1140 E+06 \\ 2.3968 E+01 & 7.1091 E+06\end{array}$

VELOCITY $(\mathrm{m} / \mathrm{s}) \quad P(\mathrm{~Pa})$

$2 . E 126 E+01 \quad 7.1037 E+06$

$2.3787 \mathrm{~B}+01 \quad 7.0989 \mathrm{E}+06$

$1.9035 \mathrm{~B}+01 \quad 7.0969 \mathrm{E}+06$

$2.0651 \mathrm{~B}+01 \quad 7.0962 \mathrm{~B}+06$

$1.7277 \mathrm{E}+00 \quad 7.3351 \mathrm{E}+06$

$2.1650 \mathrm{E}+00 \quad 7.1800 \mathrm{0}+06$

$2.1021 E+00 \quad 7.0988 E+06$

$6.1769 \mathrm{E}+00 \quad 7.0985 \mathrm{E}+06$

$9.0011 E+00 \quad 7.0976 E+06$

$1.28(4 E+0)$

$1.5711 E+01$

$2.1170 \mathrm{E}+01 \quad 7.0876 \mathrm{E}+06$

$2.3771 \mathrm{E}+01 \quad 7.0831 \mathrm{E}+06$

$2.6186 E+01 \quad 7.0777 E+06$

2. $3312 E+01$

1. $8802 \mathrm{E}+01$

$2.0344 E+017.0706 E+06$

$1.79308+00 \quad 7.3131 E+06$

$2.2339 \mathrm{E}+00 \quad 7.2576 E+06$

$2.3840 E+00 \quad 7.0737 E+06$

$6.3923 E+00 \quad 7.0734 E+06$

$9.7574 E+00 \quad 7.0726 E+06$

$1.2711 E+01 \quad 7.0712 \mathrm{E}+06$

$1.5552 E+017.0692 \mathrm{E}+06$

VELOCITY $(\mathrm{m} / \mathrm{s}) \quad P(\mathrm{~Pa})$

$1.8304 E+017.0665 E+06$

$2.0972 E+01 \quad 7.0630 E+06$

$2.3551 E+01 \quad 7.0587 E+06$

$2.5913 E+01 \quad 7.0535 E+06$

$2.2805 E+01 \quad 7.0193 E+06$

$1.8513 E+01 \quad 7.0476 E+06$

1. $9984 E+01 \quad 7.04698+06$

1. $8954 E+00 \quad 7.2980 E+06$

$2.3432 \mathrm{E}+00 \quad 7.1392 \mathrm{E}+06$

$6.3139 E+00 \quad 7.0508 E+06$
$9.6867 E+00 \quad 7.0500 E+06$

$1.2612 \mathrm{E}+01 \quad 7.0486 \mathrm{E}+0$

1. $5128 E+01 \quad 7.0467 E+06$

I. B1S8E+01 $7.0641 E+06$

$2.0809 E+01$

$2.3365 E+01 \quad 7.0367 E+06$

$2.5671 E+01 \quad 7.0317 E+06$

$2.2328 E+01 \quad 7.0278 E+06$

$1.9660 E+01$

$2.0307 E+00$

6. $3691 \mathrm{E}+00$

VELOCITY (m/s)

$9.6931 E+00$

$\therefore .2596 \mathrm{E}+02$

$1.3386 E+01$

$2.0721 \mathrm{E}+01$

2.3216E+01

$25454 E \cdot 01$

$2.1959 \mathrm{E}+0$

$1.82256+0 ?$

$1.932 \mathrm{E} \cdot 01$

4. $351+8 E+D$

$\therefore 5$ S3E.

$3.8306 \mathrm{E} \cdot 0$

S.6625E.
$235.127 \quad 2.6134 \mathrm{E}+04-7.3553 \mathrm{E}-02 \quad 3.3219 \mathrm{E}+04$ $276.552 \quad 1.9781 \mathrm{E}+04-1.1990 \mathrm{E}-01-2.2756 \mathrm{E}+0$ $164.648 \quad 1.1211 E+01-3.1288 E-01 \quad 1.0418 E+05$ $878.613 \quad 6.9776 E+01-1.7565 E+00 \quad 5.4882 E+05$

$1272.1918 .6311 E+01-2.4005 E+00 \quad 1.5971 E+05$ $1.7826 \mathrm{E}+0$ 9. $\{$ i268E+O $1.64278+04$

1. $4319 E+04$

$1614.434 \quad 9.3269 E+01-3.0821 E+00 \quad 4.4517 E+05$ $923.903 \quad 9.8110 \mathrm{E}+01-3.6181 \mathrm{E}+00 \quad 4.1152 \mathrm{E}+05$ $2200.373 \quad 1.0161 \mathrm{E}+02-.1521 \mathrm{E}+00 \quad 3.8627 \mathrm{E}+05$ $2141.258 \quad 1.0401 E+02-4.6209 E+00 \quad 3.6221 E+05$ $2656.0641 .0542 E+02-5.0854 E+00 \quad 3.1361 E+05$

$2.13038 E+04$ 2. $2342 \mathrm{E}+0 \mathrm{O}$ $2.5297 E+04$ 2. $8840 E+04$ 3. $2772 \mathrm{E}+04$

211.066 272.549 1115.809 1257.626

1544.884

T (K) effectv FF Qflow (W) Qconv (W) $836.122 \quad 1.0162 E+02-5.1812 E+00 \quad 3.2297 E+05$ $2958.8221 .8819 \mathrm{E}+01-5.1924 \mathrm{E}+00 \quad 2.3531 \mathrm{E}+05$ $3002.126 \quad 1.0075 E+00-1.5621 E+00 \quad 1.2689 E+0$ $9.3519 E-01-5.2134 E+00-6.1736 E+03$
014.980 $210.130 \quad 2.3775 E+01-7.3352 \mathrm{E}-02 \quad 3.1180 \mathrm{E}+04$

$281.2921 .9880 E+01-1.2538 E-01-2.3441 E+04$ $160.319 \quad 1.3409 E+01-3.3712 E-01 \quad 3.9996 E+05$ $860.698 \quad 6.8213 E+01-1.7719 E+00 \quad 5.5668 E+05$ $1247.191 \quad 8.5427 E+01-2.1429 E+00 \quad 4.6905 E+05$ $1585.8519 .2476 E+01-3.1432 E+00 \quad 1.5654 E+05$

$1893.608 \quad 9.7116 E+01-3.6954 E+00 \quad 1.2148 E+05$ $2170.743 \quad 1.0106 E+02-1.2499 E+00 \quad 1.0089 E+05$ $217482 \quad 1.0365 E+02-4.7342 E+00 \quad 3.7830 E+05$ $2633.486 \quad 1.0528 E+02-5.1973 E+00 \quad 3.6083 E+05$ $2818.055 \quad 1.0444 E+02-5.5543 E+00 \quad 3.4071 E+05$ $3.3115 E+04$ $2.6651 E+04 \quad 3005.061$ $2.6960 E+04 \quad 3013.611$ $1.6909 \mathrm{E}+04 \quad 246.102$

$1.7990 \mathrm{E}+04 \quad 277.296$ $9.1987 \mathrm{~K}+03 \quad 1120.165$ $1.6369 \mathrm{E}+04 \quad 1245.780$ $1.8279 E+04 \quad 1521.995$

$1.9925 \mathrm{E}+01 \quad 1826.761$

$2.2131 \mathrm{E}+04 \quad 2090.189$

$2.1978 E+01 \quad 2331.395$

2. $8434 E+04 \quad 2547.803$

$3.2317 E+04 \quad 2710.751$

$3.6235 \mathrm{E}+04 \quad 2907.081$

$2943.564 \quad 1.6861 E+01-3.3914 E+00 \quad 2.4756 E+05$

$3.2627 E+04 \quad 3024.755$

$2.6332 E+04 \quad 2992.610$

$2.6728 E+04 \quad 3003.755$

$1.7066 \mathrm{E}+04 \quad 253.373$

1.8125E+04 281.380

$288.108 \quad 1.9983 \mathrm{E}+0 \mathrm{~L}-1.1205 \mathrm{E}-01-2.1322 \mathrm{E}+0 \mathrm{~A}$

$459.785 \quad 1.2682 E+01-3.3004 E-01 \quad 3.9511 E+05$

$818.861 \quad 6.6962 \mathrm{E}+01-1.7724 \mathrm{E}+00 \quad 5.6360 \mathrm{E}+05$ $1230.637 \quad 6.1915 E+01-2.4656 E+00 \quad 1.7793 E+0 S$ $1566.575 \quad 9.2148 E+01-3.1787 E+00 \quad 1.6721 E+05$ $1873.8019 .7208 E+01-3.7110 E+00 \quad 1.3712 E+05$

9. $3508 \mathrm{E}+03 \quad 1131.038$

$1.6271 \mathrm{E}+04 \quad 1241.127$

$1.8211 \mathrm{E}+04 \quad 1513.621$

$1.9807 \mathrm{E}+04 \quad 1813.181$

T (K) eftectv FF Qf lnw (W) Qconv (W) HTC (W/sq.m*K) Twall (K) $2152.355 \quad 1.0100 E+02-1.3079 E+00 \quad 1.1526 E+05 \quad 2.1723 E+04 \quad 2319.219$ $2402.211 \quad 1.0378 E+02-1.7989 E+00 \quad 3.9418 E+05 \quad 3.8130 E+04 \quad 2538.208$ $2622.303 \quad 1.0559 E+02-5.2508 E+003.7795 E+05 \quad 3.1995 E+04 \quad 2731.530$ $2811.039 \quad 1.0466 E+02-5.5608 E+003.5840 E+05 \quad 3.5895 E+04 \quad 2904.363$

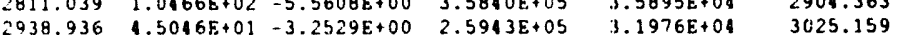

$2985.725 \quad 1.0318 E+00-1.2457 E+00 \quad 1.6027 E+04$ $3000.360 \quad 9.6532 E-01-5.1879 E+00-7.8799 E+03$ $259.747 \quad 2.0829 E+04 \quad 1.9305 E-02 \quad 3.8972 E+04$ $300.908 \quad 2.0090 E+04 \quad 6.2784 E-03-2.5410 E+04$ $164.991 \quad 1.2011 E+01-3.2589 E-01 \quad 3.8961 E+05$

$842.770 \quad 6.5753 E+01-1.7770 E+00 \quad 5.6949 E+05$ $1219.229 \quad 8.4519 E+01-2.4905 E+00 \quad 4.8640 E+05$ $1552.511 \quad 9.1911 E+01-3.2129 E+00 \quad 4.7718 E+05$ $1858.957 \quad 9.7101 E+01-3.7823 E+00 \quad 1.1948 E+05$ $2138.587 \quad 1.0103 E+02-1.3573 E+00 \quad 1.2915 E+05$

$2391.155 \quad 1.0397 E+02-1.8197 E+00 \quad 1.1007 E+05$ $2611.906 \quad 1.0596 E+02-5.2856 E+00 \quad 3.9521 E+05$ $280703 \quad 1.0484+02-5.5436 E+00 \quad 3.7635 E+05$ $2937.331 \quad 1.3201 E+01-3.1060 E+00 \quad 2.7114 E+05$ $2984.853 \quad 1.0173 E+00-1.0753 E+00 \quad 1.5691 E+04$

$2997.043 \quad 9.8217 E-01-6.9275 E+00-5.8407 E+03$ $279.547 \quad 2.0154 \mathrm{E}+04 \quad 1.5738 \mathrm{E}-01 \quad 1.8131 \mathrm{E}+04$ $320.976 \quad 2.0174 E+01 \quad 2.2280 E-01-1.2769 E+04$ 181.399 $1.1627 E+01-1.6302 E-01 \quad 1.9267 E+05$ $833.693 \quad 6.5411 \mathrm{E}+01-8.8877 \mathrm{E}-01 \quad 2.8668 \mathrm{E}+0 \mathrm{~S}$

$T$ (k) effectv FF Qflow (W) Qconv (W) $1228.426 \quad 8.1981 \mathrm{E}+01-1.2464 \mathrm{E}+00 \quad 2.1631 \mathrm{E}+05$ $1561.610 \quad 9.2584 E+01-1.6032 E+00 \quad 2.4265 E+0 S$ $1669.260 \quad 9.7862 E+01-1.8838 E+00 \quad 2.2947 E+0 S$ $\begin{array}{llll}2131.014 & 1.0191 E+02 & -2.1625 E+00 & 2.2018 E+0 S \\ 2106.16 ? & 1.019 B E+02 & -2.3935 E+00 & 2.1117 E+0 S\end{array}$ $2632.1191 .0707 E+02-2.5881 E+00 \quad 2.0434 E+05$ $\begin{array}{llll}2632.119 & 1.0707 E+02 & -2.5881 E+00 & 2.0434 E+0 S \\ 2826.991 & 1.0573 E+02 & -2.6816 E+00 & 1.9518 E+0 S\end{array}$ $\begin{array}{llll}2826.991 & 1.0573 E+02 & -2.6816 E+00 & 1.9518 E+0 S \\ 2957.653 & 1.2085 E+01 & -1.1563 E+00 & 1.1000 E+05\end{array}$ $\begin{array}{llll}2957.653 & 1.2085 E+01 & -1.1563 E+00 & 1.1000 E+05 \\ 3003.016 & 1.0717 E+00 & -1.9168 E+00 & 3.7569 E+03\end{array}$ $\begin{array}{rrrr}3003.016 & 1.0717 E+00 & -1.9168 E+00 & 3.7569 E+03 \\ 3002.113 & 1.0045 E+00 & 6.4148 E+00 & 2.7111 E+03\end{array}$

$3051.651 \quad 1.1307 \mathrm{E} 05$ S.5170E+02 -7.6138E-0 $304: .653$ 1. $276 \mathrm{E} \cdot 04-4.0307 \mathrm{E}+03 \quad 2.1760 \mathrm{E} 01$ $3032.721 \quad 1.3791 \mathrm{E}-04 \quad 8.28 .33 \mathrm{E}+03 \quad \mathbf{1} 9343 \mathrm{E}+00$ $\begin{array}{rrrr}3032.721 & 1.3791 \mathrm{E}-04 & 9.2833 \mathrm{E}+03 & \mathbf{1} .9343 \mathrm{E}+00 \\ 3024.033 & 7.2897 \mathrm{E}-04 & -1.222 \mathrm{BE}+04 & 5.6896 \mathrm{E}+00\end{array}$

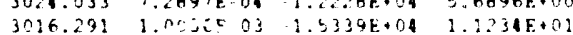

$2.6244 E+04 \quad 2988.79$ $2.6599 E+04 \quad 2998.765$ $1.7295 E+04 \quad 266.095$ $1.8327 E+04 \quad 296.826$ 9.218SE+03 1146.992

$1.6186 \mathrm{E}+0 \mathrm{O} \quad 1212.223$ $1.8158 \mathrm{E}+0 \mathrm{O} \quad 1507.769$ $1.9716 \mathrm{E}+04 \quad 1805.368$ $\begin{array}{ll}2.1802 E+04 & 2068.192 \\ 2.4523 E+04 & 2311.635\end{array}$

$2.7893 E+04 \quad 2532.832$ $3.1748 E+04 \quad 2732.131$ $3632 \mathrm{E}+04 \quad 2965.110$ $3.1386 E+04 \quad 3028.818$ $2.6229 E+04 \quad 2987.721$

$2.6521 E+04 \quad 2995.913$ $1.7529 \mathrm{E}+04 \quad 285.294$ $.85062+04 \quad 316.978$

$9.1193 E+03$

$T:=(w / s q \cdot m \cdot k)$ Twall (K) 1.8101E+04 1521.701 $1.9668 E+01 \quad 1819.050$ $2.1767 E+04 \quad 2082.877$ $2.4521 \mathrm{E} .04 \quad-328.017$

$2.7942 E \cdot 04 \quad 2551.256$

$3.1860 E+04 \quad 2752.594$ $3.5776 \mathrm{t}+04 \quad 2927.311$ $3.1251 \mathrm{E}+04 \quad 3052.183$

$2.6653 \mathrm{E}+04 \quad 3003.121$

$\therefore .3481 E+00 \quad 3050.624$ T.75BEE.01 3040.919 $\therefore$ AS37E+22 3031.114 $\therefore .016 \mathrm{E} \cdot 0.203021 .929$ $2.6692 \mathrm{E}+04 \quad 3004.323$ 


\begin{tabular}{|c|c|c|c|c|c|c|c|c|}
\hline 111 & 1OP, & 4 & & $1.3006 \mathrm{E}-01$ & $6.34105+02$ & $7.0581 \mathrm{E}+06$ & 3009.346 & $1.2497 \mathrm{~B}-03$ \\
\hline 142 & JOP. & 3 & & $5.18155-01$ & $6.9013 E+02$ & $7.03585+06$ & 3004.065 & $1.16798-03$ \\
\hline 103 & jop. & 2 & & $6.08935-01$ & $7.15915+02$ & $7.01795+06$ & 3001.523 & $1.68868-03$ \\
\hline 141 & JOP, & 1 & & $6.5497 \mathrm{E}-01$ & $7.6618 \mathrm{E}+02$ & $7.00845+06$ & 3001.076 & $1.78896-03$ \\
\hline 145 & $>\mathrm{NOZZI}$ & & ] & $6.5497 E-01$ & $1.37885+03$ & $5.5169 B+06$ & 2859.931 & $1.04945+00$ \\
\hline & & & & & & & & \\
\hline EU & NAM & & & DEN (kq/cub.m) & MACH & DVISC $\left(\mathrm{Pa}^{\circ} \mathrm{s}\right)$ & Cp $\left(\mathrm{J} / \mathrm{kg}^{*} \mathrm{~K}\right)$ & GAMaYA \\
\hline 1 & (1P. & 9 & & $9.15838+00$ & 0.12511 & $6.8132 E-06$ & $1.1964 E+04$ & 1.38018 \\
\hline 2 & IIP. & 8 & & $9.0727 E+00$ & 0.12291 & $6.8161 \mathrm{E}-06$ & $1.19665+04$ & 1.38018 \\
\hline 3 & IIP. & 7 & & 8. $9205 E+00$ & 0.11635 & $6.9072 \mathrm{E}-06$ & $1.4964 E+04$ & 1.38048 \\
\hline 1 & IIP, & 6 & & $8.73938+00$ & 0.10961 & $6.98315-06$ & $1.19615+01$ & 1.38018 \\
\hline 5 & IIP. & s & & $8.5133 \mathrm{E}+00$ & 0.10100 & $7.0705 \mathrm{E}-06$ & $1.19616+01$ & 1.38048 \\
\hline 6 & (IP, & 4 & & 8. $3256 \mathrm{E}+00$ & 0.08985 & $7.17515-06$ & $1.1964 \mathrm{~B}+04$ & 1.38018 \\
\hline 7 & IIP, & 3 & & $8.0710 E+00$ & 0.07183 & $7.31065-06$ & $1.1964 E+01$ & 1.38018 \\
\hline 8 & (IP. & 2 & & $7.7176 \mathrm{~B}+00$ & 0.05394 & $7.5226 \mathrm{~B}-06$ & $1.1961 E+01$ & 1.38048 \\
\hline 9 & (I) & 1 & & $7.1385 E+00$ & 0.02201 & $7.92586-06$ & $1.1964 \mathrm{E}+04$ & 1.38018 \\
\hline 10 & CF, & 2. & 9 & $8.09695+00$ & 0.00132 & $7.33535-06$ & $1.1964 E+04$ & 1.38048 \\
\hline & & & & & & & & \\
\hline 11 & $\mathrm{CF}$, & 1 , & 9 & $6.6370 \mathrm{E}+00$ & 0.00156 & $8.2632 \mathrm{~B}-06$ & $1.49645+04$ & 1.38048 \\
\hline 12 & BED, & 10, & 9 & $3.5153 \mathrm{E}+00$ & 0.00152 & $1.2575 \mathrm{E}-05$ & $1.1630 E+01$ & 1.39256 \\
\hline 13 & BED, & 9. & 9 & $1.81885+00$ & 0.00296 & $1.9797 \mathrm{E}-0 \mathrm{~S}$ & $1.1922 E+04$ & 1.38193 \\
\hline 14 & BED. & 8 & 9 & $1.26585+00$ & 0.00375 & $2.53285-05$ & $1.5752 E+04$ & 1.35469 \\
\hline 15 & BED, & 7. & 9 & $1.0053 \mathrm{E}+00$ & 0.00438 & $2.9620 \mathrm{E}-0 \mathrm{~S}$ & $1.63376+04$ & 1.33225 \\
\hline & & & & & & & & \\
\hline 16 & BED, & 6 , & 9 & 8. $5091 \mathrm{~B}-01$ & .00495 & $3.31686-05$ & $1.7265 \mathrm{E}+04$ & 1.31386 \\
\hline 17 & BED, & 5. & 9 & $7.5126 \mathrm{E}-01$ & 0.00551 & $3.6088 \mathrm{E}-0 \mathrm{~b}$ & $1.8309 E+04$ & 1.29071 \\
\hline 18 & BED, & 4. & 9 & $6.8316 \mathrm{E}-01$ & 0.00607 & $3.8481 \mathrm{E}-05$ & $1.9820 E+04$ & 1.26276 \\
\hline 19 & BED, & 3, & 9 & $6.3454 E-01$ & 0.00664 & $1.0441 \mathrm{~B}-05$ & $2.1727 E+04$ & 1.23429 \\
\hline 20 & BED, & 2, & 9 & $5.9881 \mathrm{E}-01$ & 0.00722 & $4.2040 E-05$ & $2.3875 E+04$ & 1.20881 \\
\hline : & & & & & & & & \\
\hline 21 & BED, & 1 , & 9 & $5.7643 \mathrm{E}-01$ & 0.00669 & 4.3119E-05 & $2.5686 \mathrm{E}+04$ & 1.19127 \\
\hline 22 & $\mathrm{HF}$, & $\therefore$ & 9 & $5.6956 \mathrm{~B}-01$ & 0.00522 & $1.3461 E-05$ & $2.6328 \mathrm{E}+04$ & 1.18571 \\
\hline 23 & $\mathrm{HF}$, & 1 . & 9 & $5.6935 \mathrm{E}-01$ & 0.00575 & $1.3469 \mathrm{E}-05$ & $2.6343 E+04$ & 1.18562 \\
\hline 24 & CF. & a, & 8 & $8.0162 E+00$ & 0.00135 & $7.3718 E-06$ & $1.4964 E \cdot 04$ & 1.38048 \\
\hline 25 & $\mathrm{CF}$. & 1, & 8 & $6.59645+00$ & 0.00158 & $8.2914 E-06$ & $1.1964 E+04$ & 1.38048 \\
\hline : & & & & & & & & \\
\hline E. & & UE & & DEN $(\mathrm{kg} / \mathrm{rub} . \mathrm{m})$ & MACH & DVISC $(\mathrm{Pa}+\mathrm{s})$ & $C p\left(\mathrm{~J} / \mathrm{kq}^{*} \mathrm{k}\right)$ & GAMMA \\
\hline 26 & BED, & 10 & 8 & $3.5993 E+00$ & 0.00151 & $1.2437 \mathrm{E}-0 \mathrm{~S}$ & $1.4637 E+04$ & 1.39229 \\
\hline 27 & BED, & 9, & 8 & $1.8561 E+00$ & 0.00296 & $1.9507 E-05$ & $1.4888 E+04$ & 1.38316 \\
\hline $2 \theta$ & BED, & 8, & 8 & $1.2895 \mathrm{E}+00$ & 0.00375 & $2.4987 \mathrm{E}-05$ & $1.5699 E+04$ & 1.35630 \\
\hline 29 & BED, & 7. & 8 & $1.0223 \mathrm{E}+00$ & 0.00138 & $2.92555-05$ & $1.6470 E+04$ & 1.33405 \\
\hline 30 & BED, & 6 & 8 & $8.6362 \mathrm{E}-01$ & 0.00194 & $3.2804 \mathrm{E}-05$ & $1.7173 E+04$ & 1.31605 \\
\hline & & & & & & & & \\
\hline 31 & BED, & s. & B & $7.60745-01$ & 0.00549 & $3.5748 \mathrm{E}-0 \mathrm{~S}$ & $1.8151 \mathrm{E}+04$ & 1.29402. \\
\hline 32 & BED, & 4. & 8 & $6.9013 \mathrm{E}-01$ & 0.00601 & $3.8181 E-05$ & $1.9586 E+04$ & 1.26673 \\
\hline 33 & BED, & 3. & 8 & $6.3960 \mathrm{E}-01$ & 0.00661 & $4.0187 E-05$ & $2.1438 E+04$ & 1.23820 \\
\hline 34 & BED, & 2. & $B$ & $0.0245 E-01$ & 0.00717 & $1.1830 \mathrm{E}-0 \mathrm{~b}$ & $2.3558 E+04$ & 1.21222 \\
\hline 35 & BED, & 1. & 8 & 5.7927E-01 & 0.00659 & 4. $2938 \mathrm{E}-05$ & $2.3360 E+04$ & 1.19421 \\
\hline & & & & & & & & \\
\hline 36 & $\mathrm{HF}$, & 2. & 8 & $5.7197 \mathrm{E}-01$ & 0.00516 & $4.3300 \mathrm{E}-05$ & $2.6020 \mathrm{E}+04$ & .18835 \\
\hline 37 & $\mathrm{HF}$, & 1. & 8 & $5.7113 \mathrm{E}-01$ & .00566 & 4. $33406-05$ & $2.6096 E+04$ & 1.18770 \\
\hline 38 & $C F$, & $\therefore$ & 7 & $7.8906 E+00$ & 0.00138 & $7.9367 \mathrm{E}-06$ & $1.4964 \mathrm{E}+04$ & 1.38048 \\
\hline 39 & $\mathrm{CF}$. & 1. & 7 & $6.3174 E+00$ & 0.00161 & $8.3434 E-06$ & $1.4964 E+04$ & 1.38048 \\
\hline 40 & BED, & 10 & 7 & $3.6467 \mathrm{E}+00$ & 0.00150 & $1.2298 \mathrm{E}-05$ & $1.46456+04$ & 1.39200 \\
\hline & & & & & & & & \\
\hline 41 & BED, & 9. & 7 & $1.8943 E+00$ & 0.00295 & $1.9197 \mathrm{E}-05$ & $1.4852 \mathrm{~F}+04$ & .38442 \\
\hline d2. & BED, & 8, & 7 & $1.3129 E+00$ & $0.003 \%$ & $2.4629 \mathrm{~F}-0 \mathrm{~S}$ & $1.5643 E+04$ & 35805 \\
\hline 43 & BED, & $?$ & 7 & $1.0386 E+00$ & 0.00436 & $2.8880 \mathrm{E}-0 \mathrm{~S}$ & $1.6400 E+04$ & 1.33595 \\
\hline 14 & BED, & 6. & 7 & a.7521E 01 & 0.00493 & $3.2438 \mathrm{E}-0 \mathrm{~S}$ & $1.7087 \mathrm{E}+04$ & 1.31814 \\
\hline 45 & BED, & 5 & 7 & $\because .6883 \mathrm{E} .01$ & 0.00547 & $3.5116 \mathrm{E}-05$ & 1. $8007 E+04$ & 1.29707 \\
\hline & & & & & & & & \\
\hline 46 & HED, & 1, & 7 & $6.9550 \mathrm{E} \cdot 01$ & 0.00601 & $3.7899 \mathrm{E} 0 \mathrm{~S}$ & $1.9381 E+04$ & 1.27033 \\
\hline 47 & BED, & 3. & 7 & $6.4290 \mathrm{k}-01$ & 00656 & $3.9962 \mathrm{E}-03$ & $2.1194 E+04$ & 26160 \\
\hline 18 & BED, & $\therefore$ & 7 & 6.0422501 & 0.00710 & $4.1660 \mathrm{E} \cdot 05$ & $2.3309 E .01$ & 1.21497 \\
\hline 49 & $\mathrm{HEO}$ & $i$. & 7 & $5.8023 \mathrm{E} .01$ & 0.00646 & 1.2802E 05 & $2.51208+01$ & 1.19643 \\
\hline 0 & $\mathrm{HF}$ & $\therefore$ & 7 & 3.12501 .01 & 0.00508 & 4. $3184 \mathrm{E}-05$ & 2. SBOSE+OA & 1.19022 \\
\hline & & & & & & & & \\
\hline F. & & AME & & DFN (kg/cub.m) & MACH & DVISC (Pa*s) & $C p\left(J / k g^{*} \cdot k\right)$ & GAMMA \\
\hline 3 & $\mathrm{HF}$. & 1. & 7 & 5.71178 .01 & 0.00555 & 4. $3250 \mathrm{E} \cdot 0 \mathrm{~S}$ & $2.5927 E+04$ & .18916 \\
\hline 3 & $\mathrm{CF}$ & 2 & 6 & $7.1404 \mathrm{E}+00$ & 0.00141 & $7.31556-\delta 6$ & $1.4964 E+04$ & 1.38048 \\
\hline 33 & $\mathrm{CF}$ & 1. & 6 & t. $4309 E \cdot C$ & 0.00163 & $8.4003 E 06$ & $1.4960 E+04$ & 1.38048 \\
\hline 14 & BED, & 10 & 6 & $3.695 .2 \mathrm{E} .00$ & 0.00150 & $1.2156 \mathrm{E} .05$ & $1.4653 E+04$ & 1.39169 \\
\hline 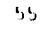 & $1 \mathrm{ED}$ & 9 & 6 & $1.9361 \mathrm{E}+00$ & 0.00294 & 1.8865F. OS & $1.4817 \mathrm{E}+04$ & 1.38570 \\
\hline${ }^{\circ}$ & & & & & & & & \\
\hline 56 & BED, & A, & is & $1.339 .2 \mathrm{k}, 00$ & 0.10374 & $\therefore 4.37 \mathrm{E}$ OS & SSBOE:04 & 00 \\
\hline s & HED, & 1. & 0 & $.0511 t+00$ & 0.00436 & $2.8462 \mathrm{E} 05$ & $.6321 E+04$ & 3ค1บ \\
\hline 3,8 & HFD, & n. & 6 & S. HAITE OI & $0.0040 ?$ & $3.2020 \mathrm{~F} 05$ & $1.6995 E+04$ & $1.3204 ?$ \\
\hline 59 & HED, & $\therefore$ & 6 & $7.7859 \mathrm{~F} 01$ & 0.00545 & $3.5024 E 06$ & $1.7850 E+104$ & 1.30046 \\
\hline 60 & HED, & 4 & G & $7.0 .30 \mathrm{~F} 01$ & 0.00549 & 3. $75,54: 03$ & $1.9143 k+04$ & 1.27459 \\
\hline : & & & & & & & & \\
\hline 61 & BED, & 3 & h & 6.4134501 & 0.00633 & $3.9673 \mathrm{E} 0 !$ & $4 F+04$ & $9 ?$ \\
\hline G: & HED, & $\therefore$ & 6 & 6.070 .401 & $0.00 \% 06$ & 1.14.'AE: OS & $.29785+04$ & $18 \% 4$ \\
\hline 63 & HED, & 1. & h & $\therefore .8 .10 E \quad 01$ & 0.00634 & 4..'603k:05 & $\therefore 4119 \mathrm{r}+04$ & 1.19967 \\
\hline$n 4$ & $H F$ & $\therefore$ & 6 & $\therefore \Rightarrow 7 \mathrm{f} 01$ & $9.0050 ?$ & 4. 3013 E. 04 & $\therefore 54935.04$ & 1.19300 \\
\hline ES & $\mathrm{HF}$ & 1. & 6 & $5.9199 \mathrm{~F} 01$ & 0.00546 & 4. 313.2505 & $25 \% 105+04$ & 1.19106 \\
\hline$:$ & & & & & & & & \\
\hline 66 & $r+$ & $\because$ & 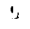 & $1.540 \mathrm{st}+00$ & 144 & 7.99618 of & 1.04 & $4 H$ \\
\hline b? & $\mathrm{CF}$ & 1. & 3 & n. $316 . t+a n$ & $0.0016 \mathrm{H}$ & $\mathrm{H}, 4 \mathrm{H}, 9 \mathrm{~F}$. OG & $1.9964 \mathrm{E}, 04$ & 1.38044 \\
\hline 的 & HFD, & 10 & ' & 3. $118 \mathrm{~B}, \mathrm{r}, 00$ & 0.00144 & A..0\%t 09 & $1.465, B E+04$ & 1.39150 \\
\hline nid & WED, & 4. & ¿ & $1,2+6+9+100$ & 11.190 .43 & 1.HOIHF OS & $1.474 .8+04$ & 1. 3 Hans \\
\hline
\end{tabular}

parge -- 102 


\begin{tabular}{|c|c|c|c|c|c|c|c|}
\hline 70 & BED, & 8,5 & $1.3579 \mathrm{~B}+00$ & 0.00373 & $2.3946 \mathrm{E}-05$ & $1.5534 \mathrm{E}+04$ & 1.36147 \\
\hline 71 & BED， & 7,5 & $1.0698 E+00$ & 0.00434 & $2.8157 \mathrm{E}-05$ & $1.6260 \mathrm{E}+04$ & 1.33982 \\
\hline 72 & BED, & 6,5 & $8.9743 \mathrm{E}-01$ & 0.00490 & $3.1724 \mathrm{E}-05$ & $1.6933 \mathrm{E}+04$ & 1.32197 \\
\hline 73 & BED, & 5,5 & $7.8435 \mathrm{E}-01$ & 0.00543 & $3.4756 \mathrm{E}-05$ & $1.7751 \mathrm{E}+04$ & 1.30265 \\
\hline 74 & BED, & 4,5 & $7.0572 \mathrm{E}-01$ & 0.00595 & $3.7332 \mathrm{E}-05$ & $1.9000 \mathrm{~B}+04$ & 1.27726 \\
\hline 75 & BED, & 3,5 & $6.4902 E-01$ & 0.00648 & $3.9502 \mathrm{~B}-05$ & $2.0725 \mathrm{E}+04$ & 1.24844 \\
\hline E* & NA & ME & DEN (kg/cub.m) & MACH & $\operatorname{IISC}\left(\mathrm{Pa}^{*} 5\right)$ & $\left(\mathrm{J} / \mathrm{kg}^{*} \mathrm{~K}\right)$ & GAMaMA \\
\hline 76 & BED, & 2,5 & $6.0733 \mathrm{E}-01$ & 0.00699 & $1.1304 \mathrm{E}-05$ & $2.2812 \mathrm{E}+04$ & 1.22069 \\
\hline 77 & BED, & 1,5 & $5.81758-01$ & 0.00621 & $4.25118-05$ & $2.4625 \mathrm{E}+04$ & 1.20117 \\
\hline 78 & $\mathrm{HF}$, & 2,5 & $5.7314 \mathrm{E}-01$ & 0.00495 & $4.2936 \mathrm{E}-05$ & $2.5355 \mathrm{E}+04$ & 1.19425 \\
\hline 79 & $\mathrm{HF}$, & 1,5 & $5.7070 \mathrm{~B}-01$ & 0.00536 & $4.3058 \mathrm{E}-05$ & $2.5574 \mathrm{E}+04$ & 1.19227 \\
\hline 80 & CF, & & $7.4066 \mathrm{~B}+00$ & 0.00148 & $7.70625-06$ & $1.1964 \mathrm{~B}+04$ & 1.38048 \\
\hline & & & & & & & \\
\hline 81 & CF & & $6.1891 \mathrm{E}+00$ & 0.00171 & $8.5815 \mathrm{E}-06$ & 1.49 & 8048 \\
\hline 82 & BED, & 10,4 & $3.7393 \mathrm{E}+00$ & 0.00148 & $1.1995 \mathrm{E}-05$ & $1.1663 \mathrm{~B}+04$ & 1.39132 \\
\hline 83 & BED, & 9,4 & $1.9998 \mathrm{E}+00$ & 0.00292 & $1.8358 \mathrm{E}-05$ & $1.4767 \mathrm{~B}+04$ & 1.38752 \\
\hline 84 & BED, & B, 4 & $1.3795 \mathrm{E}+00$ & 0.00372 & $2.3629 \mathrm{E}-05$ & $1.54835+04$ & 1.36309 \\
\hline 85 & BED, & 7,4 & $1.0850 \mathrm{E}+00$ & 0.00434 & $2.7817 \mathrm{E}-05$ & $1.6191 \mathrm{E}+04$ & 1.34178 \\
\hline & & & & & & & \\
\hline 86 & BED, & 6,4 & $9.0837 \mathrm{E}-01$ & 0.00489 & $3.1383 \mathrm{E}-05$ & $1.6865 \mathrm{E}+04$ & 1.32370 \\
\hline 87 & BED, & 5,4 & $7.9209 \mathrm{E}-01$ & 0.00541 & $3.4137 \mathrm{E}-05$ & $1.7640 \mathrm{~B}+04$ & 1.30514 \\
\hline 88 & BED, & 4,4 & $7.1088 \mathrm{E}-01$ & 0.00592 & $3.7053 \mathrm{E}-05$ & $1.8829 \mathrm{E}+04$ & 1.28047 \\
\hline 89 & BED, & 3,4 & $6.5216 \mathrm{E}-01$ & 0.00645 & $3.9273 \mathrm{E}-05$ & $2.0506 \mathrm{E}+04$ & 1.25175 \\
\hline 90 & BED, & 2,4 & $6.08985-01$ & 0.00694 & 1. $1125 \mathrm{~B}-05$ & $2.2573 \mathrm{E}+04$ & 1.22355 \\
\hline & & & & & & & \\
\hline $\begin{array}{l}91 \\
92\end{array}$ & BED, & 1,4 & $5.8264 \mathrm{E}-01$ & 0.00610 & $1.2361 \mathrm{E}-05$ & $2.4381 E+04$ & .20359 \\
\hline 92 & HF, & 2,4 & $5.7355 \mathrm{E}-01$ & 0.00490 & $4.2809 \mathrm{E}-05$ & $2.5132 \mathrm{E}+04$ & 1.19631 \\
\hline 93 & $\mathrm{HF}$. & 1,4 & $5.7041 \mathrm{E}-01$ & 0.00529 & $4.2967 \mathrm{E}-05$ & $2.5410 \mathrm{E}+04$ & 1.19375 \\
\hline 94 & $\mathrm{CF}$, & 2,3 & $7.1712 \mathrm{E}+00$ & 0.00151 & $7.8613 \mathrm{E}-06$ & $1.4964 E+04$ & 1.38048 \\
\hline 95 & $\mathrm{CF}$, & 1,3 & $6.0176 E+00$ & 0.00174 & $8.7285 \mathrm{E}-06$ & $1.4964 \mathrm{~B}+04$ & 1.38048 \\
\hline & & & & & & & \\
\hline 96 & BED, & 10,3 & $3.7304 \mathrm{E}+00$ & 0.00147 & E-05 & $1.4664 \mathrm{E}+04$ & .39130 \\
\hline 97 & BED, & 9,3 & $2.0205 E+00$ & 0.00290 & $1.8186 \mathrm{E}-05$ & $1.4751 E+04$ & .38810 \\
\hline 98 & BED, & 8,3 & $1.3935 E+00$ & 0.00371 & $2.3411 E-05$ & $1.5448 E+04$ & 1.36420 \\
\hline 99 & BED, & 7,3 & $1.0945 \mathrm{E}+00$ & 0.00431 & $2.7587 \mathrm{E}-05$ & $1.6142 E+04$ & 1.34316 \\
\hline 100 & BED, & 6,3 & $9.1476 \mathrm{E}-01$ & 0.00486 & $3.1159 \mathrm{E}-05$ & $1.6821 \mathrm{E}+04$ & .32481 \\
\hline$:$ & & & & & & & \\
\hline E* & & MME & (kg/cub.m) & MACH * & DVISC $\left(\mathrm{Pa}^{*} \mathrm{~s}\right)$ & $\mathrm{Cp} \quad\left(\mathrm{J} / \mathrm{kg} \mathrm{g}^{*} \mathrm{~K}\right)$ & AMMA \\
\hline 101 & BED, & 5,3 & $7.9607 \mathrm{E}-01$ & 0.00537 & $3.1239 \mathrm{E}-05$ & $1.7574 \mathrm{E}+04$ & 1.30663 \\
\hline 102 & BED, & 4,3 & $7.1292 \mathrm{E}-01$ & 0.00588 & $3.6894 \mathrm{E}-05$ & $1.8735 \mathrm{E}+04$ & 1.28226 \\
\hline 103 & BED, & 3 , & $6.5269 \mathrm{E}-01$ & .00640 & $3.9160 \mathrm{E}-05$ & $2.0401 E+04$ & .25338 \\
\hline 104 & BED, & 2,3 & $6.0842 E-01$ & 0.00688 & $4.1055 \mathrm{E}-05$ & $2.2482 E+04$ & 1.22466 \\
\hline 105 & BED, & 1,3 & $5.8159 E-01$ & 0.00597 & $4.2316 \mathrm{E}-05$ & $2.4308 \mathrm{E}+04$ & 1.20433 \\
\hline 0 & & & & & & & \\
\hline 106 & $\mathrm{HF}$, & 2,3 & $5.7234 E-01$ & 00483 & $E-05$ & $0 E+04$ & 690 \\
\hline 107 & $\mathrm{HF}$, & 1,3 & $5.6949 E-01$ & 20 & $E-05$ & $9 E+04$ & 58 \\
\hline 108 & CE, & 2,2 & $6.8127 E+00$ & .00156 & $8.1289 \mathrm{E}-06$ & $1.496 ; 8+04$ & 1.38048 \\
\hline 109 & $\mathrm{CF}$, & 1,2 & $5.7528 E+00$ & 0.00179 & $8.9841 E-06$ & $1.4961 E+04$ & 1.38056 \\
\hline 110 & BED, & 10,2 & $3.6768 E+00$ & 0.00146 & $1.2078 \mathrm{E}-05$ & $1.4658 E+04$ & 1.39151 \\
\hline 9 & & & & & & & \\
\hline 111 & BED, & 9,2 & $2.0286 E+00$ & .00289 & $8-05$ & $E+04$ & 1839 \\
\hline 112 & BED, & 8,2 & $.4021 E+00$ & 00370 & $\varepsilon-05$ & $1.5424 \mathrm{E}+04$ & 36496 \\
\hline 113 & BED, & 7,2 & $1.1009 \mathrm{E}+00$ & 0.00430 & $2.7418 \varepsilon-05$ & $1.6106 \mathrm{E}+04$ & 1.34421 \\
\hline 114 & BED, & 6. & $9.1913 \mathrm{E}-01$ & .00484 & $3.0991 \mathrm{E}-05$ & $1.6789 E+04$ & 1.32563 \\
\hline 115 & BED, & 5,2 & $7.9866 \mathrm{E}-01$ & 0.00535 & $3.4090 \mathrm{E}-05$ & $1.7527 E+04$ & 1.30771 \\
\hline - & & & & & & & \\
\hline 116 & BED, & 4, 2 & $7.1397 \mathrm{E}-01$ & 00585 & $\varepsilon-05$ & $E+04$ & 28354 \\
\hline 117 & BED, & 3,2 & $6.5249 E-01$ & .00635 & $3.9085 E-05$ & $2.0333 \mathrm{E}+04$ & 1.25444 \\
\hline 118 & BED, & 2, & $6.0732 E-01$ & .00682 & $\varepsilon-05$ & $E+04$ & 22523 \\
\hline 119 & BED, & 1,2 & $5.8013 E-01$ & .00584 & $4.2300 \mathrm{E}-05$ & $2.4283 E+04$ & 1.20459 \\
\hline 120 & $H F$, & 2,2 & $5.7076 \mathrm{E}-01$ & 0.00477 & $4.2765 \mathrm{E}-05$ & $2.5055 E+04$ & 1.19704 \\
\hline & & & & & & & \\
\hline 121 & HF, & 1, & $E-01$ & 00512 & -05 & $E+04$ & 11 \\
\hline 122 & $\mathrm{CF}$. & 2. & +00 & 00161 & -06 & 1.45 & .38048 \\
\hline 123 & CF, & 1,1 & $5.3851 E+00$ & .00184 & $9.3872 E-06$ & $1.4910 E+04$ & .38236 \\
\hline 124 & BED, & 10,1 & $3.5438 E+00$ & .00147 & $1.2366 \mathrm{E}-05$ & $1.4641 E+04$ & 1.39215 \\
\hline 125 & BED, & 9. & $1.9983 \mathrm{E}+00$ & 0.00288 & $1.8257 \mathrm{E}-05$ & $1.4757 E+04$ & 1.38786 \\
\hline : & & & & & & & \\
\hline E\# & & ME & $E N(\mathrm{~kg} / \mathrm{cub} . \mathrm{m})$ & MACH * & DVISC $\left(\mathrm{Pa}^{*} \mathrm{~s}\right)$ & $\mathrm{Cp} \quad\left(\mathrm{J} / \mathrm{kg}^{*} \mathrm{~K}\right)$ & GAMMA \\
\hline 126 & BED, & 8,1 & $1.3885 E+00$ & 69 & $2.3383 \mathrm{E}-05$ & $1.5443 E+04$ & 36435 \\
\hline 127 & BED, & 7,1 & $1.0921 \mathrm{E}+00$ & 0.00428 & $2.7527 \mathrm{E}-0 \mathrm{~S}$ & $1.6130 \mathrm{E}+04$ & .34353 \\
\hline 128 & BED, & 6,1 & $9.1209 \mathrm{E}-01$ & 0.00481 & $3.1108 \mathrm{E}-05$ & $1.6812 E+04$ & 1.32506 \\
\hline 129 & BED, & 5,1 & $7.9232 \mathrm{E}-01$ & 0.00531 & $3.4225 E-05$ & $1.7570 E+04$ & 1.30673 \\
\hline$\$ 30$ & BED, & 4. 1 & $7.0799 \mathrm{E}-01$ & 0.00581 & $3.6935 \mathrm{E}-05$ & $1.8759 E+04$ & 1.28180 \\
\hline$:$ & & & & & & & \\
\hline 131 & BED, & 3,1 & $.4677 \mathrm{E}-01$ & .00631 & $E-05$ & $2.0496 E+04$ & 1.25191 \\
\hline 132 & BED, & 2. 1 & $E-01$ & 75 & $E-05$ & $E+04$ & 214 \\
\hline 133 & BED, & 1,1 & $5.7495 E-01$ & 0.00574 & $4.2499 \mathrm{E}-05$ & $2.4606 E+04$ & 20135 \\
\hline 134 & HF, & 2,1 & 5.6614 E- 01 & 0.00471 & $4.2941 \mathrm{E}-05$ & $2.5365 E+04$ & 1.19416 \\
\hline 135 & $\mathrm{HF}$, & 1,1 & $5.6626 \mathrm{E}-01$ & 0.00503 & $4.2933 E-05$ & $2.5350 E+04$ & 1.19430 \\
\hline$:$ & & & & & & & \\
\hline 136 & JOP, & 9 & $5.7004 E-01$ & 0.02421 & $4.3413 E-05$ & $E+04$ & 652 \\
\hline 137 & 10P. & 8 & $5.7070 E-01$ & .06593 & $.3316 E-05$ & $52 E+04$ & 18808 \\
\hline 138 & IOP, & 7 & $9 E-01$ & 0.09879 & DE- 05 & $E+04$ & 948 \\
\hline 139 & 1OP. & 6 & $5.7003 \mathrm{E}-01$ & 0.12542 & $4.3146 E-05$ & $2.5734 E+04$ & 1.19085 \\
\hline 240 & 108 & 5 & $5.6939 \mathrm{E} \cdot 01$ & 0.14705 & 4. $3070 \mathrm{E}-05$ & $2.5597 \mathrm{E}+04$ & 1.19207 \\
\hline 141 & & & & & & & \\
\hline 141 & $10 \%$ & 4 & & 6 & -05 & $E+04$ & 16 \\
\hline 142 & lop & 3 & E. -01 & & $952 \mathrm{E}-05$ & $2.5383 E+04$ & 9400 \\
\hline 143 & $10 P$ & 2 & $5.6693 \mathrm{E} .01$ & 0.19399 & $4.2927 E-05$ & $2.5339 E+04$ & 1.19440 \\
\hline 144 & $10 \%$ & 1 & $5.6624 E-01$ & 0.19927 & $.2923 \mathrm{E}-05$ & $.5332 E+04$ & 1.19447 \\
\hline
\end{tabular}




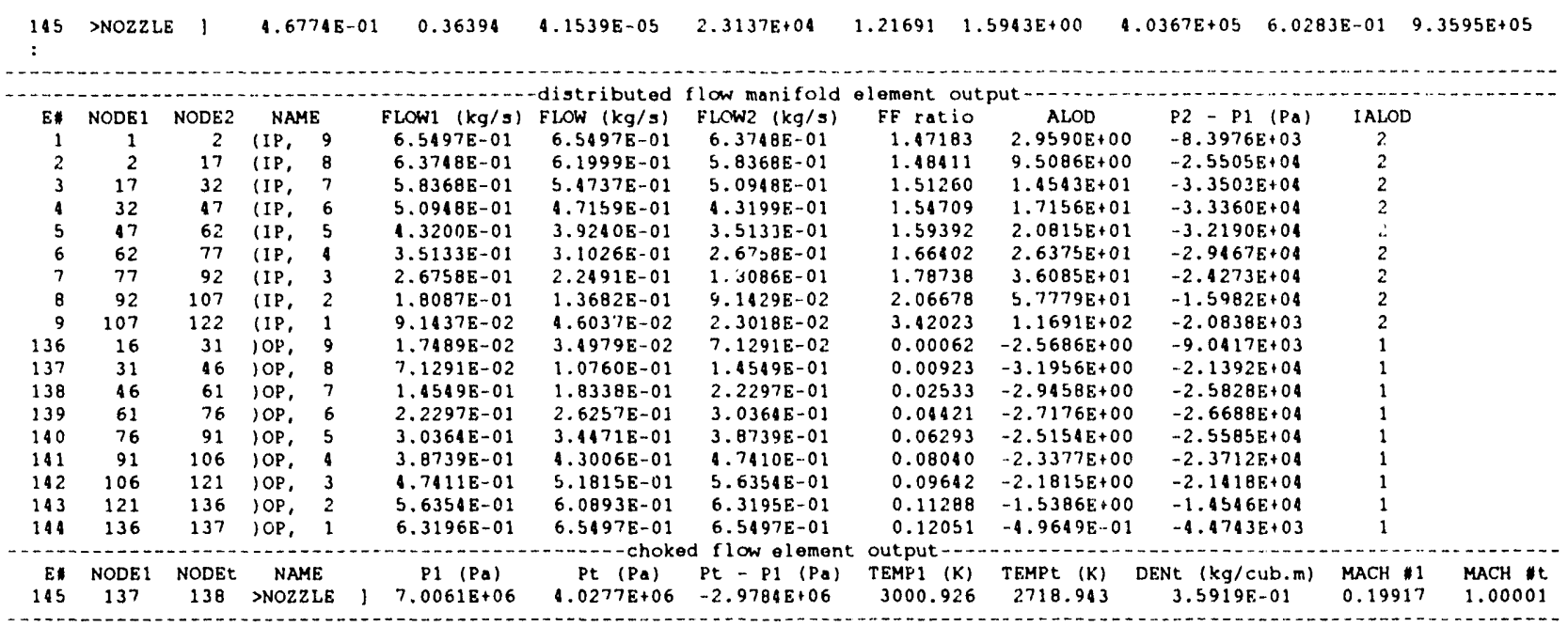

- program executed successfully - 
PROGRAM SAFSIM OUTPU' (HEAT TRANSFER)

SINGLE PBR CONICAL ELEMENT WITh 9 AXIAL LEVELS AND 14 RADIAL REGIONS

INVESTIGATE ELEMENT PEREORMANCE DURING DECAY COOLING

$\begin{aligned} & \text { v.v.v.v.v.v.v.v.v.v.v.v.v.v.v.v.v.v.v.v.v.v.v.v.v.v.v.v.v.v.v.v.v.v.v.v.v.v.v.v.v.v.v.v.v.v.v.v.v.v.v.v.v.v.v.v.v.v.v.v.v.v.v.v. } \\ &-\rightarrow \text { SYSTEM TIME }(s)=0.00000 \text { TIME STEP }\end{aligned}$

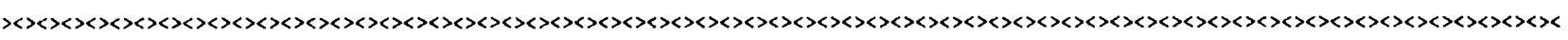

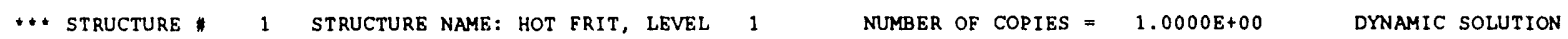

* TIME $(s)=0.00000$ SYSTEM TIME STEP $\quad 0$ SYSTEM TIME STEP $(s)=5.0000 E-03$

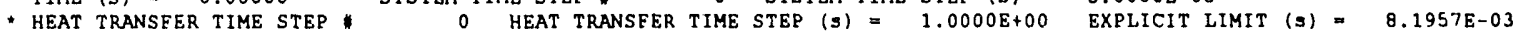

CONVECTIVE BOUNDARY CONDITION FOR SURFACE 1 AT END 1 CONNECTED TO FLUID NETWORK 1 ELEMENT 143

REYNOLDS $=4.2176 \mathrm{E}+05 \quad \mathrm{HTC}\left(\mathrm{W} / \mathrm{sq} \cdot \mathrm{m}^{*} \mathrm{~K}\right)=2.2251 \mathrm{E}+03 \quad$ FILMDROP $(\mathrm{K})=2.1 .9030 \mathrm{E}+03$

WALL TEMPERATURE $(K)=3002.693$ FLUID TEMPERATURE $(K)=3001.523$ Q $(W)=3.5286 \mathrm{E}+00$

CONVECTIVE BOUNDARY CONDITION FOR SUREACE 2 AT END 1 CONNECTED TO FLUID NETWORK 1 ELEMENT 144

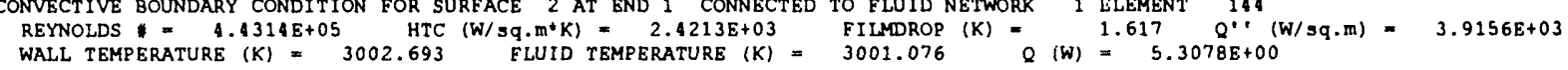

e/n I FAC Tn (K) dT/dt $(\mathrm{K} / \mathrm{s}) \mathrm{Te}(\mathrm{K}) \mathrm{dT} / \mathrm{dX}(\mathrm{K} / \mathrm{m})$ POWER (W) MATERIAL COND (W/m* $\mathrm{K}) \mathrm{C}\left(\mathrm{J} / \mathrm{kg} \mathrm{K}^{*} \mathrm{~K}\right) \mathrm{DEN}(\mathrm{kg} / \mathrm{cub} . \mathrm{m})$

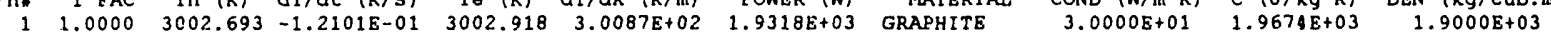

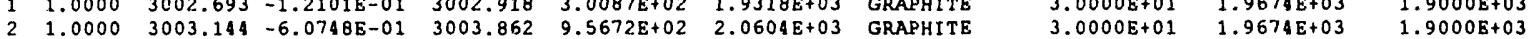

3 1.0000 $3004.579-1.0585 \mathrm{E}+00$

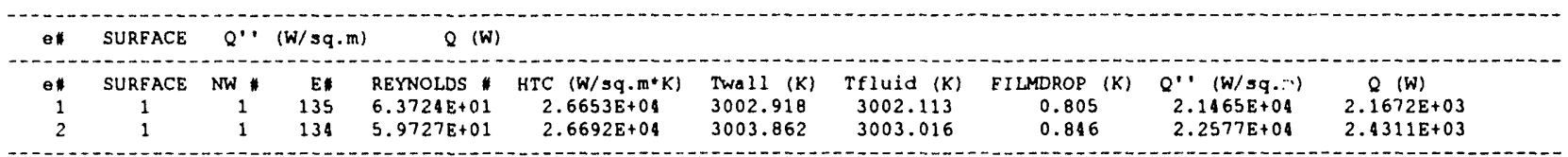

HEAT ELUX BOUNDARY CONDITION AT END 2: HEAT FLUX (W/sq.m) $=-1.9954 \mathrm{E}+05 \quad Q$ (W) $=-6.1546 \mathrm{E}+02$

STRUCTURE TOTALS: INTERNAL POWER $(W)=3.9922 \mathrm{~W}+03$ EXCHANGE POWER $(W)=3.9916 \mathrm{~W}+03$ NET POWER (W) $=5.5483 \varepsilon-01$

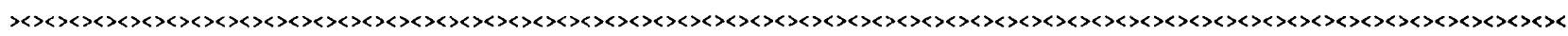

** STRUCtURE \# 2 STRUCtURE NAME: BED, LEVEL 1

NUMBER OF COPIES $=1.0000 E+00$

DYNAMIC SOLUTION

- TIME $(s)=0.00000$ SYSTEM TIME STEP $\quad 0$ SYSTEM TIME STEP ( $s$ )

- heat transfer time STEP * o heat transfer time STEP $(s)=1.0000 \mathrm{~g}+00$

$5.0000 E-03$

HEAT FLUX BOUNDARY CONDITION AT END 1 :

HEAT FLUX (W/sq.m) $=7.9818 \mathrm{E}+04$

$Q(W)=6.1546 \mathrm{E}+02$

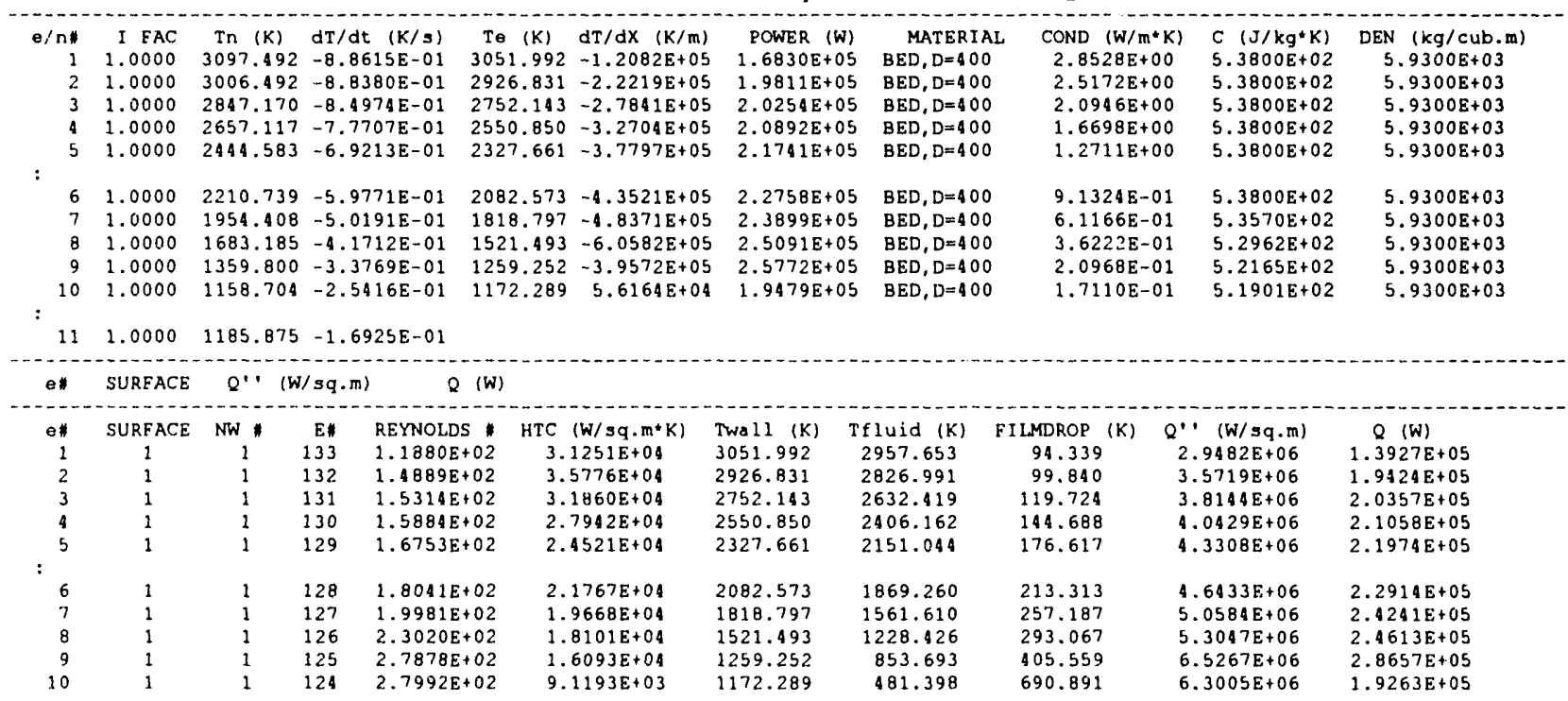

$:$

HEAT FLUX (W/sq.m) $=3.7152 \mathrm{E}+04 \quad Q(\mathrm{~W})=3.5692 \mathrm{E}+02$

STRUCTURE TOTALS: INTERNAL POWER $(W)=2.1653$ E $=06$ EXCHANGE POWER (W) $=2.1653 E+06$ NET POWER (W) $=3.5373 E-01$

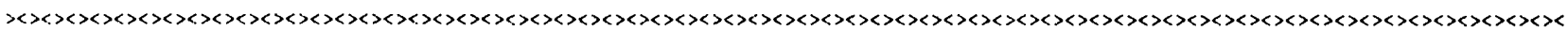

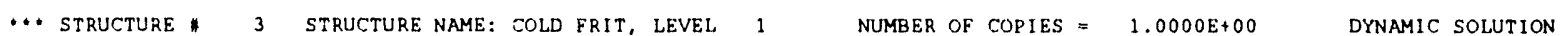

- $\operatorname{time}(s)=0.00000$ SYSTEM TIME STEP

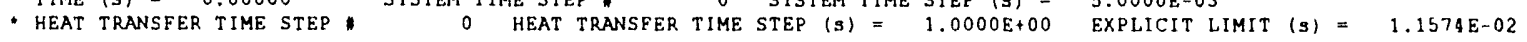

HEAT FLUX BOUNDARY CONDITION AT END 1: HEAT FLUX (W/sq.m) $=-3.7152 \mathrm{E}+04 \quad \mathrm{Q}(\mathrm{W})=-3.5692 \mathrm{E}+02$ 


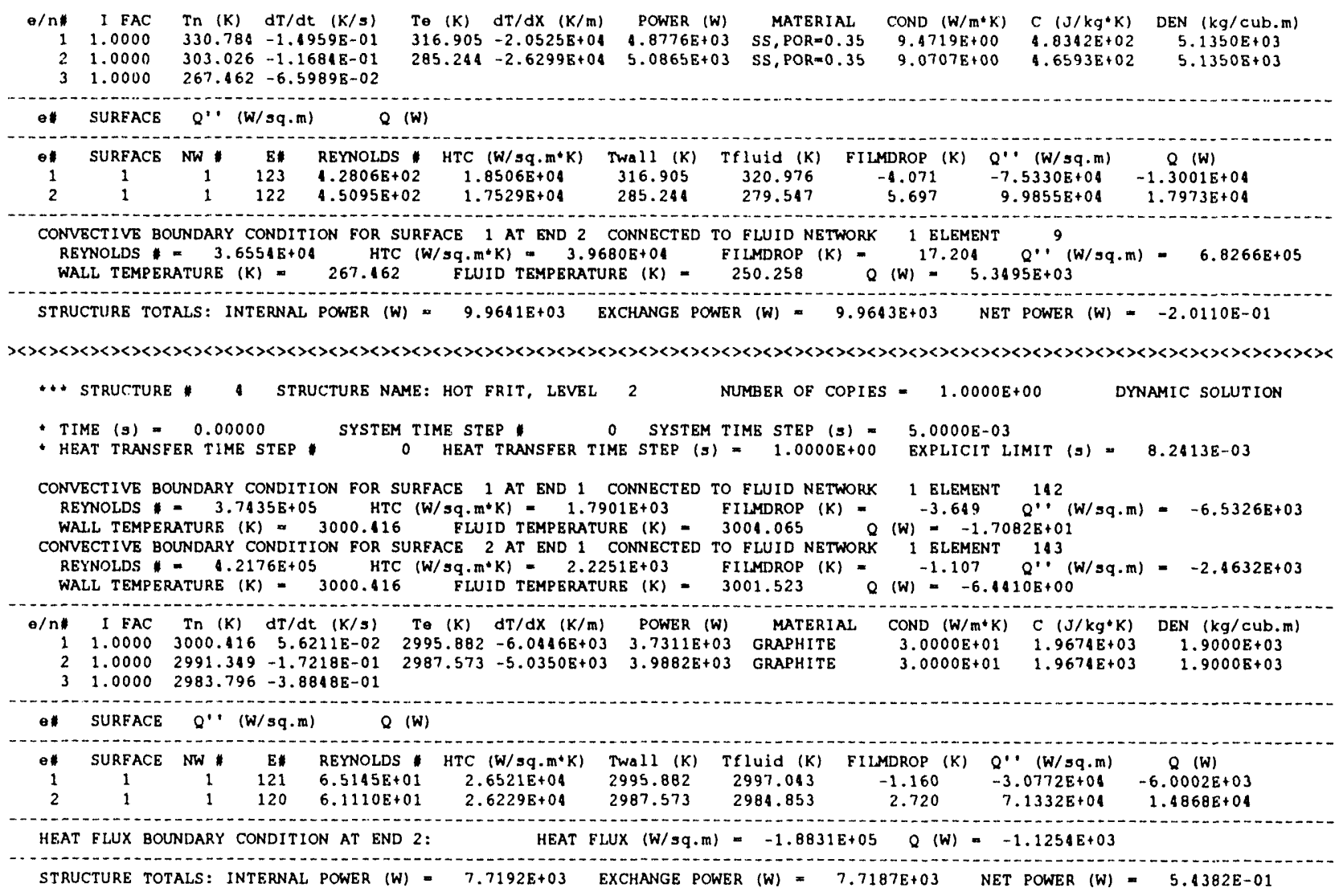

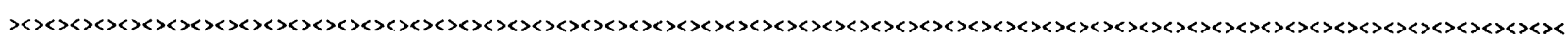

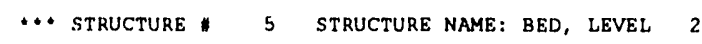

NUMBER OF COPIES - $1.0000 E+00$

DYNAMIC SOLUTION

- TIME $(s)=0.00000$
- HEAT TRANSFER TIME STEP

$5.0000 \mathrm{E}-03$

HEAT FLUX BOUNDARY CONDITION AT END 1 :

HEAT FLUX (W/sq.M) $=7.5325 \mathrm{E}+04$

EXPLICIT LIMIT (s) $=9.0521 E-03$

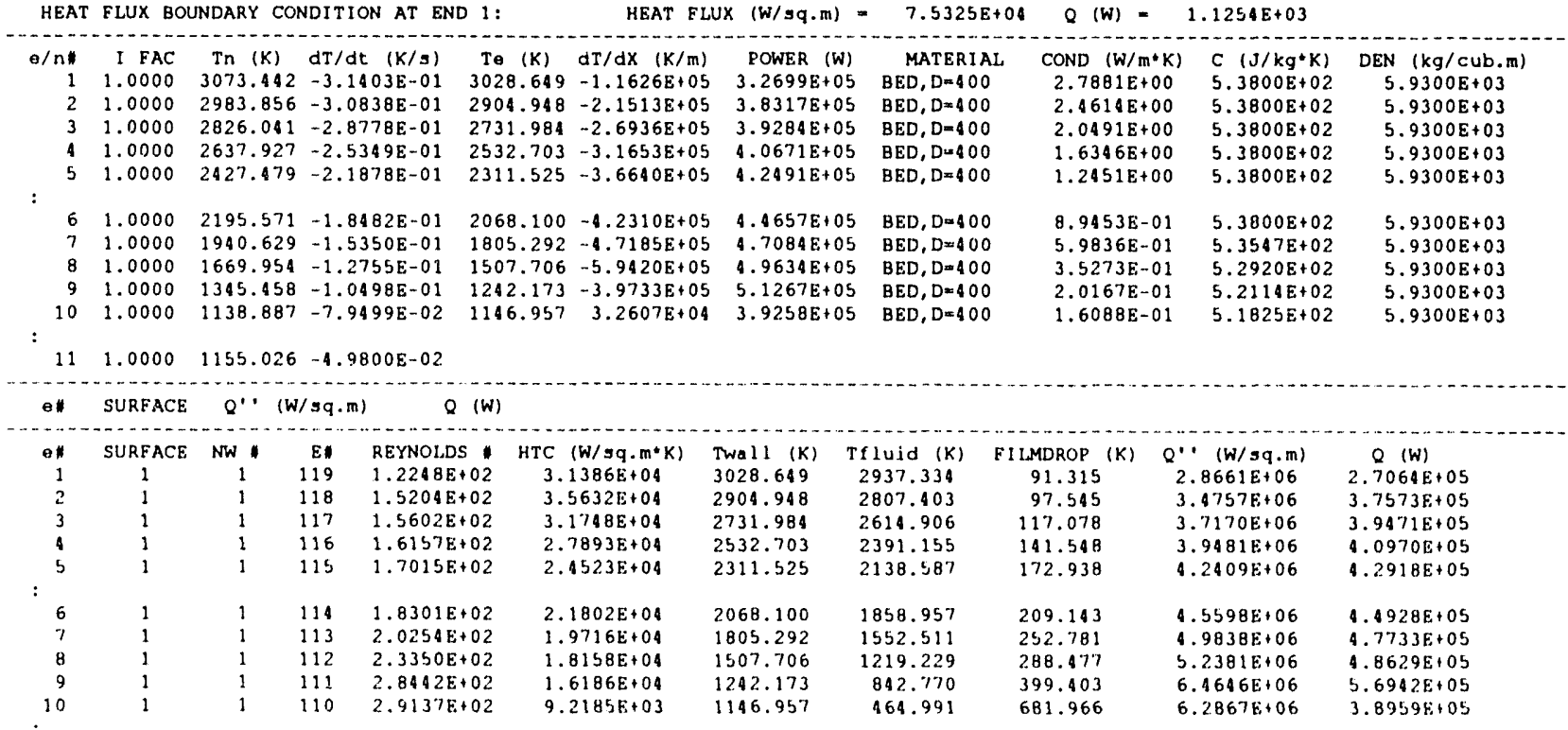

HEAT FLUX BOUNDARY CONDITION AT END 2: HEAT FluX (W/sq.m) $=3.3461 \mathrm{E}+04 \quad Q$ (W) $\quad 6.29 \% 6 \mathrm{E}+02$

STRUCTURE TOTALS: INTERNAL POWER (W) $=4.2536 \mathrm{E}+06$ EXCHANGE POWFH (W) * $4.2536 \mathrm{~W}+06$ NET POWER (W) $=$-4.3\%03E 01

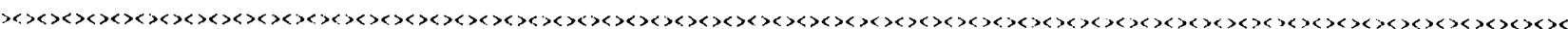

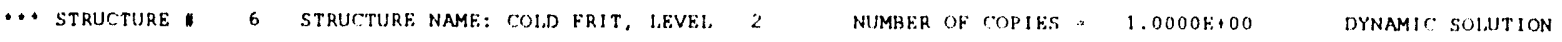

page -- 106 


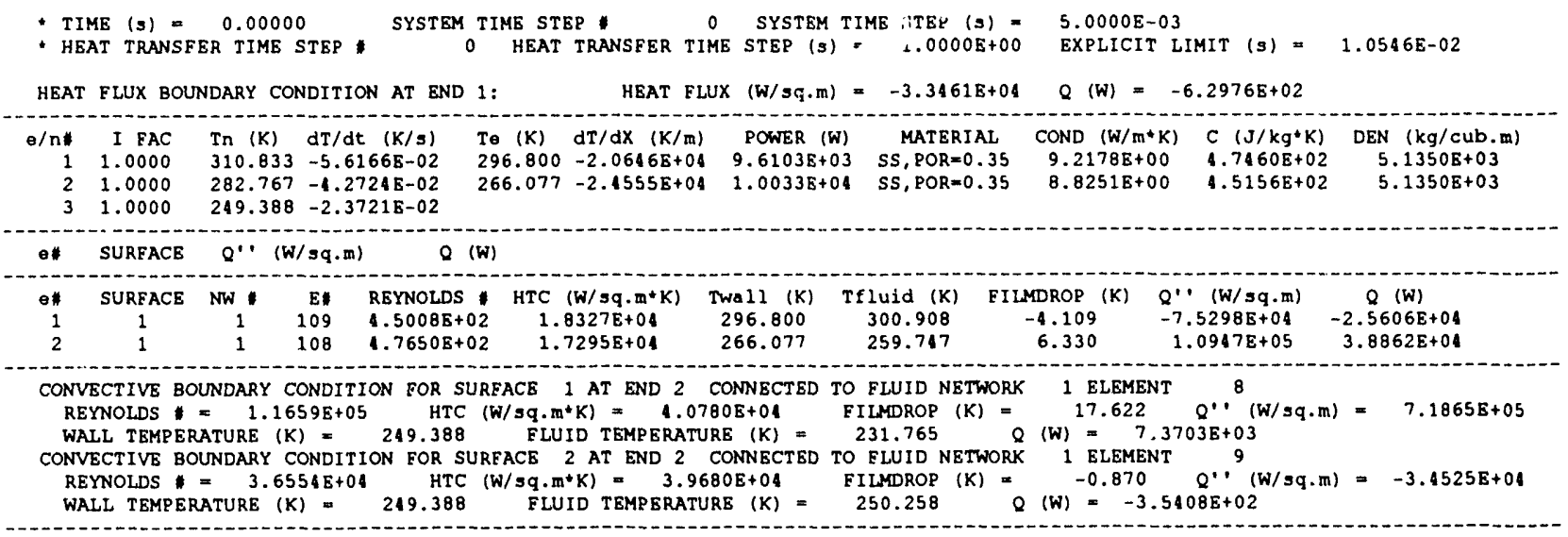

STRUCTURE TOTALS: INTERNAL POWER $(W)=1.9643 \mathrm{~W}+04$ EXCHANGE POWER (W) $=1.9643 \mathrm{E}+04$ NET POWER (W) $=-1.0679 \mathrm{E}-01$

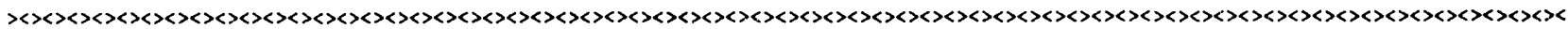

*.+ STRUCTURE * 7 STRUCTURE NAME: HOT FRIT, LEVEL 3 NUMBER OF COPIES = 1.0000 + +00 DYNAMIC SOLUTION

* TIME $(s)=0.00000$ SYSTEM TIME STEP $\quad 0$ SYSTEM TIME STEP ( $s$ ) $=5.0000$-0

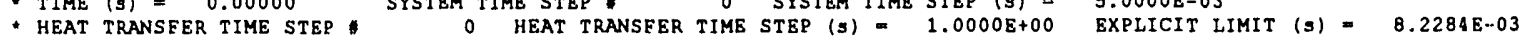

CONVECTIVE BOUNDARY CONDITION EOR SUREACE 1 AT END 1 CONNECTED TO FLUID NETWORK 1 ELEMENT 141 REYNOLDS $=3.2676 \mathrm{E}+05$ HTC $\left(\mathrm{W} / \mathrm{sq} \cdot \mathrm{m}^{*} \mathrm{~K}\right)=1.402 .0 \mathrm{E}+03 \quad$ FILMDROP $(\mathrm{K})=-5.101$ - $Q^{\prime \prime}(\mathrm{W} / \mathrm{sq} \cdot \mathrm{m})=-7.1514 \mathrm{E}+03$ WALL TEMPERATURE $(K)=3004.245$ FLUID TEMPERATURE $(K)=3009.346 \quad Q(W)=-1.7782 E+01$

CONVECTIVE BOUNDARY CONDITION FOR SURFACE 2 AT END 1 CONNECTED TO FLUID NETWORK 1 ELEMENT $142(\mathrm{~W} / \mathrm{sq} . \mathrm{m})=3.2166 \mathrm{~m}+02$ $0(w)=7.9983 E-01$

\begin{tabular}{|c|c|c|c|c|c|c|c|c|c|c|c|c|}
\hline $\begin{array}{r}\text { e/n } \\
1 \\
2 \\
3\end{array}$ & $\begin{array}{r}\text { I EAC } \\
1.0000 \\
1.0000 \\
1.0000\end{array}$ & $\begin{array}{c}\operatorname{Tn}(\mathrm{K}) \\
3004.245 \\
2993.413 \\
2984.144\end{array}$ & $\begin{array}{r}d T / d t \\
1.87 \\
4.05 \\
-9.97\end{array}$ & $\begin{array}{r}(\mathrm{K} / \mathrm{s}) \\
92 \mathrm{E}-01 \\
61 \mathrm{E}-02 \\
52 \mathrm{E}-02\end{array}$ & $\begin{array}{l}\mathrm{Te} \\
2998 \\
2988\end{array}$ & $\begin{array}{l}(\mathrm{K}) \\
.829 \\
3.778\end{array}$ & $\begin{array}{l}\mathrm{dT} / \mathrm{dX} \quad(\mathrm{K} / \mathrm{m}) \\
-7.2215 \mathrm{E}+03 \\
-6.1793 \mathrm{E}+03\end{array}$ & $\begin{array}{r}\text { POWER (W) } \\
3.5543 E+03 \\
3.8114 E+03\end{array}$ & $\begin{array}{l}\text { MATERIAL } \\
\text { GRAPHITE } \\
\text { GRAPHITE }\end{array}$ & $\begin{array}{c}\text { COND }(W / m+K) \\
3.0000 \mathrm{E}+01 \\
3.0000 \mathrm{E}+01\end{array}$ & 6) $\begin{array}{l}C\left(\mathrm{~J} / \mathrm{kg}^{*} \mathrm{~K}\right) \\
1.9674 \mathrm{E}+03 \\
1.9674 \mathrm{E}+03\end{array}$ & $\begin{array}{c}\text { DEN (kg/cub.m) } \\
1.9000 \mathrm{E}+03 \\
1.9000 \mathrm{E}+03\end{array}$ \\
\hline e* & SURFACE & $Q^{\prime \prime}(W$ & ) & & (W) & & & & & & & \\
\hline $\begin{array}{r}e \\
1 \\
2\end{array}$ & $\begin{array}{c}\text { SUREACE } \\
1 \\
1\end{array}$ & $\begin{array}{c}\text { NW } \\
1 \\
1\end{array}$ & $\begin{array}{r}\text { E* } \\
107 \\
106\end{array}$ & $\begin{array}{l}\text { REYNOLD } \\
6.6299 \mathrm{E} \\
6.2029 \mathrm{E}\end{array}$ & $\begin{array}{l}S \% \\
+01 \\
+01\end{array}$ & $\begin{array}{r}\text { HTC } \\
2 . \\
2 .\end{array}$ & $\begin{array}{l}(W / s q \cdot m * K) \\
6599 E+04 \\
6244 E+04\end{array}$ & $\begin{array}{l}\text { Twall (K) } \\
2998.829 \\
2988.778\end{array}$ & $\begin{array}{l}\text { Ifluid (K) } \\
3000.360 \\
2985.725\end{array}$ & $\begin{array}{c}\text { EILMDROP (K) } \\
-1.531 \\
3.053\end{array}$ & $\begin{array}{l}2 \%(W / \mathrm{sq} . \mathrm{m}) \\
-4.0735 \mathrm{E}+04 \\
8.0128 \mathrm{E}+04\end{array}$ & $\begin{array}{c}Q(W) \\
-7.5665 E+03 \\
1.5961 E+04\end{array}$ \\
\hline
\end{tabular}

HEAT FLUX BOUNDARY CONDITION AT END 2: HEAT FLUX (W/sq.m) $=-1.7687 \mathrm{E}+05 \quad \mathrm{Q}$ (W) $=-1.0117 \mathrm{E}+03$

STRUCTURE TOTALS: INTERNAL POWBR $(W)=7.3657 \mathrm{~W}+03$ EXCHANGE POWER $(W)=7.3656 \mathrm{~W}+03$ NET POWER (W) $=1.6784 \mathrm{E}-01$

\rangle\langle\rangle\langle\rangle\langle\rangle\langle\rangle\langle\rangle\langle\rangle\langle\rangle\langle\rangle\langle\rangle\langle\rangle\langle\rangle\langle\rangle\langle\rangle\langle\rangle\langle\rangle\langle\rangle\langle\rangle\langle\rangle\langle\rangle\langle\rangle\langle\rangle\langle\rangle\langle\rangle\langle\rangle\langle\rangle\langle\rangle\langle\rangle\langle\rangle\langle\rangle\langle\rangle\langle\rangle\langle\rangle\langle\rangle\langle\rangle\langle\rangle\langle\rangle\langle\rangle\langle\rangle\langle\rangle\langle\rangle\langle\rangle\langle\rangle\langle\rangle\langle\rangle\langle\rangle\langle\rangle\langle\rangle\langle\rangle\langle\rangle\langle\rangle\langle\rangle\langle\rangle\langle\rangle\langle\rangle\langle\rangle\langle\rangle\langle\rangle\langle\rangle\langle\rangle\langle\rangle\langle\rangle\langle\rangle\langle\rangle\langle

** STRUCTURE * 8 STRUCTURE NAME: BED, LEVEL $3 \quad$ NUMBER OF COPIES $=1.0000$ +00

- $\operatorname{TIME}(s)=0.00000 \quad$ SYSTEM TIME STEP $\quad 0$ SYSTEM TIME STEP $(s)=5.0000$ )

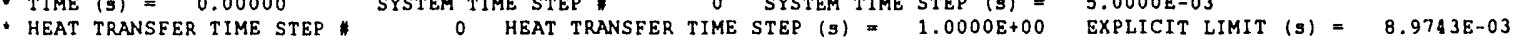

HEAT FLUX BOUNDARY CONDITION AT END 1: HEAT FLUX (W/sq.m) $=7.0750 E+04 \quad Q$ (W) $=1.0117 E+03$

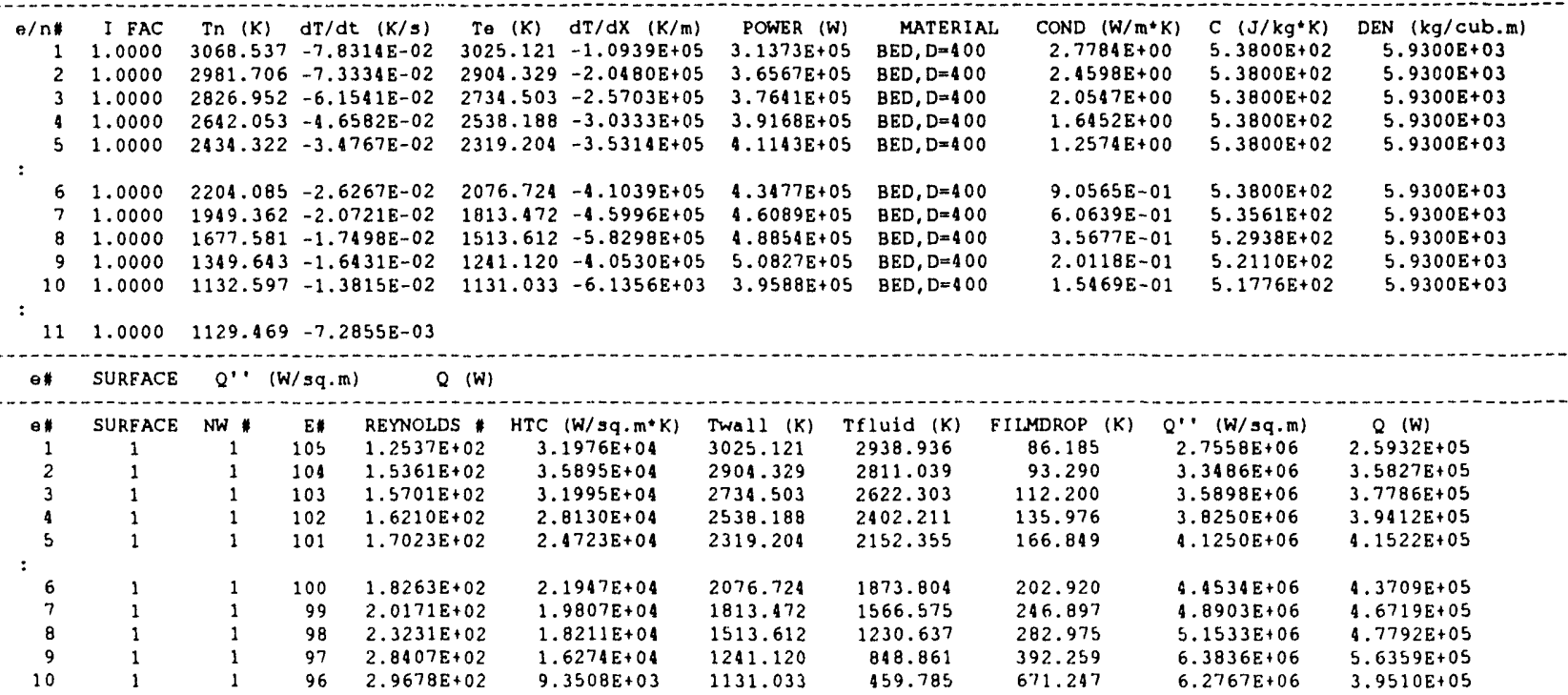




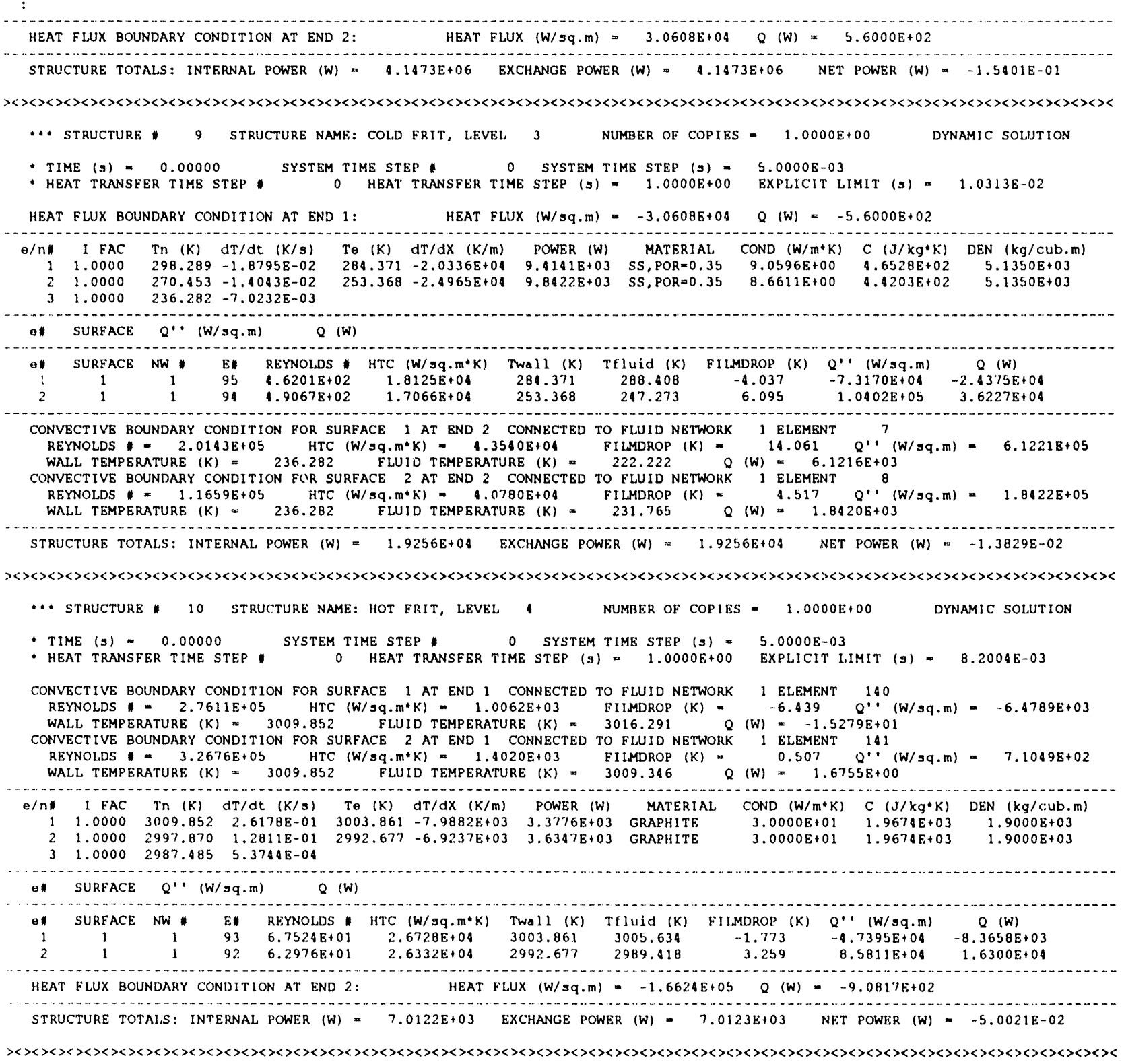

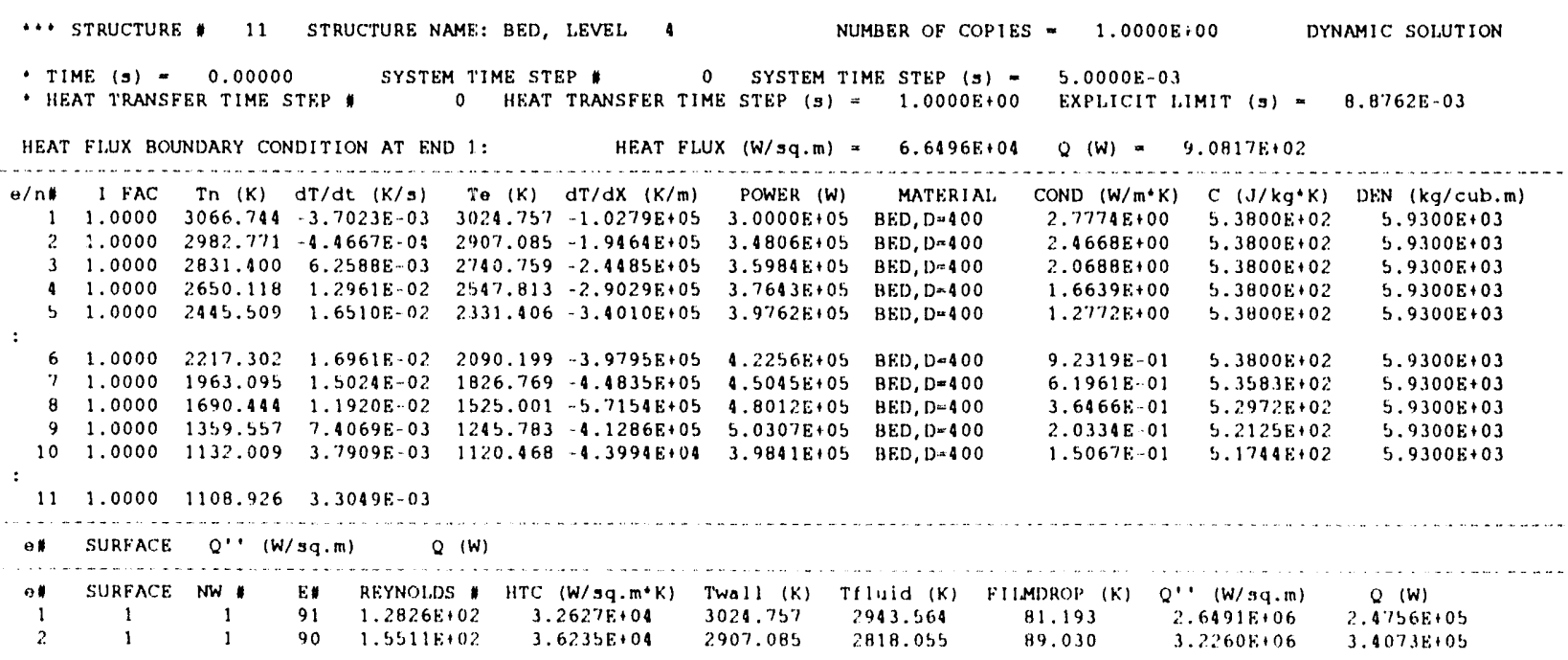

page -- 108 


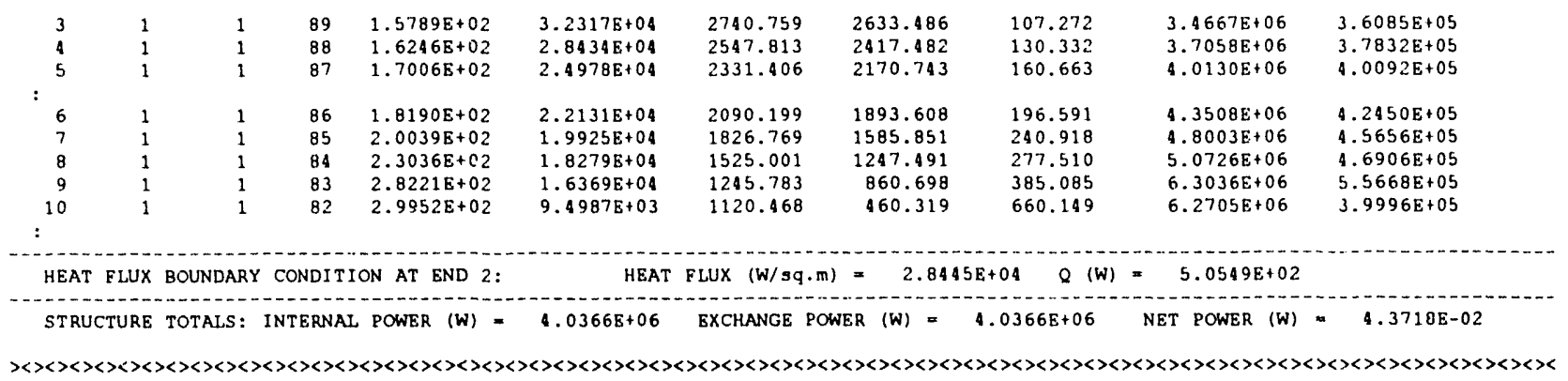

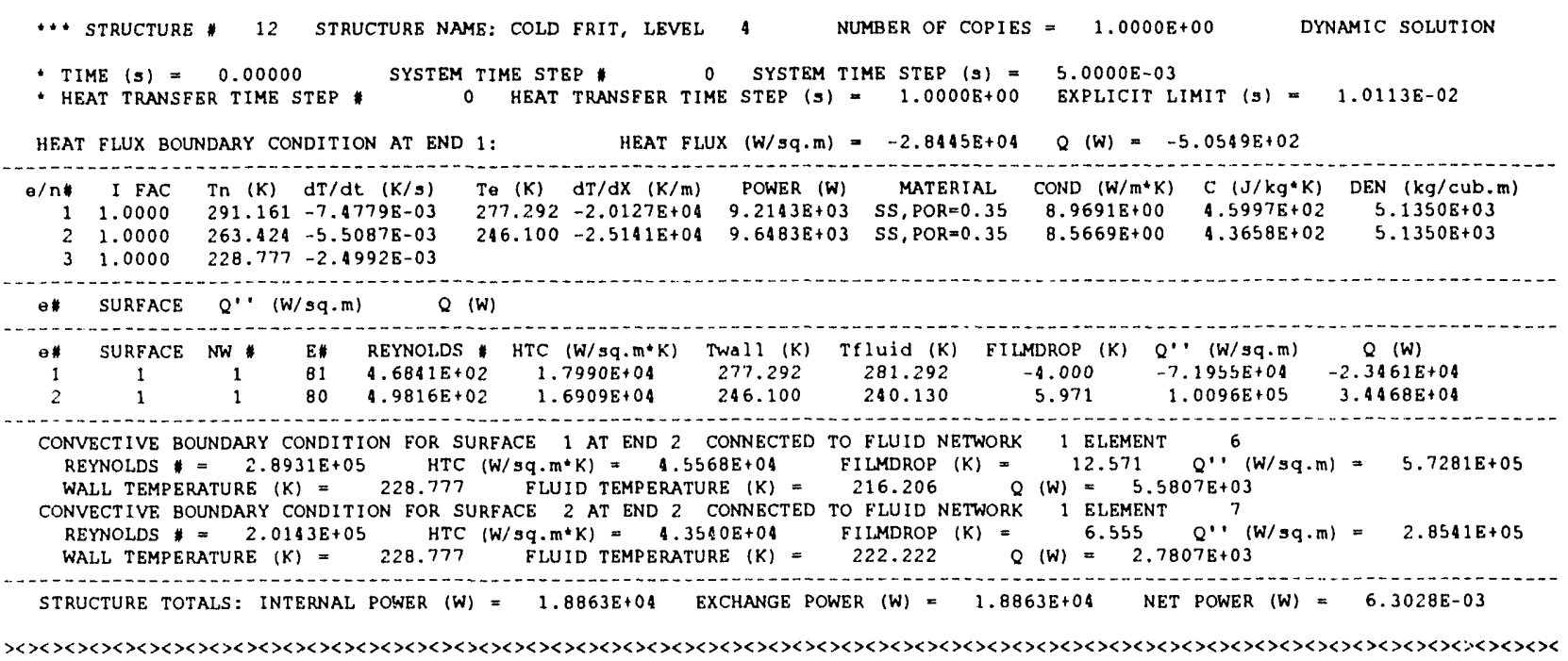

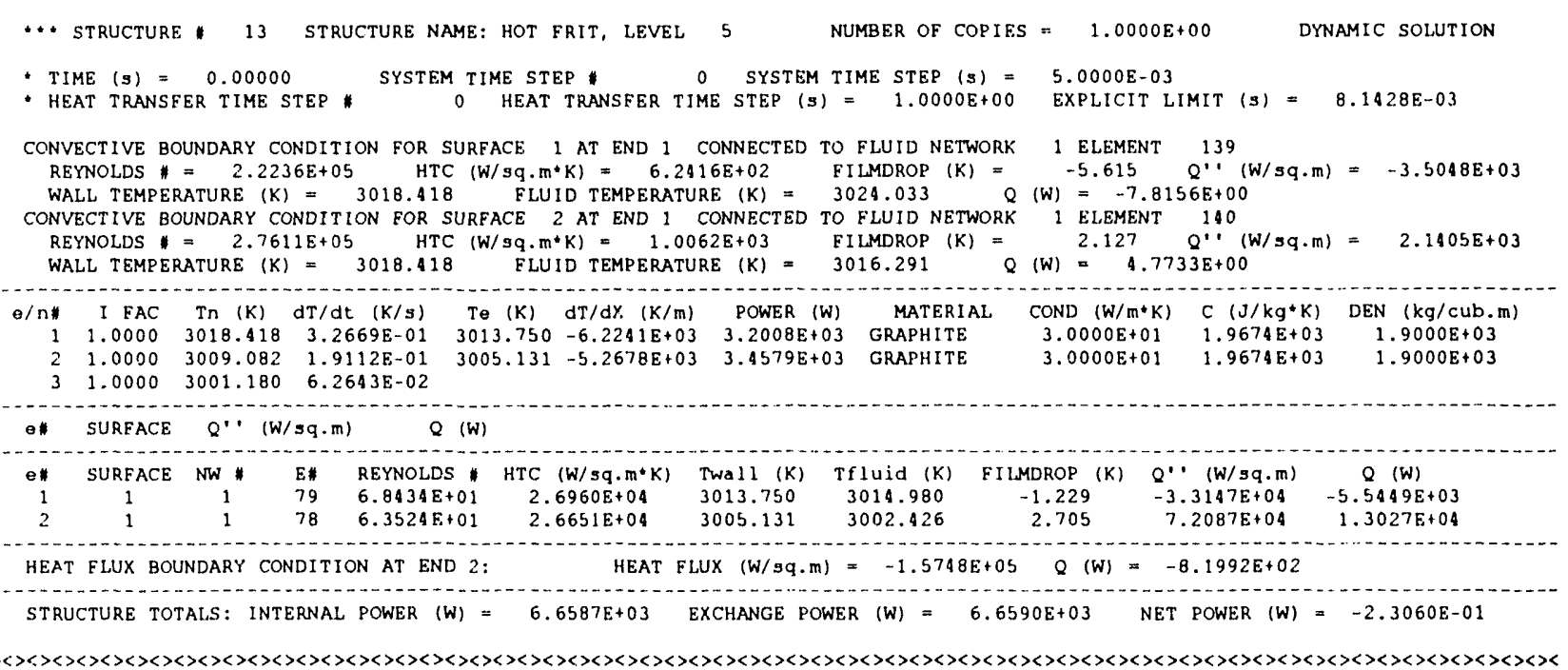

\begin{tabular}{|c|c|c|c|c|c|c|c|c|c|c|}
\hline$\cdots$ & STRUCTURE & 14 & STRUCTURE NA & AME: BED, & LEVEL & \multicolumn{2}{|c|}{ NUMBER OF COPIES } & \multicolumn{3}{|c|}{ DYNAMIC SOLUTION } \\
\hline \multirow{2}{*}{\multicolumn{2}{|c|}{$\begin{array}{l}\text { - TIME }(s)= \\
\text { - HEAT TRANSFE }\end{array}$}} & 0.0000 & 0 SYSTEM & 4 TIME STE & EP $\# \quad 0$ & SYSTEM TIM & ME $\operatorname{sTER}(s)=$ & \multicolumn{2}{|l|}{$5.0000 \mathrm{E}-03$} & \\
\hline & & ER TIME & STEP & HEAT & TRANSFER TIME & STEP $(s)=$ & $1.0000 \mathrm{E}+00$ & \multicolumn{3}{|c|}{ EXPLICIT LIMIT $(s)=8.7399 \mathrm{E}-03$} \\
\hline HEAT & \multicolumn{4}{|c|}{ FLUX BOUNDARY CONDITION AT END 1 : } & HEAT FLUX & $(W / s q \cdot m)=$ & $6.2993 E+04$ & \multicolumn{2}{|r|}{$8.1992 E+02$} & \\
\hline$e / n \|$ & I FAC & $\operatorname{Tn}(\mathrm{K})$ & $\mathrm{dT} / \mathrm{dt} \quad(\mathrm{K} / \mathrm{s})$ & $\mathrm{Te}(K)$ & $\mathrm{dT} / \mathrm{dX} \quad(\mathrm{K} / \mathrm{m})$ & POWER (W) & MATERIAI, & $\operatorname{COND}\left(\mathrm{W} / \mathrm{m}^{*} \mathrm{~K}\right)$ & $\mathrm{C}(\mathrm{J} / \mathrm{kq}+\mathrm{K})$ & DEN $(\mathrm{kg} / \mathrm{cub}, \mathrm{m})$ \\
\hline 1 & 1.0000 & 3075.439 & $3.8072 \mathrm{E}-02$ & 3034.985 & $-9.6310 \mathrm{E}+04$ & $2.8587 E+05$ & BED, $D=400$ & $2.8056 \mathrm{E}+00$ & $5.3800 E+02$ & $5.9300 E+03$ \\
\hline 2 & 1.0000 & 2994.532 & $3.9025 \mathrm{E}-02$ & 2920.721 & $-1.8459 \mathrm{E}+05$ & $3.3041 E+05$ & BED, $D=400$ & $2.5016 \mathrm{E}+00$ & $5.3800 E+02$ & $5.9300 E+03$ \\
\hline 3 & 1.0000 & 2846.910 & $4.0833 \mathrm{E}-02$ & 2758.199 & $-2.3303 E+05$ & $3.4319 E+05$ & $B E D, D=400$ & $2.1083 E+00$ & $5.3800 E+02$ & $5.9300 E+03$ \\
\hline 4 & 1.0000 & 2669.489 & $4.1218 E-02$ & 2568.739 & $-2.7800 E+05$ & $3.6100 E+05$ & $B E D, D=400$ & $1.7050 E+00$ & 5. $3800 E+02$ & $5.9300 E+03$ \\
\hline 5 & 1.0000 & 2467.989 & $3.9397 \mathrm{E}-02$ & 2354.713 & $-3.2832 E+05$ & $3.8354 \mathrm{E}+05$ & $B E D, D=400$ & $1.3156 E+00$ & $5.3800 E+02$ & $5.9300 \mathrm{E}+03$ \\
\hline \multicolumn{11}{|c|}{ 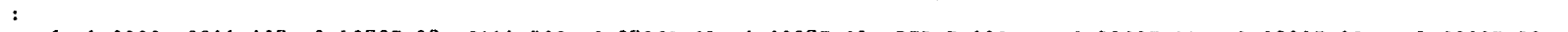 } \\
\hline $\begin{array}{l}6 \\
7\end{array}$ & $\begin{array}{l}1.0000 \\
1.0000\end{array}$ & $\begin{array}{l}2241.437 \\
1986.981\end{array}$ & $\begin{array}{l}3.5372 \mathrm{E}-02 \\
2.9739 \mathrm{E}-02\end{array}$ & $\begin{array}{l}2114.209 \\
1849.690\end{array}$ & $\begin{array}{l}-3.8736 E+05 \\
-4.3907 E+05\end{array}$ & $\begin{array}{l}4.0997 E+05 \\
4.3952 E+05\end{array}$ & $\begin{array}{l}\text { BED, } D=400 \\
B E D, D=400\end{array}$ & $\begin{array}{l}9.5503 E-01 \\
6.4284 E-01\end{array}$ & $\begin{array}{l}5.3800 E+02 \\
5.3622 E+02\end{array}$ & $\begin{array}{l}5.9300 E+03 \\
5.9300 E+03\end{array}$ \\
\hline$\theta$ & 1.0000 & 1712.398 & $2.3699 \mathrm{E}-02$ & 1544.896 & $-5.6270 E+05$ & $4.7112 \mathrm{E}+05$ & $B E D, D=400$ & $3.7872 \mathrm{E}-01$ & $5.3033 E+02$ & $5.9300 E+03$ \\
\hline 9 & 1.0000 & 1377.394 & $1.6886 \mathrm{E}-02$ & 1257.634 & $-4.2260 E+05$ & $4.9710 \mathrm{E}+05$ & BED, $D=400$ & $2.0891 \mathrm{E}-01$ & $5.2161 \mathrm{E}+02$ & $5.9300 E+03$ \\
\hline
\end{tabular}




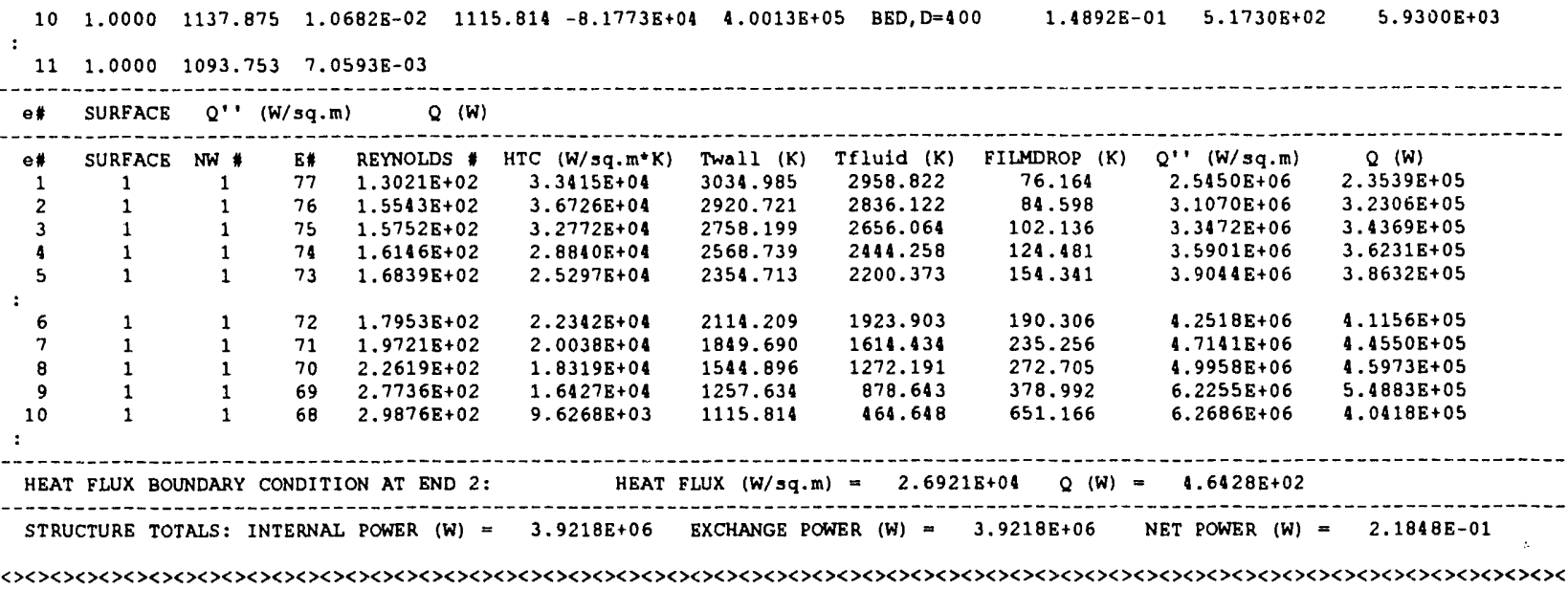

** STRUCTURE * 15 STRUCTURE NAME: COLD FRIT, LEVEL 5 NUMBER OF CODIES = 1.0000 E+00 DYNAMIC SOLUTION

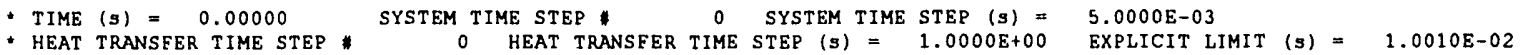

HEAT FLUX BOUNDARY CONDITION AT END 1: HEAT FLUX (W/sq.m) $=-2.6921 \mathrm{E}+04 \quad Q$ (W) $=-4.6428 \mathrm{~W}+02$

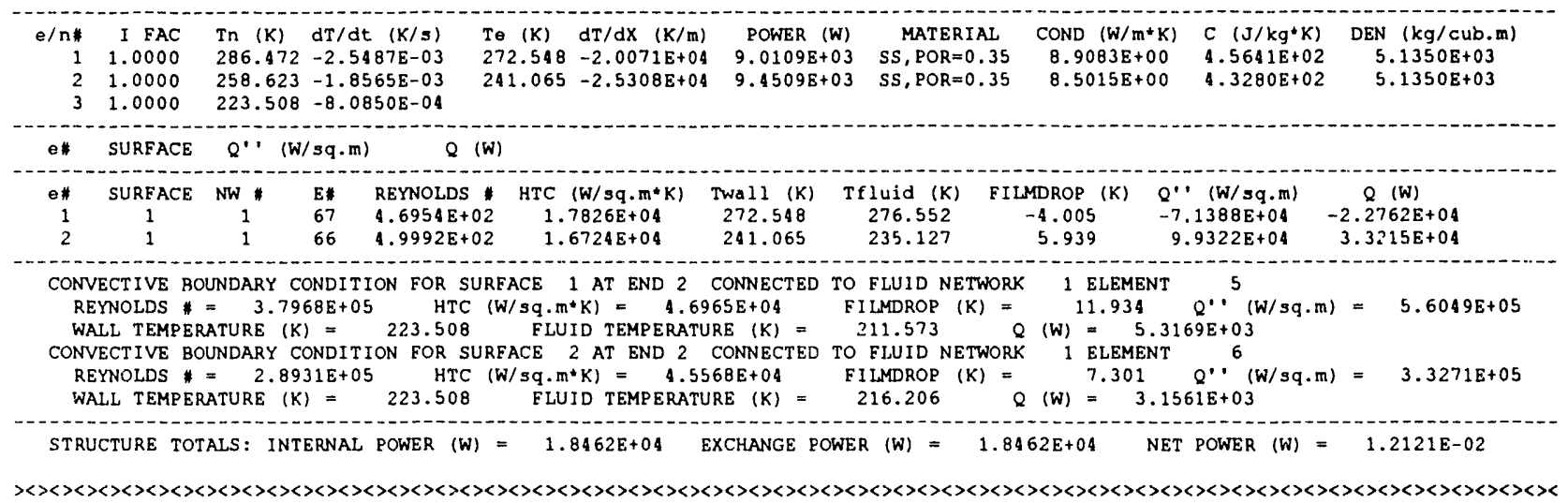

\#* STRUCTURE \# 16 STRUCTURE NAME: HOT FRIT, LEVEL $6 \quad$ NUMBER OF COPIES = 1.0000 \& $+00 \quad$ DYNAMIC SOLUTION

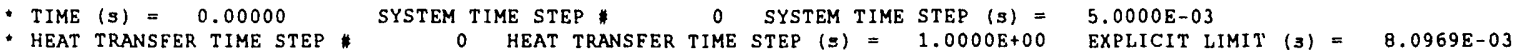

CONVECTIVE BOUNDARY CONDITION FOR SUREACE 1 AT END 1 CONNECTED TO FLUID NETWORK 1 ELEMENT 138 REYNOLDS $=1.6474 \mathrm{E}+05$ HTC $\left(\mathrm{W} / \mathrm{sq} \cdot \mathrm{m}^{*} \mathrm{~K}\right)=2.9537 \mathrm{E}+02 \quad$ FILMDROP $(\mathrm{K})=-6.668 \quad Q^{*}(\mathrm{~W} / \mathrm{sq} \cdot \mathrm{m})=-1.9695 \mathrm{E}+03$ WALL TEMPERATURE $(K)=3026.053$ FLUID TEMPERATURE $(K)=3032.721 \quad$ Q $(W)=-4.1394 \mathrm{E})=0$

CONVECTIVE BOUNDARY CONDITION FOR SURFACE 2 AT END 1 CONNECTED TO FLUID NETWORK 1 ELEMENT 139 REYNOLDS $*=2.2236 \mathrm{E}+05 \quad \mathrm{HTC}\left(\mathrm{W} / \mathrm{sq} \cdot \mathrm{m}^{*} \mathrm{~K}\right)=6.2416 \mathrm{E}+02 \quad$ EILMDROP $(\mathrm{K})=\quad 2.020 \quad Q^{\cdots}(\mathrm{W} / \mathrm{sq} \cdot \mathrm{m})=1.2605 \mathrm{E}+03$ WALL TEMPERATURE $(K)=3026.053$ FLUID TEMPERATURE $(K)=3024.033$ Q $(\mathrm{W})=2.6492 \mathrm{E}+00$

e/n* I FAC Tn (K) dT/dt (K/s) Te (K) dT/dX (K/m) POWER (W) MATERIAL COND (W/m*K) C (J/kg*K) DEN (kg/:Zub.m)

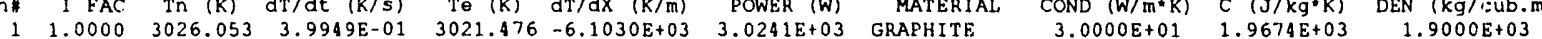

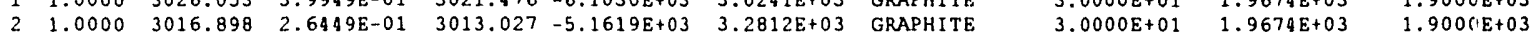
$31.0000 \quad 3009.155 \quad 1.3675 \mathrm{E}-01$

E SUREACE Q $Q^{\prime \prime}$ (W/sq.m) $Q$ (W)

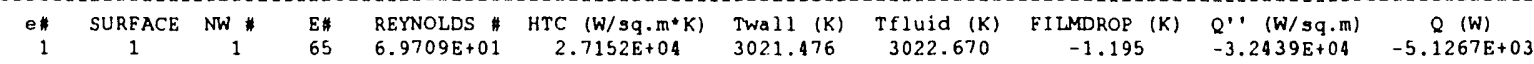
$\begin{array}{lllllllllll}2 & 1 & 1 & 64 & 6.4422 \mathrm{E}+01 & 2.6848 \mathrm{E}+04 & 3013.027 & 3010.384 & 2.643 & 7.0970 \mathrm{E}+04 & 1.2170 \mathrm{E}+04\end{array}$

HEAT FLUX BOUNDARY CONDITION AT END 2: HEAT FLUX (W/sq.m) $=-1.4872 \mathrm{E}+05 \quad 0$ (W) $=-7.3614 \mathrm{E}+02$

STRUCTURE TOTALS: INTERNAL POWER $(W)=6.3052 E+03$ EXCHANGE POWER $(W)=6.3056 E+03$ NET POWER (W) $=-4.1963 E-01$

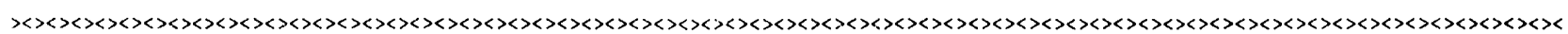

\# STRUCTURE \# 17 STRUCTURE NAME: BED, LEVEL $6 \quad$ NUMBER OF COPIES = 1.0000 E+00

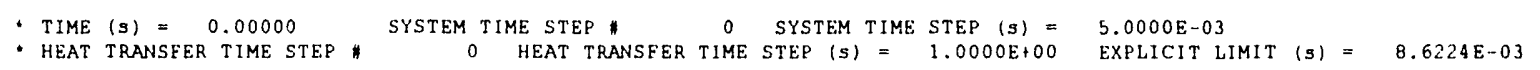

HEAT FLUX BOUNDARY CONDITION AT END 1: HEAT FLUX (W/sq.m) $=5.9488 E+04 \quad Q(\mathrm{~W})=7.3614 \mathrm{E}+02$

e/n* I FAC Tn (K) dT/dt (K/g) Te (K) dT/dX (K/m) POWER (W) MATERIAL COND (W/m.K) C (J/KG:K) DEN (Kg/CUb.m)

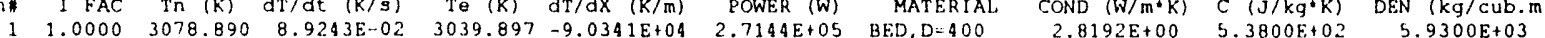




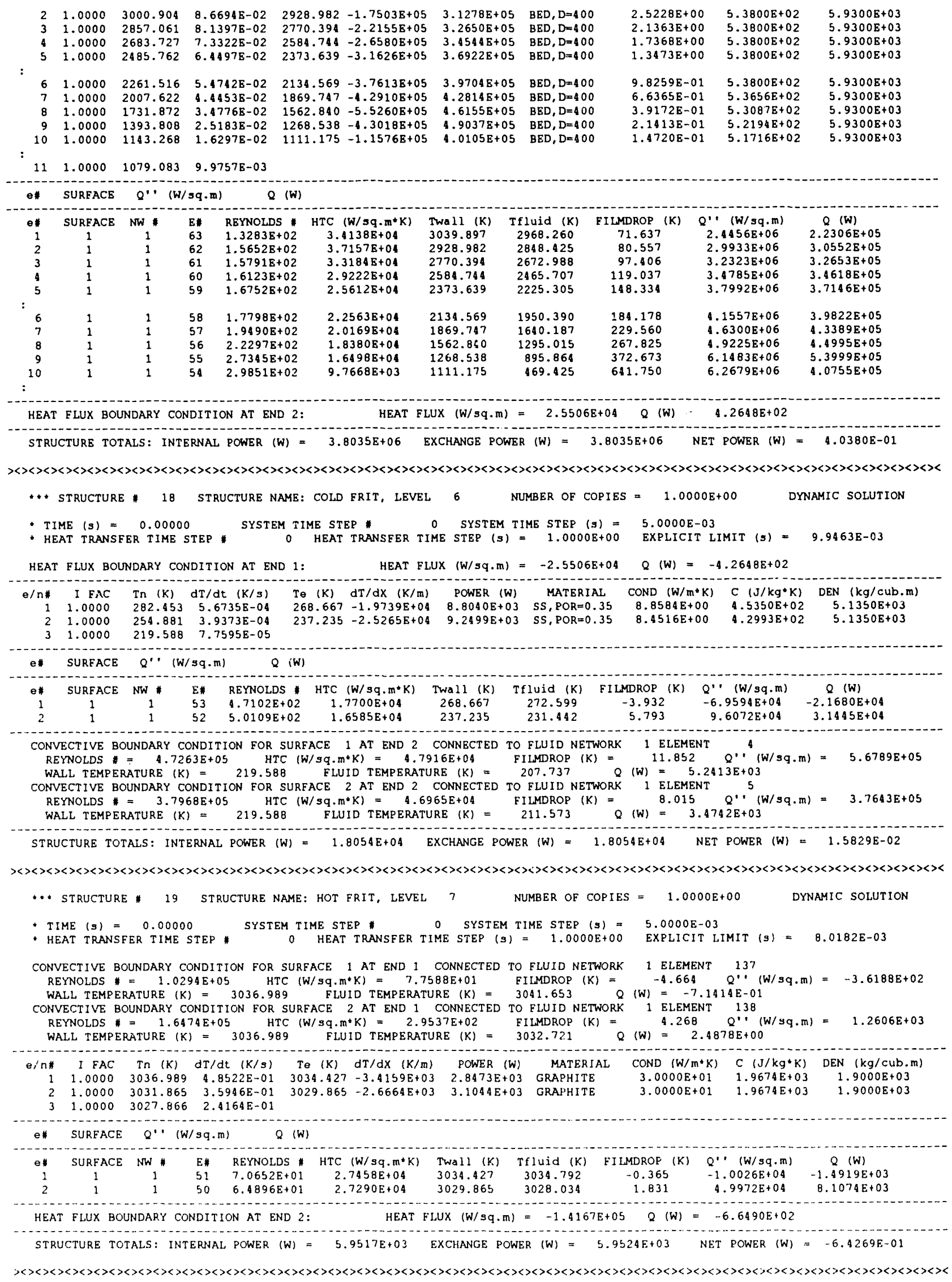




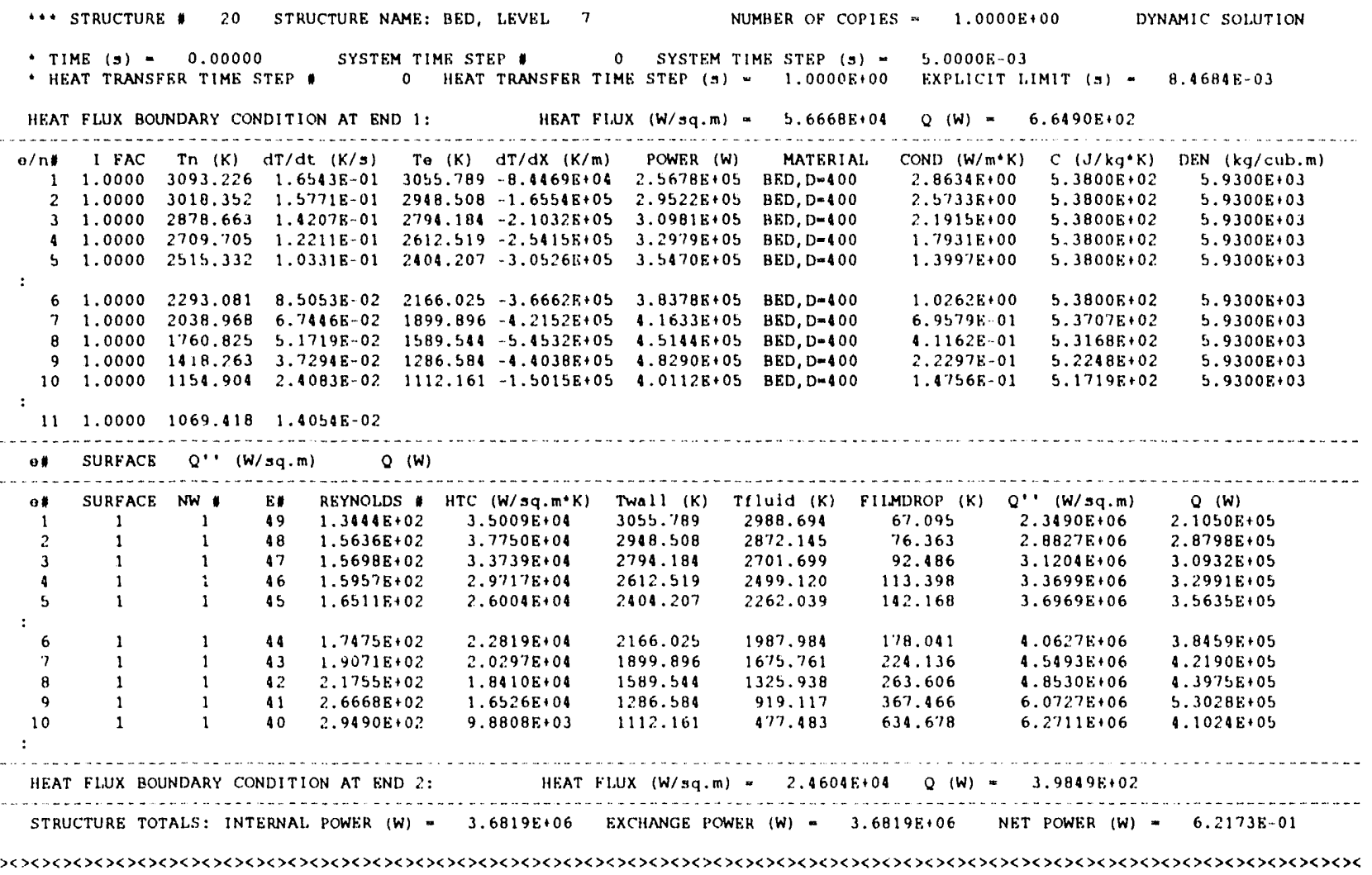

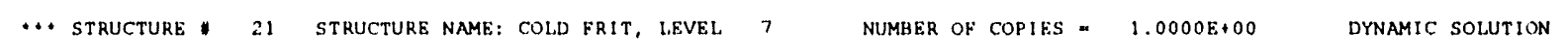

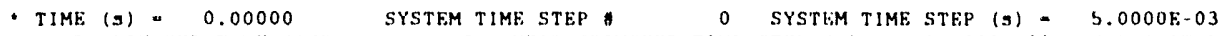

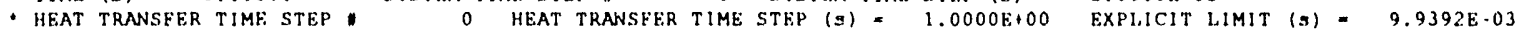

HEAT FIUX BOUNDARY CONDITION AT END 1: HFAT FIUX (W/sq.m) $=-2.4604 \mathrm{E}+04 \quad Q \quad(W)=-3.9849 E+02$

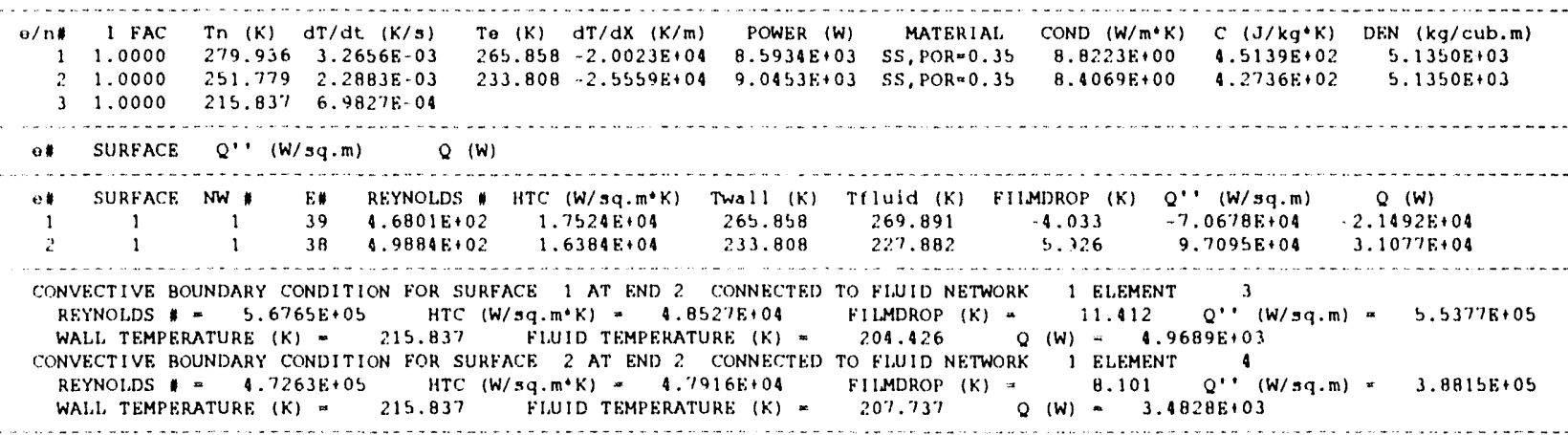
STRUCTURE TOTALS: INTERNAL POWER $(W)=1.7639 \mathrm{E}) 04$ EXCHANGE POWER (W) $=1.7639 \mathrm{E}+04$ NET POWER (W) $2.0938 \mathrm{~K}-02$ (

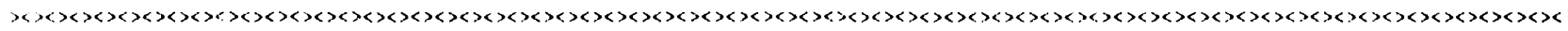

‥ STRUCTURE " 22 STRUCTURF NAME: HOT FRIT, LEVEI, 8 NUMBER OF COPIES = 1.0000 E

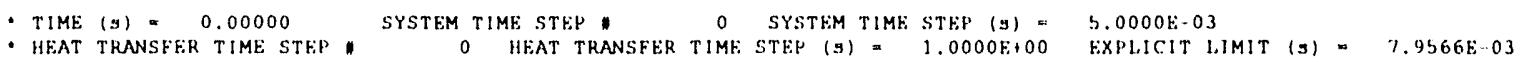

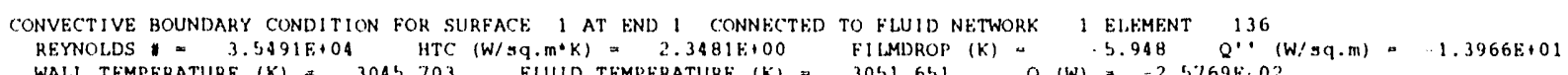

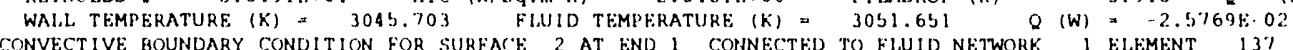

CONVECTIVE GOUNDARY CONDITION FOR SURFACE 2 AT END 1 CONNECTED TO FLUID NETWORK 1 ELLEMENT $13 \%$

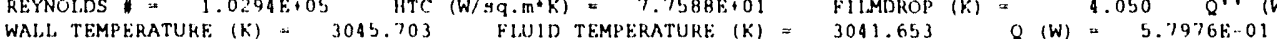

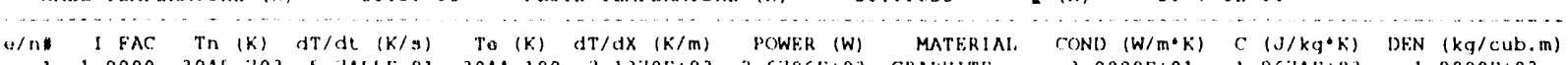

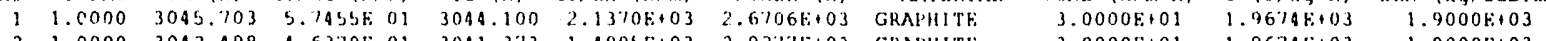

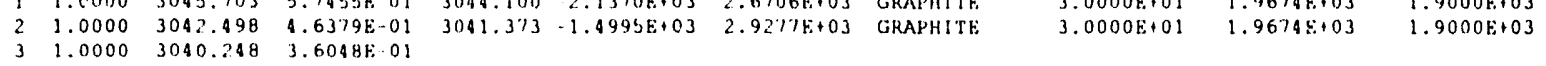

G SURFACE Q' (W/sq.m) Q (W)

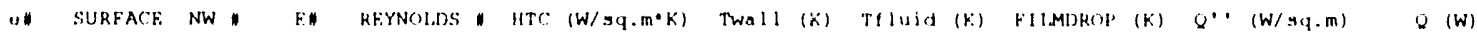




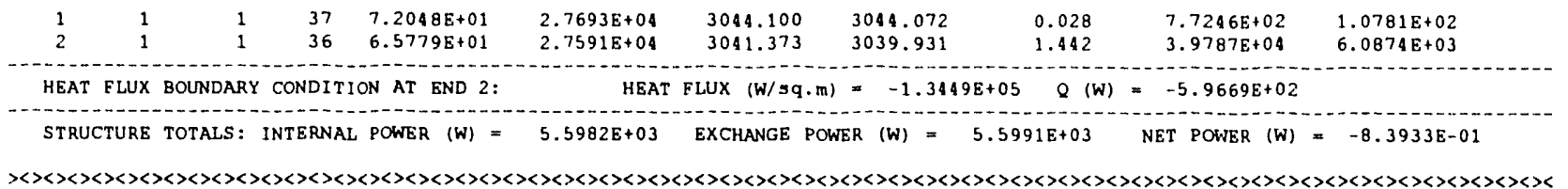

* Structure 23 STRUCTURE NAME: BED, LEVEL $8 \quad$ NUMBER OF COPIES = 1.0000 +00

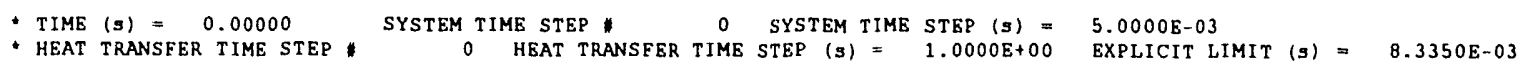

HEAT FLUX BOUNDARY CONDITION AT END 1: HEAT FLUX (W/sq.m) $=5.3796 \mathrm{E}+04 \quad Q(W)=5.9669 \mathrm{E}+02$

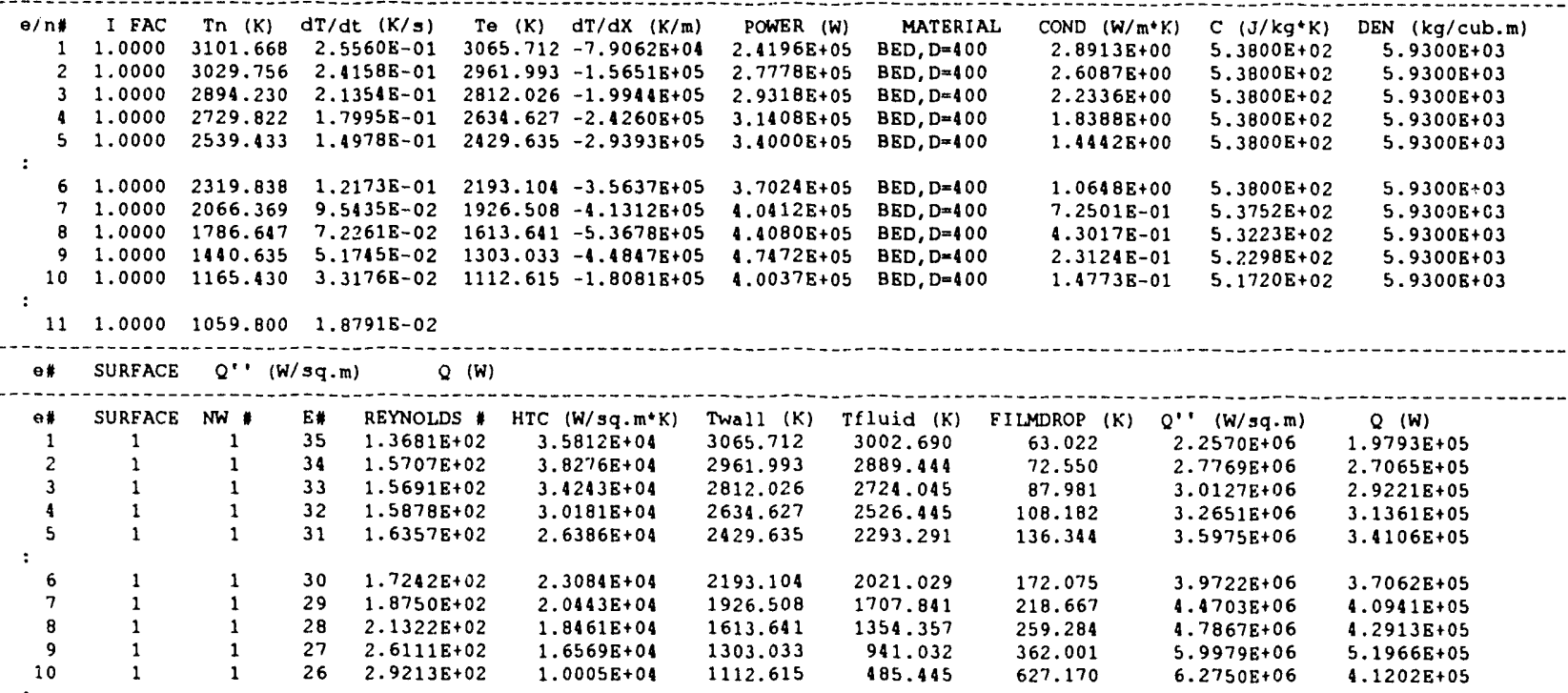

HEAT FLUX BOUNDARY CONDITION AT END 2: $\quad$ HEAT FLUX (W/sq.m) $=2.3731 \mathrm{E}+04 \quad \mathrm{Q}$ (W) $=3.7189 \mathrm{E}+02$

STRUCTURE TOTALS: INTERNAL POWER $(W)=3.5573 E+06$ EXCHANGE POWER $(W)=3.5573 E+06$ NET POWER (W) $=8.1298 E-01$ (W)

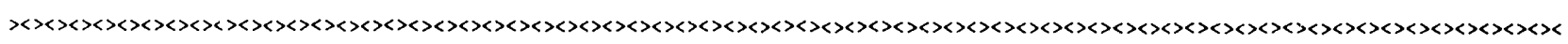

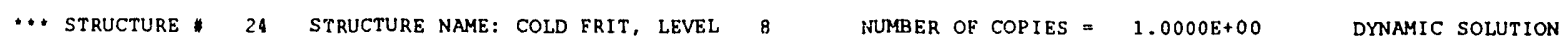

- TIME $(s)=0.00000$ SYSTEM TIME STEP *

- heat transfer time step * o heat transfer time step (s) $=1.0000 \mathrm{e}+00$ explicit Limit (s) $=9.9340 \mathrm{~s}-03$

HEAT FLUX BOUNDARY CONDITION AT END 1: HEAT FLUX (W/sq.m) $=-2.3731 \mathrm{E}+04 \quad Q(\mathrm{~W})=-3.7189 \mathrm{E}+02$

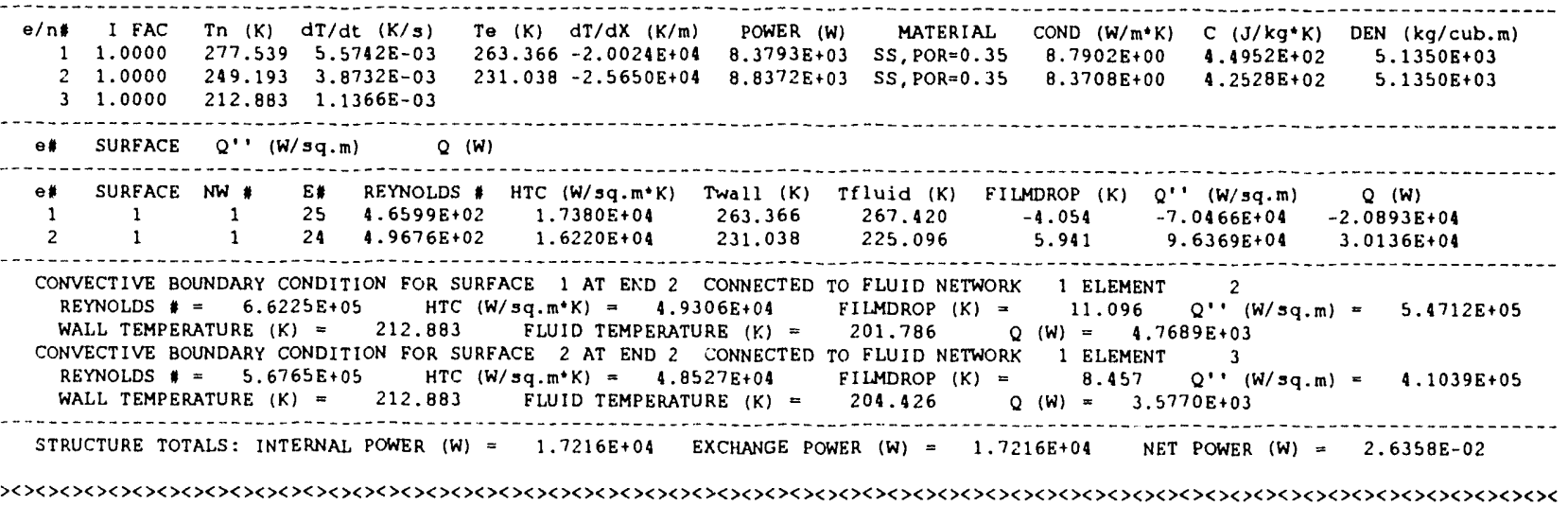

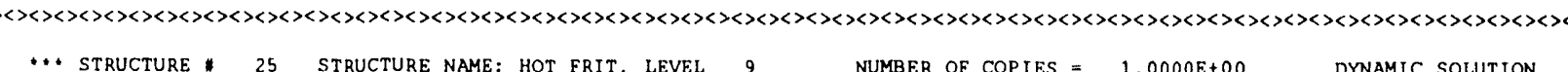

- TIME $(s)=0.00000$ SYSTEM TIME STEP $\quad 0$ SYSTEM TIME STEP $(s)=5.0000 E-03$

- HEAT TRANSFER TIME STEP $\quad 0$ HEAT TRANSFER TIME STEP $(\mathbf{s})=\begin{aligned} & 0.0000 \mathrm{~T}+00 \\ & \text { EXPLICIT LIMIT (s) }=\end{aligned}$

CONVECTIVE BOUNDARY CONDITION FOR SURFACE 1 AT END 1 CONNECTED TO FLUID NETWORK 1 ELEMENT 136

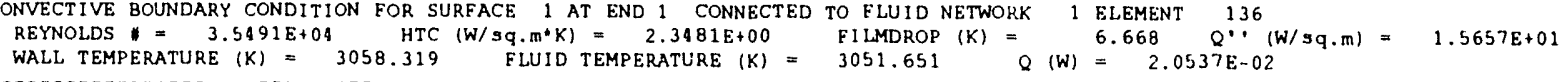

e/n I FAC Tn $(\mathrm{K}) \mathrm{dT} / \mathrm{dt}(\mathrm{K} / \mathrm{s})$ Te (K) dT/dX $(\mathrm{K} / \mathrm{m})$ POWER (W) MATERIAL COND (W/m*K) C (J/kg*K) DEN (kg/CUb.m)

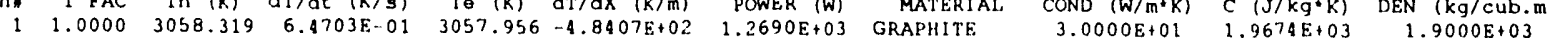




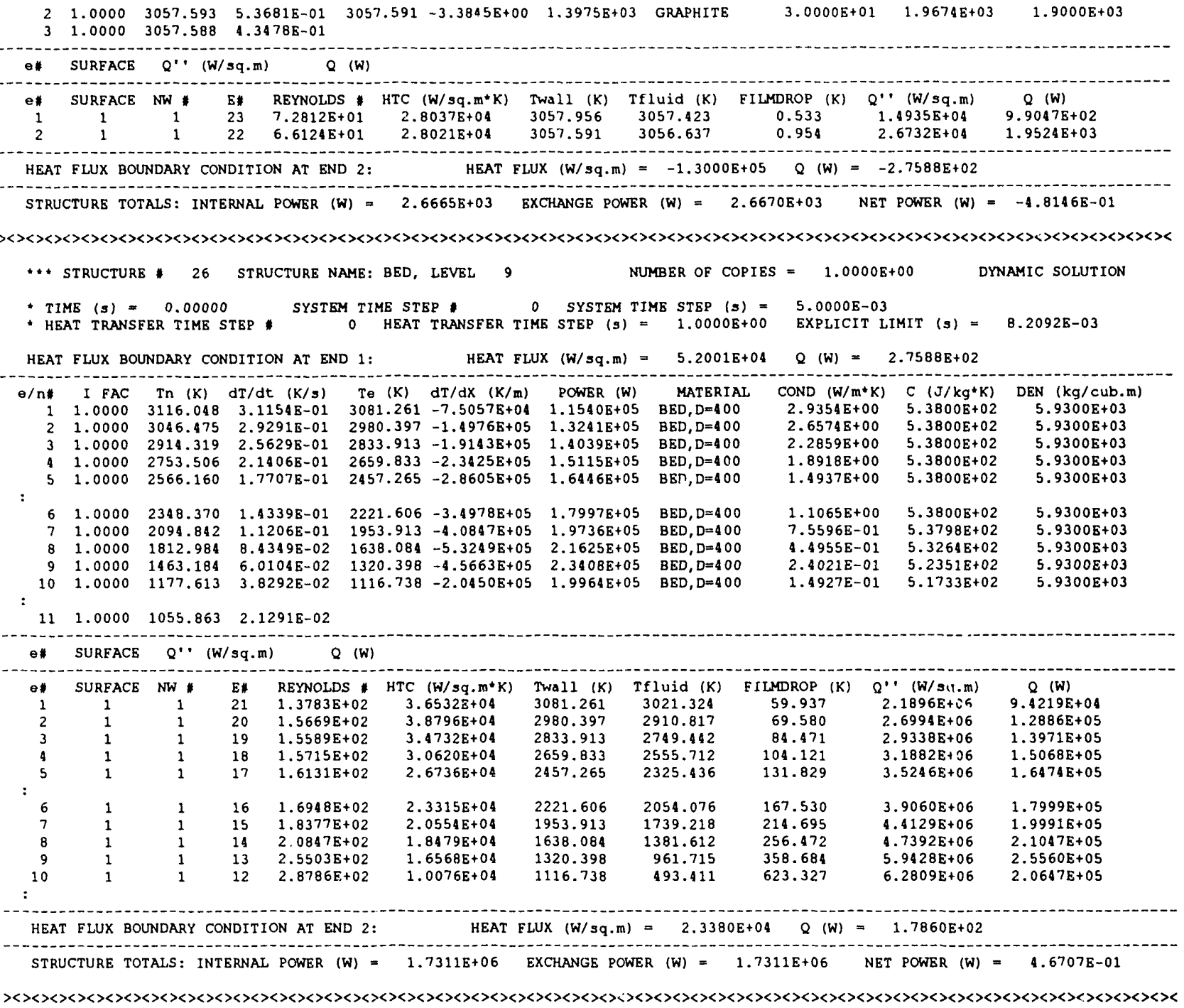

** STRUCTURE \# 27 STRUCTURE NAME: COLD FRIT, LEVEL $9 \quad$ NUMBER OF COPIES $=1.0000$ E $+00 \quad$ DYNAMIC SOLUTION

- TIME $(s)=0.00000$ SYSTEM TIME STEP

* HEAT TRANSFER TIME STEP \# 0 HEAT TRANSFER TIME STEP $(s)=1.0000 \mathrm{~s})+00$ EXPLICIT LIMIT (s) $=9.9586 \mathrm{~s}-03$

HEAT FLUX BOUNDARY CONDITION AT END 1: HEAT FLUX (W/sq.m) $=-2.3380 \mathrm{E}+04 \quad Q$ (W) $=-1.7860 \mathrm{E}+02$

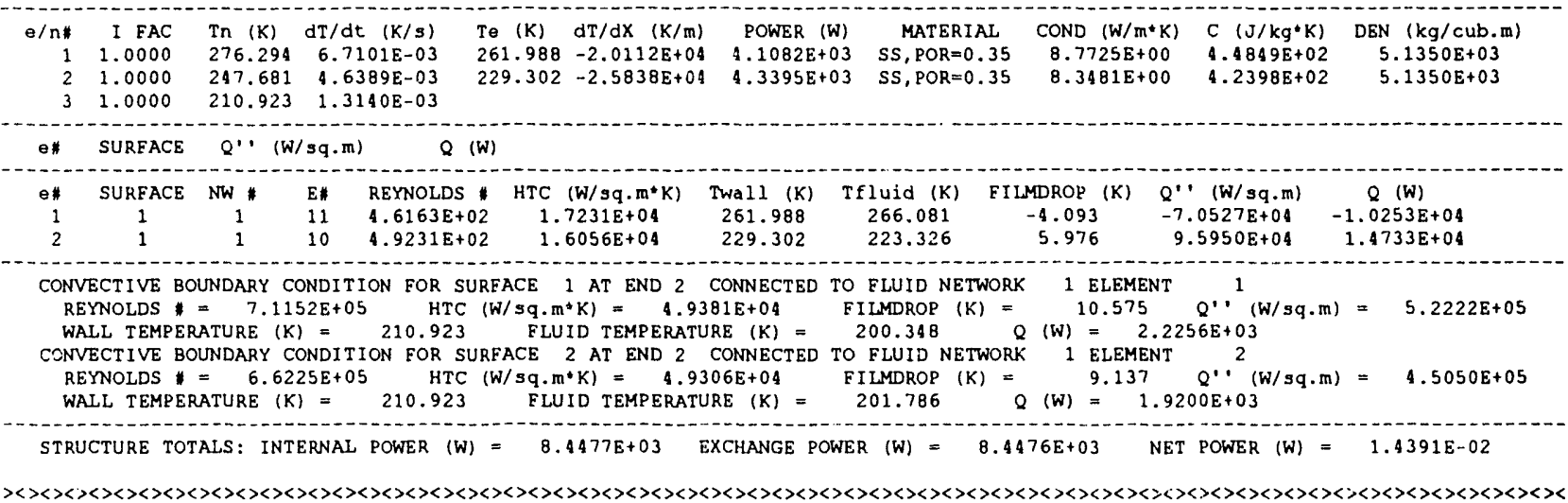

... STRUCTURE" 28 STRUCTURE NAME: FUEL PARTICLE, L9,RI NUMBER OF COPIES = 0.0000 E +00 DYNAMIC SOLUTION

- 28 STRUCTURE NAME: FUEL PARTICLE, L9,R1 NUMBER OF COPIES $=0.0000$ +00 DYNAMIC SOLUTION

* time $(s)=0.00000$ SYSTEM TIME STEP *

- heat transfer time step * o heat transfer time Step $(s)=1.0000$ e 00 explicit Limit (s) $=3.6683$ e 05

page -- 114 


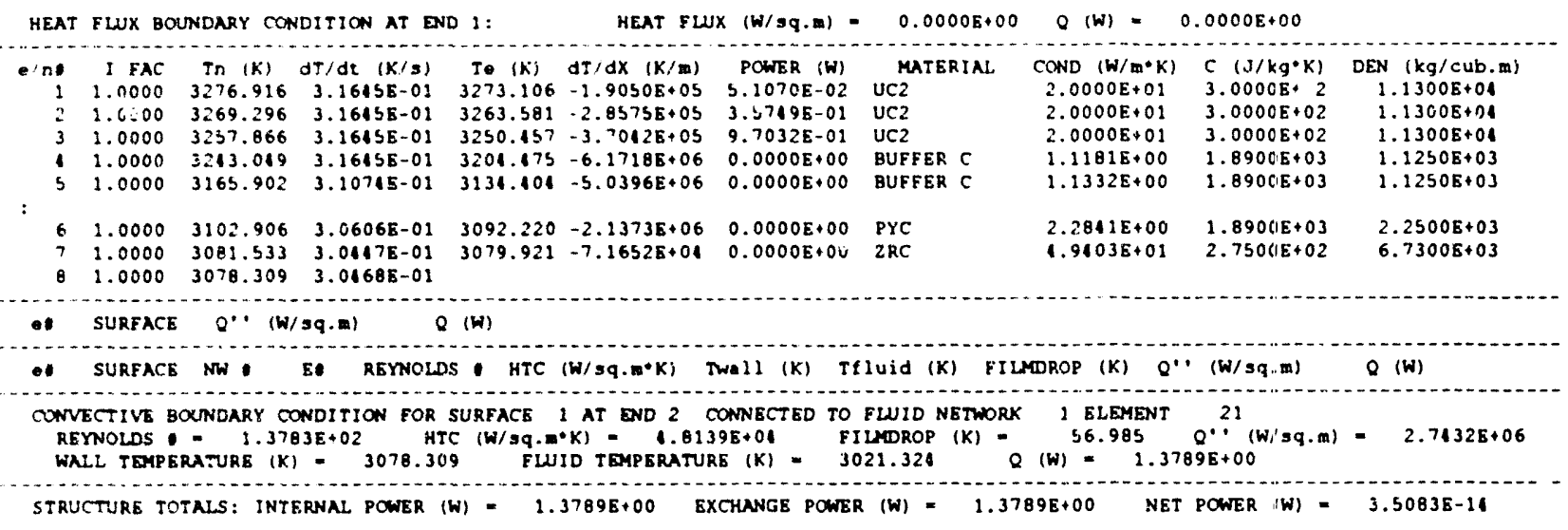

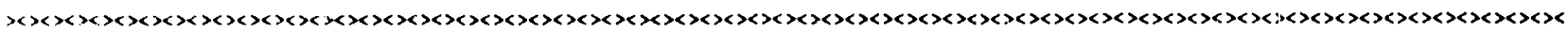

... STRUCTURE - 29 STRUCTUPE NAME: FUEL PARTICLL, L7,RI MUMER OF COPIES = 0.0000E+00 DYNAMIC SOLUTION

- TIME (S) = 0.00000 SYSTEM TIME STEP * SYSTEM TIME STEP ( 3 ) $=5.0000$-0 03

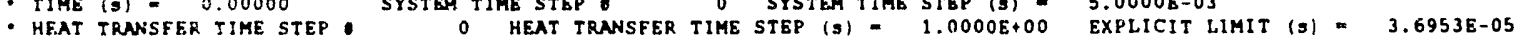

HEAT FLUX BOUNDARY CONDITION AT END $1:$ HEAT FLW (W/sq.m) $=0.0000 E+00 \quad Q$ (W) $=0.0000 E+00$

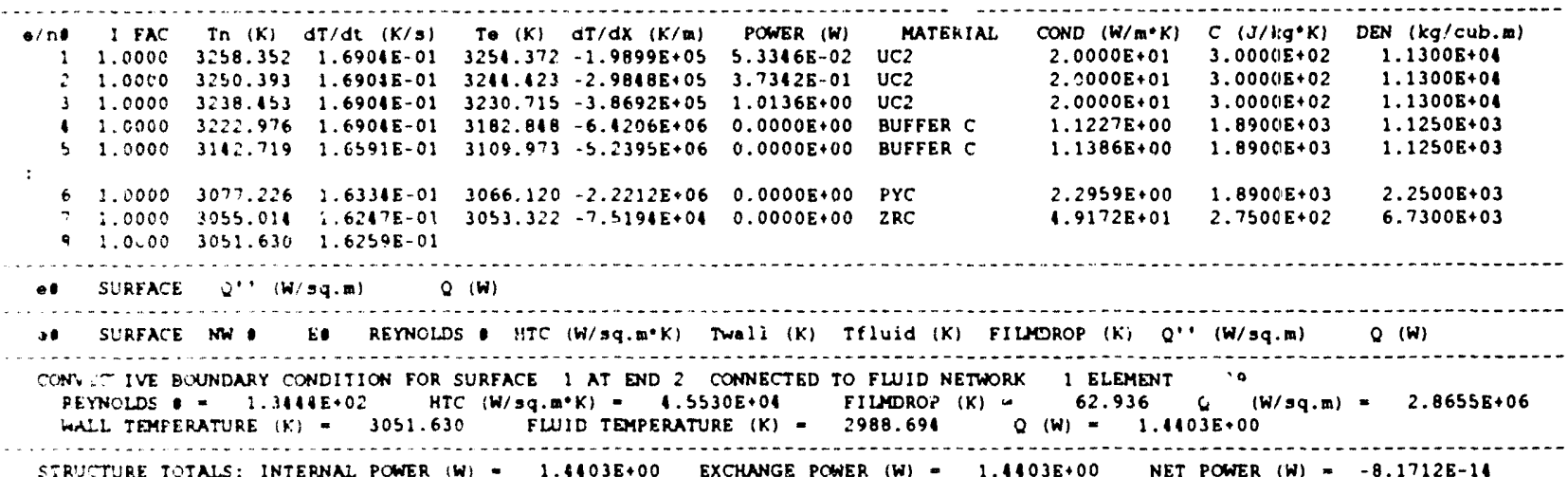

STRUTTURE TOTALS: INTERNAL POWER (W) $=1.4103 E+00$ EXCHANGE POWER (W) $=1.1103 E+00$ NET POWER (W) $=-8.1712 E-11$

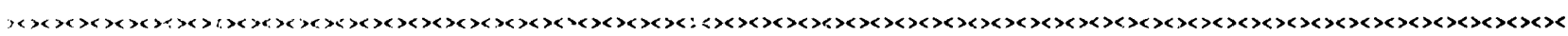

... ETRUCTURE, 30 STRUCTURE NAME: FUEL PARTICLE, LS, RI NUTEER OF COPIES = 0.0000E+00 DYNAMIC SOLUTION

- time (s) - c.00000 SYSTEM TIME STEP. SYSTEM TIME STEP (s) $=5.0000 E-03$

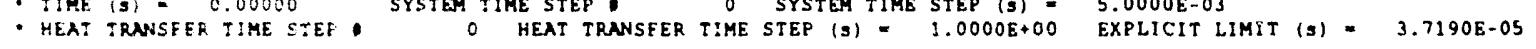

HEAT FLUP. BOUNDARY CONDITION AT END 1: HEAT FLUY (W/sq.m) $=0.00005+00$ Q (W) $=0.0000 E+00$

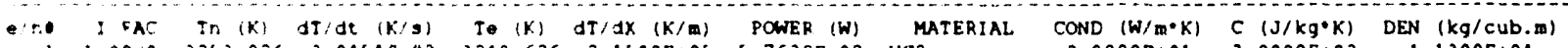

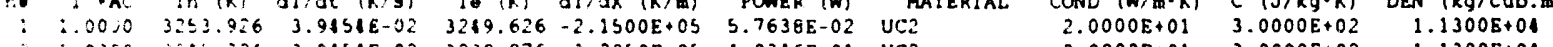

$\begin{array}{llllllllll}1.0020 & 3215.326 & 3.9654 E-02 & 3238.876 & -3.2250 F+05 & 1.0316 E-01 & \text { UC2 } & 2.0000 E+01 & 3.0000 E+02 & 1.1300 E+04\end{array}$

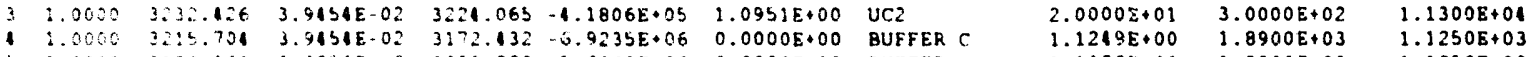

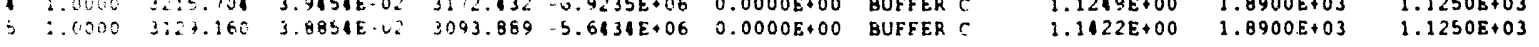

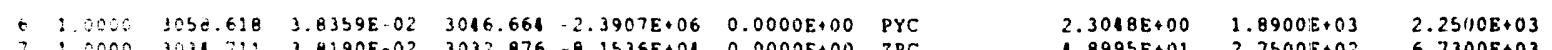

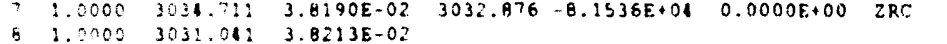

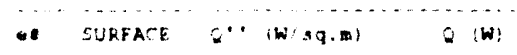

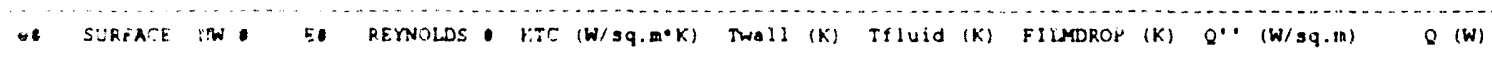

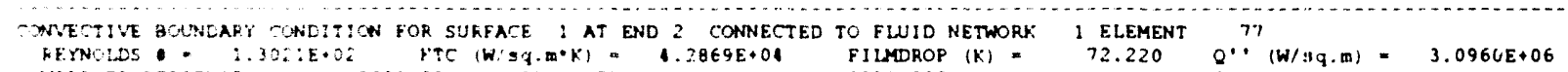

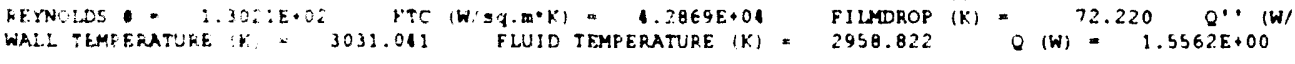

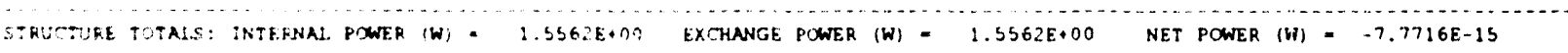

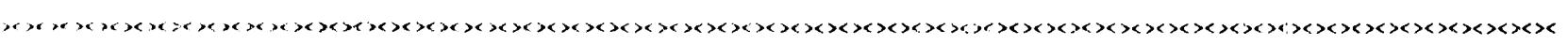

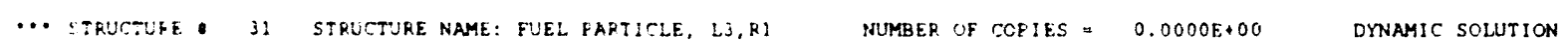

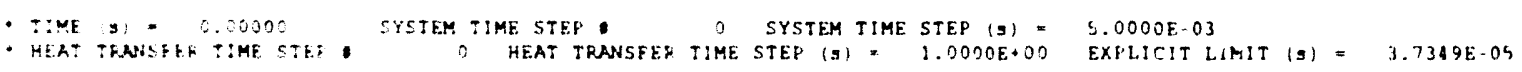

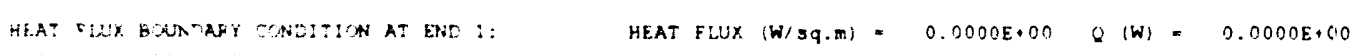

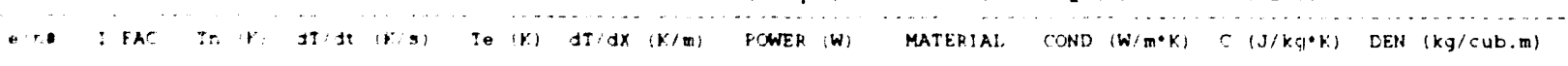




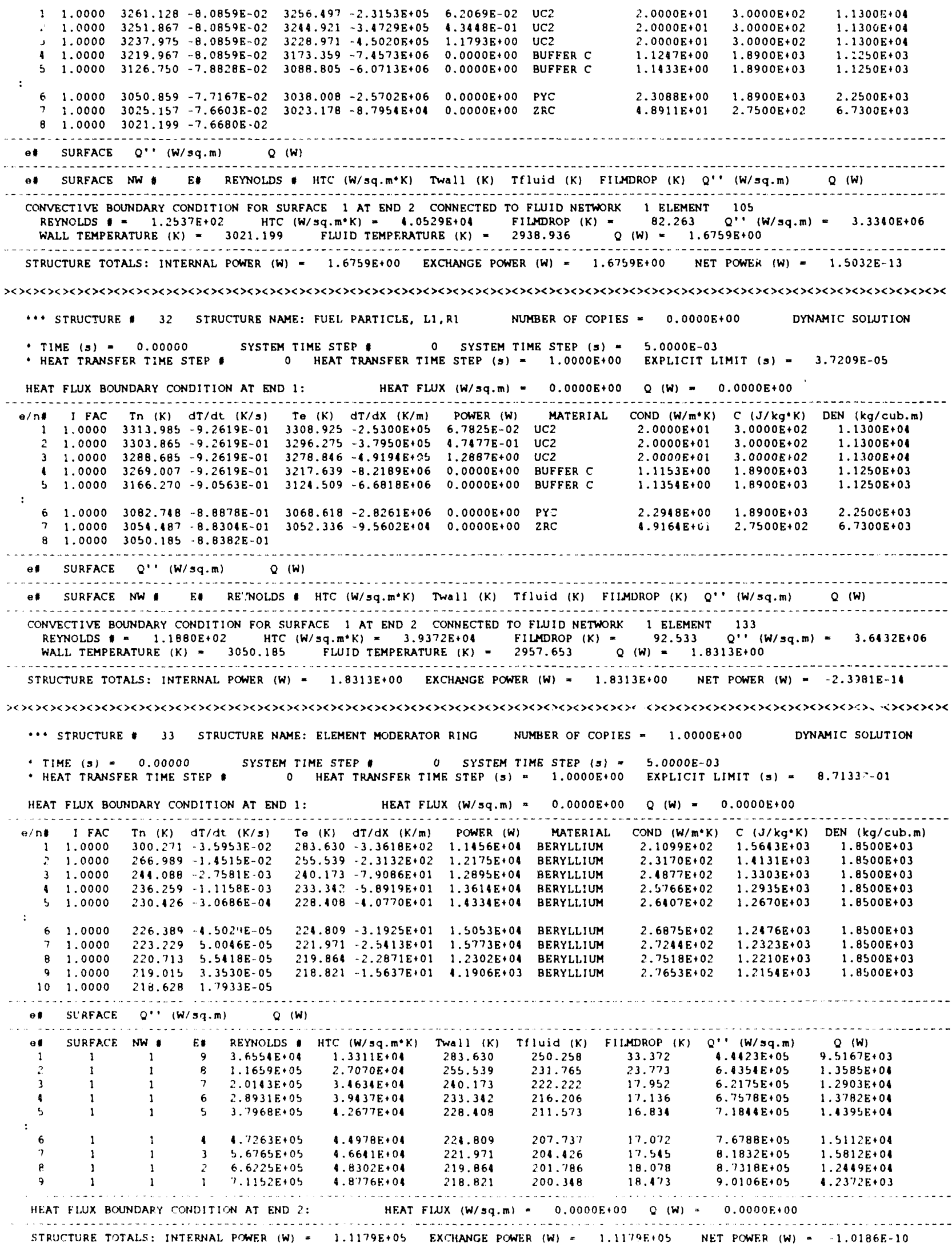

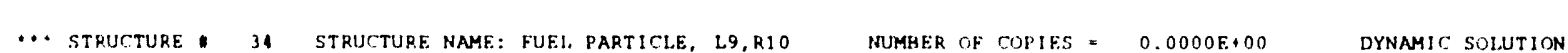

page -- 116 


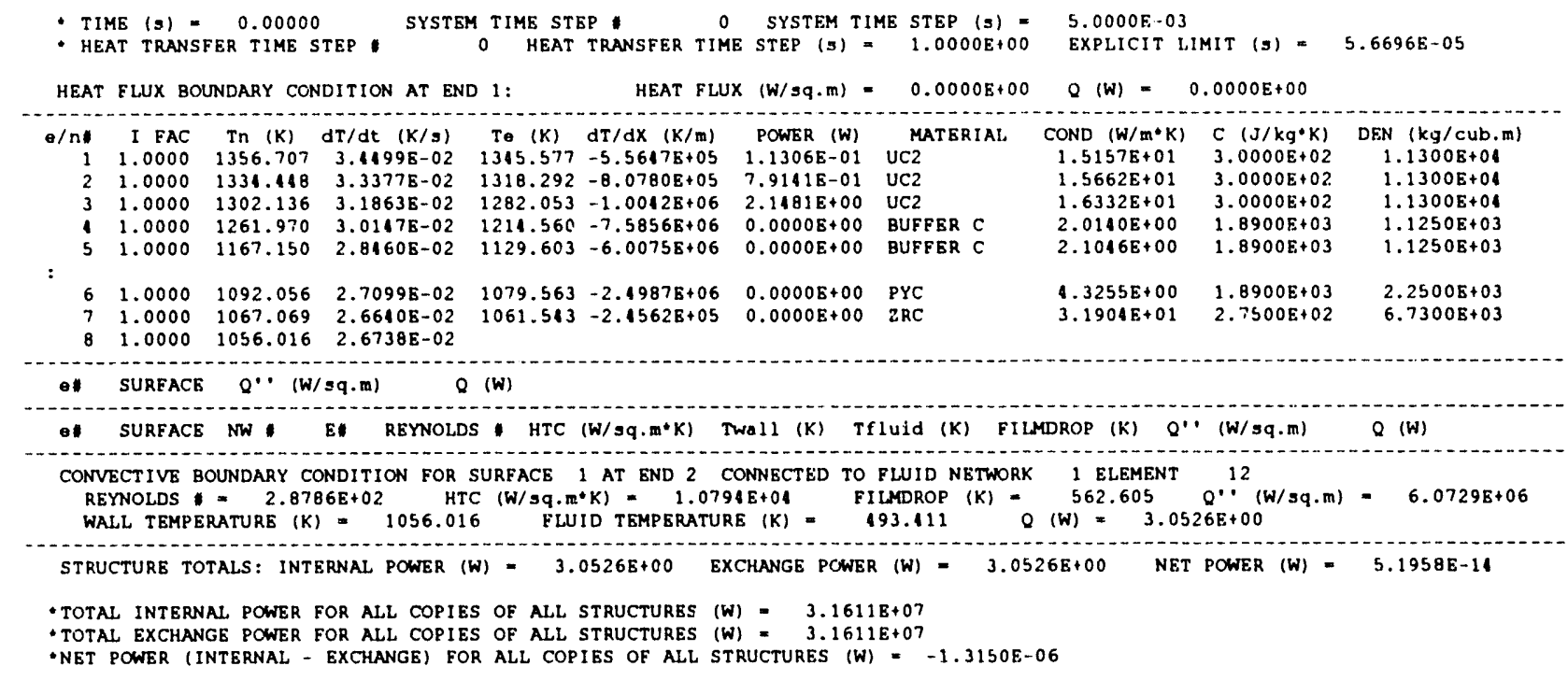


PROGRAM SAFSIM OUTPUT (REACTOR DYNAMICS):

SINGIIE PBR CONICAL ELEMENT WITh 9 AXIAL LEVELS AND 11 RADIAL REGIONS

INVESTIGATE ELEMENT PERFORMANCE DURING DECAY COOLING

v.v.v.v.v.v.v.v.v.v.v.v.v.v.v.v.v.v.v.v.v.v.v.v.v.v.v.v.v.v.v.v.v.v.v.v.v.v.v.v.v.v.v.v.v.v.v.v.v.v.v.v.v.v.v.v.v.v.v.v.v.v.v.v. $\ldots$ SYSTEM TIME $(s)=0.00000$ TIME STEP

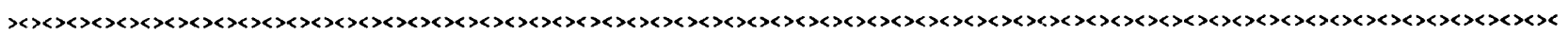

\#+ REACTOR 1 REACTOR NAME: PBR ELEMENT

INTEGRATOR OPTION 1

- TIME (S) =0.00000 SYSTEM TIME STEP. 0 SYSTEM TIME STEP (S) $=5.0000$-003

- REACTOR DYNAMICS TIME STEP 0 REACTOR DYNAMICS TIME STEP (S) = 1.0000E-04 RELATIVE ERROR = O.00OOE+OO

TOTAL REACTOR NEUTRON POWER (W) $=3.1295 \mathrm{E}+07$ dPOWER/dt (W/s) $=0.0000 E+00$ INVERSE PERIOD (1/s) $=0.0000$ (W+00 BFFECTIVE REACTOR THERMAL POWER (W) $=3.1295 \mathrm{E}+07 \mathrm{dPef} / \mathrm{dt}(\mathrm{W} / \mathrm{s})=0.0000 \mathrm{~B}+00$ INVERSE PERIOD (1/s) $=0.0000 \mathrm{O}+00$

PROMPT THERMAL POWER $(W)=3.18958+07$ DECAY THERMAL POWER (W) $=2.10036+06$ SOURCE STRENGTH (W/S) $=0.0000$ E +00 DELAYED-NEUTRON PRECURSOR CONCENTRATIONS FOR 15 GROUPS:

$\begin{array}{crr}\text { GROUP } & \text { CONCENTRATION (W) } & \mathrm{dC} / \mathrm{dt}(W / s) \\ 1 & 6.3612 \mathrm{E}+09 & 0.0000 \mathrm{E}+00 \\ 2 & 1.7103 \mathrm{E}+10 & 0.0000 \mathrm{E}+00 \\ 3 & 1.2050 \mathrm{E}+09 & 0.0000 \mathrm{E}+00 \\ 4 & 3.1253 \mathrm{E}+09 & 0.0000 \mathrm{E}+00 \\ 5 & 2.1037 \mathrm{E}+08 & 0.0000 \mathrm{E}+00 \\ 6 & 3.3270 \mathrm{E}+07 & 0.0000 \mathrm{E}+00 \\ 7 & 3.345 \mathrm{E}+11 & 0.0000 \mathrm{E}+00 \\ 8 & 5.6122 \mathrm{E}+10 & 0.0000 \mathrm{E}+00 \\ 9 & 5.9893 \mathrm{E}+10 & 0.0000 \mathrm{E}+00 \\ 10 & 1.8901 \mathrm{E}+11 & 0.0000 \mathrm{E}+00 \\ 11 & 1.9385 \mathrm{E}+09 & 0.0000 \mathrm{E}+00 \\ 12 & 1.0165 \mathrm{E}+10 & 0.0000 \mathrm{E}+00 \\ 13 & 1.8822 \mathrm{E}+09 & 0.0000 \mathrm{E}+00 \\ 14 & 1.5148 \mathrm{E}+09 & 0.0000 \mathrm{E}+00 \\ 15 & 3.3518 \mathrm{E}+08 & 0.0000 \mathrm{E}+00\end{array}$

DECAY HEAT PRECURSOR CONCENTRATIONS FOR 11 GROUPS:

$\begin{array}{ccc}\text { GROUP * DECAY HEAT CONCENTRATION }(W * s) & \mathrm{dH} / \mathrm{dt}(\boldsymbol{W}) \\ 1 & 5.7868 E+04 & 0.0000 \mathrm{E}+00 \\ 2 & 1.9001 \mathrm{E}+05 & 0.0000 \mathrm{E}+00 \\ 3 & 7.8833 \mathrm{E}+06 & 0.0000 \mathrm{E}+00 \\ 4 & 1.0679 \mathrm{E}+08 & 0.0000 \mathrm{E}+00 \\ 5 & 8.4308 \mathrm{E}+08 & 0.0000 \mathrm{~B}+00 \\ 6 & 1.5988 \mathrm{E}+09 & 0.0000 \mathrm{E}+00 \\ 7 & 1.4824 \mathrm{E}+10 & 0.0000 \mathrm{E}+00 \\ 8 & 9.8225 \mathrm{E}+10 & 0.0000 \mathrm{E}+00 \\ 9 & 2.8138 \mathrm{E}+11 & 0.0000 \mathrm{E}+00 \\ 10 & 1.9837 \mathrm{E}+11 & 0.0000 \mathrm{D}+00 \\ 11 & 2.5772 \mathrm{E}+13 & 0.0000 \mathrm{E}+00\end{array}$

DIFFERENTIAL FEEDBACK REACTIVITY DATA FOR 0 TERMS:

TERM * DIFFERENTIAL REACTIVITY INTEGRATED REACTIVITY NAME

TOTAL DIFFERENTIAL FEEDBACK REACTIVITY $=0.0000 E+00$ (\$ 0.0000$)$

TOTAL INTEGRATED FEEDBACK REACTIVITY $=0.0000 \mathrm{E}+00$ (\$ 0.0000$)$

PROGRAMMED dRHO/dt $=0.0000 \mathrm{E}+001 / 3$ (\$ $/ \mathrm{s} 0.0000)$ INTEGRATED PROGRAMMED REACTIVITY = -3.7269E-20 (\$ 0.0000)

TOTAL INTEGRATED REACTIVITY $=-3.7269 \mathrm{E}-20$ (S 0.0000 ) EFFECTIVE NEUTRON MULTIPLICATION FACTOR $=1.000000$ 
PROGRAM SAFSIM OUTPUT (FUNCTION-CONTROLLED VARIABLES AND FUNCTIONS):

SINGLE PBR CONICAL BLEMENT WITh 9 AXIAL LEVELS AND 14 RADIAL, REGIONS

INVESTIGATE ELEMENT PERFORMANCE DURING DECAY COOLING v.v.v.v.v.v.v.v.v.v.v.v.v.v.v.v.v.v.v.v.v.v.v.v.v.v.v.v.v.v.v.v.v.v.v.v.v.v.v.v.v.v.v.v.v.v.v.v.v.v.v.v.v.v.v.v.v.v.v.v.v.v.v.v.
$-\rightarrow$ SYSTEM TIME (s) $0.00000 \quad$ TIME STEP

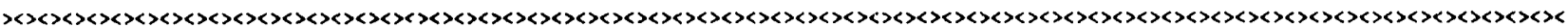

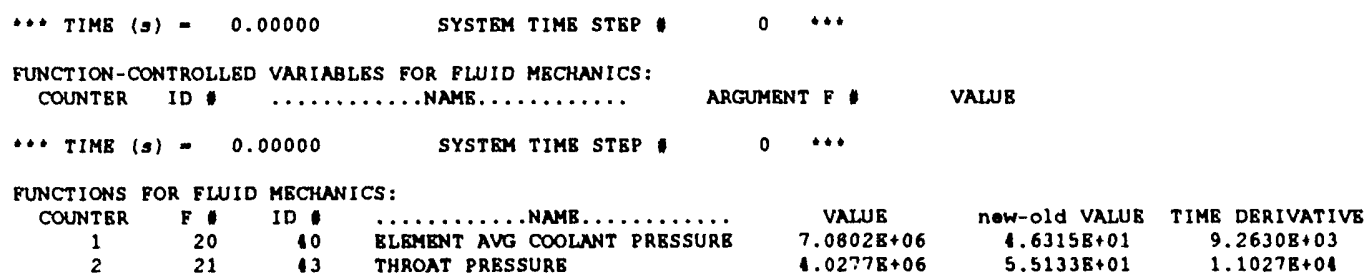

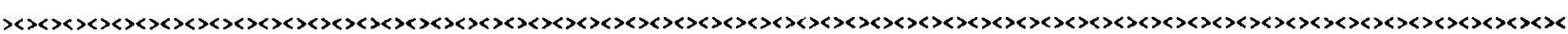

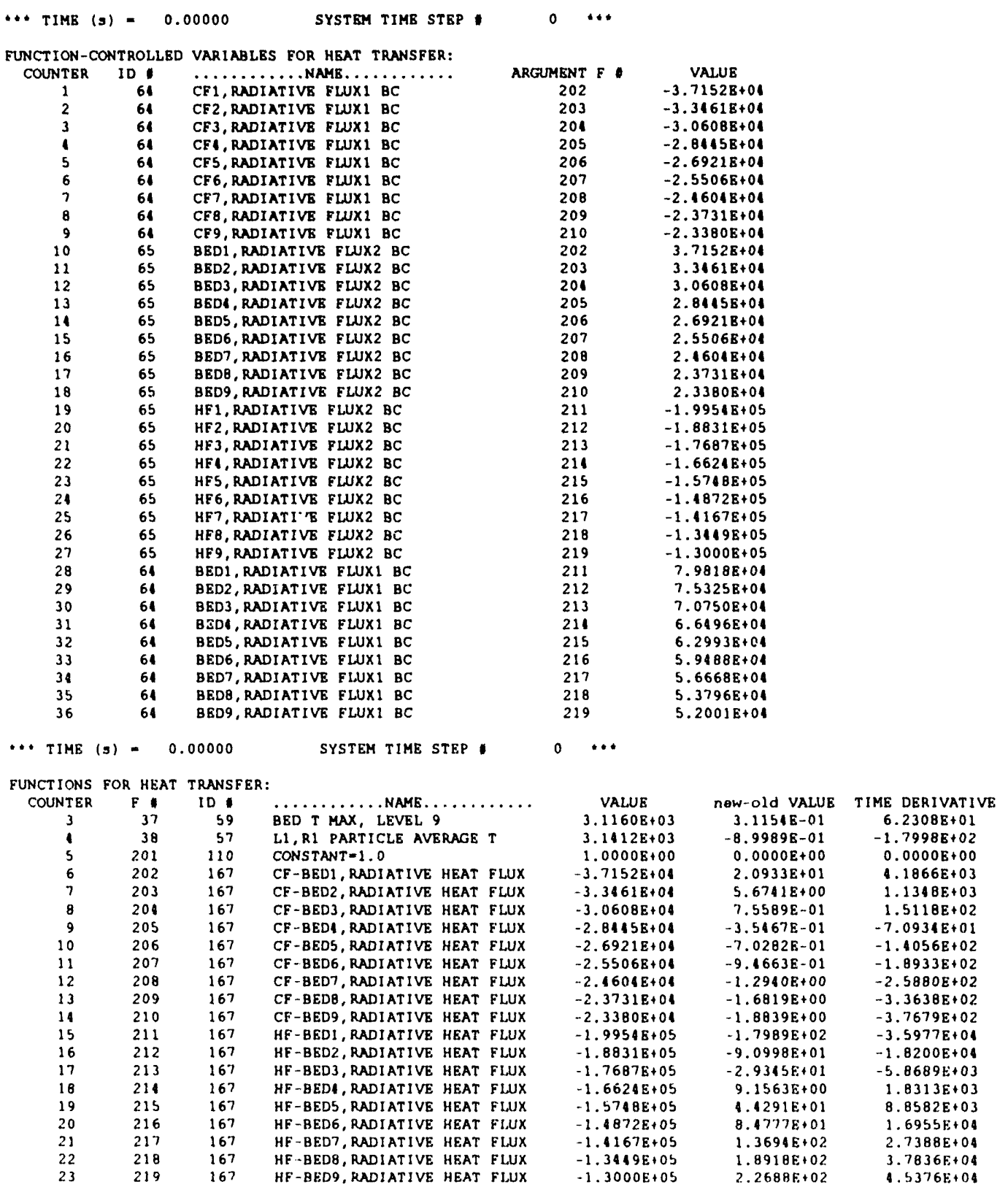




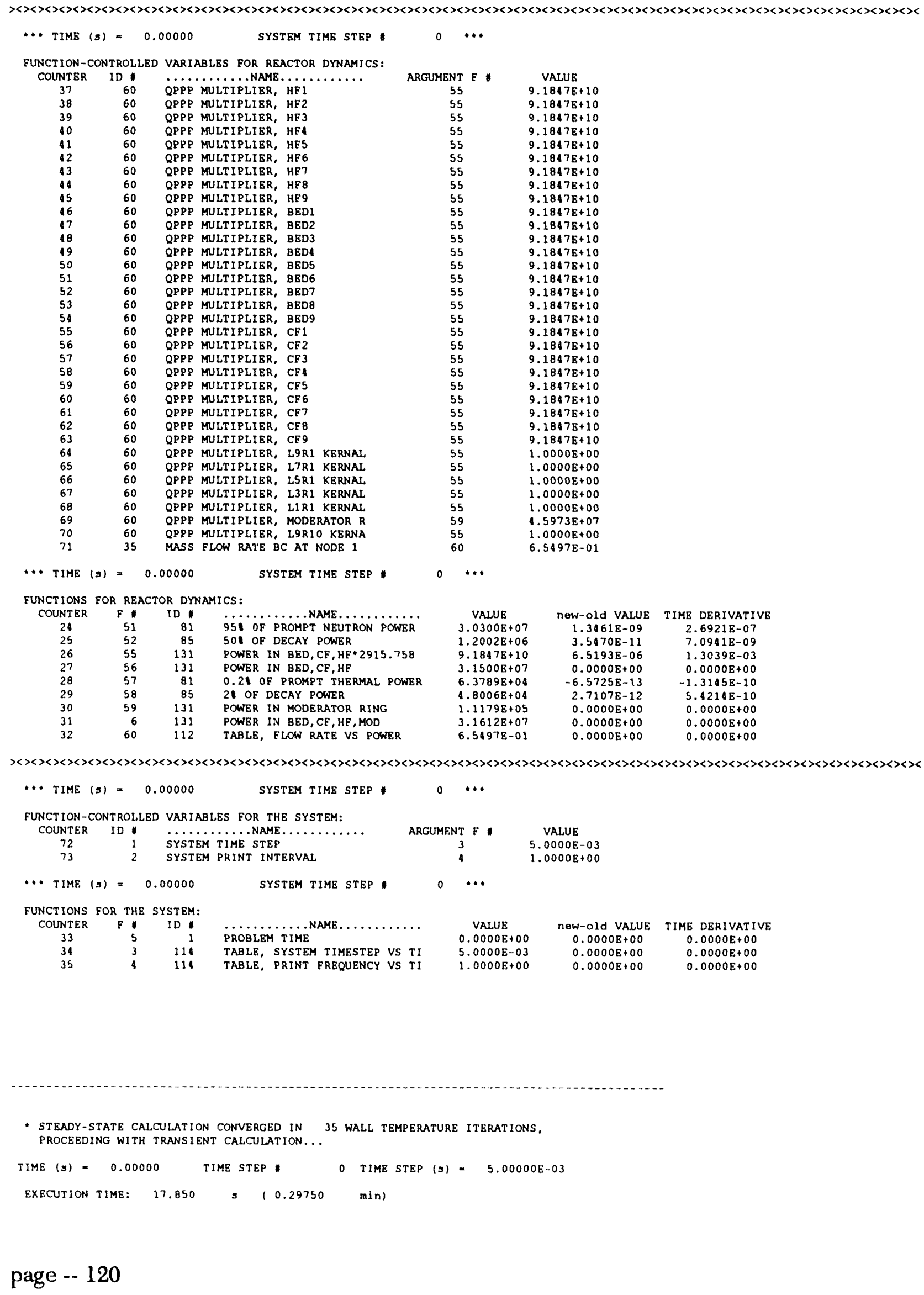


1 Aldemir, Tunc

Department of Mechanical

Engineering

Ohio State University

206 West 18th Avenue

Columbus, OH 43210

1 Anghaie, Samin

University of Florida

202 Nuclear Sciences Center

Gainsville, FL 32611

1 Barattino, Maj. William

Phillips Laboratory/TAS

Kirtland AFB, NM 87117-6008

1 Bennett, Gary L.

NASA Headquarters

Code RP

Washington, DC 20546

1 Best, Frederick R.

Texas A\&M University

Nuclear Engineering Department

129 Zachry Engineering Ctr.

College Station, TX 77843-3133

1 Bhattacharyya, Samit K.

Argonne National Laboratory

9700 South Cass-Bldg. 207

Argonne, IL 60439-4841

1 Bleeker, Lt. Col. Gary

3550 Aberdeen Avenue SE,

Phillips Laboratory/VT-X

Kirtland AFB, NM 87117-5776

1 Bohl, Dick J.

Los Alarnos National Laboratory

P. O. Box 1663 - MS-E561

I.os Alamos, NM 87545
1 Borowski, Stanley K.

NASA Lewis Research Center

Adv Space Analysis Office

21000 Brookpark Road

Mail Stop AAC-2

Cleveland, $\mathrm{OH} 44135$

1 Breen, J. A.

Pratt \& Whitney GESP

P. O. Box 109600

West Palm Beach, FL

33410-9600

1 Brengle, Bob

Rockwell International Corporation

Rocketdyne Division

6633 Canoga Avenue

Canoga Park, CA 91303

1 Buden, David

Center for Nuclear Engineering and Technology

INEL

P. O. Box 1625

Idaho Falls, ID 83415-2516

1 Buska, John

Mail Stop K551

P. O. Box 1663

Los Alamos National Laboratory

Los Alamos, NM 87545

1 Carroll, Wade P.

U. S. Department of Energy

NE- 52

19901 Germantown Road

Germantown, MD 20874

1 Clark, John

NASA Lewis Research Center

21000 Brookpark Rd.

Cleveland, OH 44135 
1 Dahl, Wayne B.

Aerojet Propulsion Division

P. O. Box 13222

Department 9810

Sacramento, CA 95813

1 Cappiello, Mike

Los Alamos National Laboratory

MS K551

P. O. Box 1663

Los Alamos, NM 87545

1 Difilippo, Felix C.

Oak Ridge National Laboratory

P.O. Box 2008, Bldg. 6025, MS-6363

Oak Ridge, TN 37831-6363

1 Donahue, Benjamin B.

Boeing Aerospace

P. O. Box 240002

MS JX-23

Huntsville, AL 35824-6402

2 El-Genk, Mohammed

Institute for Space Nuclear

Power Studies

Chemical and Nuclear Engineering

Department

University of New Mexico

Albuquerque, NM 87131

1 Emrich, Bill

MS EP53 Flash 4666

NASA Marshall Space

Flight Center

Huntsville, AL 35812

1 Felty, Jim

U. S. Dept. of Energy

DP-241

19901 Germantown Rd.

Germantown, MD 20585
1 Gerrish, Harold

NASA Marshall Space

Flight Center

Huntsville, AL 35812

1 Glass, James F.

Systems Engineering \& Analysis

Rocketdyne Division

Rockwell International Corp.

6633 Canoga Avenue

Canoga Park, CA 91303

1 Haloulakos, V. E.

McDonnell Douglas Space Sys Co

Internal Mail Code A3-Y833-13/3

5301 Bolsa Avenue

Huntington Beach, CA 92647

1 Haman, Nelson A.

Argonne National Laboratory

9700 So. Cass Ave.

Building 207

Argonne, IL 60439-4841

2 Hampston, Ken

3550 Aberdeen Avenue SE

Phillips Laboratory/VT-X

Kirtland AFB, NM 87117-5776

1 Haskin, Eric F.

Institute for Space Nuclear

Power Studies

Chemical and Nuclear Engineering Department

University of New Mexico

Albuquerque, NM 87131

1 Haslett, Robert

Grumman Aerospace Corp.

MS B09-25

Bethpage, NY 11714 
1 Hendrix, Robert

NASA Lewis Research Center

Techpark 1

Space Propulsion Technology Div.

Cleveland, $\mathrm{OH} 44135$

1 Howe, Steve

Los Alamos National Laboratory

P. O. Box 1663

MS F643

Los Alamos, NM 87545

1 Husser, Dwayne

Babcock \& Wilcox

P. O. Box 11165

Lynchburg, VA 24506-1165

1 Jones, Lee

MS EP53 Flash 4666

NASA Marshall Space

Flight Center, AL 35812

1 Kerrebrock, Jack L.

Massachusetts Institute of Technology

Rm. 33-411

77 Massachusetts Ave.

Cambridge, MA 02139-4307

1 Klein, Andrew C.

Department of Nuclear Engineering

Oregon State University

Radiation Center A112

Corvallis, OR 97331-5902

1 Latham, T. S.

United Technologies Research Ctr.

Silver Lane

East Hartford, CT 06108

1 Lenard, Lt. Col. Roger

Phillips Laboratory/VT-X

Kirtland AFB, NM 87117-6008
1 Lee, Stacy $\mathrm{K}$.

Texas A\&M University

Nuclear Engineering Department

129 Zachry Engineering Ctr.

College Station, TX 77843-3133

1 Ludewig, Hans

Brookhaven National Laboratory

Building 701

Upton, NY 11719

1 Luth, W. C.

DOE/ER

U. S. Dept. of Energy

ER-15, J317/GTN

19901 Germantown Rd.

Germantown, MD 20585

1 Maise, George

Brookhaven National Laboratory

Bldg. 701

Upton, NY 11973

1 Mangus, Jim

Westinghouse Electric Corporation

Box 158

Madison, PA 15663-0158

1 Martinell, John A.

Idaho National Engineering

Laboratory

P. O. Box 1625

Idaho Falls, ID 83415

1 Matson, Warren

Idaho National Engineering

Laboratory

P. O. Box 1625

Idaho Falls, ID 83415

1 McElroy, Steve $\mathrm{H}$.

Babcock \& Wilcox

P. O. Box 11165

Lynchburg, VA 24506-1165 
1 McDaniel, Patrick J.

Phillips Laboratory/WSA

Kirtland AFB, NM 87117-6008

2 Metzger, John D.

Grumman Electronics Systems

Division

MS B09-25

Bethpage, NY 11714

1 Miller, Tom

NASA Lewis Research Center

21000 Brookpark Rd.

Cleveland, OH 44135

1 Mims, James E.

Advanced Systems Analysis

6739 Academy Road NE

Albuquerque, NM 87109-3345

1 Mo'dy, Capt. Jay A.

3550 Aberdeen Avenue SE

Phillips Laboratory/VT-X

Kirtland AFB, NM 87117-5776

l Moore, R. L.

Advanced Reactor Design

EG\&G, Inc.

2145 E. 17th Street

Box 1625

Idaho Falls, ID 83415-1575

I Parsley, Randy C.

Rocket Conceptual Design

Pratt \& Whitney

P. O. Box 109600

Mail Stop 714-65

West Palm Beach, FL, 33410-9600

I Pelaccio, Dennis G.

Science App. International Corp.

21151 Western Avenue

Torrence, CA 9050I
I Perkins, Ken

Brookhaven National Laboratory

Bldg. 701

Upton, NY 11973

1 Perry, R. T.

MS K551

P. O. Box 1663

Los Alamos National Laboratory

Los Alamos, NM 87545

1 Powell, jaines $\mathbf{R}$.

Building 701

Brookhaven National Laboratory

Upton, NY 11973

1 Reid, Hank

Babcock \& Wilcox

Space Systems Engineering

Mt. Athos Road - Rt. 726

P. O. Box 11165

Lynchburg, VA 24506-1165

1 Roberds, Richard M.

Engr. Science \& Math

University of Tennesee Space Institute

B. II. Goethert Parkway

Tullahoma, TN 37388

1 Sapyta, Joseph J.

Babcock \& Wilcox

Space Systems Fngineering

Mt. Athos Road - Rt. 726

P. O. Box 11165 - MC\#08

lynchburg, VA 24506-1165

I Schuller, Michael J.

Phillips Laboratory/AWYS

Kirtland AFB, NM 87117-6008 
1 Shepard, Kyle

General Dynamics Space

Systems Division

P. O. Box 85900

San Diego, CA 92138

1 Sheppard, Susan J.

Babcock \& Wilcox

Space Systems Engineering

Mt. Athos Road - Rt. 726

P. O. Box 11165 - MC\#08

Lynchburg, VA 24506-1165

1 Smith, John M.

NASA Lewis Research Center MS 301-5

21000 Brookpark Rd.

Cleveland, $\mathrm{OH} 44135$

1 Solon, Marty

Grumman Space Electronics

Division

South Oyster Bay Road

MS B09-25

Bethpage, NY 11714

1 Suzuki, David E.

Massachusets Institute of

Technology

Building NW12/Rm. 309

Cambridge, MA 02139

1 Tepes, Frank

Grumman Space Electronics Division

MS B0-25

Bethpage, NY 11714

1 Walter, Carl E.

Lawrence Livermore National Laboratory

7000 East Avenue L-144

MS L-197; P. O. Box 808

Livermore, CA 94550
1 Walter, P. B.

Nuclear Engineering Department

Pennsylvania State University

231 Sackett Building

University Park, PA 16802

1 Walton, James

NASA Lewis Research Center

MS AAC-2

Cleveland, OH 44135

1 Walton, Lewis A.

Babcock \& Wilcox

3315 Old Forest Rd.

Lynchburg, VA 24506

1 Warren, John

Division of Defense Energy

Projects

Office of Nuclear Energy

U. S. Dept. of Energy, NE-52

Washington, DC 20545

1 Watson, Ron

Babcock \& Wilcox

Space Systems Engineering

Mt. Athos Road - Rt. 726

P. O. Box 11165

Lynchburg, VA 24506-1165

1 Witter, Johnathan K.

Dept. of Nuclear Engr.

Massachusetts Institute of Technology

NW12-306A

Cambridge, MA 02139

1 Zubrin, Robert

Martin Marietta Astronautics

P. O. Box 179

Denver, CO 80201 


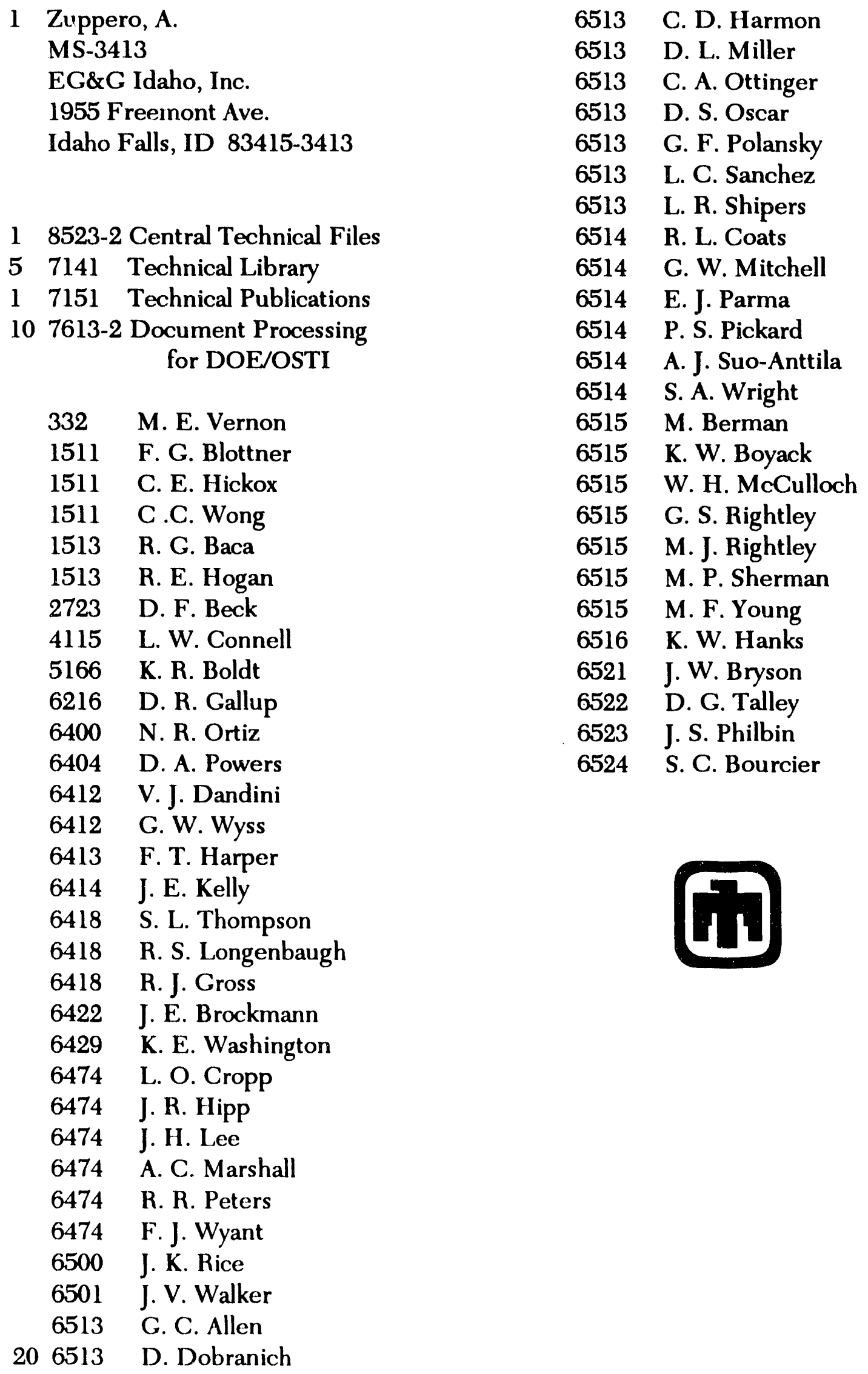



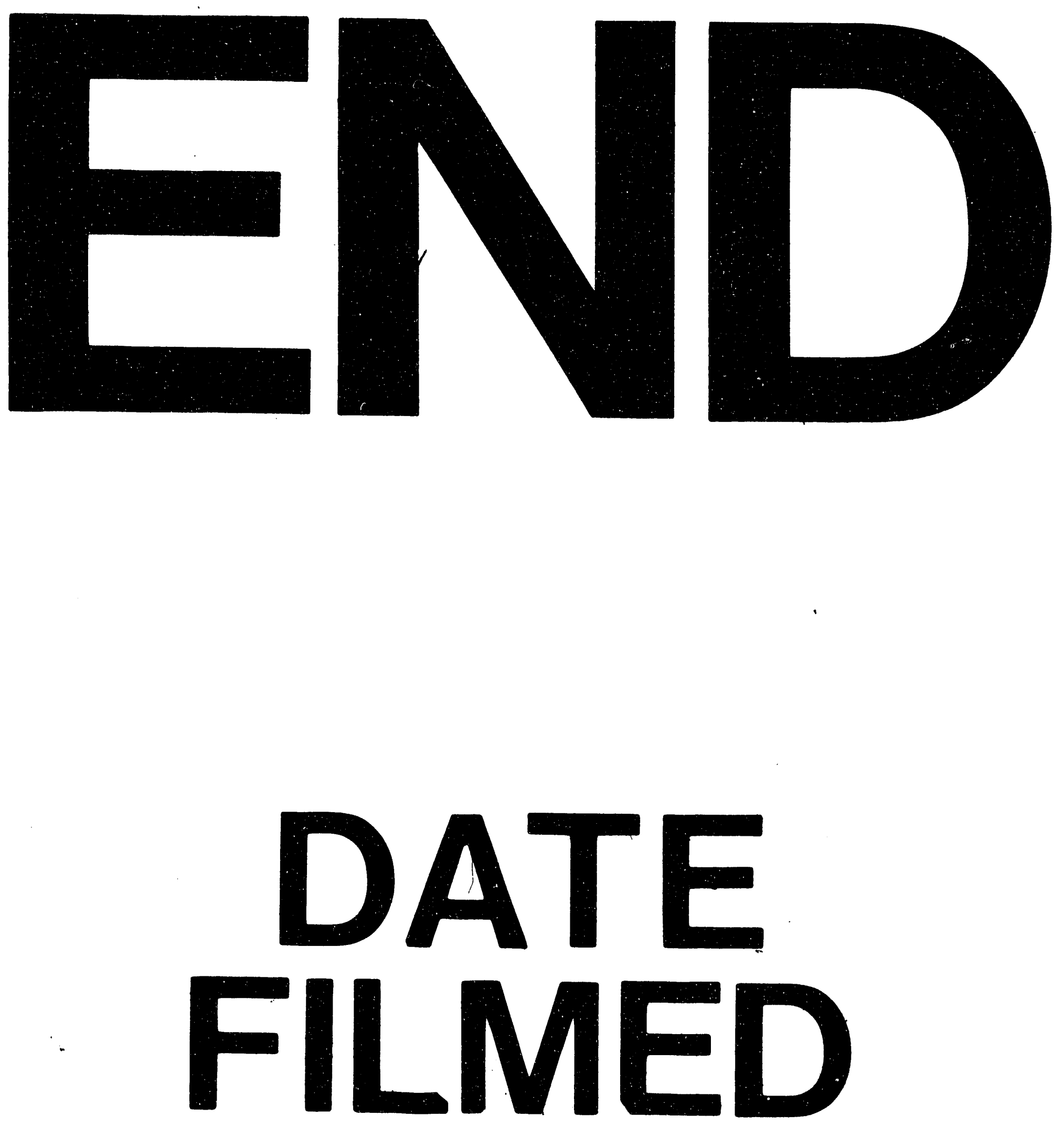

1

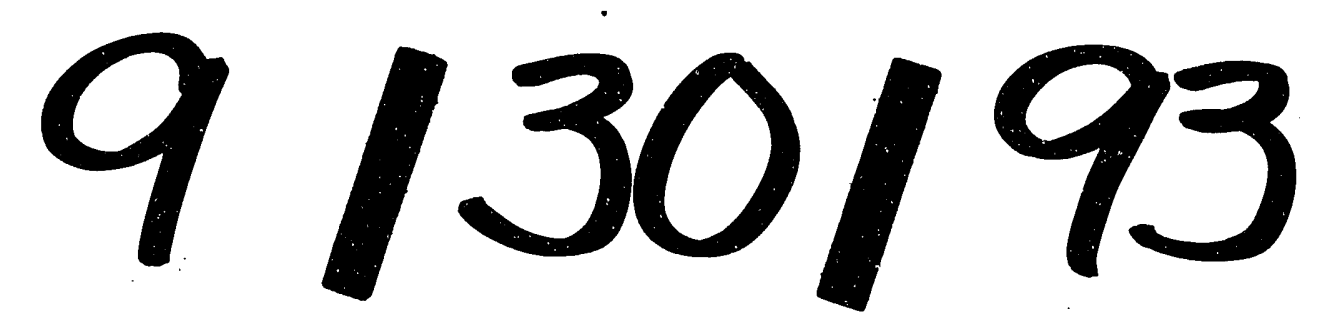


